\title{
DEMYSTIFYING MYTHS \\ THE ROLE OF TOURISM AS A SUSTAINABLE DEVELOPMENT STRATEGY
}

ANTONIO MARTINEZ SANCHEZ

THESIS

$\mathrm{PhD}$ in International Studies of Peace, Conflict, and Development

UNESCO Chair of Philosophy for Peace 


\section{DEMYSTIFYING MYTHS \\ THE ROLE OF TOURISM AS A SUSTAINABLE \\ DEVELOPMENT STRATEGY}

ANTONIO MARTINEZ SANCHEZ

\section{THESIS}

First part

$\mathrm{UK}$

$\mathrm{PhD}$ in International Studies of Peace, Conflict, and Development

UNESCO Chair of Philosophy for Peace

Supervised by Irene Comins Mingol

Jaume I University

$2017-2018$ 


\section{TABLE OF CONTENTS}

FIRST PART

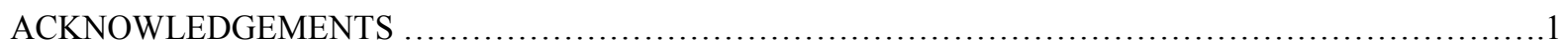

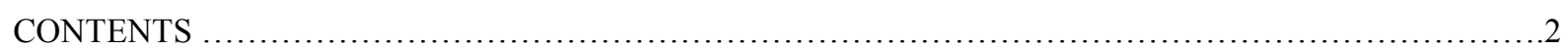

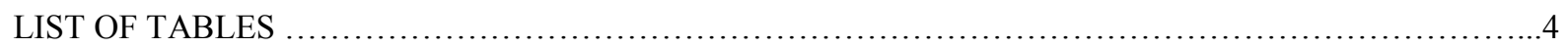

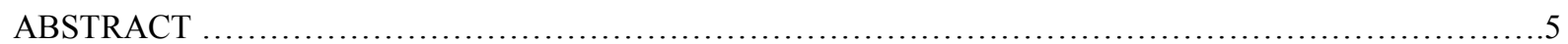

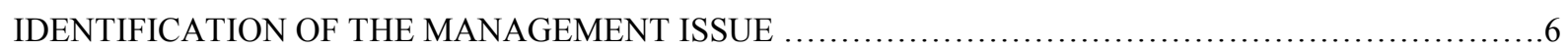

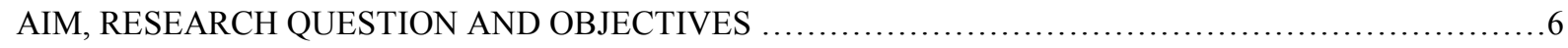

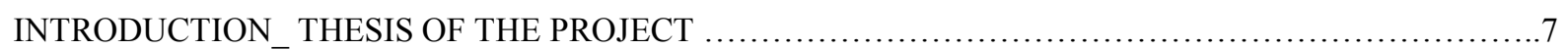

CHAPTER 1_ TOURISM, DEVELOPMENT AND SUSTAINABILITY _..............................

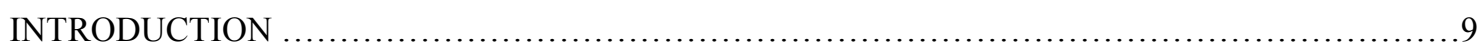

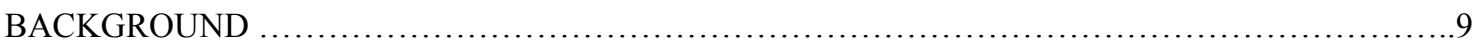

THE NATURE AND SIGNIFICANCE OF THE TOPIC ........................................

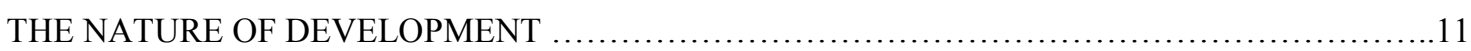

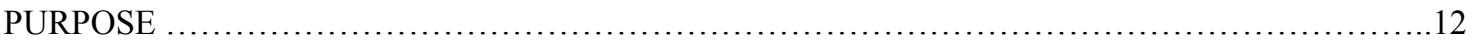

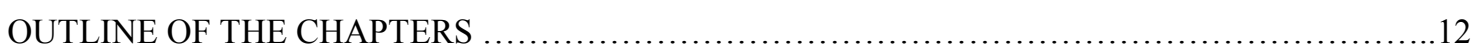

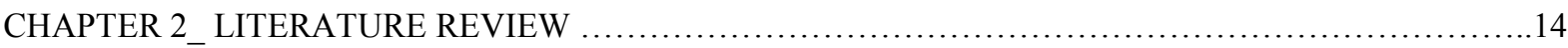

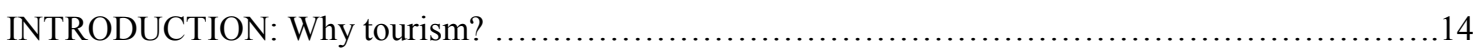

SETTING THE SCENE: HISTORICAL BACKGROUND …......................................

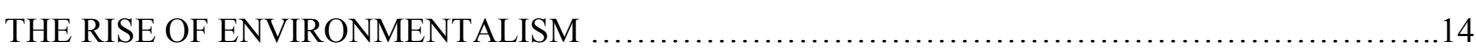

ORIGINS AND INTERPRETATION OF SUSTAINABLE DEVELOPMENT ….....................16

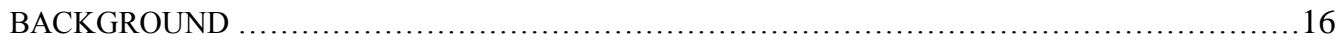

WHAT IS SUSTAINABLE DEVELOPMENT ……......................................... 19

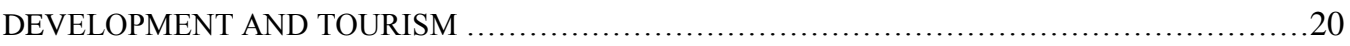

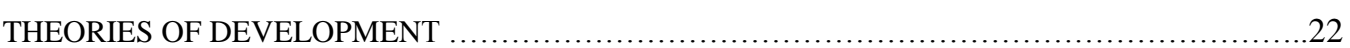

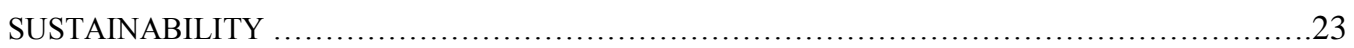

THE APPLICATION OF SUSTAINABLE DEVELOPMENT TO TOURISM ….....................24

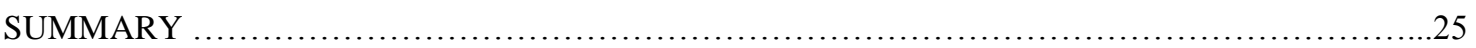

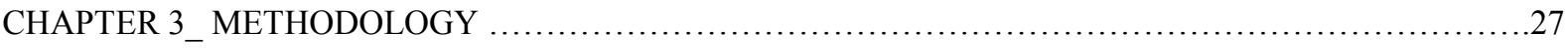

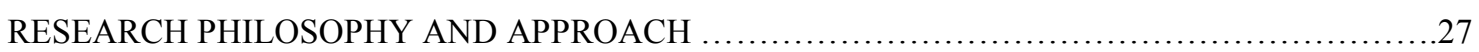

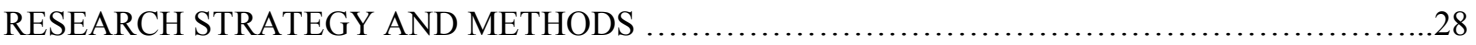

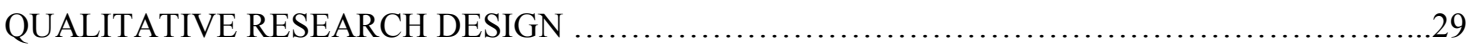

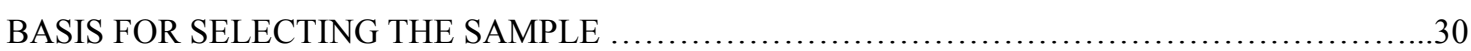

INSTRUMENTATION: DESCRIBING RESEARCH TOOLS AND PROCEDURES ….................34

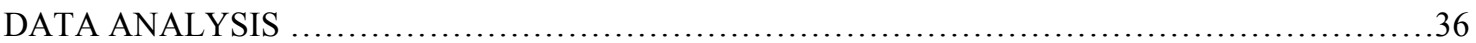

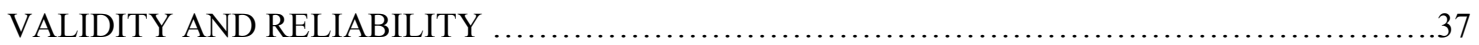

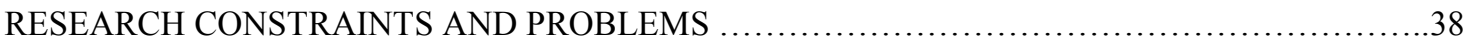




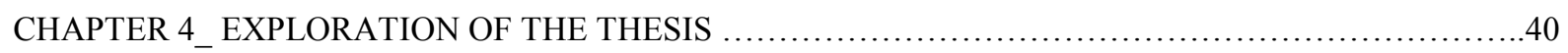

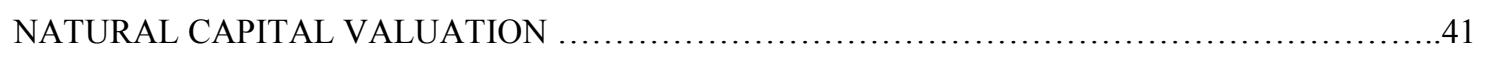

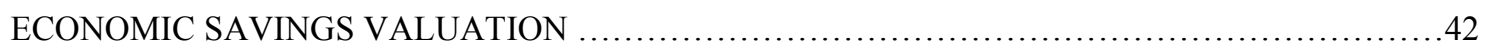

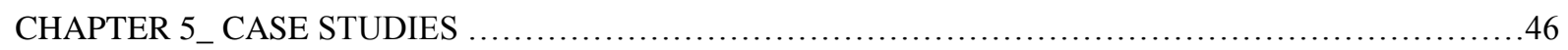

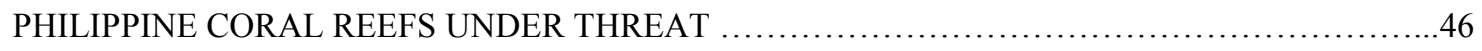

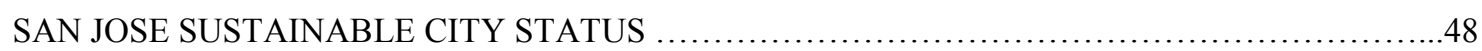

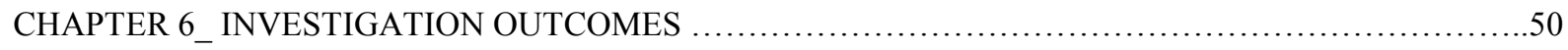

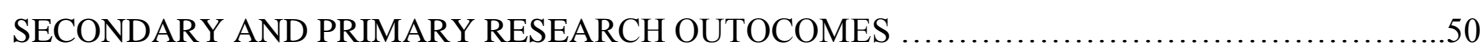

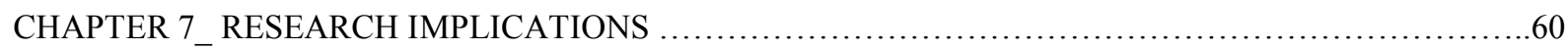

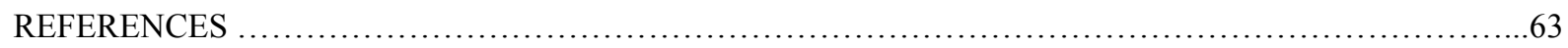

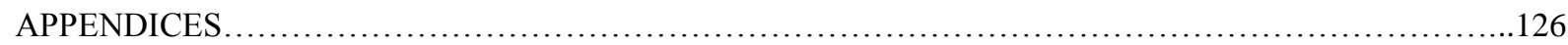

SECOND PART

TOURISM: FROM EVIL TO CUSTODIAN

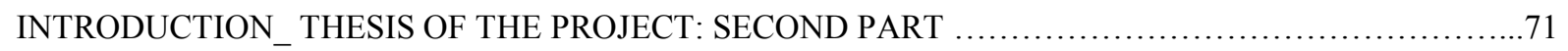

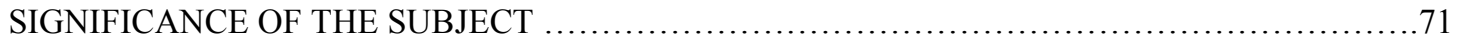

THE NATURE OF PUBLIC GOODS AND COMMON RESOURCES .............................72

REVERSE EVIDENCE: THE CASE OF GHADAMES OASIS. LIBYA .........................73

CHAPTER 1_TOURISM, SUSTAINABILITY, COMMON RESOURCES ..............................77

INTRODUCTION ............................................................. 77

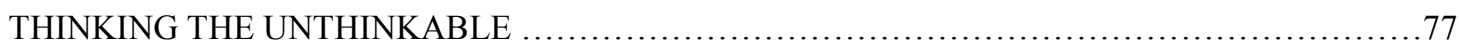

CHAPTER 2 LOOKING BACKWARDS IN ORDER TO GO FORWARDS ...........................79

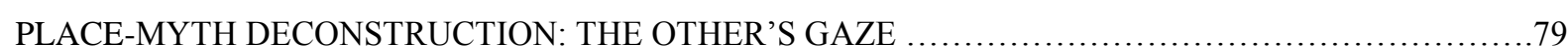

CONTEXT: SOCIAL AND CULTURAL CONSTRUCTION OF SPACE ..........................79

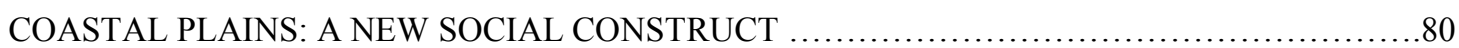

CHANGING THE ENVIRONMENTAL PERCEPTION ....................................... 80

CONSTANT TRANSFORMATION OF SPACE: PLACE REPRESENTATION ...................81

FURTHER SIGHTS / INSIGHTS: MYTH, PARADISE, NEOCOLONIALISM ......................82

CHANGING SOCIAL SPATIALISATION: BEACH AS A ZONE OF EXCLUSION / INCLUSION 83

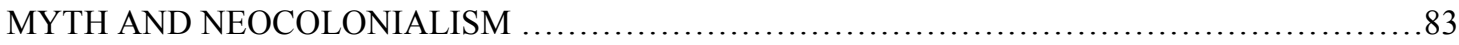

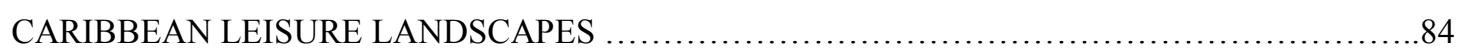

CASE STUDY: The case of Punta Cana and Bávaro Beach. Dominican Republic .....................85 
POLITICAL ECONOMY, TOURISM PLANNING AND THE ROLE OF THE STATE TO OVERCOME INEQUITY.

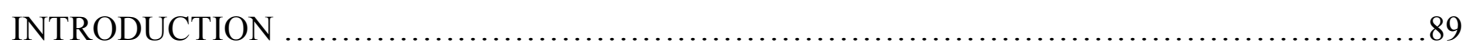

CONCEPTUAL FRAMEWORK: THEORIES OF DEVELOPMENT .............................91

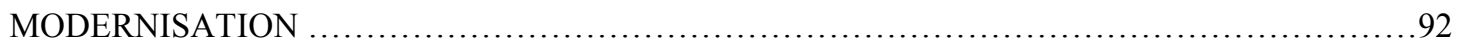

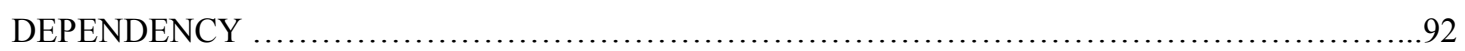

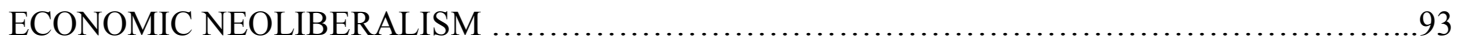

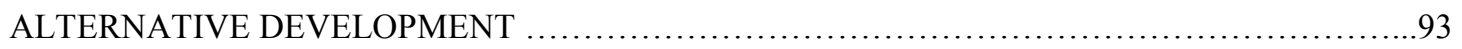

DEVELOPMENT, INEQUALITIES, TOURISM PLANNING: THE CASE AND CONTEXT OF

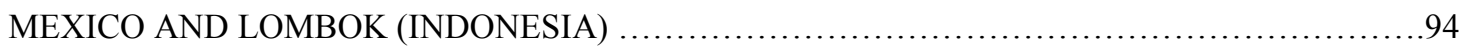

THE CASE AND CONTEXT OF MEXICO: 25 YEARS OF TOURISM (Adapted from Clancy, 1999)

THE CASE AND CONTEXT OF LOMBOK. INDONESIA. (Adapted from Fallon, 2001) ...........95

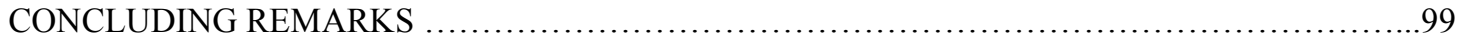

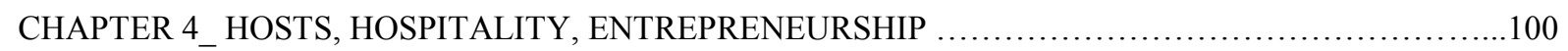

ON ENTREPRENEURSHIP: THE CASE AND CONTEXT OF SRI LANKA ............................

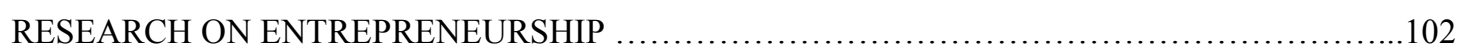

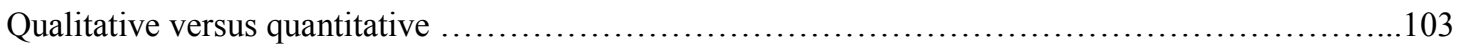

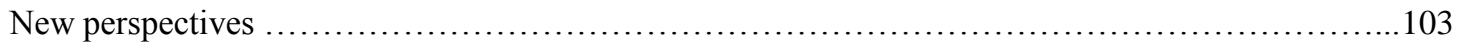

EXPERIENCES FROM THE GLOBAL IN A LOCAL SETTING ................................. 104

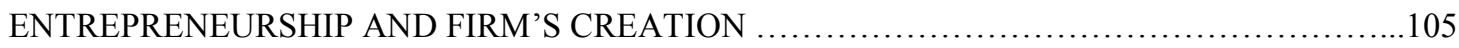

THE CASE AND CONTEXT OF SRI LANKA (Adapted from Kodithuwakku and Rosa, 2002) ......105

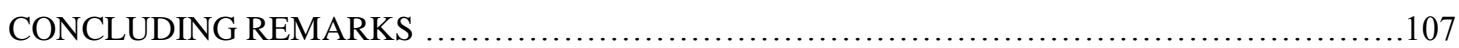

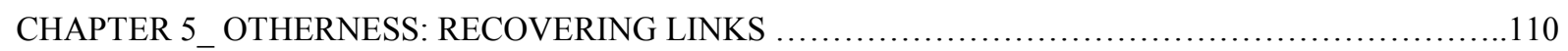

BHUTAN KEEPS THE LINKS AMONG INHABITANTS, HABITS, HABITATS .................110

CHAPTER 6_ TRADITIONAL SYSTEMS: ANY LESSON? ......................................114

ON THE LONG-STANDING SUSTAINABILITY OF ENDOGENOUS COMMON RESOURCES

Subak traditional system in Bali .................................................... 117

Sasi traditional system in Raja Ampat, Indonesia ............................................118

Nakaiy traditional calendar in Maldives Islands ........................................118

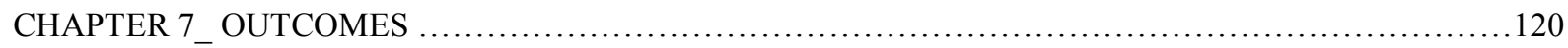

ARMCHAIR THINKING, DESK RESEARCH, FIELD TRIPS ................................ 120

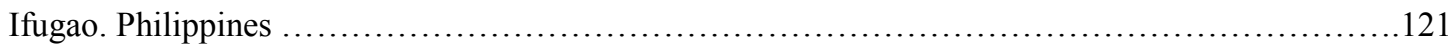

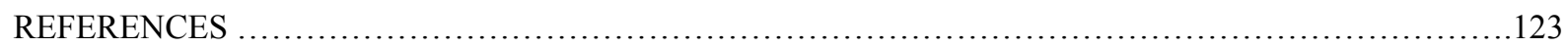

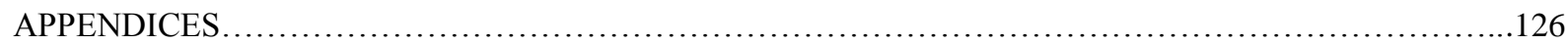

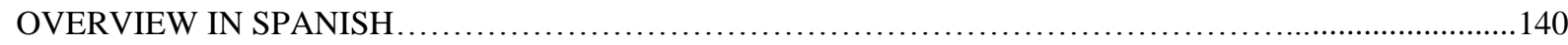




\section{ACKNOWLEDGEMENTS}

I express gratitude to all those Organisations, companies and public Institutions that have collaborated in this investigation. I am thankful to each one of the persons who have devoted their time and have shared their thoughts and perceptions with respect to this research subject.

To my father and my mother, the best persons I have ever met.

Antonio Martinez Sanchez 


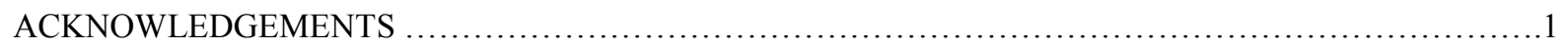

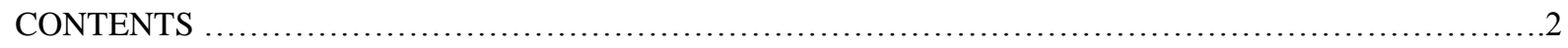

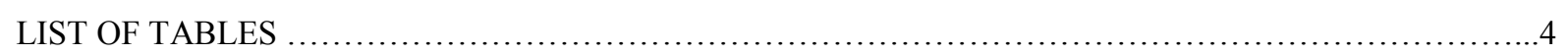

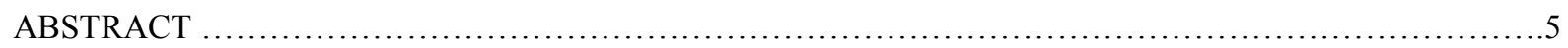

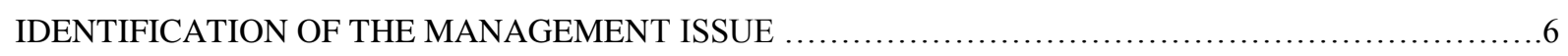

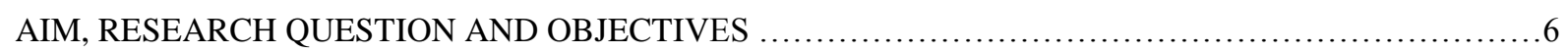

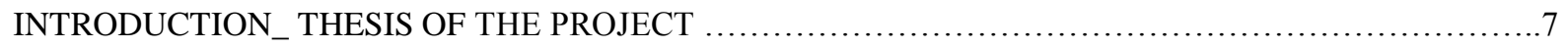

CHAPTER 1_ TOURISM, DEVELOPMENT AND SUSTAINABILITY ..............................

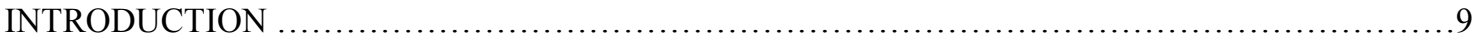

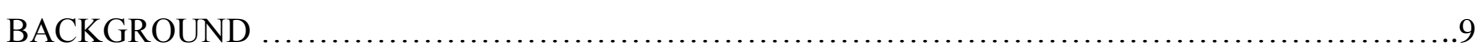

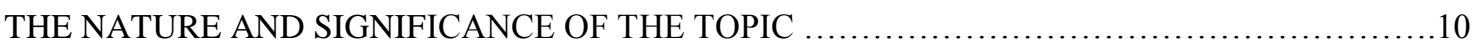

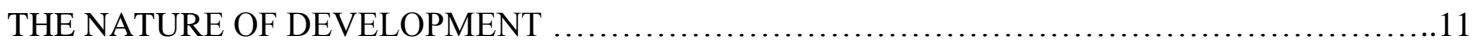

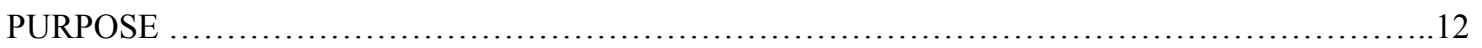

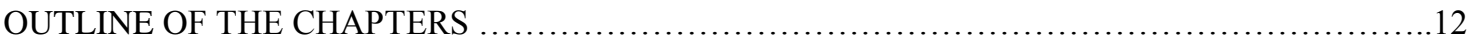

CHAPTER 2_ LITERATURE REVIEW ...................................................14

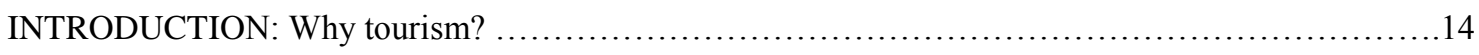

SETTING THE SCENE: HISTORICAL BACKGROUND ...................................... 14

THE RISE OF ENVIRONMENTALISM ............................................. 14

ORIGINS AND INTERPRETATION OF SUSTAINABLE DEVELOPMENT .......................16

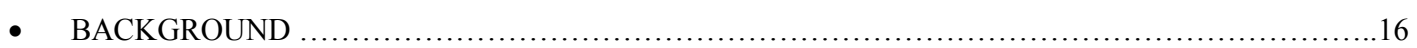

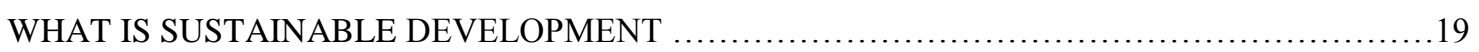

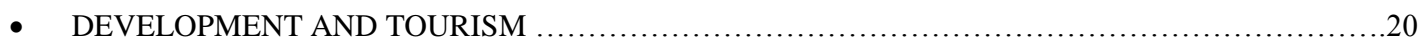

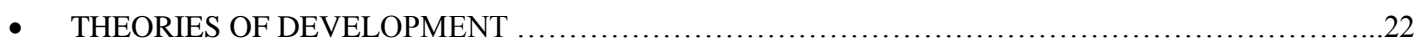

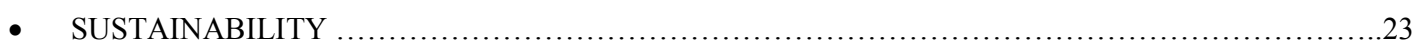

THE APPLICATION OF SUSTAINABLE DEVELOPMENT TO TOURISM ........................24

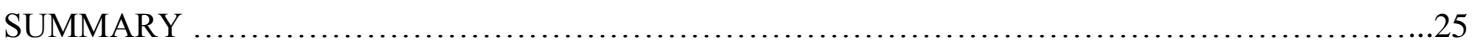

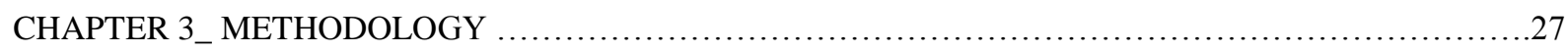

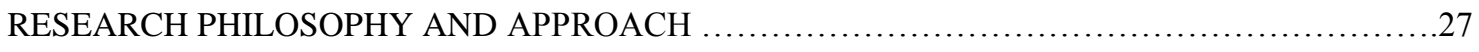

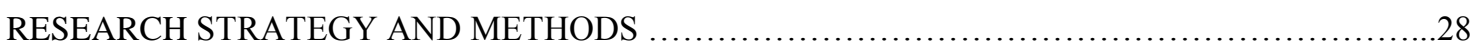

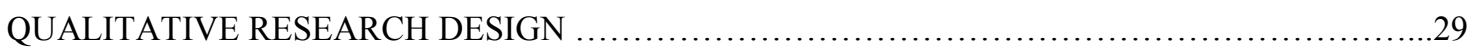

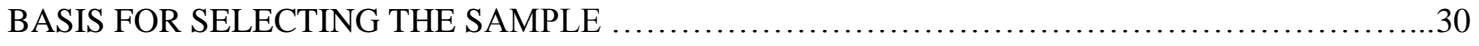

INSTRUMENTATION: DESCRIBING RESEARCH TOOLS AND PROCEDURES ...................34

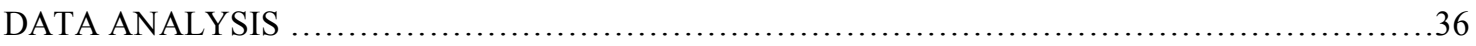

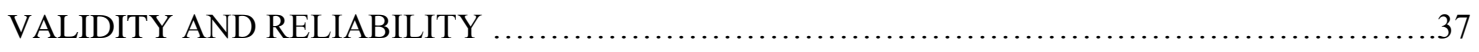

RESEARCH CONSTRAINTS AND PROBLEMS ............................................ 


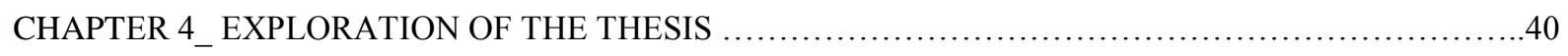

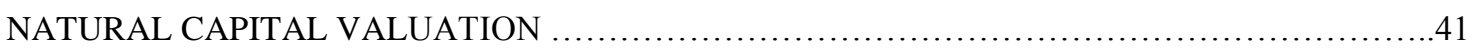

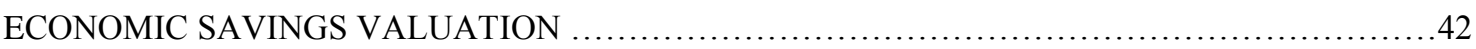

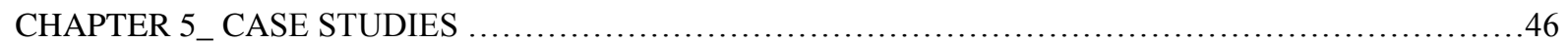

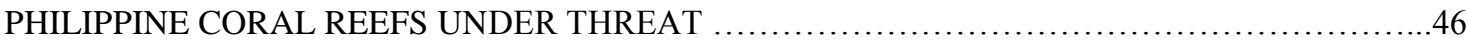

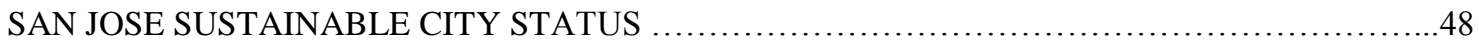

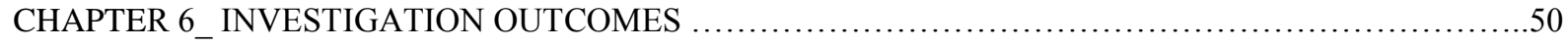

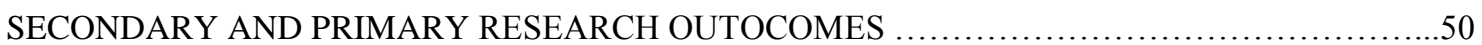

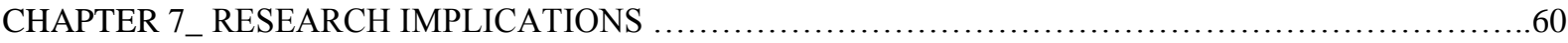

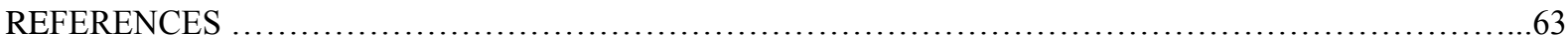

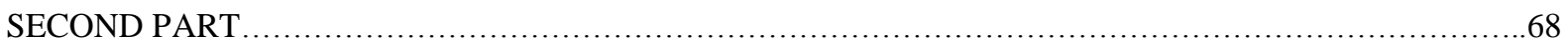

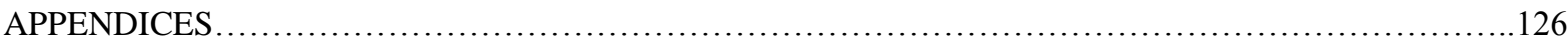

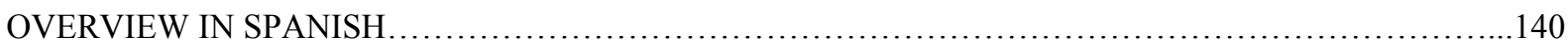




\section{LIST OF TABLES}

3.1 Semi-structured Formal Interviews. Interviewees' details. (Key informants) .31

3.2 Short Informal Semi-structured Interviews. Interviewees' details (Travel agents) .......................33

6.1 Travel agents' perceptions on their clients' environmental requirements in Spain and UK: outcomes 59 


\section{ABSTRACT}

This study has investigated the differences between rhetoric and praxis regarding much contested conceptual debates on the economic sustainability of sustainable development and sustainable tourism. Within the general quest for what is the role of tourism as a sustainable development strategy this study aims to examine the extent to which sustainable tourism can be considered economically sustainable and how some key practitioners within the tourism industry in England and Spain perceive it. The research question has tried to evaluate the economic sustainability of sustainable tourism. The apparent divide between rhetoric and praxis has been examined through each one of the research objectives. In order to meet these objectives desk research and fieldwork have been combined. Desk research has been conducted from March 2003 to May 2004 and from March to May 2005 in the UK. Fieldwork was conducted in Spain and in England from May to December 2003. Eight interviews have been conducted covering seven key informants of the private sectors and one of the public sector (industries in general) in relation to tourism and development. Finally, sixty travel agents have been visited in Spain (32) and in England (28) in order to assess travel agents' perceptions on their customers' level of environmental awareness and requirements upon demanding tourist services. This study has found a number of outcomes presented and analysed in chapter six. The investigation's aim and purpose are evaluated through the research question response in chapter seven. This investigation has found that while academics have been working on sustainability and its parental terms, sustainable development and sustainable tourism for long, public sector's practitioners are relatively recently making efforts in order to implement concepts and practices of sustainable development and sustainable tourism, while private sector's practitioners initiatives regarding sustainability are framed, constrained and conditioned by their economic sustainability within a restrictive legislation and free market-led framework. Private sector's practitioners argue that sustainability needs to be made economically profitable if sustainable development and sustainable tourism are to be implemented. Finally, travel agents in both countries argue that, to date, they have not faced environmental requirements of whatever sort coming from their clients. The second part counters praxis versus rhetoric producing lively evidence and not so conventional outcomes through examining tourism, the managing of sustainability, the valuation of common pool resources from the Other's perspective. Traditional systems, autonomous by being autochthonous, use the managing of sustainability for long time. Evidence is of its feasible praxis versus its rhetoric. 


\section{IDENTIFICATION OF THE MANAGEMENT ISSUES}

One of the main restrictions to the normalization of the sustainability principles implementation in tourism resides in its alleged economic costs in one hand and on the other hand, on the practitioners' perception of sustainability as delivering lower investment cost-benefit return ratios (awareness inertia). Business observers seem to confirm that although companies can achieve tangible gains from environmental initiatives, business managers perceive environmental issues and sustainability as a cost and as a risk but not as a potential source of added value and positive cash flow (Greeno et al, 1998). In the case of tourism, tour operators appear to be reluctant to reduce tourism negative impacts through economic investments unless immediate economic profits can be anticipated (Tepelus, 2005). Therefore, it is the tourism private sector who must finance (directly and indirectly) such normalisation and the principles of sustainability, making of them an integrated management feature. However, the world of business is run and fuelled by and through economic and market facts, forces and rules (often following political interests rather than economic laws), being academic rhetoric and political speech easy (boring?) to read through and listen to, though difficult to be followed for those who have to economically materialise both on day-to-day terms (praxis) within a global market-led context.

\section{RESEARCH AIM AND PURPOSE}

To evaluate the economic practical viability of the concept of sustainability applied to tourism development within the general quest for what is the role of tourism as a sustainable development strategy. The investigation is substantiated through two detailed conceptual analyses (literature review and the exploration of the thesis), representative case studies, and the evaluation of the Spanish and English tourism private sector practitioners' perceptions on the economic sustainability of sustainable tourism to demystify some myths through true praxis.

\section{RESEARCH QUESTION:}

Is sustainable tourism economically sustainable?

\section{OBJECTIVES:}

- To analyse the strategic economic viability of sustainable tourism in comparison with the present mass tourism development model (sustainability versus maintainability) through the literature and key informants' perceptions.

- To evaluate forms of proving that sustainable tourism may be not only economically viable but also sustainable by examining secondary sources, the analysis of key practitioners' perception, and case studies based on the managing of sustainability valuing common pool resources. 


\section{INTRODUCTION_ THESIS OF THE PROJECT}

\section{BASIS OF THE INVESTIGATION: THEORETICAL, CONCEPTUAL AND MANAGERIAL}

Managing natural capital (common pool resources) and pricing intangibles (i.e. tourism know-how) may be highly debatable although somehow unavoidable. Tourism, for obvious reasons, as an industry should be called to become one of the first economic sectors in incorporating these concepts in its accountancy (i.e. Satellite Accounts) and not simply use them as marketing strategies, commonly known as green-wash strategic marketing, often disguised as sustainability, being in fact a form to maintain the traditional western (capitalist, now neoliberal and postcolonial) development model. This rhetoric claims consideration with certain urgency since tourism's inputs are basically constituted by natural capital (i.e. beaches, cultures), whose degradation directly threatens tourism viability at all levels. The intangibles (i.e. tourism services) compliment the natural capital components, being the obvious form to make the latter consumable by the tourists / general public, who unconsciously assume that they are part of the tourism supply (Mihalic,2002). However, paradoxically both have been somehow relegated to the last positions in the tourism industry priorities, which may lead to and accelerate the stagnation stage of a tourism business / destination (i.e. Mediterranean mass tourism enclaves) since once the tourism destination's attractiveness fades away, tourists may seek that original attractiveness somewhere else (i.e. Dominican Republic). Common pool resources are those inputs free of cost such as sun, beach, climate, landscape, culture and so on, which if were priced would constitute a basic and integrated component of the balance sheet of payments, making of it more realistic and accountable, which it is argued should be at the core of the sustainable tourism economic sustainability and tourism private sectors' worries and debates in opposition to its economic maintainability through, for instance, a green-wash marketing strategy and policy.

\section{THE NATURE AND SIGNIFICANCE OF THE SUBJECT}

Why this research subject? Private sector (explicitly) and hosts / guests (implicitly) appear to claim that academic rhetoric and public sector legislation reflect on and are replete with good intentions regarding to the principles and concept of sustainability and, in this case, regarding to sustainable tourism. The main points to debate on sustainability are constrained mainly by economic realities and awareness inertia. Academics' work and governments' legislation may become useless if socioeconomic private sectors do not find sustainability economically profitable as a first stage (Martinez, 2004). The academic rhetoric and judiciary framework might be interpreted and consequently diverted to maintain the present socioeconomic dynamics disguised as sustainability vested in intangible good intentions, which feed international conferences and political speech and all of this vicious circle apparently falling in the green-wash realm (i.e. marketing strategies). However, tourism 
private sector appears to claim that sustainability should be, first and foremost, economically sustainable (Martinez, 2004). In order to achieve this goal it should be proved to the private sectors' practitioners that it is economically profitable at all levels due to the achieved gains in the efficient and optimal use of the necessary resources (inputs), leading to important economic savings and increasing output quality and, consequently, the brand / destination image valued appreciation, which in turn may allow to charge an extra price through meeting or even exceeding the present and prospective customer's expectations before pursuing a social and environmental sustainable development of tourism, which should be integrated within the rest of sectors conforming, as a whole, a sustainable development. In order to examine tourism's strategic potential role in sustainable development Sharpley argues that "it cannot be viewed in isolation from the broader development context of which is meant to be a part" (Sharpley, 2000:3). In sum, if sustainability it is not economically profitable and its profits not only maintainable but sustainable, the private sectors are to look for rising profits where and by any means they may be risen (i.e. through massive resource depletion). Private sector practitioners in Spain and in the UK, when interviewed, have raised these debates and worries. Added to these claims it is, more often than not, found that sustainability and maintainability are overlapped in meaning and practice.

The following first chapter introduces the much contested concepts of development, tourism and sustainability, which constitute the foundation on which the first part of the study builds on. 


\section{CHAPTER 1_ DEVELOPMENT, TOURISM AND SUSTAINABILITY INTRODUCTION}

"Resources management and sustainable development seem to be more inextricably intertwined than ever. References to ideas, principles and policies underpinning sustainability are everywhere, from planning policy guidance to good practice guides to inclusions in development plans. Yet it is also widely acknowledged that there is no single way forward to pursue sustainability. In fact, some even dispute that is desirable at all, others disagree over what the concept means and diverse views also exist into its interpretation and implementation. However, its principles have garnered widespread support even if it means different things to different people at different places; it can provide a touchstone for reflection. By thinking about sustainability we can understand the tensions and dilemmas these issues rise, since having something more than a much desired quality of life it requires us also to consider the interests of strangers in time and space as well as considering ecological limits and all species. Moreover, it requires a holism that is often missing when we concern ourselves solely with the here and now" (Layard et al, 2001:1-2).

\section{BACKGROUND}

In words of Wall (2002) sustainable development as a concept delivers contradictory meanings. Sustainability gives a sense of durability in perpetuity and at the same time development implies a sense of change from one present situation to an improved or superior stage, underpinning a sense of endless material growth. Some proponents of sustainable development may emphasise a balance between human needs and the sustainability of the resources and environment, while others propose the improvement of life conditions of those peoples that do not know "where their next meal is coming from" (Wall, 2002:89) using the available resources. This semantic and conceptual diverse understanding is claimed to come from the "considerable latitude in the meaning of both, sustainable and development" (Wall, 2002:89) rising doubts on "what is to be sustained and what is understood by development" (Wall, 2002:89).

The Brundtland Commission and the literature reflected on the inherent conflicts of interests among economic growth, people and the environment. However, there are many other issues to be addressed that need sustenance such as culture and social equity. Authors such as Ryan (2002) argue if making tourism sustainable would be enough. He poses questions such as: "What if sustainability is perceived as retention of the status quo to protect a cultural or a physical environment but does not recognise the social inequity inherent in those current situations? Who is to deny the potential for economic advancement to the children of subsistence or rural 
cultural traditions?" (Ryan, 2002:17). Harrison (1996) points one basic issue in this regard. He says "how far, for instance, a culture, a people's way of life passed on from generations can be regarded as affixed quantity to be maintained, sustained and defended against all comers?" (Harrison, 1996:78). Following this conceptual thinking Wall (2002) argues critically that "if a fishing community is no longer able to support itself through fishing but successfully turns to tourism to maintain its well-being, albeit with associated lifestyle changes, should this be viewed positively or negatively from a sustainable development perspective?" He fosters further debates by questioning "if one should attempt to sustain tourism or whether it would be better to explore how far tourism contributes to sustainable development." He wonders "if tourism should be seen as a means rather than an end or it should be viewed as a temporary activity while other development options are being sought" (Wall, 2002:89).

\section{THE NATURE AND SIGNIFICANCE OF THE TOPIC}

Development, according to Cowen and Shenton (1996), seems to resists definition, being an ambiguous concept. Sharpley and Telfer (2002) claims that development implies and refers to a positive change and to the plan guiding the process towards the achievement of development itself, although to whom it benefits is not always clear. These authors suggest that development can be viewed as a philosophy and as the outcome of its process, although the speed of renewable and non-renewable resources depletion consumed in its process has not been taken into consideration until recently. Modernisation implies a western style of economic growth as basement upon which the welfare state has been built on and it is maintained, which is the tourism's raison d'être.

According to Telfer (1996a) "development theory and tourism have evolved along similar lines. However, there seems to be little work connecting both fields of study" (Telfer, 1996a, cited by Sharpley and Telfer, 2002:35). This author considers that it is surprising since the main focus of tourism development still relies on a policy of perennial economic growth (modernisation theory), which makes that even countries traditionally rejecting tourists, turn to tourism as a strategy of economic development since, within this concept of development, tourism has played and plays a prominent role by generating revenues, employment and attracting investment, though it is suggested that locally tourism could be used to maintain the environment upon which it is developed (Wilkinson, 1992, cited by Telfer, 2002). Britton (1982) suggests that tourism development can foster economic growth in developing countries, however, he considers quite debatable if tourism leads to self-government, since more than economic independence usually creates dependence on international tour operators and international affairs, neither of which a tourist destination can control, even within industrialised countries (i.e. Benidorm. Spain). 


\section{THE NATURE OF DEVELOPMENT}

Authors such as Sen (1999) claims that, in spite of the advancements achieved, there are still persistent traditional and new problems regarding human development contained and delivered within the term of development. Telfer refers to the words of Sen and mentions “poverty, lack of freedom, women's rights, threats to the environment and the sustainability of economic welfare, which both rich and poor nations continue to face" as some of these problems (Telfer, 2002:36).

After the Second World War, the concept of development was viewed as a linear constant economic growth conveying a sense of endless positive progress (Telfer, 2002). Later, this concept embraces social, ethical and environmental aspects as far as "they facilitated growth" (Brohman, 1996a, Malecki, 1997, cited by Telfer, 2002:36). According to the work of Todaro (1999) there are three core values: "sustenance, self-esteem and freedom" and three objectives within the concept and term of development: "the increase of the availability and distribution of basic needs, the standard of living rise, involving better education, higher incomes, more jobs for all and greater attention to cultural and humanistic values, thereby promoting greater individual and national self-esteem and finally, the expand of the range of economic and social choices so that individuals are not dependent on other people or other countries" (Todaro, 1999, cited by Telfer:36-37).

Later, due to environmental debates, sustainability became a part of the term of development, though not without raising debate (Redclift, 2000). A number of international conferences and summits dealt with these new growing aspects of development, reflecting on issues traditionally ignored. No longer was pure economic growth considered enough. The World Commission on Environment and Development (WCED, 1987:43) defines sustainable development as: "development that meets the needs of the present without compromising the ability of the future generations to meet their own needs" (quoted by Telfer, 2002:37). In 1992 the United Nations Conference on the Environment and Development, known as Rio Conference, developed Agenda 21 that basically guides and fosters through an action plan the achievement of sustainability by using a bottom-up approach, that is, by involving local communities. The second Earth Summit, known as Rio+5 focused on the need to plan in advance and pointed out that developing countries were turning to tourism as a strategy of development (mainly economic). World Summit on Sustainable Development (WSSD), held in Johannesburg in 2002, has further spread the need to implement at all levels the concept of sustainable development. These worldwide known international conferences and summits give evidence of the increasing significance of sustainable development, although they do not seem to consider the role of tourism as a development agent. 


\section{PURPOSE}

Giving the much contested nature of sustainable tourism to current theoretical approaches and the lack of a clear definition make questionable if sustainable tourism will be developed both theoretically and practically or if it will remain as a rhetoric debate (Mowforth and Munt, 1998). Lately, some tourism stakeholders seem to have embraced the principles of sustainability through their own initiatives (i.e. Tour Operators Initiative for a Sustainable Development, 2003; World Tourism Organisation Committee on Sustainable Development of Tourism, 2000). However, the former authors, Mowforth and Munt, question whether these "are significant or cosmetic and superficial changes" (2003:199).

Other authors such as Wight, (1993) warns that "unless sustainable tourism can become attainable by all stakeholders, it will follow the path of ecotourism, whose popularity has (arguably) suffered as a result of it being perceived as little more than a marketing label" (Wight, 1993, cited by Hardy et al, 2002:491). On the other hand, in the views of Hardy, Beeton and Pearson (2002), sustainable tourism, as its parental concept of sustainable development, developed within a context of change in the people's appreciation and understanding of environmental issues, affecting the economy and the tourism development. These authors argue that the concept of sustainable tourism is "based on the general popular believe, and this is more likely to be developing beyond rhetoric" (Hardy et al, 2002:491). This view might be widely contested since the surge of the umbrella term 'sustainability' and the rechristened concepts of sustainable development and sustainable tourism have not raised from bottom-up line, but from summits, conferences and reports well away from people of whatever condition, specially practitioners and consumers of tourism services. This divide between rhetoric, public sector's and private sector's practitioners (Jenkins, 1999, Pike, 2003) and on-the-street people that in the case of this study are travel agencies' clients, frames this study. The idea behind this study is to examine within the general quest for what is the role of tourism as a sustainable development strategy if sustainable tourism is economically sustainable and how this is perceived by some key practitioners in the tourism industry in England and Spain.

\section{OUTLINE OF THE CHAPTERS}

Once the subject of the investigation has been outlined, chapter two reviews the related literature covering concepts such as environmentalism, development, sustainability and tourism in a form that let this conceptual scenario unfold and, in so doing, current debates and current thinking on the topic have emerged (general conceptual study). Chapter 3 presents the range of methods used, research design, basis for selecting the sample, tools, procedures and data analysis. An account of the investigation is explained and issues regarding reliability, 
validity, research constraints and ethics are acknowledged. Chapter 4 explores the thesis of the investigation (specific conceptual study). Chapter 5 presents two representative case studies aiming to substantiate (or otherwise) the former discussions. Chapter 6 presents the investigation results, and the secondary and primary data analysis outcomes discussed in relation to each one of the conceptual study approaches and tourism private sector's informants' perceptions. Both countered against travel agents' perceptions analysis. Chapter 7 evaluates the investigation's aim and purpose through the research question response. Finally, an open question derived from this investigation incentives subsequent research. 


\section{CHAPTER 2 _ LITERATURE REVIEW}

\section{INTRODUCTION: Why Tourism?}

According to Sharpley "throughout the world the most compelling reason for pursuing tourism as a development strategy is its alleged positive contribution to the local or national economy" (2002:14). It is claimed that tourism is a source of relatively quick foreign exchange, which contributes positively to the countries' national balance of payments. This and its multiplier effect are suggested to be the principal reasons why governments welcome and promote tourism development (Opperman and Chan, 1997). Tourism acts as an economic catalyst and it is increasingly used as an economic resource in new or declined areas where past economic developments are no longer profitable, fostering traditional activities by creating their demand and producing directly or indirectly new economic activity (Mowforth and Munt, 2003; Sharpley and Telfer, 2002).

\section{SETTING THE SCENE: HISTORICAL BACKGROUND}

The Club of Rome published in 1972 'The Limits of Growth'. This publication showed that if growth trends continued unchanged the limits of physical growth on the planet would reach within 100 years. Many were who refused to accept its conclusions. These authors published 'Beyond the Limits' twenty years later, in 1992. They showed that a sustainable society was possible by making a balance of long and short goals with much greater care, fostering equity and welfare (Meadows et al, 1992). These authors suggested that human use of the Earth's resources had surpassed sustainable limits, however, decline was not inevitable and a sustainable society was still feasibly possible.

\section{THE RISE OF ENVIRONMENTALISM}

The 1970s witnessed an increase in popular environmental concern that led to a revival of the ideas of environmentalism. These came from the Germany of mid-19th century, where Ernest Haeckel's work created the term of ecology, proposing that mankind was only one component more of the ecosystem (Chase, 1995, cited by Southgate and Sharpley, 2002). Some publications such as 'Our Common Future' (WCED, 1972), 'Only One Earth' (Ward and Dubos, 1972) and 'Man and Nature or Physical Geography as Modified by Human Action' (Perkings, 1965) fostered perceptions of an environmental crisis announcing environmental disasters as result of mankind's developmental actions and the rapid increase in the world's population. These publications questioned the Earth's capacity to match mankind's demands and actions. According to Southgate and Sharpley (2002) all of that made Malthusian school of thought come into being again spreading ideas of environmental disasters due to mankind's depletion of resources and world's rapid population increase. These ideas were 
somewhat forgotten during the successful period of socio-economic growth after the Second World War. However, neo-Malthusian ideas were already spread throughout the literature. World's population high rates of increase worries came into scene during the 1950s attracting the attention of authors such as Russell (1953), who published 'Man's Role in Changing the Face of The Earth'. Paul Ehrlich's book (1968) 'The Population Bomb' supported Malthus' warnings on the limited capacity of the planet to support endless population growth (cited by Sharpley and Southgate, 2002). However, many of the announced environmental threats and disasters have not occurred in spite of the speed of Western economic development during the 1960s and 1970s, although it affected and modified the social and natural environment. Rachel Carson's book (1965) 'Silent Spring' warned on the massive agricultural usages not in tune with nature's laws (Southgate and Sharpley, 2002). During the 1970s the Massachusetts Institute of Technology published 'The Limits to Growth' (Meadows et al, 1972) on behalf of Club of Rome. This publication and 'Blueprint for Survival' (Goldsmith et al, 1972, cited by Southgate and Sharpley, 2002) were thought to be at the head of the environmentalism in the 1970s (Southgate and Sharpley, 2002). However, the former publication was criticised by Simon (1981) due to its methods and use of simple computer technology (cited by Southgate and Sharpley, 2002).

These publications fostered debates and fears on the Earth's limits to support human's endless pursuit for economic growth. However, scientific and technical progresses seemed to have invalidated such environmental fears since high rates of economic growth and rapid population increase were witnessed. In words of Boserup (1965): “the environmental and development discourse embraced a new optimism about mankind's ingenuity and capacity to institute the social and institutional changes to promote effective environmental management" (cited by Southgate and Sharpley, 2002:236). However, Malthus's ideas still warned on the environmental consequences of this model of development. The 1980s was a decade where these former beliefs on science as a problem solving for all became unsustainable. Claims for a development model more in tune with environmental requirements were heard. The negative effects of globalisation preceded its economic effects in regard the fact that the "effluence of affluence" (Southgate and Sharpley, 2002:233) did not (and does not) respect national borders, that is, that one country's activities could have global consequences as a number of catastrophic events (i.e. Chernoville) served to give substance to those reborn environmentalists' concerns. Acid rain, radioactivity, massive losses of fertile soil and many more are direct consequences of this pursuit of the Western model of socioeconomic development that far from diminishing they are steadily increasing. According to Bernstein and Gro (1995) nowadays attention is towards the uneven allocation of the available resources, mainly exploited by Westerners, and the unfair economic and political consequences of globalisation rather than the former worries 
on the growth of the planet's population, which help understand the spread of negative crisis affecting the lot of disadvantaged people around the world.

The events of the 1970s, the Malthusian environmental threats and The Limits to Growth's School (in spite of being criticised as naïve and simple in its methods) "shaped the emergence of a popular environmentalist movement" (Sharpley and Southgate, 2002:236), which during 1970s and 1980s saw the emergence of a 'general green philosophy' as did arguably the alternative tourism perspective that also emerged in the 1980s (Eckersley, 1992). According to Eckersley (1992) a new wave of environmental and political recursive speech derived from the 1960s socialist philosophy was witnessed, which focused on popular participation. All of this fostered the expansion of environmental publications and the surge of protest movements. It is against this background that the concept of sustainability, embracing its parental terms of sustainable development and sustainable tourism, has risen from to heat debates between rhetoric and praxis.

\section{ORIGINS AND INTERPRETATIONS OF SUSTAINABLE DEVELOPMENT}

In Sharpley's words the concept of sustainable development "has raised debate and analysis from different disciplines. However, the concept suffers the same definition problem as it does in tourism" (2000:2). It is claimed the need for a clear semantic and conceptual definition of sustainable development but it becomes hardly achievable since the term is used and understood in many ways; probably as many as disciplinary fields use it for their own purposes (Heinen, 1994, cited by Sharpley, 2000). Redclift, (1989) points out as well as Wall (2002) the inherent ambiguity of the term, spreading opposed meanings of sustainability at the same time as those of progress based on continuous resources consumption. He suggests that it is not clear if "the concept of sustainable development contains any significance to issues of environment and conservation" (cited in Sharpley: 2000:2). Authors such as Friend (1992) questions how resources can be sustained at the same time they are used to support economic growth (cited by Sharpley, 2000). Giving the former apparent contradictions exposed through these lines it is hardly surprising the ongoing debates that sustainability, sustainable development, and sustainable tourism provoke.

\section{BACKGROUND}

The beginning of the spread of the term and concept of sustainable development comes from the 1960s environmental concerns and institutional approach to it. This decade witnessed the rise of an environmental conscience within the industrialised countries, mainly led by the UNESCO Biosphere Conference held in Paris 
in 1968 and the Ecological Aspects of International Development held in Washington the same year. Both questioned the Earth's ecological viability to keep pace with socioeconomic development demands.

Early conservation practice come from so back in time as from Mesopotamia where large areas were put aside to serve exclusively as hunting reserves, refraining logging, agriculture and uncontrolled hunting. During the $1800 \mathrm{~s}$ and 1900s forestry management was established. Mid 1900s witnessed a romantic wave, making people turn to see nature as a source of beauty and health. It is claimed that the industrialisation era was at the back of this environmentalism worries. This period of industrialisation made social and cultural issues come into scene, rising arguments and debates of inequity and exploitation that economic development far from diminishing fostered, revealing poverty at the heart of European countries. The environmental consequences of this model of economic development were at the origin of the United Nations Conference on the Human Environment held in Stockholm in 1972 (Hardy et al, 2002) referred earlier. According to Reid (1995) it was noticeable for being "the first concerted international effort to address environmental problems and it is described as a milestone in the development of global responses to environmental issues" (cited by Sharpley and Southgate, 2002:238). Within the literature the concept of sustainable development delivered ideas of environment and economic growth. At this time a number of cornerstone publications come into scene such as the earlier mentioned 'The Limits of Growth' (Meadows et al, 1972), which questioned "the transactional assumption that the natural environment provided unlimited resources able to support continuous population and economic growth and the belief that nature could cope with the increasing amounts of waste and pollution caused by industrialised societies" (Harding, 1998, cited by Hardy et al, 2002:479). In 1973 it was published 'Ecological Principles for Economic Development' that related economic growth with the environment (Dasman et al, 1973, cited by Hardy et al, 2002). In the same way appeared 'World Conservation Strategy' (IUCN, 1980), "which was endorsed by various countries and further developed Dasman et al's ideas to link the environment with economic development" (Hardy et al, 2002:479). 'Caring for the Earth' followed this edition in 1991, published by International Union for the Conservation of the Nature (referred earlier as IUCN), United Nations Environment Programme (UNEP) and World Wide Fund for Nature (WWF). Some other publications such as 'Our Common Future' widely known as the Brundtland Report (World Commission on Environment and Development, 1987) contributed to the conceptual evolution of sustainable development (Romeril, 1998), giving relevance to both, the economic growth and the care of the environment. "The Brundtland Report brought sustainable development further into the political arena and had a positive effect upon government and non-government organisations" (Hardy et al, 2002:480). Joppe (1996) suggests that this Report convinced many leaders and contributed enormously to make 
the concept of sustainable development widely known. The Brundtland Report (WCED, 1987:43) defines sustainable development as "a process to meet the needs of the present without compromising the ability of future generations to meet their own needs" (quoted by Hardy et al, 2002:480). This definition has become widely acknowledged and discussed within the literature. However, Southgate and Sharpley (2002) claim that these notions were and are not valid for all since while industrialised countries experienced concerns of environmental threats, developing countries remarked that was, and it is, precisely the absence of socioeconomic development which threats their populations and future and therefore, the environment. It seems that there are quite different readings (interpretations) for the same conceptual debates on development, as it is understood in the West.

The international acceptance of the concept of sustainable development brought about by 'Our Common Future' was assumed at the G-7 Economic Summit held in Paris in 1989. According to Brown (1996) "this was the first time that the leaders of the rich industrialised countries such as USA, Canada, France, Germany, Britain, Italy, and Japan admitted the necessity of international environmental policy and the connection between development, international debts and the environment" (cited by Hardy et al, 2002:480). The Brundtland Commission published prior to the wide world known report the 'North-South: A Programme for Survival' that was followed three years later by a second edition of 'Common Crisis: North-South' (ICIDI, 1980:50). This edition declared that "No concept of development can be accepted, which continues to condemn hundreds of millions of people to starvation and despair" (quoted by Sharpley and Southgate 2002:239). It posed questions on the modernisation theory as a panacea for all the socioeconomic devils of the planet. It delivered the idea that quality of life had not been taken into account within the development theory and model to date. The experienced problems in developing countries were not considered as related to economic growth per se (Western model), but to external economic occurrences such as international crisis, monetary instability and international trade fluctuations. Thus, according to Southgate and Sharpley 'North-South' "proposed a new philosophy of economic growth based on multilateral, international cooperation and increased resources flows from North-South, a subject that was further followed in the Commission second report" (2002:239). However, in spite of its modern ideas only a few of its propositions were implemented and the Commission was dismantled soon after the second Report to the General Assembly (Sharpley and Southgate, 2002). The Commission was known for failing to integrate political and economic problems. Furthermore, "the proposed concept of mutuality of interests based on that the northern economic growth was depending upon growth in the South, failed to win widespread support" (Sharpley and Southgate, 2002:239). According to Southgate and Sharpley "by the 1980s the promotion of economic growth in 
the South, initiated by a reformed global economic system and based upon a perceived mutuality of economic interest, was seen to hold the key to sustainable development” (2002:240). In 1992 the Earth Summit of United Nations Conference on Environment and Development (UNCED) gave new relevance to debates on sustainable development. It aimed to revise the Brundtland Report and foster further debates and advancements in order to ensure that the foundations of sustainable development were developed (Hardy et al, 2002). The Rio Earth Summit Conference created Agenda 21, which supported sustainable development in the next century (Sharpley and Southgate 2002). Southgate and Sharpley claim that "Agenda 21 incorporates the philosophy of community empowerment and proactive gain-roots development, while articulating the formal structures of planning, legislation and governance in which it should take place". These authors suggest that "it has indeed gone in some way to bridge the gulf between greed ideology and a politically viable environmental policy" (2002:240). However, it is argued that if sustainable development was accepted internationally was due to some contemporary international happenings such as socio-economic, political and environmental problems coming at the same time (Hardy et al, 2002). It was politically supported because it did not refrain economic growth, but the opposite, delivering ideas of environmental enhancement, that is, a perfect combination of capitalism and environmentalism framed by a free market (Wood, 1993 cited by Hardy et al, 2002) that would ensure sustainable material growth (Hunter, 1995).

Despite the messages spread by these successive reports on the understandings of sustainable development its meaning still remain contradictory presenting ideas of change at the same time that fosters sustenance for the environment and its limited resources. All of this work on sustainable development delivered by these conferences has not found responses for international problems such as economic and political inequity. Any solution is presented to resolve the global paradox of sustainable development consisting in asking how increasing high rates of economic growth can be held at the same time that Earth's limited resources are preserved and sustained for the coming generations (Sharpley and Southgate, 2002). On the other hand, as Butler (1998) suggests, the apparent positive willingness of the public regarding environmental issues and sustainability as concepts seems that has not received equal economic support. In a similar vein, Wilbanks (1994) argued that "Sustainable development is more of a slogan or a screen behind which resources are being allocated and decisions made regardless of whether the forcing term is understood or not" (quoted by Hardy et al, 2002:480).

\section{WHAT IS SUSTAINABLE DEVELOPMENT?}

As earlier discussed, the concept of sustainable development alike sustainable tourism seems to not easily admit definition. Butler (1998) suggests that an agreed definition on sustainability is not the point but the process to 
operationalise this concept. He further argues that the issue is to study traditional problems in order to find solutions rather than going on implementing the same developmental practices in new areas claiming that they are sustainable. The concept of sustainable development contains two terms that deliver contradictions and a sense of ambiguity coming from their semantic and conceptual implications. This lack of semantic and definitional clarity make of it a concept subjected to numerous definitions and interpretations depending on who uses it and for what purpose. Its paradox poses doubts onto its practicality. O'Riorden (1981a, 1981b) suggests that "in a context of neoclassical economics and the traditional ecological perspective the techno-centrism (economic growth versus resource substitution) approach to development is diametrically opposed to the ecocentric approach which represents virtually a rejection to even the sustainable exploitation of nature's resources" (cited in Sharpley 2002:2). This lack of definition provides a broad forum for discussion, which in a sense becomes its strength since fosters debates open to all. That is, according to Skolimouski (1995, cited by Sharpley, 2002:2) and Hunter's (1995) concept of an adaptive paradigm, “its inherent ambiguity is paradoxically its strength and weakness. Its strength resides in that it allows a forum of discussion where participants are able to expose their views and its weakness comes from its difficulty to be implemented" (Wall, 2000:90). From what has been presented it seems that the term will remain ambiguous and open to all interpretations (Sharpley, 2000). However, as Lele (1991) suggests "the philosophy of sustainable development may be explored by splitting it into development and sustainability and assessing each concept separately since (arguably) sustainable development is the juxtaposition of two separate objectives and processes. Thus, the theory of sustainable development can be explored by combining development theory and the concept of sustainability" (cited by Sharpley, 2000:3).

\section{DEVELOPMENT AND TOURISM}

In spite of the acknowledged acceptance of tourism as a development feature, it seems that not much attention has been devoted to tourism as driver of development and even less efforts have been done "to draw on development theory in the tourism literature" (Sharpley, 2000:2). Nelson (1993) argues that tourism and development remain each one within their own conceptual parameters. Some authors have tried to relate development theory to tourism, as it is the case, according to Sharpley, (2000:3) of Britton (1982), Erisman (1983), Lea (1988), Pearce (1989), Harrison (1992), de Kadt (1992) and Oppermann (1993). However, in order to examine tourism's strategic potential role in sustainable development Sharpley argues that "it cannot be viewed in isolation from the broader development context of which is meant to be a part" (Sharpley, 2000:3). 
As earlier discussed, development is both semantically and in terms of its inherent processes an ambiguous concept opened to all. Generally, it delivers meanings of socio-economic change for the betterment measured by standard indicators. Lately the concept of development has embraced social, cultural and environmental issues that sooner or later will be measured by monetary analysis using economic indicators such as the increases in per capita income. Mihalic points out some of the issues involved in the concept of development such as: "a reduction in the poverty level among masses; more social justice; modernisation in terms of social changes; higher levels of employment and literacy; wider access to medical treatment, and a better life with more egalitarian opportunities for self-improvement" and so on (Mihalic, 2002:82). Once the characteristics of development have been presented it is appropriate to introduce some of the characteristics of underdevelopment since to achieve a broader understanding of development and the tourism's role in its pursuit will help appreciate concepts and contexts in regard development, tourism and sustainability. It is not so clear which are the specific characteristics of underdevelopment, consequently, also unclear is the extent to which particular development tools, such as tourism are effective means of addressing developmental challenges and problems. From the point of view of the West it is developing world which suffers of underdevelopment. However, tourism also plays an important role in some areas of the industrialised countries (Sharpley, 2002). Todaro (2000) explores in detail third world countries as well as some areas within developed countries. Although both vary greatly there are some features such as economic dependence on the primary sector, low standards of education, health and quality of life that usually are accompanied by high rates of birth and child mortality.

As previously discussed tourism is widely regarded as a means of achieving development, and in so doing, it changes the former underdevelopment features. The raison d'être of tourism, the justification for its promotion and implementation within industrialised or developing countries is its contribution to the general economic development. Its role has been officially sanctioned by the World Tourism Organisation (WTO), in the Manila Declaration (WTO, 1980:1):

"Tourism can contribute to the establishment of a new international economic order that will help to eliminate the widening economic gap between developed and developing countries, and ensure the steady acceleration of economic and social development and progress, in particular in developing countries" (quoted in Sharpley, 2002:13)

In this sense, the focus of the WTO is primarily "on the tourism's contribution and social change by redistributing wealth and power, acting as a catalyst of development, diversifying the economy, generating 
employment and transferring knowledge from north to south" (Sharpley, 2002:13). However, it is argued that tourism could foster dependency on external affairs, which cannot be controlled by any destination.

\section{THEORIES OF DEVELOPMENT}

The concept of development is continuously changing from one stage to another as well as its attributes or features which have evolved from an exclusive economic view to embrace human characteristics. Within the last thirty years the concept of development has evolved from an economic view to embrace human development led by social principles, though the economic aspects remain. According to Sharpley the question to be addressed now is "how is development achieved in particular through tourism" (Sharpley, 2000:4). It seems that in order to establish the basis to answer this question a brief review of the theories of development in regard tourism will help. Development theory and tourism have evolved along similar time lines since the Second World War, although their respective fields of study have not always been closely connected even if have shared similar focuses. Since the early 1950s, four main schools of development thought or paradigms have evolved. Each paradigm has emerged as a result of the accumulated knowledge coming from the development process and as a result of this the preceding paradigm is supposedly rejected (Wall, 1997). Tourism research has evolved along similar patterns as those in the main development theories. However, according to Telfer (2002:76) "there has been little work connecting the two areas of study".

Tourism research has advanced after the 1940s with the rise of mass tourism (Britton, 1982a). However, papers on tourism can be traced back to the 1930s and earlier. The bulk of the tourism literature evolved from 1960s and 1970s (Pearce, 1993). Tourism research was used as a tool of development with the majority of the research being conducted by planners and economists who worked for organisations including the United Nations, the World Bank and so on (Graburn and Jafari, 1991). During the 1960s tourism was seen as synonym of socioeconomic development, which was part of the first development paradigm, that is, modernisation, within which there was a belief in that tourism created increases in foreign exchange and employment, and that tourism expenditure generated a large multiplier effect, which stimulated the local economy (Graburn and Jafari, 1991). However, "modernisation was criticised for its lack of control of the tourist industry, which led to neocolonialism" (Telfer, 2002:50).

In the $1980 \mathrm{~s}$ and $1990 \mathrm{~s}$ the neoliberal development paradigm and tourism studies focused on international markets and competitive exports such as tourism, which was considered as an invisible export industry within the tertiary sector. Dependency theory was dominant in the late 1960s and 1970s. According to Lea (1988) 
"dependency theory has informed much tourism research particularly with respect to the way in which international tourism reflects historical patterns of colonialism and dependency". This theory proposes that "capitalism development in the core metropolitan centres perpetuates underdevelopment in the periphery as a result of economic surpluses in the periphery being expropriated (and shifted back) by foreign enterprises, misused by the state or appropriated by local elites". Sharpley (2000:5) argues: "there are evident correlations between dependency theory and the political economy of international tourism". Telfer argues (2002:50) that “dependency theorists criticised modernisation as producing not so large benefits, with lower multiplier effects than expected and with linkages closer to reality". Butler (1993), Wall (1993) and Holden (2000) suggest that it is only recently that tourism research has dealt with the concept of sustainability as part of the alternative theory since it seems to be the logical continuum within the evolution of the development theory. Some authors have written on a variety of topics within this paradigm. Telfer introduces some of these topics. Some of them are: "indigenous tourism, local entrepreneurial response, empowerment of the local communities in the decision making process, the role of women in tourism and sustainable tourism development" (Telfer, 2002:58). Alternative development advocates a rupture from preceding linear economic growth-based policies (Redclift, 1987). Sharpley points out that "alternative development, in contrast, proposes a broader resource-based bottomup approach embracing sustainability, human and environmental concerns" (2000:6). There are evident links between alternative development and tourism. For example, Dernoi (1981) proposed alternative tourism as a new style in North-South relations. The concept of environmental harmony (Budowski, 1976) and self-reliance, fundamental requirements of alternative development also became the focus of research into alternative tourism. The latter manifested in the literature on local community involvement in tourism development (Murphy, 1983; 1985; 1988; Haywood, 1988, cited by Sharpley, 2000:6). “Alternative development also provides the foundation for sustainable development, conceptualised as the fusion of development theory and sustainability" (Sharpley, 2000:6).

\section{SUSTAINABILITY}

In words of Sharpley (2000:6) "development theory has evolved from the narrow, classical economic growth perspective into the broader alternative development approach, as did environmental concern, the driving force behind sustainability that evolved from the narrow conservation ideology of the 1900s into some broader environmental movement of the late $20^{\text {th }}$ century". Since the 1960 s environmentalism embraces all socioeconomic issues and not only those related to the environment. Sharpley (2000:6) suggests that "the focus on environmentalism first and sustainability later have been supported by concepts such as Boulding's notion of 
spaceship Earth, which presents the Earth as a delimited space containing limited resources that are renewable and non-renewable". This conceptual framework is cyclical and not linear which it is clearly the opposite to the Western economic model of perennial economic growth and material progress. According to Sharpley (2000) it is what set the parameters for the concept of sustainability. He presents this argument as an equation "where the variables are: a) the rate at which the stock of natural non-renewable resources is depleted relative to the development of substitutes, b) the rate at which wastes are deposited back into the ecosystem and c) global population levels and per capita consumption" (Goodland, 1992:31, cited by Sharpley, 2000:7). Riordan (1981) argues "Obviously, perspectives on sustainability and sustainable tourism vary according to environmental ideologies, definitions and how it may be achieved, which are different to eco-centric from techno-centric approaches that are themselves underpinned by alternative, political and socio-economic ideologies" (cited by Sharpley, 2000:7). In sum, the concept of sustainability implies a sense of cyclical continuance in opposition to the Western endless linear economic model of development.

\section{THE APPLICATION OF SUSTAINABLE DEVELOPMENT TO TOURISM}

This section aims to deal with how sustainable development principles may be incorporated into the tourism industry in order to achieve a sustainable tourism development. Duimal (1996) refers to "sustainable activities when talking about the emergent phenomenon of linking industry sector's names with concepts of sustainable development following its popularisation" (cited by Hardy et al, 2002:481). However, it could be argued that the evolution of the concept of sustainable tourism was in existence in the literature before the sustainable development term was officially used. There are a number of examples that show this affirmation. One example of this is Rosenow and Pulsipher (1979, cited by Hardy et al, 2002:481) who called for new tourism that enhances and maintains the environment. According to these authors this new tourism could preserve and enhance towns, heritage sites and educate tourists. It is argued that all of these aspects could be developed within an alternative paradigm. Other example includes Butler's Destination Life Style Model (1999), which it is argued to be a reflection of the sustainable development as well as the concept of carrying capacity (Hunter 1995). On a formal level, according to Hardy et al (2002:481), "the Brundtland Report (WCED, 1987) detailed various common challenges and recommendations including conservation outside protected areas, wildlife-based tourism and the role of small scale tourism culturally and environmentally sensitive involving aboriginal communities". However, as earlier discussed elsewhere, tourism was given limited attention in its role as an agent of sustainable development at the Earth Summit in Rio de Janeiro. Hardy et al point out in this regard that "chapter 11 of the Agenda 21 recommended that governments should promote ecotourism as a method to 
enhance sustainable forest management and planning” (UNCED, 1992 cited by Hardy et at, 2002:481). In 1995, the World Travel and Tourism Council produced 'Agenda 21 for the Travel and Tourism Industry' in partnership with World Tourism Organisation and the Earth Council. This document promoted areas of action and objectives for moving tourism industry closer towards achieving sustainable development in line with the Rio’s Agenda 21 principles. Another document was the 'Declaration of Male on Sustainable Tourism' (1997) produced by the Asian-Pacific Ministers Conference on Tourism and Environment that was organised by the World Tourism Organisation. This Declaration does pledge support for the goals of a sustainable future as articulated in the Brundtland's report and Agenda 21 (Gee and Fayos-Sola, 1997).

\section{SUMMARY}

Chapter two has reviewed the literature on environmentalism, development, sustainability and tourism as a former background of development theories and concepts in a chronological order. A conceptual and semantic review has been presented through a brief introduction to the reasons of 'why tourism' has been chosen. In second place, it has been reviewed the background against which sustainability appears, that is, environmentalism, reflecting debates between Malthusian theories and other schools of thought such as modernisation amongst others promoting linear endless economic growth. During the 1970s and 1980s a number of publications addressed the environmentalism focus, attracting the attention on the limits of the Earth. It was Bouldwing who developed this concept of the existence of limited renewable and non-renewable resources and the capacity of the environment to assimilate wastes. During these decades, it was believed that scientific and technological advances would overcome such fears and limitations on the use of environmental resources since the previewed disasters and consequences of the fast increase of the Earth's population failed to materialise. However, the limits to the use of renewable and non-renewable resources became evident. The notion that what a country does affects other countries was substantiated due to a number of environmental catastrophes (i.e. Chernoville). According to Bernstein, Crow and Johnson (1995) today's attention is on the uneven allocation of the limited available resources and not so much on population growth. The events of the 1970s, the Malthusian interpretation of the environmental crisis and The Limits of Growth's school of thought shaped the emergence of a popular environmentalist movement and activated protest groups.

During the 1980s the also called 'alternative tourism' emerged within the alternative development paradigm. The concept of sustainable development has attracted debates and analysis from virtually all standpoints. However, to date, its definition and operability remains unresolved so as its monetary sustainability. Further debates explored 
the theoretical divide between tourism and sustainable development. It is argued that "tourism remains embedded in early modernisation theory", that is, unlimited linear economic growth, while "the principles of sustainable development overlook the characteristics of the production and consumption of tourism" (Sharpley, 2000:1). As a result, "significant differences between the concepts of sustainable tourism and sustainable development suggest that the principles and objectives of sustainable development cannot be transposed onto the specific context of tourism, although it does not deny the important role of tourism as a tool to foster socioeconomic development" (Sharply, 2000:14). 


\section{CHAPTER 3 _ METHODOLOGY}

\section{RESEARCH PHILOSOPHY AND APPROACH}

This investigation aims to evaluate the economic practical viability of sustainability applied to tourism development, the extent to which sustainable tourism is economically sustainable and how it is perceived by some key practitioners in the public and tourism industry private sectors in Spain and England. Within the general quest for what is the role of tourism as a sustainable development strategy the research question investigates if sustainable tourism is economically sustainable. Through a revision of the literature this study examines the concepts of sustainable development and sustainable tourism within the current conceptual and economic debates. This study does examine both concepts within the four main development theories: modernisation, dependency, economic neoliberalism and alternative development. These development theories help in the conceptualisation of tourism's role in sustainable development. They constitute the framework where Clarke's (1997) four shifts in the perception of sustainable tourism are framed. These theories and shifts in the understandings and perceptions of sustainable development and sustainable tourism constitute the framework of this study since private sectors' practitioners' / stakeholders' perceptions have been used to illustrate the investigation in contraposition to what has been published these last years on the subject. In order to investigate if sustainable tourism is not only maintainable but economically sustainable and which is its role as a sustainable development strategy this study has tried to evaluate if there is (or if there is not) a divide between rhetoric (publications) and private sectors' practitioners / stakeholders' perceptions on same concepts and management issues. As this study suggests, there seems to exist a paradox that this research aims to investigate and in so doing to be of some value in advancing knowledge and understanding, which in turn may help to bridge the nexus between what has been published and day-to-day practitioners' realities within the conceptual, human and physical boundaries of this study.

As the focus of this study has been to understand practitioners' professional realities and perceptions on development, sustainability and tourism development regarding their economic sustainability in comparison to what has been published in regard to these above exposed concepts a multi-method, iterative style of data collection has been chosen. Data collection has involved the use of a range of methods in parallel and consecutive phases, which have informed each other (Bryman, 1988). This methodology is mostly qualitative, although quantitative aspects are used. This investigation combines desk research, eight formal semi-structured interviews and sixty brief and informal semi-structured interviews. The research strategy goes from the general to the specific using a combination of exploratory, descriptive (inductive) and explanatory (deductive) research 
strategies. The strength of this combination in qualitative research is that it is progressive and flexible. It allows modifying the focus of the research as it unfolds (Stephenson and Johnson, 2002). The overall philosophy is empiricism and the conceptual approach lies in the social science. In sum, the choice of research paradigms is a combination of interpretative-inductive and hypothetic-deductive research approaches.

This chapter presents the research strategy and methods, qualitative research design, basis for selecting the sample, instrumentation, conduct of the investigation, data analysis, research validity and reliability and the investigation constrains and problems. Ethical issues are examined in the last section of this chapter.

\section{RESEARCH STRATEGY AND METHODS}

This study is based on qualitative enquiry. The selection of this qualitative methodology in contraposition to quantitative methods is based on the investigation aim, purpose and research question since commonly quantitative methods have been used to investigate what people / customers / tourists think in order to take decisions. In this case, it was considered that to investigate practitioners' / stakeholders' perceptions would probably uncover commonalities and divergences in a more trustworthy manner than questionnaires and surveys in one hand and on the other hand, desk research alone would have revealed theoretical insights and ongoing conceptual debates but probably had not clarified if all this academic innovative research and theoretical advancement on the subject has reached the practitioners / stakeholders. Both methods are used in tourism research, however, it was felt that surveys were not entirely feasible since respondents can answer in a way that they do not translate into their daily life (i.e. purchasing decision process) and therefore, academic and institutional research can remain for paper and conference presentations without influencing practitioners at any level. So, this study focused on: first, to evaluate what has been published on the subject. This strategy aims to counter academic publications (secondary research) against practitioners' perceptions and professional realities (primary research), that is, to assess the degree of convergence and divergence between both sources of information (rhetoric versus praxis) regarding each relevant aspect dealt with through this study. Secondly, to investigate practitioners' perceptions in their daily professional activity and sector in regard to the research topic, since they are the ones who are in a position to transfer academic knowledge, institutional projects and good intentions into realities, that is, to implement actions to ease the practical implementation of sustainable tourism within a sustainable development framework. Finally, this strategy has included travel agents' perceptions regarding their clients' level of environmental awareness / requirements upon demanding a tourist product / service, which summarises all of the former respondents' work and research done by academics and consultants, 
since it is claimed that the bottom-up approach is the direction in the implementation of the concept and practice of sustainable tourism and, in so doing, to contribute to the operability of a more sustainable development. Consumers' / tourists' preferences become demand and demand can modify business' practices by influencing the direction, speed and quality of the change, in this case to promote and implement sustainable tourism's principles and practices in an integrative manner with all other sectors that conform and create development.

\section{QUALITATIVE RESEARCH DESIGN}

This section presents the qualitative research design of this study. A brief introduction to qualitative research in tourism will help to justify the selected approach, methods and techniques. It is generally acknowledged the difficulty inherent to qualitative research in regard to quantitative research. In words of Jamal and Hollinshead (2001:63) qualitative research is seen as "the underserved power of qualitative inquiry", since it is claimed that qualitative inquiry dig deeper in meanings, needs, desires of the main factor within the tourism business, the human being. From the standpoint of the quantitative approach, qualitative inquiry falls into the realm of subjectivity that must justify its existence compared with the more traditional positivist and scientific paradigms. However, the cannons of good praxis in the social science are changing and, in the tourism field, qualitative enquiry is being increasingly recognised as a tool to discover and uncover the human being's factor. One possible reason behind this tendency is that on a post-industrial era and especially within the tertiary sector, numbers and figures need to be accompanied by knowledge, which is constituted by bits of powerful information that numbers not always can deliver. The rationale behind this qualitative approach is to use the literature and the public and private sectors' practitioners' perceptions to investigate if sustainable tourism is economically sustainable within the general quest for what is the role of tourism as a sustainable development strategy. The concept of sustainability should not be any longer a source of academic rhetoric or political speech alone, but a practicality as it has been explained in the introduction and literature review chapters. However, it appears that even if the practical implementation of these concepts is an increasing imperative, the bulk of the population has not become ready to use such rhetoric yet, although according to several surveys, conferences and public opinion polls consumers are becoming greener (i.e. as in Miller, 2003, WTO, 1989, and International Ecotrans, 1991).

Where does all of this fit into the research design? This study aims to approach the research aim, purpose, question and objectives by examining public and private sectors practitioners' perceptions. The reasons, as already discussed, are to look for meanings rather than numbers. Practitioners' perceptions on the current debates will contribute to evaluate and examine if practitioners have interiorised the current thinking in regard 
sustainable tourism. It is claimed the inherent difficulty on implementing good practices in order to achieve sustainability. However, if those ones who are in the position to transfer what has been investigated and published into practice do not understand and share the practical, economic and environmental implications (quality of life, economic profits, equity, etcetera) the change from tourism to sustainable tourism and the change from development to sustainable development is going to remain in the rhetoric and good intentions realm, although good examples (i.e. WTO, 2000; Tour Operators Initiative, 2003) will continue appearing in this scenario. However, it appears that they will carry on representing only a small proportion of the whole.

\section{BASIS FOR SELECTING THE SAMPLE}

This section follows Ruderstam and Newton (2001) guidance to present coherently the research design stages. This section determines where and from whom data and information have been collected, which is directly analogous to sampling (Ruderstam and Newton, 2001:90-101).

According to Katz's (1995, cited by Ruderstam and Newton, 2001:92) the criteria for selecting sources of secondary data and participants are "deliberately diverse and representational". In this study geographical and human boundaries of the investigation were selected for academic and practical reasons. Academic reasons were, as formerly mentioned, diversity of sources of information in order to avoid or at least minimize the alwayspresent danger of bias and researcher's preferences. Accuracy has been pursued throughout each investigation stage. In order to meet these criteria, as well as for academic and practical reasons, two countries were selected, Spain and England. Four geographic areas were selected. They were Ibiza (Balearic Islands), Castellon (a medium size town by the Mediterranean Sea), Valencia (a big city by the Mediterranean Sea) and London (a cosmopolitan city). The first three areas are placed in Spain. All these areas are characterised by an intense socio-economic activity including tourism, which plays a very important role in their respective economies. These characteristics were the reasons for their selection. Ibiza was visited in August, Castellon and Valencia in October and November 2003. London was visited in December 2003. Locations and season of the year were selected due to high rates of activity as well for practical reasons. London (England) was selected for its obvious socio-economic activity as well for practical reasons. All four areas cover a triangle, not only geographic but also socio-economic and cultural. All four areas attract people and business from around the world. These factors were thought to deliver a diverse and broad range of sources of information and facilitated the selection of the participants' sample. Such variety of geographical locations, human, cultural and socio-economic backgrounds aimed to enrich the investigation and at the same time to avoid or minimize researcher's biases and cultural 
background influences that could affect the research design and the study's processes. Once the geographical boundaries presented, reasons and justifications upon selecting participants are explained.

As already pointed out, formal semi-structured interviews were conducted in both countries covering key informants holding relevant positions in their respective fields and organisations. All of them were actively

Table 3.1 Semi-structured Formal Interviews. Interviewees' details. (Key informants)

\begin{tabular}{|l|l|l|l|l|l|}
\hline Inter & Sector & Name & Position held & Org. & Place \\
\hline 3 & Private & Manuel & Manager & $\begin{array}{l}\text { FEH: Federation of Hotel } \\
\text { Enterprises (Hotel Association: HA) }\end{array}$ & IB \\
\hline 5 & Private & Carlos & Delegate of Politours & Politours (Tour Operator: TO) & VLC \\
\hline 6 & Private & Vicente & Executive Manager & Europa Travel Agency (TRA) & VLC \\
\hline 7 & Private & Custodio & Director & Iberojet (Tour Operator: TO) & VLC \\
\hline 9 & Public & Eduardo & Institutional Relations & $\begin{array}{l}\text { IMPIVA: Valencian Medium and } \\
\text { Little Enterprise Institute. }\end{array}$ & VLC \\
\hline 12 & Private & Monica & $\begin{array}{l}\text { Membership's representative and } \\
\text { Lawyer }\end{array}$ & $\begin{array}{l}\text { FEHVP: Hospitality Federation } \\
\text { of the Province of Valencia } \\
\text { (Hospitality Enterprises: HSF) }\end{array}$ & VLC \\
\hline 13 & Private & Keith & Head of the Consumer Affair & $\begin{array}{l}\text { Emerald Global Limited (Tour } \\
\text { Operator: TO) }\end{array}$ & L \\
& & Alyn & Group Development Manager & Travel Agents (TRAA) & L \\
\hline
\end{tabular}

Source: Martinez, 2004. HA: Hotel Association. TO: Tour Operator. TRA: Travel Agency. HSF: Hospitality Federation. TRAA: Travel Agents Association. IBZ: Ibiza; VLC: Valencia; L: Central London

involved in the public sector (regional level) and private sector (tour operators, hotel associations, travel agents associations, hospitality federations, travel agents associations). This phase of the investigation consisted in an initial exploratory stage using information based on previous studies. Before visiting prospective key informants, some public Institutions and private organisations were selected. After studying the available institutions, associations and firms in the downtown of Ibiza, Castellon and Valencia (Spain) a selection of them were done (see tables 3.1, 4.1 and appendix 1) in order to initiate a number of visits without prior warning. This strategy consisted in trying to grasp the key informant's professional setting. After this exploratory stage, interviews were arranged. This strategy has been time consuming but effective. Reasons behind this strategy were that applying for a meeting by email, phone or formal letter would have probably made the process slower and, till some extent, unproductive since the selected key informant could easily reject the requirement as it was the case in a few number of times. However, the main reason at the back of this strategy was to avoid (when possible) responses prepared in advance that therefore, would not reflect the real perceptions of the respondents. This builds up the second stage of the investigation. 
The initial stage or phase of this research design consisted in desk research. Following Lincoln and Guba's design considerations it is important to determine from where, from what source and from whom data and information have been collected (Lincoln and Guba 1985). Two countries were selected to conduct this secondary research. Two universities' libraries constituted the main source of general and specific bibliography (books, journals, projects and institutional and conference reports). In order to access to bibliography other than that of the academic sector, it was decided to visit and consult the Agencia Valenciana de Turismo (Valencian Tourism Agency) specialised library. This is the most important tourism organisation in the Valencia's Autonomy (Valencia, Spain). It was decided to examine such specialized library in order to access to a broad range of views on the topic through the consultation of official, institutional and general documents. Permission was agreed as long as needed. In sum, three different physical and cultural settings, three different libraries and three diverse languages: Valencian, English, Spanish, have framed the secondary sources. As already explained, reasons were to reach "a deliberately diverse and representational sample" of secondary sources (Ruderstam and Newton, 2001:92). The same principle was used to select related publications. Such sources and details of the former sample are presented in the account of the conduct of the investigation (procedures section).

Finally, it is explained the basis for selecting the final research stage sample, composed by travel agencies' agents, directors, managers and owners (in appendices 2-4 and table 3.2). This third phase was not originally previewed as already indicated in the first pages of this study. The reasons for its inclusion came up when conducting secondary and primary research, since as long desk and field research progressed it was felt the need to investigate how all of the environmental concerns and debates introduced in chapters one and two had reached travel agencies' clients and if they were already using all of this information when demanding / selecting a tourism product / service which, in fact, it is claimed to sum up these questions. The rationale behind this is the argued consumer's role in the pursuit of sustainable tourism and sustainable development, since the bottom-up direction is claimed to be fundamental to achieve the implementation of the former concepts and practices in all sectors. In order to check the viability of this third stage a pilot study was conducted in Spain. Very soon it became evident the impossibility to interview a reasonable and significant number of prospective tourists. So, it was decided to conduct short informal interviews to travel agents. The pilot study consisted in conducting these brief informal interviews to three travel agents in Valencia and another three in Castellon (Spain). It became quite clear that each travel agent could briefly summarise, due to years of professional experience, how and till what extent all of this information regarding sustainability and environment had reached their clients and until to 
Table 3.2. Short Informal Semi-structured Interviews. Interviewees' details (Travel agents)

Source: Martinez, 2004. T. agent: Travel agent. V+ name: The name of the travel agency.

\begin{tabular}{|c|c|c|c|c|c|c|c|c|c|c|}
\hline & \multicolumn{2}{|c|}{ Valencia. Spain } & \multicolumn{2}{|c|}{ Castellon. Spain } & \multirow[b]{2}{*}{$\mathrm{N}$} & \multicolumn{2}{|c|}{ London. UK } & \multirow[b]{2}{*}{17} & \multicolumn{2}{|c|}{ London. UK } \\
\hline $\mathrm{N}$ & Position & Org. & Position & Org. & & Position & Org. & & T.agent & Thomas Cook \\
\hline 1 & Director & V.Kontiki & T.agent & V.Barcelo & 1 & T.agent & Goinglaces & 18 & Manager & First Choice \\
\hline 2 & T. agent & V.Marsans & T.agent & V.Tirado & 2 & T.agent & $\begin{array}{l}\text { Thomas } \\
\text { Cook }\end{array}$ & 19 & T.agent & Lunn Poli \\
\hline 3 & Director & V.Gheisa & T.agent & V.Equus & 3 & T.agent & First Choice & 20 & T.agent & L'AventureTravel \\
\hline 4 & T.agent & V. Barcelo & T.agent & V.Orange & 4 & T.agent & STA Travel & 21 & T.agent & Air New Zealand \\
\hline 5 & T.agent & V.Halcon & T.agent & V.Marsans & 5 & T.agent & $\begin{array}{l}\text { Thomas } \\
\text { Cook }\end{array}$ & 22 & $\begin{array}{l}\text { Tourist } \\
\text { info } \\
\text { assistant }\end{array}$ & $\begin{array}{l}\text { Britain and London } \\
\text { Visitor }\end{array}$ \\
\hline 6 & Owner & Ridocci & T.agent & V.Equus & 6 & T.agent & $\begin{array}{l}\text { Virgin } \\
\text { Travel Store }\end{array}$ & 23 & $\begin{array}{l}\text { Tourist } \\
\text { info } \\
\text { assistant }\end{array}$ & $\begin{array}{l}\text { Spanish Tourist } \\
\text { Office }\end{array}$ \\
\hline 7 & T.agent & V.Marsans & T.agent & V.Iberia & 7 & T.agent & $\begin{array}{l}\text { The Sicilian } \\
\text { Experience }\end{array}$ & 24 & $\begin{array}{l}\text { Leisure } \\
\text { manager }\end{array}$ & Baxter Hoare \\
\hline 8 & $\begin{array}{l}\text { Head } \\
\text { office }\end{array}$ & V.Iberia & T.agent & Altretur & 8 & T.agent & $\begin{array}{l}\text { Boscolo } \\
\text { Tours }\end{array}$ & 25 & $\begin{array}{l}\text { Specialist } \\
\text { consultant }\end{array}$ & Bridge the World \\
\hline 9 & T.agent & V.Ovni & T.agent & V.Crisol & 9 & $\begin{array}{l}\text { Tourist } \\
\text { info } \\
\text { assistant }\end{array}$ & $\begin{array}{l}\text { The Big Bus } \\
\text { Company }\end{array}$ & 26 & T.agent & All SeasonsTours \\
\hline 10 & T.agent & V.orange & $\begin{array}{l}\text { Head } \\
\text { office }\end{array}$ & V.Halcon & 10 & T.agent & $\begin{array}{l}\text { Going } \\
\text { Places }\end{array}$ & 27 & $\begin{array}{l}\text { Office } \\
\text { assistant }\end{array}$ & Ana World Tours \\
\hline 11 & $\begin{array}{l}\text { Head } \\
\text { Office }\end{array}$ & V.Crisol & T.agent & $\begin{array}{l}\text { Conicab } \\
\text { Viatges }\end{array}$ & 11 & Manager & $\begin{array}{l}\text { APA Travel } \\
\text { Service Ltd }\end{array}$ & 28 & T.agent & $\begin{array}{l}\text { Stephen Neill } \\
\text { Travel }\end{array}$ \\
\hline 12 & $\begin{array}{l}\text { Head } \\
\text { Office }\end{array}$ & V.Iberia & T.agent & Rural Viajes & 12 & T.agent & $\begin{array}{l}\text { STA Travel } \\
\text { UK Division }\end{array}$ & & & \\
\hline 13 & T.agent & V.Turia & Manager & V.Castellon & 13 & $\begin{array}{l}\text { Travel } \\
\text { agent }\end{array}$ & $\begin{array}{l}\text { Thomas } \\
\text { Cook }\end{array}$ & & & \\
\hline 14 & T.agent & TUI & T.agent & V.Ecuador & 14 & $\begin{array}{l}\text { Branch } \\
\text { manager }\end{array}$ & Travel Care & & & \\
\hline 15 & T.agent & V.Hippo & T.agent & V.Barcelo & 15 & T.agent & Lunn Poly & & & \\
\hline 16 & T.agent & V.Ecuador & T.agent & V.Azahar & 16 & Manager & First Choice & & & \\
\hline
\end{tabular}

what extent they were already using this information upon demanding, selecting and buying a tourism product.

The reasons behind this decision were that travel agents meet hundreds of clients year around, belonging to some variety of tourism segments. By contrast, to interview one prospective tourist in a travel agency or on the street would have facilitate one person's views and therefore, as formerly explained, his / her responses would not be absolutely reliable (Miller, 2003) since not many persons would answer that they do not feel any environmental worry or that what matters is price and not environmental issues especially. There is one key observation to point 
out: if the respondent answer were "yes, I respect environment", the interviewer would gather information that probably does not represent the truly intentions and the environmental awareness level of the respondent. In contraposition, if the respondent demands a product claimed to be green, he / she would fear a price-raising, since there seems to be quite generally accepted that one thing inherently brings the other, that is, environmental awareness is ok to say, but if you want put it into practice when purchasing, one should be prepared to pay more. This example seems to have been corroborated by this field research. Furthermore, it is claimed that surveys in this regard are not completely reliable for reasons already discussed (Miller, 2003). On the whole this is the rationale behind this final research phase. However, travel agents' perceptions as well as those of key informants are their own views and opinions and as such are considered. Detailed account of this field research phase will be presented in the account of the investigation section.

The overall field research strategy, except for desk research, was based on the surprise effect. That is, it was not previewed to obtain well prepared answers from neither both groups of interviewees but to naturally grasp each one's level of knowledge and practice in regard to sustainable development and sustainable tourism. The aim was to obtain direct answers from each respondent / informant and not answers prepared in advance. In several occasions interview questions were required several days in advance, especially in the public sector. It was noticeable the form and content of those interviewees' answers, which seemed, more often than not, taken from books or prepared in advance.

\section{INSTRUMENTATION: DESCRIBING THE RESEARCH TOOLS AND PROCEDURES}

This section follows Lincoln and Guba's (1985) design considerations in determining the research tools and techniques. The aim of this section is to describe which qualitative tools / techniques have been used and the account of the investigation. In order to focus the investigation five questions were designed, which upon investigation it was expected to answer the research question and meet the research aim and purpose.

A range of methods has been used to investigate the study objectives. During the first investigation stage, the related literature has been examined, analysing secondary sources in general (literature review) and in close relation to the investigation aim, purpose, research question and objectives (exploration of the thesis). The aim of this first task has been to set out the scenario and by analysing this scenario to let emerge the current thinking in sustainable development within which sustainable tourism is framed. At this stage, the technique / strategy was to review the literature by referring to a Venn's diagram, which guided the process. It consisted in three intersecting stages. The first was background literature or 'long-shot', which dealt with general readings. The 
second stage of the Venn's diagram dealt with the topic's relevant literature. It was looking for 'medium shots' and finally the last task consisted in looking for very relevant literature, which was looking for 'short-shots'. (Ruderstam and Newton, 2001:63).

The second research phase consisted in interviewing key practitioners holding relevant positions in their respective fields and organizations (public and private). The interviews consisted in five semi-structured questions derived from the analysis of secondary sources. The interviews' length was between 20 and 30 minutes, although this estimated length was adapted to each interviewee's circumstances. Five research questions were always presented in the same order to every interviewee. Of the eight formal and semi-structured interviews, six of them were conducted in Spain and two in Central London. They were tape recorded except one that was recorded in note-taking form. Each interviewee agreed permission to be recorded. The interview procedure consisted in asking one by one each question and at the same time interviewee's answers were tape recorded and relevant points annotated. Observations were written down in the right column of the interviewee's answer sheet, while on the left side interviewee's key arguments were annotated. Both were expanded just after the meeting. The strategy was to record the speech at the same time that key arguments and observations (setting, body language ...) were annotated. Each interview's observations and notes were recorded in a sheet of paper with the interview's personal data, date, place and length of the interview. Tape-recorded interviews have been transcribed in full. The interview not tape recorded due to the setting circumstances was developed further just after the interview.

In England two interviews have been conducted and tape recorded. The two interviews have been transcribed in full. The interview procedure, strategy and technique have always been the same as in Spain. In both countries the qualitative research design has been rightly implemented. Desk research was completed in both countries. Interviews covering private and public sector's practitioners were satisfactorily conducted. However, not every prospective key informant accepted to be interviewed and not every organization accepted to make an interview appointment. This failure of potential respondents to help is an occupational hazard inherent to the research process, which in this case was previewed in advance. In order to complete the research design second and third phases, more contacts and visits were arranged than those necessary in order to cover all sectors practitioners' perceptions. In Spain only one association (in Castellon) declined the request for an interview. In England one tour operator and an academic researcher rejected to be met. However, in substitution to this, both facilitated documents containing all the organization's information in regard the topic and further sources of information. 
Finally, the third research phase was fully accomplished in Valencia and Castellon (Spain) where 16 travel agents were briefly and informally interviewed in Valencia, while in Castellon were interviewed another 16 travel agents. In Central London 28 travel agents were required to be interviewed (see travel agents details in appendices 2-4). The travel agencies were nearly all located in the respective downtowns. These areas were thought to offer a broader variety of people that could require the services of a travel agency. In the case of the travel agencies, alike the formal interviews, not everyone visited accepted to answer the two short and informal questions. This fact was previewed in advance and more travel agencies were visited than necessary to accomplish the research design.

In sum, in Spain five formal and semi-structured interviews were tape-recorded and another one was annotated. They were conducted between August and the first week of November 2003. In England two formal and semistructured interviews were conducted. They were all conducted in Central London between the first week of June and the first week of December 2003 (see table 3.1 in appendix 1). Thirty-two short and informal semi-structured interviews were conducted in Spain to travel agents during October and the first week of November 2003 (in Castellon and Valencia). Finally, twenty-eight short and informal semi-structured interviews to travel agents were conducted in Central London between the second week of November and the first week of December 2003. These sixty short informal semi-structured interviews (travel agents' details in appendices 2-4 and table 3.2) were thought to be tape-recorded but it became evident during the pilot study that due to the travel agencies' settings and work conditions it was not possible to do it. So, all of them are recorded in form of notes.

\section{DATA ANALYSIS}

This study has followed "the constant comparative method of analysing qualitative data" proposed by Lincoln and Guba (1985, cited by Maykut and Morehouse, 1994:126). Succinctly, this method of qualitative data analysis followed the next steps: tape-recorded interviews were transcribed in full detail and printed (one example in appendix 11). Once this step was over each transcript was coded to be identified easily and by reading through, units of meaning arose. These units of meaning were then categorized (see appendices 5-9). This study data analysis has used the five interview questions as a range of codes. Within each code further units of meaning were identified which fell into each interview question components. This process continued until every transcribed answer was processed. Once this was done with every transcript, the constant comparative process started systematically comparing the units and subunits of meaning. Then, they were categorized again within a framework. This framework has corresponded to the professional position and organism of each 
respondent broadly split up by public and private sectors. The constant comparative method of analysing qualitative data followed to refine the established units and subunits of meaning, exploring relationships and looking for commonalities and disparities across units of meaning. This process has closely examined many propositional statements that stood by their own and other that fell into groups. Both have informed the study's inquiry. This analysis of the transcriptions has revealed some common and divergent perceptions and views on the same issues, a number of themes and some arguments with respect to each interview question that have informed the primary research outcomes (empirical study). These have been compared with what has revealed the review of the literature (first conceptual study) and the specific exploration of the thesis of this study. At this point, again similar and divergent perceptions, views and new or recent arguments so as concepts have been compared. What has emerged from this systematic reasoned comparative qualitative data analysis constitutes the secondary and primary outcomes. The last comparison has consisted in to counter the first and second research stages results against what the third investigation phase has uncovered (travel agents' perceptions). This final step has consisted in discussing systematically the investigation outcomes. Some evidence of this process is presented in appendices 5-9. However, it is generally recognised the implicit difficulty to attach all the material developed in the process as evidence due to its volume.

\section{VALIDITY AND RELIABILITY}

Validity means the extent to which the information collected "truly reflects the phenomenon being studied" (Veal, 1997:35). Reliability means that "data and their analysis are not affected by the research instrument producing same results time after time it is used" (Denscombe, 2003:300). In tourism, empirical research is largely concerned with people's behaviour, views, needs and attitudes. In this case, the researcher relies on secondary information and on people's (respondents) perceptions and opinions. Consequently, it is argued that the validity and reliability of qualitative data can rarely be as certain as that of the natural sciences (Veal, 1997).

This study is qualitative in nature what means that validity and reliability in qualitative research cannot be fully met, since measures and outcomes used and found in a qualitative study probably are not going to be exactly achieved again by another research even though following exactly the same research process. Triangulation has been used in order to counter data and information from different source and in so doing attempts to increase the level of reliability (see instrumentation section). For instance, each interview produced three methods of checking the accuracy of the process and data obtained. At the same time the interviewee spoke, his / her speech was tape recorded in seven out of eight interviews, notes were taken and observations were annotated. The idea 
has been to be as accurate as possible as well as to record the information in various forms to check and make sure that the interviewees' speech was not misunderstood. (Ideally, a team of researchers using a qualitative research analysis protocol conducts this process). The interviewees' answers were supported due to their respective held positions within each sector, respective organization and professional experience. The avoidance of the researcher's bias and intrinsic preferences has been behind the research design and conduct of the investigation. It was also the reason for selecting two counties; two university's libraries and one governmental institution as sources of secondary data; eight key informants and sixty travel agents interviewed in two countries and 4 cities. Silverman (2001:226) following Kirk and Miller (1986) considers that "reliability can be addressed in qualitative studies by using standardized procedures". Reliability in qualitative studies is associated with what Seal (1999) calls "low inference description which involves to be as concrete as possible, including accounts of what people say: verbatim, rather than researcher's reconstructions which would allow researcher's personal perspectives to influence the reporting" (cited by Silverman, 2001:226). This study has intended to follow these precepts. Following Veal (1997:36), "any research findings relates only to subjects involved at the time and place the research was carried out", therefore, they are not generalizable, which in the case of this study have delimited and limited this investigation.

\section{RESEARCH CONSTRAINTS AND PROBLEMS}

The research constraints have been, in a sense, those inherent to the research process, which means a challenge faced probably not for the first time in this case. Problems have been the abundance of bibliography on the topic containing rather dispersed conceptual arguments that made difficult its retrieval although delivering a wealth of insights. Problems upon selecting sample, conducting fieldwork and processing data are quite common and therefore should be expected especially within qualitative research. In this case, the investigation has enjoyed high rates of collaboration from people and organisations approached and only a few rejections have been encountered as already explained. However, interviewing and transcribing have been time consuming since interviewees have delivered lengthy answers, extending on subjects not so specifically required or have not addressed so directly the questions. It has affected data analysis, making of it a rather lengthy matter, but this is inherent to semi-structured interviews where interviewees are free of expressing themselves on the question addressed. Time, length and depth of a qualitative approach constraints the study, which is time consuming and, in this case, financially demanding. Different cultural backgrounds and languages of communication (verbal and written) have made the process somewhat slower. However, neither of them has represented a major barrier to the conduct of the investigation. Ethics have been taken into consideration by respecting the rights and dignity 
of informants, avoiding any harm to them coming from their collaboration and by operating with accuracy and integrity in the research process so as in the exposition of outcomes (Denscombe, 2003). Informants' privacy has been pursued although all of them agreed permission to be recorded and their answers' output discussed in this study.

The next chapter initiates the second side of this study first part. Chapter four presents with certain detail the exploration of the thesis of this study, which constitutes the threshold of the empirical study. 


\section{CHAPTER 4_EXPLORATION OF THE THESIS}

Within the quest for what is the role of tourism as a sustainable development strategy the next lines deem to explore with certain detail the research question: is sustainable tourism economically sustainable? It has been a time consuming task to research on this subject for which it appears to have not much published literature to date (Garrod and Fyall, 1998) within the key tourism domain. This chapter deals with a review on the economic sustainability of sustainable development and sustainable tourism as an introduction to the market-led economic viability of sustainability. The former discussion is illustrated through some selected examples of the extent to what, to date, sustainability may be economically sustainable.

The evaluation of the economic sustainability of sustainable development and sustainable tourism may be approached from two of its components: the valuation of the natural capital (Garrod and Fyall, 1998) conformed by tangible and intangible environmental goods (i.e. nature and culture) and tangible and intangible savings (Ayala, 1995; Tepelus, 2005) generated through optimisation under the principles of sustainability. These two aspects, among others, appear to have an especial repercussion on the private sector within an increasingly global and competitive market-led economy (economic neoliberalism), which has to strive among the judiciary constraints, the exigencies of a highly competitive international market and an endless search for new destinations where reinitiate the product's life-cycle (Mowforth and Munt, 2003). The latter case it is argued to be so because natural common pool resources do not represent, so far, any monetary cost to companies that extract from them part of their rents by using them within a short time span vision (Garrod and Fyall, 1998, Mihalic, 2002). Tourists and consumers assume that these natural goods (i.e. beach, landscape, climate ...) are part of the supply (i.e. a service or a product). Mihalic (2002) argues that this process is explained by the theory of the tourism valuation of natural goods. This theory states that "profitless or value-less aspects of nature and culture (i.e. the material and the symbolic) may be converted into premium prices if sold on the tourism market" (2002:107) or in any other feasible market might be argued. They are conformed by "public and non-priced goods" (Mihalic, 2002:105) that "have not to be built or created" (Sharpley, 2002:19). These common pool resources are appropriated by endogenous and exogenous companies and used at no monetary costs. This lack of costs fosters their massive and careless consumption, which may witness two stages. The first, when due to the fix amount of these free resources the increasing demand derives into higher prices producing economic rents for the supply side ownership, which very often it is found to be exogenous with respect to the tourism destination. The second consists in the devaluation of such assets' attractiveness due to their deterioration, which "would require a visitor rent in the form of lower prices" (Mihalic, 2002:107). At this point, it may occur that new 
destinations are sought where to reinitiate the product's life-cycle (Mowforth and Munt, 2003). According to Mihalic (2002) this process constitutes a form of neo-colonialism "whereby control of national property is taken over by foreign capital" (2002:106). However, although tourism companies' durable success thrives on these common pool resources (i.e. their pristine attractiveness), they are not usually willing to maintain them or repair the damaged caused through their activities (Mihalic, 2002) unless immediate positive economic gains can be anticipated (Tepelus, 2005). Mihalic argues that those costs (externalities) are passed onto the host. However, it may occur that such natural and cultural goods (natural capital) have "limited or no alternative use" (Jenkings, 1991:86, cited in Sharpley, 2002:19) or are value-less due to a lack of awareness or expertise, allegedly from the part of the hosts who traditionally have used the interests of the natural capital (renewable resources) "rather than eat into the underlying capital of the earth" (non-renewable resources) (Mowforth and Munt, 2003:112). In this case their valuation or added value may be zero, producing scarce or no economic benefits to the host population, being in some occasions a source of underdevelopment and economic poverty from the questionable Western point of view (i.e. remoteness, ethnicity). However, according to Mihalic (2002), Garrod and Fyall (1998) tourism may bring rents into the host population economy through the valuation of such resources otherwise value-less, that if strategically managed for the preservation and enhancement of the environment as a whole may generate further and new sources of income and socioeconomic activity not seen before (Greeno et al, 1998). If part of these rents is invested on the common environmental capital, tourism might contribute to the preservation of those common pool resources upon which the industry thrives by representing a sustainable contribution into the host's economy, being the economic profitability (praxis) the main motto to preserve those endowments not because of themselves but because they produce immediate and sustainable tangible economic gains (i.e. visitors taking pictures of a group of lions in, say, Kenya instead of killing them, is it economically profitable? Is it sustainable?). As a derived sub-product from these processes sustainable tourism may become economically sustainable and therefore, attractive and beneficial to all the stakeholders involved within the actual so as the foreseeable global market-led economic neoliberalism. The former conceptual and managerial reasoning, in a sense, could be argued to conform somehow the strategic role of sustainable tourism as a tool of sustainable development. However, the question to pose would be: Whose development? Whose progress?

The second approach to the economic sustainability of sustainable development and sustainable tourism is constituted by the economic valuation of tangible, intangible, symbolic savings generated through optimisation following the principles of sustainability. However, the principles of sustainability may be interpreted from a wide range of interests as discussed at length in the literature review. This lack of conceptual, semantic and 
practical clarity within an increasing judiciary constraint has originated, as formerly discussed, some strategies within the private sector in order to be able to cope with (apparently) legal, social, environmental and economic requirements. Green-wash marketing is quite commonly applied disguised as sustainability, which seeks to meet and fit all the former range of interests in order to maintain the business running within a western linear model of development vested in sustainable development and sustainable tourism (Mowforth and Munt, 2003). However, there are companies interpreting sustainable development by looking ahead throughout an open field of challenging business opportunities not seen before (Greeno et al, 1998).

Eco-efficiency appears to be a new word in the managers' jargon, embracing both economic and environmental sustainability. So, the new proactive approach in business appears to contemplate environmental protection, social responsibility and economic profitability within a holistic though economically pragmatic managerial framework that allows companies to anticipate market, social, environmental opportunities and competitive advantages while go a step ahead from the increasingly regulatory and judiciary scene. A shift from Fordism to post-Fordism business approach demands equilibrium between a roaring demand for quality, constant novelty (in services especially) and the management of the economic sustainability of the necessary resources (inputs) and entrepreneurship through technological innovation and know-how development (i.e. bioengineering, ecotechniques, natural capital valuation). It may be argued that it appears to be cheaper and easier to keep in permanent good conditions those necessaries resources (inputs) than let them deteriorate within a short time span since recovering them (White et al, 2000) or mining new ones may be considerably much more expensive (i.e. building prior inexistent infrastructure). However, Mowforth and Munt criticise that "regardless how much damage may be done culturally, socially and environmentally, it is perfectly acceptable if the economic profitability of the scheme is great enough to cover the damage, ease the discontent or suppress the protests" (2003:103), as in the case of Mexico (Yucatan's rain forest massive destruction) or Tunisia (sea shoreline massive building). These authors claim that economic sustainability should not compete with other components of sustainability's concept since in itself is of equal importance although "who gains and who loses financially" (2003:103) defines issues of inequity and uneven power. Ayala (1995) argues that eco-efficiency may require dealing with "rethinking, reusing, reducing, rationalising, optimising, recycling, recovering", preserving and enhancing (1995), which lead to positive cost-benefit-saving ratios whose gains go further on than immediate positive cash-flow. The economies of saving are the most visible advantage, quite especially for entrepreneurs, however, the former processes deliver intangibles such as strategic comparative advantage, market position, much needed know-how, and favourable business' image (among others) that may turn into cash in the medium 
and long term, which appears to be related to an economically sustainable development and sustainable tourism. Mowforth and Munt (2003) argue that although the economic profit keeps moving forward the private sector, there are examples of good environmental practice (i.e. WTO, 2000; Tour Operators Initiative for a Sustainable Development, 2003). However, the "profit maximisation has a tendency to subvert and subjugate other considerations, ethical and environmental" (Mowforth and Munt, 2003:179). These words appear to reinforce the thesis of this project's argumentation since mainly (except non-profit organisation) the monetary profitability and financial benefit from the managing of sustainability are, first and foremost, the main motto to translate the concept, which is rhetoric, into a tangible implementation, that is praxis. Sustainability should be sustainable.

Envisaged economic gains within the sustainability domain would start a snowball of private sector's initiatives (i.e. International Hotel Environment Initiative) around the world in a straightforward manner while judiciary tightness and environmental discourse lead to the question of whether superficial and cosmetic acceptance of the sustainability rhetoric, more often than not understood as maintainability, would lead us anywhere further than the Fordism western model of development, which may hold scarce significance within other cultural contexts and therefore, dubious success (i.e. as in some former African colonies). In words of Greeno et al "ultimately what drives an investment in sustainable development is the conviction that the company's strategic shift and new products serves its customers better and positions the company to achieve a dramatic growth based on the three pillars of sustainable development: building a sustainable company, reducing environmental impacts and creating wealth" (1998:7). In the case of tourism this perspective is defined as "tourism that allows for the enjoyment and understanding of the nature and culture of a destination while producing economic benefits and actively promotes environmental conservation" (Ayala, 1995:6). Eco-efficiency may deliver value for companies as they optimise daily operations and inputs across the entire life-cycle of new or existing products and services. Furthermore, these processes show potential growth in existing (i.e. mass tourism) and new areas (i.e. allinclusive resorts) that may lead companies beyond the known short term limits, influencing the whole business value chain (vertically and horizontally). For instance, "replacing stuff with information" (Greeno et al, 1998:3) may save tons of raw materials, considerably reduce processes while optimising every single input unit, all of that produces the non-use of massive quantities of those inputs (resources) at the same time that companies save thousands of millions (currencies) from minimising or even avoiding damage within the environment and hosts' livelihoods as a whole, delivering higher than average quality in their products and services (outputs' total quality management). These former processes enhance revenue, not only in monetary terms but also through higher quality performance (added value through zero damaging management), new product and service niches 
that address sustainability principles and through pricing, for instance, all the gallons/litres of raw sewage not generated so as all of those pollutants not necessarily emitted: i.e. $\mathrm{CO} 2, \mathrm{SO}_{2}$ and $\mathrm{NO} 2$. The latter could be priced through government's taxes devolution and official prestigious monetary awards, which would act as incentives in the pursuit of sustainability as a differentiated managerial feature from maintainability.

There are companies that are already enjoying economic profits (savings) as in the case of Electrolux that has designed, among other items, a solar-powered lawn mower, which makes slight noise releasing zero emissions. The company has realised that when the relation price-quality exceeds customer expectation, clients are willing to buy and pay a bit more while the company reduces significantly its overall costs. Xerox sells the function of photocopying rather than doing that itself. When these machines reach the end of their useful life, Xerox recaptures parts of the material which are refurbished and go into other new machines. In so doing, Xerox has saved US\$ 70 million in 1995, while acquiring a competitive advantage at the same time (i.e. these savings might be invested in further research on managing sustainability, what would generate further savings). Intel has reengineered processes formerly requiring eight months into only three, which has reported economic savings at all levels. Baxter has saved US\$ 2 million from reengineering its packaging processes by recycling, which has delivered a total US\$ 25 million in savings across the company. Baxter realised that clients value low prices and reliable delivery over environmental worries, which appears to support Butler's theories regarding consumers' dubious willingness to economically support sustainability issues. Greeno et al (1998:7) claim that companies are learning practical lessons (generating anew know-how) upon adopting sustainable business practices, which may well provide relative and absolute competitive advantages, while easing a large range of tangible, intangible savings, discovering sources of new business opportunities not seen before when "looking with fresh eyes in and out the firm's interactions" (Greeno et al, 1998:7) within a proactive and sustainable development approach.

In the case of tourism, sustainability may be addressed through merging the concept of Eco-hotel and the traditional tourism (Poon, 1989, cited in Ayala, 1995) by implementing policies and practices leading to the preservation of each destination's pristine attractiveness, where tourism facilities mute within the environment as in the case of the Great Barrier Reef Resort in Hayman Island (Australia) and The Rockresorts in Amboseli and Mara Game Lodges (Kenya), which visually and functionally mute within the primary natural landscape. Going even further, the Laguna Beach Resort recovered a deserted open-air tin mine on Pucket Island (Thailand) by replanting indigenous vegetation as to mute the former mine within the surrounding original landscape. Other hotels reserve a large proportion of their property as in, for instance, Las Bahias de Hutalco (Mexico), where 
51,900 acres $(70 \%)$ have been preserved in their original sate (Ayala, 1995). However, the latter might be argued to be simply a form to usurp massive properties for future speculation or following expansion, taking advantage of the privileged low-cost buying conditions and tax-holidays that governments usually offer to open virginal lands to the international tourism as in the case of Riviera Maya, Chetumal (Yucatan Peninsula. Mexico) and Mayaworld project (extending across five Central American nations). Another example is constituted by the 80 Paradores de España, which from as early as the 1920s are implementing these modern debates by adapting and transforming existent convents, castles and palaces (Spanish national heritage) in high standard hotels owned by the Spanish State that by giving them a new economic utility, preserve them from speculation and abandonment within a multi-layered approach (Hall et al, 1993, cited in Ayala, 1995), targeting selected segments and pursuing moderate promotion of inland Spain (Ayala, 1995). These former models appear somehow to follow Elkington's (1997) triple-bottom line concept to implement sustainability, where not only financial profits are accounted but also those social and ecological benefits that become latent cash within the medium and long term as formerly explained, which emerge when a sustainable innovation represents clear important costs reduction. It means that the company faces lower costs (economic, social, and ecological) than those its competitors have to bear, easing investment positive returns within a real competitive field such as, for instance, a mature mass tourism.

The following chapter deems to substantiate the study's thesis argumentation through two case studies. The first case study analyses sustainable tourism and the valuation of the common pool resources. The second case study analyses urban sustainable development and its generated tangible, intangible and symbolic savings' valuation. 


\section{CHAPTER 5_CASE STUDIES}

This chapter presents the case and context of "Philippine Coral Reefs under Threat: the Economic Losses Caused by Reef Destruction" (2000) and "San Jose Sustainable City Status" (1998), which substantiate (or otherwise) the debates on the economic viability of sustainability.

\section{CASE STUDY_PHILIPPINE CORAL REEFS UNDER THREAT: THE ECONOMIC LOSSES CAUSED BY REEF DESTRUCTION (Adapted from White et al, 2000)}

Philippine archipelago is formed by 7,000 islands bountifully endowed with natural beauties in the South China Sea. Coral reefs protect most of the islands shorelines from the fury of the open ocean at the same time that traditionally have provided with abundant fisheries, since coral ecosystems are among the most diverse and productive in the world, contributing around US\$ 1 billion to the country's economy annually. For instance, live fish exports in 1996 amounted US\$ 32 million (White et al, 2000). However, a demanding growing population, over-exploitation, aggressive fishing methods (poison, sodium cyanide, dynamite), sewage and sedimentation due to the rain forest massive clearances, have seriously affected coral reefs' health, their productivity and therefore, the fishing villages' economy and traditional food supply (around $50 \%$ of the total animal food is constituted by fish). The studies conducted in the Philippine areas of Bacuit Bay and Palawan has revealed that a primary unspoilt coral reef produces on average 20 tons of diverse fisheries per $\mathrm{km} 2$ in one year. Lately catches have fallen down up to 4 tons in the same areas that in market terms may suppose around US\$19,000 less per year (and there are 27,000 km2 of coral reefs), plus potentially less tourism revenue per year (less vital foreign exchange) (White et al, 2000). In order to refrain and possibly reverse these processes a number of sustainable management projects have been undertaken in areas of Apo island, Batangas, Mactan Island, Cebu and Panglao Island with the aim of demonstrating that damaged coral reefs may be environmentally managed with the participation of all affected stakeholders. These studies have focused on demonstrating the economic valuation of losses as a strategy to raise awareness on the national importance of the damaged caused through real economic figures rather than academic rhetoric. So far, results have demonstrated that the investment costbenefit ratio is clearly positive in the sustainable management of the coral reefs, since more money than expected has been raised through fishing catches control, small scale domestic and international tourism (i.e. scuba diving) and small entrance fees in the case of the studied areas and marine reserves. Furthermore, these studies have detected visitors' willingness to economically contribute (i.e. US\$ 300,000 annually in Mabini and Batanga areas alone) to the recuperation and sustainability of the areas under study in exchange for their visitation, what in essence appears to be a kind of natural capital valuation, that is, giving a monetary value, through pricing their 
intangible benefits such as the enjoyment of nature's wonders, to these natural endowments owned (supposedly) by the respective villages. Over 15 years Apo Island (1 km2 marine reserve since 1986), which receives annually 1,000 visitors, has proven the feasibility of its sustainable management program, with an initial cost US\$75,000 and an annual management cost of US\$ 5,000, rising on average US\$ 50,000 per year from catches and tourism (White et al, 2000). This is a new and renewable source of money since, traditionally, villagers have appreciated and economically valued only their catches (in local currency), of which an important part are consumed locally and therefore not exported, being the coral reefs in themselves value-less with no other economic utility further than fishing. The most immediate effect obtained through their sustainable management has been to release pressure on the coral reefs ecosystems including the coral's natural recuperation through the economic positive cost-effective ratio, coral reefs' valuation, awareness rising, know-how transfer and self-reliance increase. These studies have estimated that no less than US\$1,35 billion are raised from the Philippine 27,000 square kilometres of coral reefs despite that, according to White, Vogt and Arin (2000), 95\% of them are not in good conditions.

The former economic valuations have been calculated in US\$ dollars, which if exchanged for Philippine national currency (pesos) would multiply considerably. Furthermore, if these calculations were compared with the local average living costs regarding average monthly individual income in pesos, it would reveal that the economic gains are astonishingly higher. For instance, on average one international tourist may well spend in one day what a Philippine worker gets in one month if he or she is fortunate enough to enjoy some kind of stable salary, which it is not the case for a vast majority of local villagers. Evidence of this argument is, among others, the importance of tourism as invisible exports and one quick deliverer of foreign exchange with which to pay international debts since national Third World nations' currencies worth not much when buying or selling within a global market mainly dominated by US dollar transactions. Added to these economic foreign exchange calculations it may be argued that natural capital (material and symbolic) stands on itself at no monetary costs. It is only when it is wrongly managed and, therefore, deteriorated that it requires investments. This basic way of reasoning appears to demonstrate that these inputs are free of costs (i.e. mild climate in the Mediterranean tourism destinations) that in the case of tourism produce important marginal benefits (added extra surpluses). A common for all convincing argument is that of real positive economic profits. After the materialisation of these tangible gains into cash, the rest of nice arguments about sustainability may be accepted, however, it appears dubious that the rhetoric discourse works the other way round. 
CASE STUDY_SAN JOSE SUSTAINABLE CITY STATUS REPORT. JUNE 1998. USA. (Adapted from San Jose Government Report, 1998)

According to Dennis Church "environment, economics, welfare and fiscal solvency are interlocking issues and not competing goals" (1978, cited in Hart, 1992). In this sense, "San Jose is working for 17 years to become environmentally and economically sustainable" (Council Report, 1998:1). In 1978 Dennis Church wrote 'Towards a Sustainable City. A Report on Natural Resources and the City of San Jose' (California. USA). This report, showing that answers are conformed by simple common sense analysis, was the beginning of a radical change in the city's sustainable development approach and economic policy model. By the end of the 1970s a sustainable approach was definitely adopted. It was reinforced by "the oil crisis and a major sewage spill" (Hart, 1992:1) that revealed the 782,000 citizens' untreated wastes and sewage wonders. Consequently, Dennis Church was hired to apply his ideas for the city of San Jose (California. USA).

To date, the city is a leader in sustainable efficiency that allows the council to save annually US\$15 million (Hart, 1992). The council started with a water saving scheme that considerably reduced the sewage pressure. This was followed by the installation of public electric low-consume devices that saved in its first year US\$1,5 million to the council. Nearly another annual US\$ 6 million were saved by contracting two different companies for collecting and disposing the city's garbage that previously was a monopoly. In this way, prior inexistent competence was created and a pressure to recycling wastes was put into force if competing companies wanted to get their contracts renewed. The council invested part of these savings in recycling schemes, returning the rest to the community (Hart, 1992). This tangible economic fact made citizenship to stand by sustainability, since San Jose was improving the quality of public services while saving peoples' money (Hart, 1992). It appears that when praxis (economic facts) comes first, the rhetoric of sustainability (academic and political) is much better understood and supported later. Denis Church believed that reducing one cost (saving) makes to reduce a long range of overlapped and interconnected costs. For instance, San Jose city's council buys recycled paper, saving not only money but tones of new paper that have not to be produced, what reduces tree-cutting (one tone of recycled paper saves 17 trees), what reduces water consumption (each ton saves 7,000 gallons), what reduces energy consumption (each ton saves $4,200 \mathrm{kwh}$ ), what reduces the use of chemical substances, what reduces pollutants, what reduces pollution, what free citizens' money (less taxation) to live better and invest within the productive private sector (one economic multiplier), contributing less to the climate change and so on, or to all the opposite mechanism in case of pursuing the usual linear western model of perennial economic development. Denis Church thought that "to waste one is typically to waste several; to conserve one may be to conserve them 
all" (Church, 1978, cited in Hart, 1992:1). He proved it and the Office of Environmental Management was created in 1986, where several schemes were conjointly managed following the former maxim (Hart, 1992).

San Jose city focused on several strategic areas. Regarding energy, the council annually saves US\$ 500,000 from an unique US\$ 2,2 million investment. Energy savings come from better and efficient building and management in the public and private sectors. For instance: one million trees are to be strategically planted to reduce air conditioning needs through shadow and, therefore, natural heat reduction. Traffic design (i.e. traffic lights and signals), drivers training, vehicles efficient use of energy (renewable energies) and available space optimisation (i.e. not solo-driven) may save annually US\$ 25 million (council report, 1998:1). Free distribution of low-flow shower heads and low consume toilet facilities to all the households have already saved US\$ 68 million in water treatment. Moreover, gardens are designed and built to consume less water. San Jose city council requires the use of durable devices and building materials that can resist earthquakes and minimise continuous deficiencies and subsequent reparations, including all new and old buildings (public and private). According to Hart (1992) policies in this regard are not so much punitive as proactive through free professional advice and affordable credits.

The council properties and management have become in themselves an example to be followed by the rest of the citizenship regarding sustainability. The council recycles part of its wastes (44\% in 1996) and buys, where it is feasible, recycled materials. There are programs to collect household pollutants to avoid their dispersion, safeguarding population's security and health, which prevent future unnecessary medical expenditure, losses in the quality of life and economic productivity. Finally, the council abandoned the constant on-going expanding of the built city's area by optimising the urban interior available space, which reduces commuting and therefore, unnecessary transport, reducing at the same time pollution and traffic congestion, while preserving highly productive agricultural land that conforms an economically profitable, healthy and aesthetic green belt. These measures have proved to be successful not only economically but also in the betterment of the citizenship's quality of life and the environment. Then, it could be argued that tourism resorts/destinations should do it easier.

This case study appears to demonstrate that the economic profitability of sustainability should not belong exclusively to the rhetoric and political discourse but to the public and private sectors' day-to-day realities. Thus, having reached this point through the former case studies' evidences and exploration of the investigation's thesis (specific conceptual study), the question to pose would be, why does sustainability have so scarce practical repercussion within the tourism business context? 


\section{CHAPTER 6_INVESTIGATION OUTCOMES}

Dennis Church appears to define the arguments behind this investigation's outcomes in a few words: “Answers are not always complicated, technical and understandable only to experts. But it always seems to take teams of experts conducting years of complicated technical analysis to establish the truth of simple common sense perception" (Church, 1980:5). Denis Church observed that: "To waste one is typically to waste several, to conserve one may be to conserve them all" (Church, 1978, cited in Hart, 1992:1), which seems to follow John Muir's words "When we try to pick out anything by itself, we find it hitched to everything else in the universe" (cited in Hart 1992:1). John Hart translates the former thoughts into plain words regarding the case of San Jose city: "Once you begin looking at government operations with an eye to extending resources and saving money, opportunities turn up everywhere" (1992:5). These former authors' quotations appear to explain the complex interconnectedness of natural and man-made mechanisms and, therefore, the inherent difficulty to understand their interrelations by studying them separately. From Taylor (late 1800s) and Henry Ford (early 1900s) the speed of resources depletion has not comparison to any other epoch in the Human's history. This capitalist mass production-consumption model has undeniably eased the Westerners' welfare state. However, this investigation seems to reveal that the merge between traditional simple common sense and technological advancements, leaving behind the focus on mass resource consumption, focusing on technology innovation and expert human resources, appears to configure the next form of mature market-led socio-economic wisdom (as it was the shift from agriculture to industrialisation), since sufficient warnings and evidence exist (i.e. Gross National Product does not always match energy consumption) to re-address this linear development model in a more circular and sustainable manner, given that it appears to be neither sustainable in the West nor viable in other geographic and cultural contexts. This fact has greatly magnified the uneven wealth distribution of the Earth resources and, therefore, the geostrategic relations of power that in the case of tourism seem to be based, to date, on a perennial implicit (political) and explicit (organisational) master-servant relationship (Ryan, 1998:87) too much in tune with the dependency theory of development (Telfer, 2002). The former arguments and quotations frame and somehow summarise the outcomes derived from the core desk research (exploration of the thesis) on the economic viability of sustainable tourism, which are countered against those of the primary research (empirical study) as a means to bridge or otherwise rhetoric to praxis.

\section{SECONDARY AND PRIMARY RESEARCH: DATA ANALYSIS' OUTCOMES}

This section presents and analyses those arguments raised through the exploration of the thesis (secondary research) and the perceptions of some Spanish and English tourism public and private sector's key practitioners 
(primary research) on the sustainability issue. This study's thesis focuses on the apparently ignored key role of the economic profitability throughout the sustainability scene, which is theoretically (conceptual: exploration of the question), politically (local: San Jose City) and economically (practical: Philippine Coral Reefs) investigated.

A number of interesting insights have crystallised along the conceptual study (Richardson, 1994, cited in Stevenson, 2002). These outcomes are classified in: the valuation of the common pool resources (i.e. beaches, culture), and the synergetic range of savings by inputs and moneys not wasted, generated through optimisation under the principles of sustainability once implemented. Both contextualised within the present global marketled neoliberal economy (Telfer, 2002). The conceptual study first approach on natural capital valuation and the pricing of intangibles (i.e. know-how) has revealed that:

1. Common pool resources are free of monetary costs. It appears to provoke its unbridled and careless consumption within a short term vision. In so doing, tourism as an industry commits suicide since the loss of the very attractiveness it sells may condemn the business to fade away, forcing to seek other virginal places where to restart the process. The latter might be disguised as green tourism vested in international help. However, Carlos (TO.Valencia) admits that 'I have never though before how resources and tourism development could be matched'. He claims that 'In spite of all, tourism economic benefits are enough to compensate its negative effects' while Manuel (HA.Ibiza) argues that 'Hoteliers have always been green. They have always looked for savings in processes and resource consumption'. Monica (HSF.Valencia) supports this view by claiming that 'Hoteliers and tourism entrepreneurs in Valencia have a great respect for the environment as it is what they sell. Furthermore, Valencian and national regulations are strictly compulsory.

2. Consumers unconsciously assume that these resources are part and parcel of the product or service. So, they do not care or value them per se. In so doing, both demand and supply undermine the source of their rents. The former does it in tangible terms (economic) and the latter in intangible terms (enjoyment). It might be argued that this behaviour parallels a Fordism approach of mass production-consumption (and throw-it-away) inherent to the modernisation theory of development (Telfer, 2002). Manuel (HA.Ibiza) claims that 'Customers are not ready to pay for a sustainable tourism', what is corroborated by Monica (HA.Valencia) 'But tourists do not seem willing to share such environmental awareness and it is a problem', while Vicente (TRA.Valencia) argues that 'sustainability means a rise in prices, and then tourists go to other places that are cheaper'. Keith (TRAA.London) argues that 'In the UK, government does not incentive sustainable tourism. In this way tourists and holiday-makers are not pursuing it'. 
3. This issue could be solved through the application of the Theory of the Tourism Valuation of Natural Goods. It states: "profitless or value-less aspects of nature and culture (i.e. the material and the symbolic) may be converted into premium prices if sold on the tourism market" (Mihalic, 2002:105). However, none of the interviewees (tourism private and public sectors key practitioners) have talked about valuating natural capital.

4. Sharpley claims that "they do not have to be built or created" (2002:19), what inherently increases the derived economic rents of tourism since part of the main inputs (i.e. climate, culture) are free out of monetary costs and maintenance. It is argued that those costs are passed onto the hosts as negative rents (minus profits). Again, tourism private sector practitioners, when interviewed, have neither mentioned any concern regarding the valuation of natural capital nor the possible derived economic gains (i.e. as in the case of Philippine Coral Reefs)

5. Therefore, natural capital (material and symbolic) in such free conditions is appropriated (usurped?) by exogenous agents regarding the tourism destination at no monetary costs. This fact, according to Mowforth and Munt (2003) is exacerbated in some countries due to cultural and socioeconomic mores resembling colonies and plantations. It is claimed that it is a form of neo-colonialism much in tune with the dependency theory of development (Telfer, 2002). Key practitioners, when interviewed, have not mentioned any of such issues.

6. It is argued that the free appropriation of natural capital may pass through two quite different phases: initially, due to the fix amount of the natural capital, ownership's / companies' rents increase. However, when it deteriorates visitors may require lower prices (visitors' rents) otherwise they do not go to those places, which may undermine their image and therefore, their viability as tourism destinations. Key practitioners have not mentioned any related issue. Perhaps they assume these processes as obvious.

7. Business observers claim that tour operators are not willing to preserve or repair such common pool resources unless immediate economic gains are guaranteed. It appears advisable to demonstrate them the actual gains through the appropriate optimisation of the resources as the former case studies have proven. It should be economically demonstrated that it is cheaper to sustain the destination's original attractiveness than building the entire necessary infrastructure in a new place (White et al, 2000). However, Manuel (HA.Ibiza) argues that 'Hoteliers are obtaining ISO 14000 quality certificates, although not many adopt an Environment Management System'. Again Carlos (TO.Valencia) admits that 'To be honest, I had never thought what we can do to not take people to a place in order to not spoil it. I think it is a dream'. Custodio (TO.Valencia) claims that 'Companies are too busy and worried about their economic profitability. They look for immediate benefits. If companies see economic benefits coming from their customers' environmental worries, then they will adopt sustainable tourism 
practices'. On the other hand Alyn (TO.London) argues that 'So, you cannot change the evolution. I do not think ever happens. It takes twenty-five years to emergent countries to make their own mistakes while growing up'.

8. The exploration of the thesis has revealed that sometimes natural capital (the material and the symbolic) may be profitless or value-less for the host population, who have consumed traditionally their rents instead to eat the finite Earth's resources stock (Mowforth and Munt, 2003) what, in essence, is a form of sustainable development. However, from the questionable western point of view, what these endowments have done, more often than not, has been to delay those peoples' economic development (i.e. due to remoteness, traditions). Tourism may turn those endowments into foreign exchange if sold (usurped?) in the tourism market. Carlos (TO.Valencia) claims that 'Where tourists reach, if we do not spoil the environment we spoil people'.

All interviewees' perceptions appear to reinforce this investigation's thesis since all move around an apparent misconception on that sustainability is a dream; that it is more expensive; that it is risky; that would raise prices; that would make tourists go to competitors not charging more due to claims on behalf of environmental sustainability and so on. Then, all around the concept of sustainability within the Spanish and English tourism private sector seems to be based on and move around partial and biased information. This may be one of the clearest findings that somehow validates the thesis of this study and empirically confirms the literature review insights. Interviewees have not made any reference neither to natural capital's valuation nor pricing intangibles, what clearly contrast with the conceptual study's analysis and case studies' evidences. In the latter case, one of the most shocking insights is that sometimes natural capital is profitless or value-less allegedly regarding the hosts. If these were appropriately priced and managed these common pool resources could represent a source of new socioeconomic activity and rents not seen before (as evidenced by the Philippine Coral Reefs case study) for them and their descendants at a minimum cost, since what they should do is to take care of their own heritage, considering the new rents as renewable in the same form that fisheries, agriculture or handicrafts, but this time rents come from their natural capital that has always been there and that is free of costs (i.e. fisheries and coral reefs). These new rents should be added to their prior traditional revenue as extra surpluses but not become dependent on them by managing a diversified economy. The new economic value of these for-everpresent resources is generated by those peoples (visitors) that are in the process of losing their own natural capital, who are more than willing to enjoy it where and when it may be found yet. For that, they are ready to pay in American dollar, British pound, European euro or Japanese yen that automatically multiplies the economic profitability when exchanged for local currencies. However, corruption, repatriation of benefits 
(leakages) and all the diverse consequences of the demonstration effect (i.e. accelerated raises in the local living cost) menace, so far, the former factual scenario.

Finally, the conceptual study (exploration of the thesis) second approach on the economic savings valuation generated through optimisation under the sustainability principles has revealed that:

1. The concept of sustainability is subjected to many different interpretations as the literature review has analysed at length. It is argued that this fact generates a plethora of rhetoric discourse while seems to refrain its actual implementation. Evidence of this is the apparent scarce transferability of the sustainability discourse into managerial practicalities. Keith (TRAA.London) points out in this regard 'I think you are right. Everybody understands something different. There is no fix definition. Nobody knows what sustainability really means. Nobody understands many of the other labels in these areas'.

2. Apparently tourism green-wash marketing has been somehow developed in order to meet and fit some stakeholders' increasing requirements regarding sustainability because it is in vogue, which disguises maintainability as sustainability and overlaps both concepts in meaning and practice. Vicente (TRA.Valencia) argues that 'Ecotourism is another marketing strategy', which is corroborated by Alyn (TO.London) 'You have situations now where, I mean, we are talking about ecotourism as being a marketing password' to what Keith (TRAA.London) adds 'Ecotourism might be seen as nothing else than a clever marketing tool'. Regarding what is or what is not marketing Keith (TRAA.London) explains that 'The Travel Foundation has been set up in November 2004. All major tourism businesses are in. They collect around 20 pounds per package sold. The smallest tour operator adds 15 pence to each package sold. All this money goes into the Travel Foundation to finance projects. So, my view is that the fact you have got the main stream mass market tourism industry to be in this kind of issue must show that we are moving in the right direction. They recognise the need to protect the very thing they are selling. That is an optimistic thing and if it works, that's great'. From this excerpt it could be interpreted that all of it somehow might not refer to a form of green-wash marketing although it is not clear.

3. Eco-efficiency management may deliver economic, social and environmental benefits as it optimises daily operations and inputs across the entire life-cycle of the product or service. These processes may uncover potential growth in existing and in new areas beyond the short term limits, influencing the whole business value chain (horizontally and vertically). It helps implement the sustainable principles within a managerial framework that may bridge the acute divide between rhetoric and praxis through envisaged tangible gains produced, among others, by Environmental Management Systems and ISO 14000 schemes. However, only Manuel (HA.Ibiza), when interviewed, has mentioned environmental management systems and quality certificates. 
4. The former delivers not only tangible economic gains but intangibles such as competitive advantage, corporate image appreciation and so on that, in strategic management terms, are latent cash in the medium and long term. Again no one of the interviewees has mentioned explicitly any perception regarding intangible gains delivered by sustainability.

5. It is argued that the change from Fordism to post-Fordism as a model of production would benefit from a mix of technological innovation and know-how generation. Bioengineering, eco-techniques and natural capital valuation, among others, are components of such mix. None of the interviewees has mentioned these techniques.

6. Mowforth and Munt (2003) openly criticise the fact that economic gains justify environmental excesses and silence discordant voices. The veracity of this critique appears widely supported through a hybrid between a laissez faire and economic neoliberalism political approach witnessed in some tourism destinations (i.e. Tunisia or Yucatan Peninsula. Mexico). With this respect Carlos (TO.Valencia) argues that 'Well, tourism creates business. It is good at an economic level but not regarding ecology'. However, Vicente (TRA.Valencia) points out that 'In general, the negative impacts are greater than the positive ones. However, this model of tourism development has made possible that many people can enjoy holidays'. On the other one hand Keith (TRAA.London) argues that '... in high season local people in Cyprus remain without running water for a number of days a week. If you think that they do not mind that necessarily because they know the benefits that come from tourism, which are probably greater than not having running water every day or week, but it is not how it should be because you should care of the needs of the local people first, who are bringing benefits and not the other way round but still you know, in terms of economy, fantastic for Cyprus'. He adds 'Sustainable Tourism means working with the hosts who are the custodians of the tourism destination'.

7. Again these authors claim, so as Sharpley (2000), that economic sustainability should be integrated within social and environmental aspects of the sustainable development since all together constitute a sustainable development. However, who gains and who losses financially reveal inequities and the uneven balance of power, since profit maximisation tends to subjugate other considerations. Through these arguments Mowforth and Munt (2003) appears to support the thesis of this project. Carlos (TO.Valencia) argues again that '...tourism creates business. It is worth doing it because it is economically profitable but it is not so regarding the environment'. No one of the interviewees has pointed out anything else with respect to inequity or uneven power though all of them agree in that the economic benefits outweighs social and environmental issues to date. 
8. The use of eco-techniques may lead to cost-benefit-savings favourable ratios, which it is argued may act as incentives for the private sector regarding the adoption of sustainability as a management feature, since it is in fact latent cash in the medium and long term. However, except Manuel (HA.Ibiza) none of the interviewees appears to mention any technique, management model or sustainable profits as incentives in order to implement the principles of sustainability, even less they consider any intangible advantage as latent cash. In this respect Keith (TRAA.London) points out 'In most other industries they have done a lot in terms of sustainable development. I mean, not in the service sector, but manufacturing sectors for obvious reasons. They are well ahead. They have the support of government'. He adds 'They have other incentives to improve things. None of that exists in the tourism industry'. He argues that '...you incentive trading through tax breaks or that kind of things. They could do that but they don't and because there are no incentives, the consumer and the holidaymaker aren't driving sustainable tourism'.

9. Envisaged economic profits move forward private business (Greeno et al, 1998:7), which are in themselves key generators of wealth. Actually, praxis (tangible benefits) should feedback rhetoric (intangible knowledge) through the generation of practical know-how, which is transferable through its adaptation. Alyn (TO.London) agrees in that 'Tourism is a far too big revenue driver for governments and countries'. He thinks that '...there is no other industry growing so fast and generating so quick benefits'. Again all interviewees' perceptions appear to remain close to and framed by conventional issues regarding debates on the pros and cons of sustainability. Private sector practitioners' perceptions seem to be framed by economic factors.

10. Greeno et al (1998:3) claim that replacing stuff with information (i.e. knowledge management) may save large quantities of raw materials (resources) and processes (time) that should be priced and therefore, converted in added value and motivating cash (as incentive). Bearing in mind Dennis Church's theories (1978, 1980) the former savings may multiply themselves across the entire value chain as demonstrated through the analysed case studies' evidences. None of the interviewees, however, have expressed any thought regarding knowledge management, resource optimisation, economic savings, natural capital valuation, and so on.

11. The former strategic management approaches may enhance the product or service quality that generates added value, what may allow charging higher than average prices, while acquiring a competitive advantage. Interviewees have not mentioned anything regarding the possibility of charging higher prices due improved quality of service. However, Vicente (TA.Valencia) argues that he has serious doubts with respect to the real implementation of sustainable tourism because, he thinks, that it is much more expensive and then prices would go up. Then cheaper destinations would attract the bulk of the tourists. He points out lower labour's costs 
and unspoilt novelty as factors against the implementation of sustainability in western destinations. He argues ' $I f$ prices are higher, then less people can do holidays and then a social and ethical debate will arise asking whose interest must come first, the general or the private interests?'

12. It could be claimed that the former managerial approach to sustainability within an economic neoliberal market-led scenario might deliver a range of consecutive savings. Optimisation of the resources leads, for instance, to remarkable reductions in pollutants' emissions that if priced would amount attractive profits, which should be managed as incentives in the pursuit of a sustainable development and a sustainable tourism. However, none of the key practitioners interviewed has mention any word on savings' tangible/intangible valuation, pricing intangibles, comparative advantage or the valuation of natural capital.

13. According to Butler (1998), consumers (and producers) are not so willing to economically support sustainability. However, companies looking at sustainable development with fresh eyes may uncover business opportunities not envisaged before, obtaining real tangible and intangible profit/benefit. These profits may allow companies offer trustworthy better quality of service while making customers to save money. This appears to be a convincing incentive to make consumers support sustainability issues. However, Carlos (TO.Valencia) argues that 'a tourist that chooses rural tourism is because he or she is of a lower economic level'. Vicente (TRA.Valencia) points out that '...but is the tourist who is starting to demand better quality though not so much issues regarding sustainability'. Monica (HSF.Valencia) insists in that 'Tourists do not show such environmental awareness and this is a problem'. Keith (TRAA.London) confirms this tendency 'No one in the tourism industry is going to buy because it is clearly more sustainable'. He adds 'Customers do not accept impositions'. The ecotax in Majorca (Spain) appears to substantiate the latter.

14. It could be argued that the former range of evidences sound somehow more convincing than tight regulatory and judiciary measures around the concept of sustainability (i.e. liabilities are fines / price charged on environmental damage). It could be criticised that constraining policies may achieve the opposite objective, forging and forcing to generate alternative strategies such as green-wash marketing that would maintain the so criticised present situation (resource depletion). Furthermore, it appears remarkable that natural capital is priced uniquely through liabilities (monetary fines) but not as incentives and key inputs. Monica (HSF.Valencia) claims that 'We work hand in hand with the Administration'. Eduardo (IMPIVA.Valencia) argues that 'In Valencia, the IMPIVA (Institute for the Medium and Little Enterprise of Valencia) is economically supporting industries to implement sustainable features. In so doing, we help what tourism sells be in good conditions'. He adds 'We help and guide industries to achieve ISO 14000 certificates of environmental quality'. Keith (TRAA) remarks 
that 'Other industries have incentives. Nothing of that exists in the tourism industry. We talked with the government because the government's theory is based on tax'.

15. In this manner the negative demonstration effect's factors might be reversed and used to demonstrate that sustainable development and sustainable tourism are not only maintainable but economically profitable. In the same vein, the multiplier effect of tourism might enact the imagined benefits for all, since added to the much studied economic multiplier effects of tourism, these investigation's outcomes magnify the environmental, the social and the economic benefits of environmental economies of scale (i.e. saving multiplier effect) framed into the rational optimisation of resources, managing the sources rather than the effects (proactive versus reactive management). In this vein Keith (TRAA.London) argues 'We (Association of British Travel Agents) talked with the government because the all government's theory is based on tax it (tourism). It (money) just goes into the treasury and the government'. He suggests 'We should learn from other industries, but most cannot follow, so, it is difficult'.

Finally, this analysis of the investigation outcomes appears reinforced by the overwhelming agreement of the 32 out of $32(100 \%)$ in Spain and 22 out of $28(78.57 \%)$ travel agents briefly and informally interviewed in both countries, who claim that, to date, they have not faced any kind of environmental requirement coming from their clients. This unexpected result seems to empirically corroborate key informants' perceptions on the scarce willingness of the customers to accept to be charged on behalf of sustainability. However, this majority vividly contrast with only just a few and dispersed voices found throughout the literature and conceptual study, which express doubts on the apparent willingness of consumers to economically support sustainable development and sustainable tourism (i.e. Butler, 1998). This situation is somehow summarised by Keith Richards, Head of the Consumer Affairs of the Association of British Travel Agents (ABTA): 'Apart from what are they saying that they would like to have more of the local experience, that's fine, but your average holidaymaker is not going to buy a product because it is clearly more sustainable'. Based on the conceptual study and especially on both case studies it could be argued that sustainability should not necessarily bring implicitly, in management terms, a general price rising but completely the opposite due to the acquired large tangible and intangible savings. That is not to say that some segments are willing to pay higher than average prices as previously discussed for more than expected quality of service (i.e. lodges, boutique hotels). However, it does not mean that those firms' inputs are similarly expensive but the opposite, since it is the intangibles for what clients are charged rather than for the tangibles (tangible inputs). Contrary to popular current thinking this investigation outcomes reveals that sustainability is not necessarily a more expensive investment producing expensive products and services as 
illustrated and substantiated throughout this investigation. The former popular belief and the investigation's outcomes appear to reinforce and widen the apparent divide between rhetoric and praxis (Jenkins, 1999; Pike, 2003) that open a field of investigation in order to demystify the myths around sustainability, uncovering an endless range of business opportunities not seen so far (Hockers, 2001, Greeno et al, 1998).

Travel agents' perceptions on their clients' environmental requirements in Spain and UK: Outcomes.

1_When customers ask for whatever sort of tourist product, do they show any environmental awareness? 2_Suppliers, do they mention environmental issues to be sold?

\begin{tabular}{|c|c|c|}
\hline Summary of the responses & Place & Respondents' comments: some demonstrative examples \\
\hline $\begin{array}{l}16 \text { out of } 16 \text { of the travel agents answered } \\
\text { negatively both questions }(100 \%) .\end{array}$ & $\begin{array}{l}\text { Castellon } \\
\text { (Spain) }\end{array}$ & $\begin{array}{l}\text {-She says that in } 10 \text { years working in the business she has not } \\
\text { observed any environmental requirements coming neither from } \\
\text { her clients nor from suppliers (interview 2). }\end{array}$ \\
\hline $\begin{array}{l}16 \text { out } 16 \text { travel agents answered negatively } \\
\text { both questions }(100 \%) \text {. }\end{array}$ & $\begin{array}{l}\text { Valencia } \\
\text { (Spain) }\end{array}$ & $\begin{array}{l}\text {-She says that in her } 25 \text { years of professional experience any } \\
\text { client has shown any environmental criteria to select and buy a } \\
\text { tourist product (Interview 14). }\end{array}$ \\
\hline $\begin{array}{l}22 \text { out of } 28 \text { of the travel agents answered } \\
\text { negatively both questions }(78.57 \%) .5 \text { of } \\
\text { them rejected the interview and one said to } \\
\text { have no idea }(21.43 \%) \text {. }\end{array}$ & $\begin{array}{l}\text { London } \\
\text { (UK) }\end{array}$ & $\begin{array}{l}\text {-He says that price is the main purchasing criteria. Clients do } \\
\text { not mention any environmental criteria (Interview 4). } \\
\text {-He says that nobody mentions neither any environmental } \\
\text { criteria when selecting a tourist product nor do suppliers. Price } \\
\text { quality relation is the main criteria to purchase (Interview 7). }\end{array}$ \\
\hline
\end{tabular}

Source: Martinez, 2004.

Thus, it appears that all of the range of academic rhetoric, political speech, institutional publications and advertising campaigns have not reached travel agents' clients yet, or at least they do not use or show any requirement in words of the travel agents interviewed within the areas of Castellon, Valencia and Central London at the date this field research was conducted (October-December 2003).

The words of Church (1978) "environment, economics, welfare and fiscal solvency are interlocking issues and not competing goals" (cited in Hart, 1992) appear comprehensive and feasible once the research outcomes have been analysed and then presented. Throughout this investigation Church's theory stating that answers to sustainability's practicalities are based on traditional common sense, frames Hart's (1992) views on that once the concept of sustainability is approached through coherent schemes, savings opportunities arise everywhere, making difficult to understand why does sustainability have so scarce repercussion within the tourism business context if quality of service may be enhanced and profits increased while saving resources, peoples' money plus reducing pollution. This paradox remains one of apparent difficult explanation. 


\section{CHAPTER 7_ RESEARCH IMPLICATIONS}

According to Milne "sustainability raises the issues of the scale of the economic activity in relation to the ability of natural ecosystems (including human societies) to continue to support such levels of activity indefinitely" (1996:6), which appears to counter the present tendency to persistently ignore non-market issues allegedly conformed by common pool resources (i.e. nature). This fact directly affects political and corporate decisionmakers' accuracy since their decisions are somehow based on incomplete information that could be argued might be behind the present unsustainable situation.

This may be substantiated, for instance, using decisions made for decades regarding oil extraction, which have consistently considered natural gas (usually found on top of the oil supplies) as a worthless impediment and therefore, have burnt it (and still do it polluting the atmosphere while burning literally a substantial part of their rents) without showing much awareness on the strategic and monetary value of natural gas and even less considering it as a cleaner and less damaging source of energy than oil in itself till recently. In fact, natural gas may twofold the strategic and therefore, economic profitability of the operation (following the former Church's, Muir's and Hart's observations). In the context of tourism, as an industry, this thesis may be better illustrated by reminding the time when, for instance, the government of Kenya promoted game hunting (natural capital destruction) as a tourism activity producing foreign exchange (capital accumulation), showing somehow a lack of understanding of the most basic economic laws since visitors studying, observing or taking pictures of those animals produce much more consistent revenue following, as already observed, a simple economic precept, that is, this fauna and landscapes (natural capital) stand on themselves at no monetary costs, however, if shot down they generate cash at once (i.e. as it was in the 1800 s in central US), while if alive they do constitute a perennial source of revenue free of costs applying the theory of the tourism valuation of natural goods and Elkington's (1997) triple bottom line model of sustainable development, which in management terms means that the main inputs are free of costs, rising the outputs' marginal benefits, that in turn directly multiplies themselves due to foreign exchange higher rates with respect to the local currency (i.e. shillings) and the local average cost of living (significantly much lower), while acquiring a differentiated and competitive advantage (which become latent cash). In addition, this economic approach may allow future generations to access to and benefit from this resource (natural capital accumulation). In so doing, Brundtland Commission's (1987) definition of sustainable development may be fully met in this case. These examples illustrate the apparent lack of accuracy (and equity, might be claimed) of decisions based on partial and biased information delivering lengthy negative consequences and incomprehensible procedures (starting a snowball effect). For instance, Brazilian much appreciated precious 
timber is burnt and smashed (natural capital destruction) to let grow value-less grass (capital destruction), which becomes a multiplier source of poverty and inequity (and world's climate change). These uninformed decisions' consequences are not stated on the "traditional management accountancy" (Milne, 1996:1) that ignores, among others, "non-market valuations techniques and social cost-benefit analysis" (Milne, 1996:1) and therefore, the caused damage does not exist in the corporative annual account. Consequently, it appears that it is neither taken into consideration nor intervenes in the corporate decision-making process, allegedly because the damage caused does not represent monetary costs for the company who passes them onto the host (i.e. oil extraction in Ecuador by a Canadian Company). These are the so well-known externalities.

It could be argued that, apparently, this prolonged short-sighted economic approach has not managed wisely such valuable issues leading to the actual massive and accelerated resource depletion, pollution and uncertain future of the western model of socioeconomic development in itself, commonly deemed as unsustainable. Furthermore, it does raise the need of a multidisciplinary "integrated corporate decision support system" (Gray, 1990, cited in Milne, 1996:1). This socioeconomic way of development appears to have misused, misinterpreted and therefore, depleted a large proportion of the Earth's finite stock, borrowing those resources from generations to come at the same time that has ignored consistently obvious (i.e. natural gas, methane) tangible and intangible sources of sustainable wealth by overlooking plain common sense synthesised in John Muir's words 'When we try to pick out anything by itself, we find it hitched to everything else in the universe" (cited in Hart, 1992:1).

According to Garrod and Fyall "The time has come to move from defining sustainable tourism to begin to consider how it may best be implemented in practice" (1998:1). They suggest the use of the environmental economic approach as a way forward. Butler (1998) claims in a similar vein that the question is how to make mass tourism sustainable, since this model is not going to diminish but the opposite due to the emergent new economies (i.e. Eastern Europe; South East Asia), in order to refrain moving mass tourism into new destinations where to reinitiate and maintain the same model disguised as green or sustainable. However, the challenge is constituted by the technical and economic difficulty to demonstrate that sustainability is not only an abstract concept at the core of a plethora of academic and political discourse, but to substantiate and critically detail procedures on its managerial practicalities and profitable viability within an economic neoliberal market-led global scenario as concisely evidenced through both case studies, substantiated trough the conceptual study and illustrated by the investigation results analysis. 
Ayala (1995) argues that the merge of ecotourism (i.e. small scale local tourism) and international tourism (mass tourism) places the current model of resort development under scrutiny. This author suggests that the eco-resort master-planning approach contemplates the resort as an overall system, where resort mutes and merges with the destination from the very beginning in order to maximise sustainability and quality through design, planning and environmental management spreading benefits for the society, the environment and the economic health of the business. However, according to Tepelus (2005) the truly actor in this play is the tour operating system, which has a major role in translating the sustainability rhetoric into practical operations since, so far, research on the field has concentrated on sustainable tourism strategies rather than on how these strategies should be applied by tourism practitioners (praxis). Tour operators, due to their central position at the core of the demand and supply of the tourism development system, have a decisive role to play within tourism private sectors in contributing to reverse the apparent tourism suicidal cycle by seeing with fresh eyes through the sustainability lens (i.e. relative and absolute competitive advantage), dealing with something else than sending tourists faraway with meagre marginal benefit (Tepelus, 2005). Garrod and Fyall (1998) argue that although attaching monetary value to nonmarket issues is contemplated by "the theory of environmental economics", it is not so clear the tourism industry willingness to apply it or whichever other technique such as eco-efficiency. However, Reinhardt (1999:83) points out: "The Earth is sick and therefore, it ought to be profitable ways to help it to return to good health" (cited in Hockerts, 2001:12). Having reached this point so far, if applied sustainability may enhance quality of service and increase tangible and intangible profits while reducing costs, saving resources, people's money plus reducing sources of pollution, why does sustainability have so scarce repercussion within the tourism business context? This paradox remains one of apparent difficult explanation so far though, perhaps, that explanation resides within the public sector (Martinez, 2004), while solutions are on traditional systems.

The second part counters praxis versus rhetoric. 


\section{REFERENCES. First part}

Ayala, H (1995) Eco-resort: A Green Masterplan for the International Resort Industry, International Journal of Hospitality Management, vol 14 (3/4) 1995: 351-374

Butler, R (1998) Sustainable Tourism: Looking Backwards in Order to Progress? In Hall, CM and Lew, A, Sustainable Tourism: A Geographical Perspective. Essex: Longman, pp: 25-34

Bryman, A (1988) Doing Research in Organizations. London: Rutledge

Church, D (1980) EcoIq Services. Retrieved on 9 of May, 2005 from http://www.ecoiq.com/dcproducts/prod_twdsustaincty.html

Denscombe, M (2003) The Good Research Guide for Small-scale Social Research Projects ( $2^{\text {nd }}$ eds). Philadelphia: McGraw Hill

Eckersley, R (1992) Environmentalism and Political Theory: Toward an Eco-centric Approach. London: UCL Press

Garrod, B and Fyall, A (1998) Beyond the Rhetoric of Sustainable Tourism? Journal of Tourism Management, vol 19 (3) 1998: 199-212

Greeno, L, Hedstrom, G and Shopley, J (1998) The Sustainable Development Challenge: Using EH\&S to Create Business Value and Strategic Advantages, Corporate Environmental Strategy, vol 5 (3) 1998: 40-46. Retrieved on 9 of May, 2005 from http://www.sciencedirect.com

Hardy, A, Beeton, R. and Pearson, L (2002) Sustainable Tourism: An Overview of the Concept and Its Position in Relation to Conceptualisations of Tourism, Journal of Sustainable Tourism, Vol 10 (6) 2002: 475-494

Harrison, D (1996) 'Sustainability and Tourism: Reflections from a Muddy Pool'. In Briguglio, L, Butler, R, Harrison, D and Filho, W (eds) Sustainable Tourism in Islands and Small States: Issues and Policies. London: Cassell Imprint, 69-87.

Hart, J (1992) City Power: Flexing Municipal Muscles, In Context. A Quarterly of Humane Sustainable Culture, $\mathrm{n}^{\mathrm{o}}$ 33. Retrieved on 9 of May, 2005 from www.context.org/ICLIB/IC33/Hart.htm

Hockerts, K (2001) What does Corporate Sustainability Actually Mean from a Business Strategy Point of View? Center for the Management of Environmental Resources. Institute for the Environment and Economy. Fontainebleau (France): Oikos Virtual Campus

International Ecotrans (1991) Interés de una Red Internacional de Información para el Fomento de un Turismo Consciente y Responsable, Tomo I. Valsain (España): WTO

Jenkins, C (1999) 'Tourism Academics and Tourism Practitioners: Bridging the Great Divide'. In Pearce, D and Butler, R (eds) Contemporary Issues in Tourism Development. London: Routledge, 52-64. 
Layard, A, Davoudis, S and Batty, S (2001) Planning for a Sustainable Future. London: SPON Press.

Martinez, A (2004) What is the Role of Tourism as a Sustainable Development Strategy. Unpublished Master Dissertation.

Maykut, P and Morehouse, R (1994) Beginning Qualitative Research: A Philosophic Practical Guide. London: The Palmer Press.

Meadows, D, Meadows, D and Randers, J (1992) Beyond the Limits: Global Collapse or a Sustainable Future. London: Earthscan Publications

Meadows, D and Meadows, D (1972) The Limits to growth: A Report for the Club of Rome's Project on the Predicament of Mankind. London: Earth Island

Mihalic, T (2002) 'Tourism and Economic Development Issues', in Sharpley, R and Telfer, D (2002) Tourism and Development: Concepts and Issues. Clevedon: Cambrian Printers Ltd 81-111

Milne, M (1996) On Sustainability: The Environment and Management Accounting, Management Accounting Research, $\mathrm{n}^{\mathrm{o}}$ 7, 1996: 125-161

Miller, G (2003) Consumerism in Sustainable Tourism: A Survey of UK Consumers, Journal of Sustainable Tourism, vol 11 (1) 2003: 17-37

Mowforth, M and Munt, I (1998) Tourism and Sustainability: Development and New Tourism in the Third World. London: Routledge.

Mowforth, M and Munt, I (2003) Tourism and Sustainability: Development and New Tourism in the Third World ( $2^{\text {nd }}$ eds). London: Routledge.

Oppermann, M and Chan, K (1997) Tourism in Developing Countries. London: International Thomson Business Press

Pike, S (2003) A PhD Reflection, Tourism Review vol 58 (1) 2003: 16-18.

Redclift, M (1987) Sustainable Development: Exploring the Contradictions. London: Routledge,

Ruderstam, K and Newton, R (2001) Surviving your Dissertation. A Comprehensive Guide to Content and Process. London: Sage Publications.

Ryan, C (2002) Equity, Management, Power Sharing and Sustainability: Issues of the New Tourism, Tourism Management, vol 23 (1) 2002: 17-26.

Ryan, C (1998) The Tourist Experience: A New Introduction. London: Redbooks

San Jose Government (1998) San Jose Sustainable City Status Report. June 1998. Retrieved on 9 of May, 2005 from http://www.sanjoseca.gov/esd/Word-Excel/SJSCEXSM.DOC. 
Sharpley, R (2000) Tourism and Sustainable Development: Exploring the Theoretical Debate, Journal of Sustainable Tourism, vol 8 (1) 2000: 1-15.

Sharpley, R (2002) ‘Tourism: A Vehicle for Development?' in Sharpley, R and Telfer, D (2002) Tourism and Developmen: Concepts and Issues. Clevedon: Cambrian Printers LTD, 11-34

Sharpley, R and Southgate, C (2002) 'Tourism, Development and Environment', in Sharpley, R and Telfer, D (eds) Tourism Development: Concepts and Issues. Clevedon: Cambrian Printers LTD, 231-262.

Sharpley, R and Telfer, D (2002) Tourism and Development: Concepts and Issues. Clevedon (UK): Cambrian Printers LTD

Stevenson, M and Johnson, A (2002) Postgraduate Dissertations. A Guide to Successful Completion ( $3^{\text {rd }}$ eds). London: Business School. London Metropolitan University,

Stevenson, M (2002) Travelling to Ancestral Homelands: The Aspirations and Experiences of a UK Caribbean Community, Current Issues in Tourism, vol 5 (5) 2002: 378-424

Telfer, D (2002) 'The Evolution of Tourism and Development Theory', in Shapley, R, and Telfer, D (eds) Tourism and Development: Concepts and Issues. Clevedon (UK): Cambrian Printers LTD, 135-178.

Tepelus, C (2005) Aiming for Sustainability in the Tour Operating Business. Journal of Cleaner Production, vol 13 (2) 2005: 99-107. Retrieved May 9, 2005 form http://www.sciencedirect.com

Tour Operators Initiative for Sustainable Tourism Development (2003), Sustainable Tourism: The Tour Operators' Contribution. Paris: Tour Operator Initiative.

Veal, A (1997) Research Methods for Leisure and Tourism: A Practical Guide ( $2^{\text {nd }}$ ed). London: Pitman Publishing.

Wall, G (2002) Sustainable Development: Political Rhetoric or Analytical Construct? Tourism Recreation Research, vol 27 (3) 2002: 89-91

White, A, Vogt, H and Arin, T (2000) Philippine Coral Reefs under Threat: The Economic Losses Caused by Reef Destruction, Marine Pollution Bulletin, vol 40 (7) 2000: 598-605. Retrieved May 6, 2005 from WwW.sciencedirect.com

World Commission on Environment and Development (1987) Our Common Future. Oxford: Oxford University Press

World Tourism Organisation (2000) Sustainable Development of Tourism: A Compilation of Good Practices. Madrid: WTO 
SECOND PART 


\section{DEMYSTIFYING MYTHS \\ TOURISM: FROM EVIL TO CUSTODIAN \\ BHUTAN}

ANTONIO MARTINEZ SANCHEZ

THESIS

$\mathrm{PhD}$ in International Studies of Peace, Conflict, and Development

UNESCO Chair of Philosophy for Peace 


\section{DEMYSTIFYING MYTHS \\ TOURISM: FROM EVIL TO CUSTODIAN \\ BHUTAN}

\section{ANTONIO MARTINEZ SANCHEZ}

\section{THESIS}

Second part

Spain

PhD in International Studies of Peace, Conflict, and Development

UNESCO Chair of Philosophy for Peace

Supervised by Irene Comins Mingol

Jaume I University

$2017-2018$ 
SECOND PART

TOURISM: FROM EVIL TO CUSTODIAN

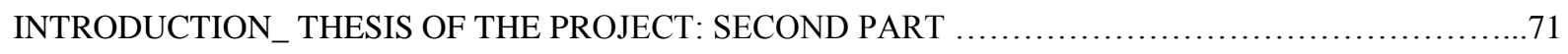

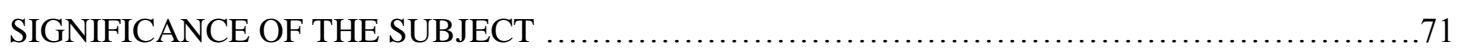

THE NATURE OF PUBLIC GOODS AND COMMON RESOURCES …........................72

REVERSE EVIDENCE: THE CASE OF GHADAMES OASIS. LIBYA .............................73

CHAPTER 1_ TOURISM, SUSTAINABILITY, COMMON RESOURCES ….............................77

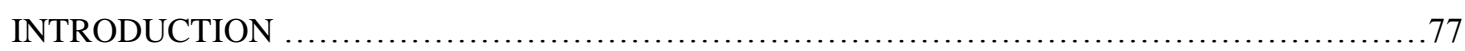

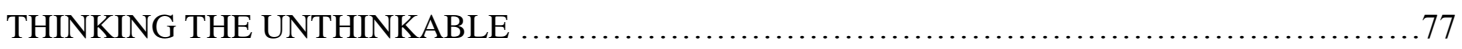

CHAPTER 2_LOOKING BACKWARDS IN ORDER TO GO FORWARDS …..........................79

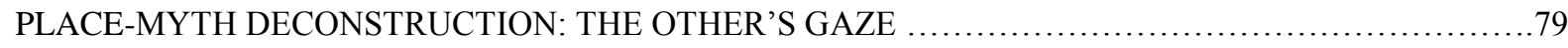

CONTEXT: SOCIAL AND CULTURAL CONSTRUCTION OF SPACE …..........................79

COASTAL PLAINS: A NEW SOCIAL CONSTRUCT .............................................. 80

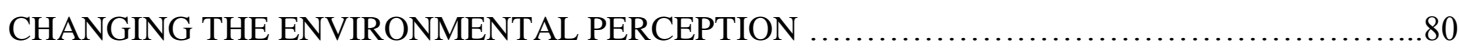

CONSTANT TRANSFORMATION OF SPACE: PLACE REPRESENTATION .......................81

FURTHER SIGHTS / INSIGHTS: MYTH, PARADISE, NEOCOLONIALISM .......................82

CHANGING SOCIAL SPATIALISATION: BEACH AS A ZONE OF EXCLUSION / INCLUSION 83

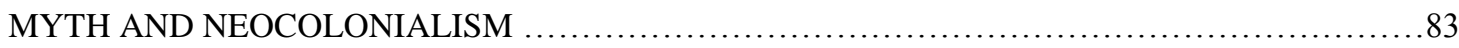

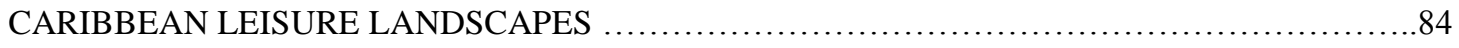

CASE STUDY: The case of Punta Cana and Bávaro Beach. Dominican Republic ......................85

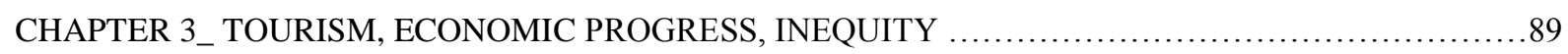

POLITICAL ECONOMY, TOURISM PLANNING AND THE ROLE OF THE STATE TO OVERCOME INEQUITY.

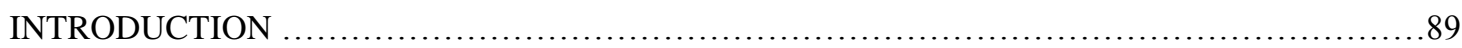

CONCEPTUAL FRAMEWORK: THEORIES OF DEVELOPMENT ...............................91

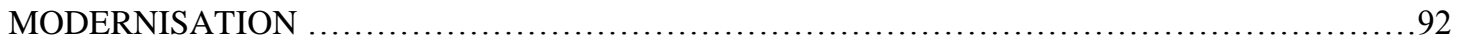

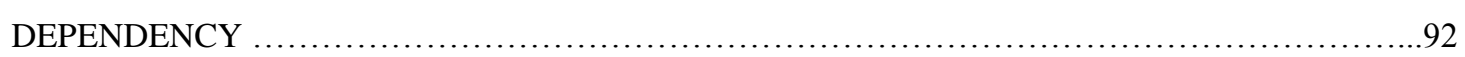

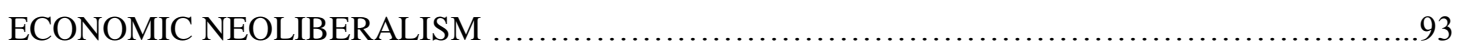

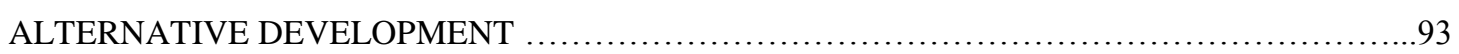

DEVELOPMENT, INEQUALITIES, TOURISM PLANNING: THE CASE AND CONTEXT OF

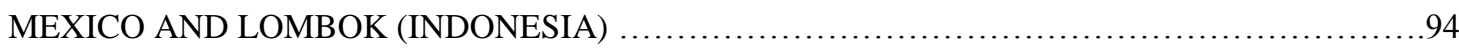

THE CASE AND CONTEXT OF MEXICO: 25 YEARS OF TOURISM (Adapted from Clancy, 1999)

THE CASE AND CONTEXT OF LOMBOK. INDONESIA. (Adapted from Fallon, 2001) ............95

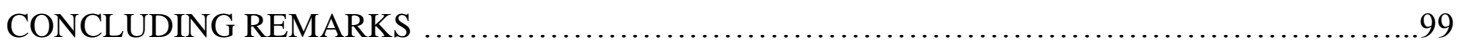




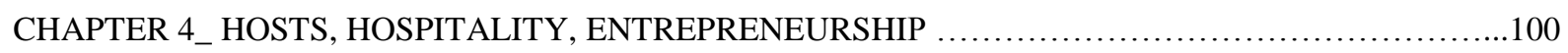

ON ENTREPRENEURSHIP: THE CASE AND CONTEXT OF SRI LANKA ..........................100

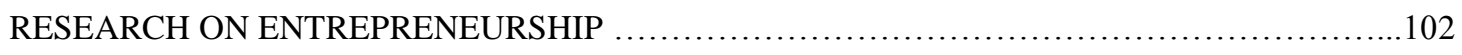

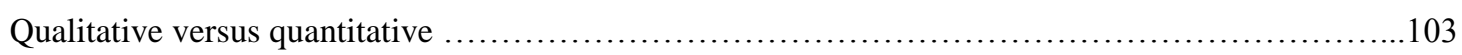

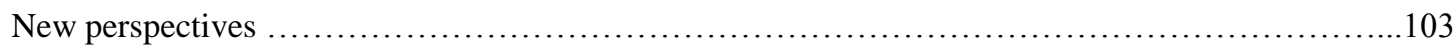

EXPERIENCES FROM THE GLOBAL IN A LOCAL SETTING ............................... 104

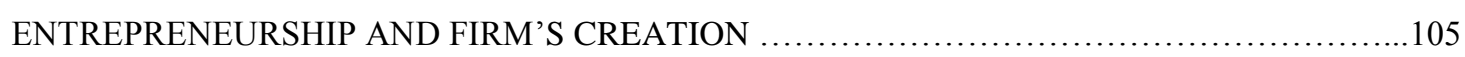

THE CASE AND CONTEXT OF SRI LANKA (Adapted from Kodithuwakku and Rosa, 2002) ......105

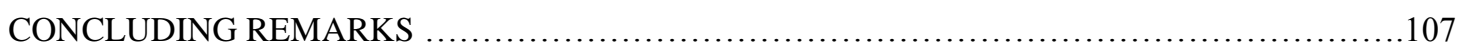

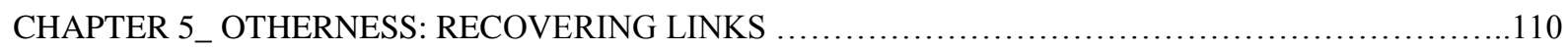

BHUTAN KEEPS THE LINKS AMONG INHABITANTS, HABITS, HABITATS ..................110

CHAPTER 6_ TRADITIONAL SYSTEMS: ANY LESSON? ...................................... 114

ON THE LONG-STANDING SUSTAINABILITY OF ENDOGENOUS COMMON RESOURCES

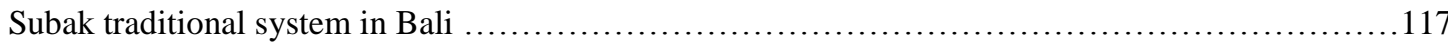

Sasi traditional system in Raja Ampat, Indonesia ........................................118

Nakaiy traditional calendar in Maldives Islands ............................................. 118

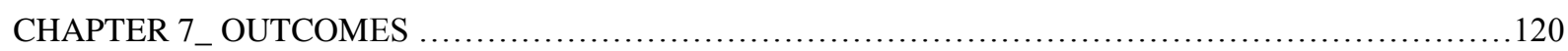

ARMCHAIR THINKING, DESK RESEARCH, FIELD TRIPS ................................ 120

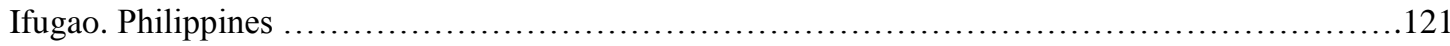

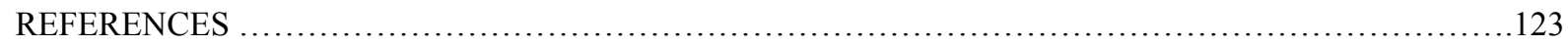

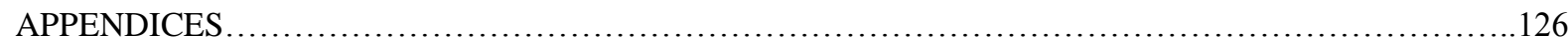

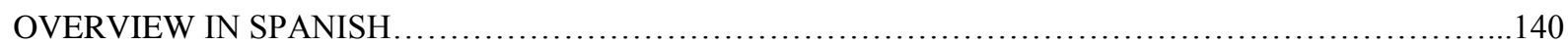




\section{INTRODUCTION_THESIS OF THE PROJECT: SECOND PART}

The first part of this project is devoted to theory and rhetoric. The second part deals with praxis. Sustainability as a term remains unclear. As a concept carries on delivering a wide range of meanings while a short range of agreement. Within the first part of this project, the literature review and the exploration of the thesis on this term and concept have been examined with certain detail. The second part of this project aims at counter rhetoric versus praxis. The informants interviewed focus on the economic sustainability of sustainable tourism if it is to be implemented. So far, informants declare that neither clients nor suppliers mention sustainability at the time of making decisions. Price and quality appears to be a factor but sustainability it is not an issue for the demand and supply sectors. In the long run this divide between rhetoric and praxis persists although thought like left aside.

The public sector does not economically depend neither on the economic sustainability of sustainable tourism nor on the economic sustainability of sustainable development. The term and the concept are nice to read and listen to but how are materialised is quite another issue. So far each sector carries on managing misconceptions. Such persistent fact contrasts with the sustained operability of sustainability within many traditional systems, as evidenced in some case studies. Maintainability it is not same concept as that of sustainability.

\section{SIGNIFICANCE OF THE SUBJECT}

Tourism; the managing of sustainability; the tangible, intangible, and symbolic valuation of the common pool resources are examined, so as their interrelations and dependency analysed. The latter two constitute part and parcel within nearly all of those traditional systems around the world. It turns out surprising such a fuss on a concept being implemented for centuries. Tourism sells aesthetics and services delivered by the common pool resources, which are an evidence of the managing of sustainability. Therefore, the question to pose is whether tourism; the managing of sustainability; the tangible, intangible, and symbolic valuation of the common pool resources, are friends or foes. Tourism may be both depending on how it is designed, implemented and managed. Hosts are the custodians of what tourism looks for, although they are left aside on deciding about commons. To work out this persistent divide the second part of this project aims at raising awareness of who is who, when and where. In so doing, to look for bridging rhetoric and praxis proposing guests like custodians of what they look for to enjoy. They do not pay for what has no price. However, as stated in the first part of this project, tourists assume that common pool resources are part of the product, the service. It is not the case: Guests are not owners. 


\section{THE NATURE OF PUBLIC GOODS AND COMMON RESOURCES}

Public goods are those made at the expense of the Public Treasure (for the use of citizenship), they cannot stand by themselves. However, the common pool resources are for free and stand by themselves. The latter are the main motto of tourism as it is the case of climate, temperatures, weather, bio-cultural landscapes, culture, and the like. Therefore: the more faraway the destination, the more the common pool resources become a stronger motto to travel to enjoy them. As free of costs as are they, these endogenous resources are appropriated so much by the tourism industry as the tourists themselves (guests). On the other hand, it is estimated that tourism industry is constituted by a majority of local family owned businesses, who usually are hosts at the same time, while the major industry, most times than not, is exogenous regarding the destination.

Tourism: From Evil to Custodian, investigates synergetic ways in which the destination's tourism industry, the hosts, and also the guests may turn out custodians of all the local endogenous common pool resources. That is, tourism industry and guests should become custodians upon what precisely tourism sells at no cost and guests think they buy through price. Since hosts are the truly custodians of the endogenous common pool resources they should carry on managing them as they have always been managed. In itself the managing of sustainability could be an intrinsic attractive for the visitors. Traditional systems through centuries of wise use and management have shown and demonstrated what sustainability it is all about. These traditional systems have systematically been overrun in favour of a derailed modernity out of the truly custodians' say, the hosts. Actually, what tourism sells at no cost result in the systematic misunderstanding, and somehow destruction, of what guests look for and enjoy. As such, tourism behaves as if it were a resource curse. It could turn out to be more of a devil than of one bless.

Perhaps the thesis of this unreasonable behaviour is: First, the costs are passed onto the common pool resources and hosts as externalities; second, tourism sells what has not paid for; third, guests assume that those endogenous common pool resources are part and parcel of the product and service they have paid for, which it is not the case. There is a fourth factor: compulsory taxes, liabilities, and laws. Throughout this value chain could become clear that the truly custodians of the common pool resources, and their long-standing wisdom and know-how in the managing of sustainability, are left aside so much by the public sector, tourism industry as guests themselves. Reaching this point it becomes difficult to understand such a lack of common sense even from an acute selfish stand. There are voices in the literature claiming that because tangible profits are repatriated, taxes and liabilities appropriated and costs externalised, there is no motivation to behave reasonably. On top of the former, more 
often than not, maintainability overlaps sustainability in meaning and practice.

All in all, still there are some misunderstandings on terminology (still orphan of meaning?), conceptual frames (more often than not exogenous?), endogenous facts and data (not taken into account?), bio-cultural landscapes, idiosyncrasies, and ownerships (used for granted?), that appear not to call a much needed attention. The more rhetoric, the less praxis? The question to pose is: Is sustainable tourism economically sustainable? It could be as a custodian in the long run. Using the benchmarking method tourism industry should learn from the traditional systems, which function through the managing of sustainable ways of doing in tune with the nature of physic laws and the principle of minimum intervention. They do so for generations upon producing their livelihoods in so harmonic as bountiful bio-cultural landscapes still in place: The Aurea's Proportion in tune with all beings.

Therefore, it turns out convenient reminding the fact that common pool resources stand by their own free of costs, while public goods do not. By the same token, more often than not, there seems to be somehow certain confusion on the inherent meaning in maintainability like sustainability. Once and once again all comes across such kind of misunderstandings. However, Paradores de España gives anew a profitable life to some heritage by proper use of buildings through rent as self-preserving at the same time that maintain well such heritage. However, in order to achieve such goal built heritage needs of common pool resources all around such as local cultures, traditions, popular architectures, and bio-cultural landscapes among other ones with certain particular idiosyncrasy. In this way both public goods and common pool resources may be valued in a tangible, intangible and symbolic way. It is in itself an idea to integrate different goals at the same time by using what already was, and it is, available. In turn, because such way of doing maintains by use and rent all around benefits from an unintended sustainability.

\section{REVERSE EVIDENCE: THE CASE OF GHADAMES OASIS. LIBYA}

Regarding the work on dry lands, property rights, natural resources of Camilla Toulmin, fore director of The International Institute for Environment and Development (London), some desk research was done on Ghadames oasis (Libya). I use testimony, and photo-essay, and visual storytelling as research tools and methods to generate empirical evidence ( $+/$ - expected) and, what I am most interested on: negative evidence (unexpected), in the quest of findings. Since I have already been in places like this oasis, I did it using just only three contrasting images on same place telling somehow about a derailed modernity on the basis of a resource curse: petrodollars. It is an example of a common pool resource: water springs. Springs are diverted from productive activities: food, fodder and family income, to unsustainable western-like town building not valid in this natural environment. As 
a consequence, many times these new towns are quasi abandoned. Following three images teach us key lessons:

First lesson: "Tight clusters of traditional mud-brick-and-palm houses have stood for centuries in Ghadames, Libya, a pre-Roman oasis town in the Sahara.” (George Steinmetz. National Geographic, 2-2013)

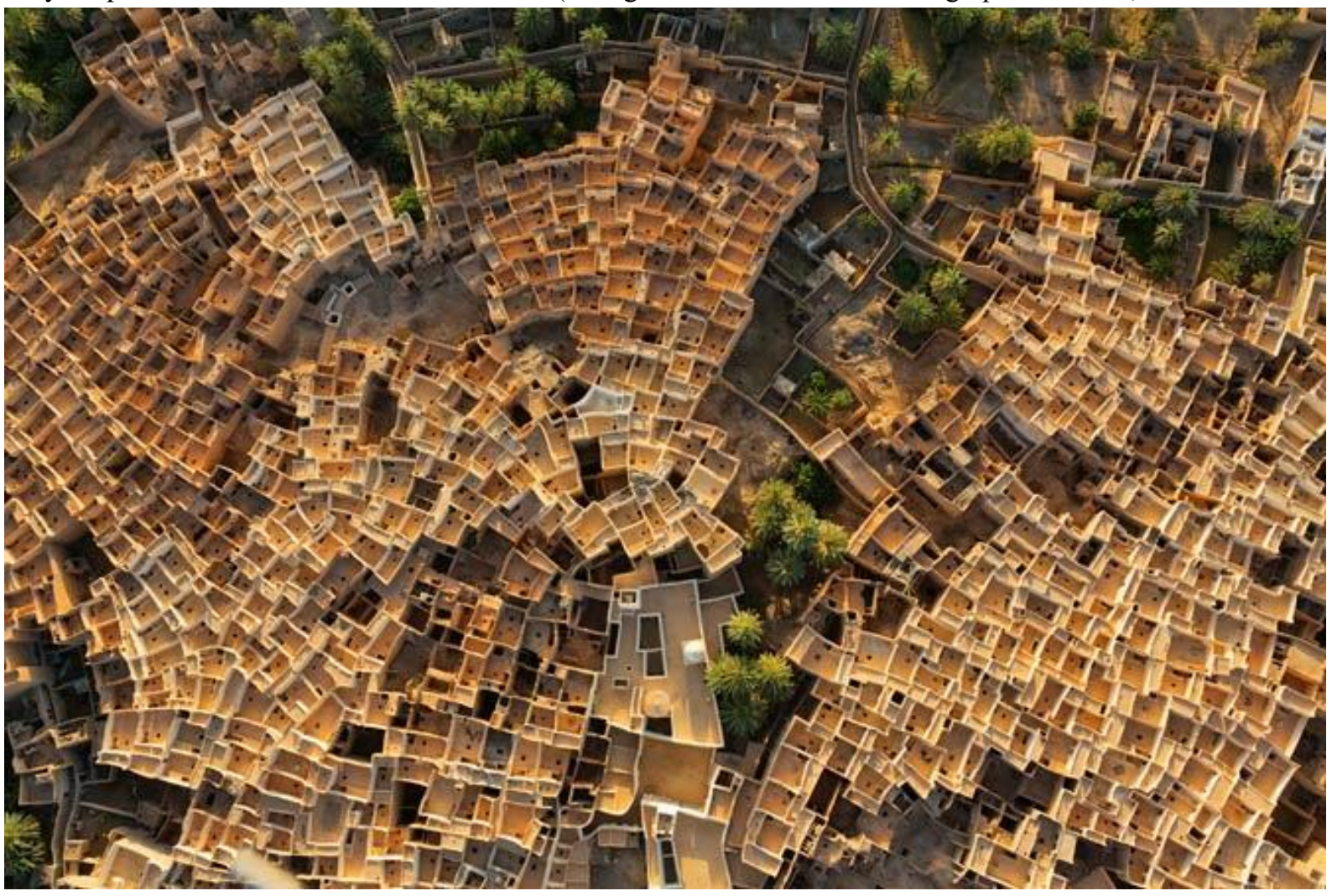

Second lesson: At the edge of Ghadames oasis after the eviction of people from their own houses and gardens to live in the new town. They call gardens to their orchards among the forest of date palm trees.

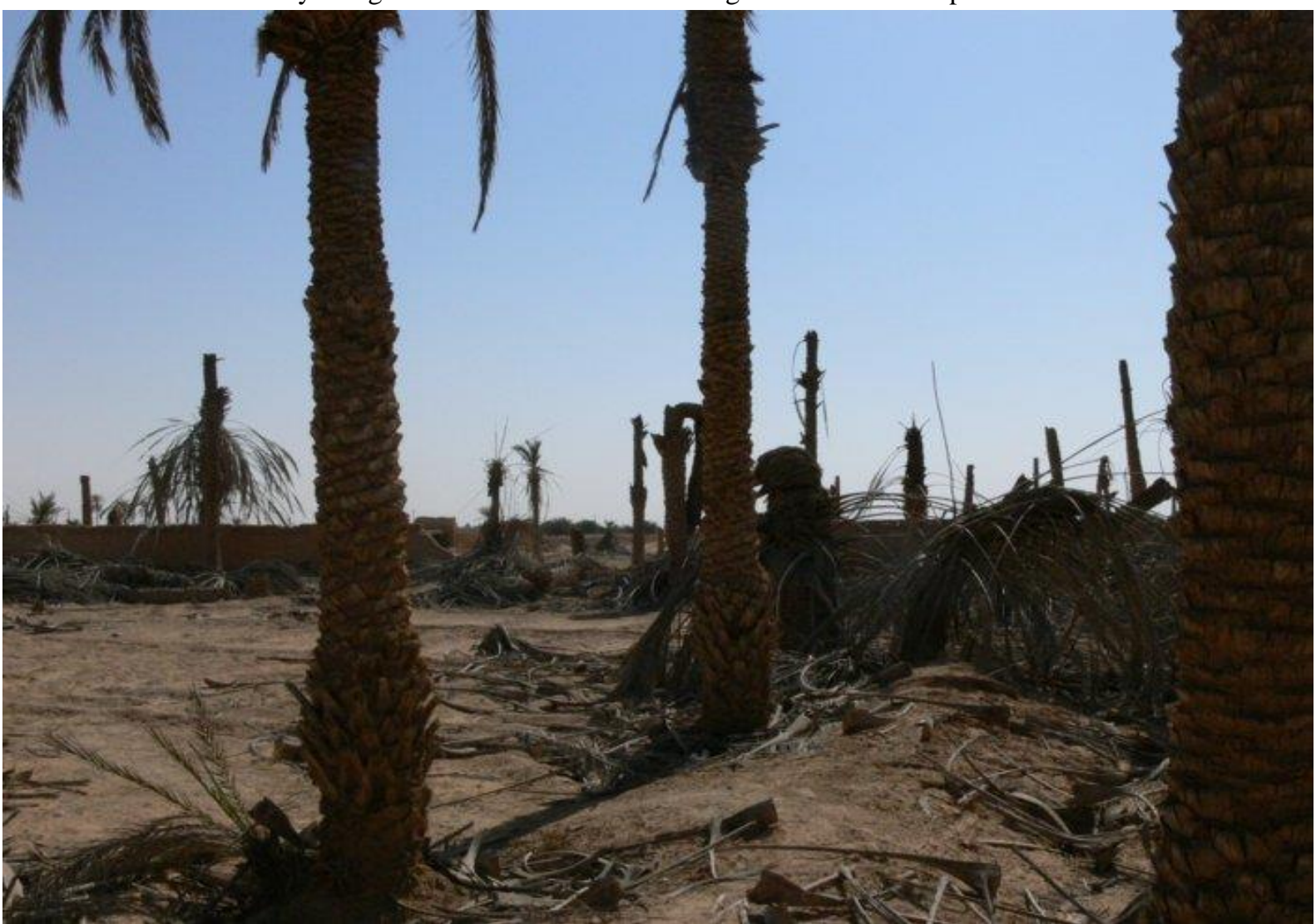


Third lesson: New Ghadames from the air. Petrodollars act as a curse. Does it sustain new Ghadames? How long?

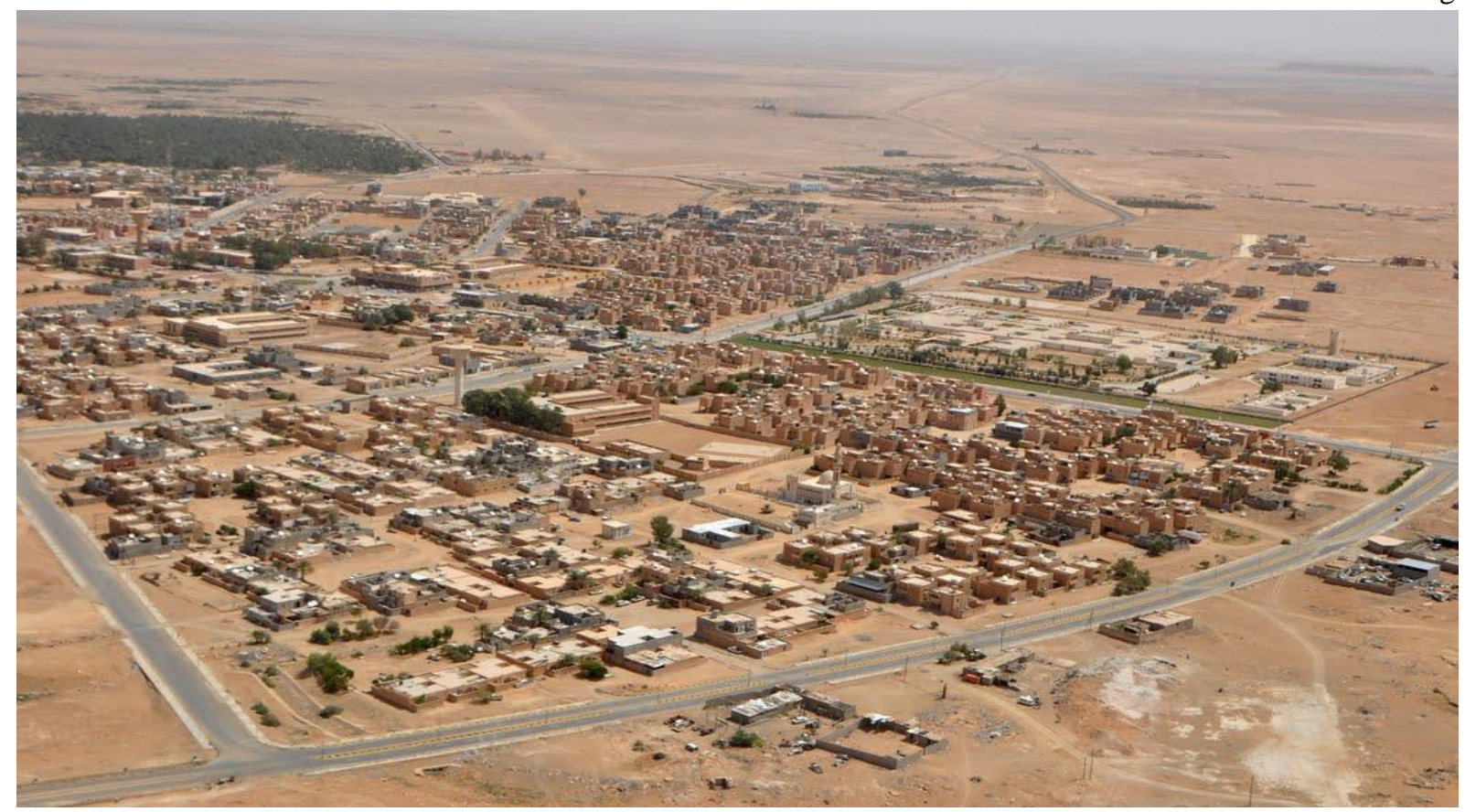

Camilla told me: Images convey a message often more powerful than words. It did reinforce the use of them in the present second part of this project. The traditional village is the outcome of the power of needs to live in such environment. However, the second one spreads lessons of inequity for all sentient beings, while the third image turns out the outcome of the needs of power. The traditional village kept for centuries the links between habitats, habits and inhabitants in a long-standing relationship, which shows that sustainability is not new but essential. However, the eviction of villagers to live in the western-like new town plus their common pool resources, such as springs, diverted from food production to build and maintain the new town has dried up parts of the oasis with some range of unknown consequences for all three: the preservation of the traditional village; the oasis as such; the capacity and will of the environment to allow inhabitation for long. On the other hand, tourism looks for and sells precisely what has been thrown away on behalf of a folly exogenous development; ways of doing and living from which tourists scape for some few days looking for those common pool resources and the managing of their sustainability, both kept going by hosts through centuries of isolation. It is about the power of needs versus the needs of power. The former has provided food, water and fodder in such long sustainable way, while it is not all too clear whether the needs of power are able to do so in the long run. There are other cases where these new towns remained unfinished and half empty. They are not adapted to the harsh environment, while the traditional village follows the nature of physic laws, such as thermic inertia. The managing of sustainability it is in itself an attractive motto to visit the watering system, the bio-cultural landscape from which the traditional village is part and parcel. Hosts are the truly custodians of the common pool resources. In turn their achievements are the main 
attraction for the international tourism. The question would be to devise synergies when using the endogenous know-how to make of tourism and guests custodians of what the former has not paid for but sells, while the latter travel to gaze upon.

What's looked for, the quest, throughout the second part of this research project on tourism; the managing of sustainability; and the tangible, intangible, and symbolic valuation of the common pool resources is to ease the feasibility of noble concepts by bridging somehow the gap between rhetoric (words) and praxis (viability).

In this pursuit some initial chapters of the second part of the project deal with looking backwards in order to go forwards. They do review and adapt several selected (by related) pieces of former research conducted by the author of the present project in order to throw some kind of light into these days apparently intractable problems. Perhaps they are so only from a Western point of view. However, fortunately enough, like it or not, there may be many ways of gazing upon by leaving aside Western lenses and just stare at praxis. The first piece of research counters feelings of enjoyment against feelings of escapism from same places on the margin. The former feed from leisure landscapes, while the latter feed from marginality. The second piece of research examines: Many authors have argued that tourism development exacerbates or produces socio-economic inequalities in less developed countries (LDCs), where the question is: To what extent states use tourism planning to overcome inequity. The third piece of research deals with entrepreneurship regarding little and medium size family owned businesses within tourism destinations. 


\section{CHAPTER 1_TOURISM, SUSTAINABILITY, COMMON RESOURCES INTRODUCTION}

"We believe that the failure of a great many development projects to achieve even their most fundamental objectives is due to a reluctance to appreciate the significance of history. Projects are designed as if time began with the project implementation schedule. Past lessons are seldom examined and still fewer professionals bother to enquire into the historical circumstances of the people their intervention seek to assist. There is little doubt now that as development professionals they have failed ... We have attempted to describe how so many good intentions can yield so many poor outcomes." (Doug Porter, Bryan Allen, and Gaya Thompson. Development in practice: Paved with Good Intentions, 1991: xv-xvii, quoted in Joseph Morgan Hodge, 2007:254)

\section{THINKING THE UNTHINKABLE}

"Theorists who cogitate about the wealth of nations and technocrats who specialise in formulating projects to increase production and raise living standards may be mistaken about the design of a development model, but they do not appear to entertain the slightest doubt as to the chances of development itself. For them, to consider the impossibility of development is to think the unthinkable." (Oswaldo de Rivero, 2001:109)

"The gurus of the myth of development, who measure everything, have virtually a quantitative vision of the world. They pay no heed to qualitative historical and cultural processes, to the non-linear progress of society, to the ethical point of view, and they even disregard the environmental impacts. They misconstrue economic growth as the development of a capitalist modernity that does not exist in the poor countries. With such a perspective, they only perceive the economic epi-phenomena such as GNP growth, export performance or the behaviour of the stock market; they do not notice the profound qualitative cultural, social, environmental and structural dysfunctions that prefigure the non-viability of the underdeveloped quasi nations-states in the new millennium." (Oswaldo de Rivero, 2001:117)

At the far end of the former introductory quotation of Hodge and statements of Rivero, those traditional ways of managing endogenous resources such as forests, pastures, agricultural lands, watering systems and the like, have been sustainably managed by hosts, whose first and foremost motivation was, it is, to endlessly preserve those biotopes in good health, since what was at play was their daily food availability. Added to this, each generation aims to pass all to the next in better healthy productive conditions. Actually, they are reciprocity right-on-theground well in advance democracy was known as a modern Western political system. Those traditional systems have been developed all over the world. They care of what's locally available instead of worrying about what is 
out of hosts' reach and understanding. On the other hand what tourism and tourists (guests) look for to enjoy it is what hosts know for long as traditional hospitality, the managing of sustainability, the common pool resources.

Dealing with caring guests (tourists): In such tiny remote locations traditional hospitality should be re-enacted instead of imposing an alien tourism as such. Men have their role. Women have their role. In this way hosts feel comfortable applying their own rules on receiving guests at their own pace. Added to the former, guests would experience an added sui generis enjoyment not often expected. My concept: Leaving behind Western lenses to gaze upon, it is all about: The managing of selfishness from a win-win perspective. What it is proposed is at the far end of understanding hosts like zoo's residents. At the end of the day those who are out of sync are tourists: Why do they travel so far? Who is at home? Who has ever invited them? Hosts have lived for centuries without tourists. Who do think tourists they are? Hosts are the custodians of what motivates tourists to travel so far away. The former do not need the latter, whereas the latter look for the former. Why? Does it mean that tourists show problems of missing, nostalgia, oddness, low self-esteem and the like? Nostalgia delivers a powerful motivation.

How hosts' progress could be achieved in particular through tourism; the managing of sustainability; and the tangible, intangible and symbolic valuation of the common pool resources? The latter two are already at the core of those harmonic and bountiful bio-cultural landscapes following the power of needs, whereas the former should transient from evil to custodian leaving aside the needs of power while out of home. Tourism turns out a resource curse or managed like one bless. The case of Bhutan gives paradigmatic lessons. Bhutanese authorities avoid the already-known problems generated by the unbridled arrival of tourists and fierce intervention of the exogenous tourism industry through the enforcement of an autochthonous policy: Low volume-high value. You cannot enter into the country and walk with a backpack. Visa and advanced compulsory daily spending of no less than 250 USA dollars appears the implementation of: The Managing of Selfishness from a Win-Win perspective. It is the application of The Precautionary Principle. Nepal holds differences regarding Bhutan. Tourists must devoid some careful thinking on what they look for, where it is, why do they travel so far away. At the end of the day they should bear in mind that they are no more than peculiar guests, guests of the local hosts. This temporary relationship should be ruled through hosts' traditions on hospitality and never imposed, especially by the more often than not exogenous tourism industry. All in all tourism and hospitality is about the enjoyment delivered by the common pool resources and wise managing of sustainability resulting in bio-cultural landscapes, main motto to travel so far. Following author's piece of research examines: Place-Myth Deconstruction: The Other's Gaze. 


\section{CHAPTER 2_ LOOKING BACKWARDS IN ORDER TO GO FORWARDS}

This Chapter two of the second part of the project deals with looking backwards in order to go forwards. It does review and adapt a related author's former piece of research to throw some background understanding into these days apparently intractable problems from a western point of view. This first piece of research counters feelings of enjoyment against feelings of escapism from those same places on the margin. The former feed from leisure landscapes, while the latter feed from marginality.

\section{PLACE-MYTH DECONSTRUCTION: THE OTHER'S GAZE}

"Marginal places, those towns and regions which have been 'left behind' in the modern race for progress, evoke both nostalgia and fascination. Their marginal status may come from out-of-the-way geographic locations, being the site of illicit or disdained social activities, or being the Other's pole to a great cultural centre. In all cases the type of geographic marginality ... is a mark of being a social periphery. That is, the marginal places that are of interest are not necessarily on the geographical peripheries, but first and foremost, they have been placed on the periphery of cultural systems of space in which places are ranked relative to each other" (Shields, 1991:3)

\section{CONTEXT: SOCIAL AND CULTURAL CONSTRUCTION OF SPACE}

Social and cultural constructions of space are those explicit and implicit particularities that differentiate societies within determined geographies as it is, for instance, the case of tourism resorts, where the real is built up by social constructs of inauthenticity, conformed by tourists' access to wealthier commodities and life styles with not much in common with their ordinary life, creating a tourist bubble as social construct far from those surrounding hosts' realities (their own social constructs). This is an example of a social construct that uses those geographies on 'the margin' to enact literary and induced aspirations.

Furthermore, the physical geography of space varies in meaning and significance from that of the social construction of space, which delivers perceptions forged by ancestral traditions and varied influences, lately educated through "a mediating value-framework which differentiates the facticity of the environment in which one lives" (Shields, 1991:32) with respect to the Other's ones. This spoils forms of seeing the Other's social constructs within real geographies and lengthy developed spatiality, which are his contextual realities not easily tolerate and less understood, simply being used as one pleasure periphery, where satisfy Westerners' inner sense of post-modern conquerors (conquistadores), ready to use the Other's space, geographies and landscapes like post-modern lords of those new mono-crop plantations, that is, like guests of all-inclusive resorts enclaves. 
According to Shields (1991) physical geography is used and transformed as deemed right by humans beings, who developed socioeconomic constructions of this space, derived from a localised and perennial culture generation, modelled and framed by centuries of selfishness, leading to, somehow, believe in the supremacy of a society on another, ranking the former the latter as marginal, not only economically but culturally and socially and therefore, in a need to be conquered, colonised and saved from its barbarism / poverty. This still applies to the postmodern golden hordes (tourists), which spread images of one culturally and economically superior core or centre (according to Occident's values and understandings of what it is) that, in the case of the Dominican Republic, refers to those western societies upon which coloured all-inclusive resorts' staff gaze, raising in them feelings of escapism from these same places on the margin. These agents compose actual "social and cultural constructions of space" that recreates neo-colonial servant-master landscapes, disguised as a source of economic help, first step in the Other's development take-off process.

\section{COASTAL PLAINS: A NEW SOCIAL CONSTRUCT}

Taking as a framework an actual landscape, leisure and tourism forces develop and modify, or even create, a new social construct by means of which that landscape is invested and mediated with a wide range of meanings that fit tourist's expectations, becoming a tourist product. In this process, leisure and tourism mechanisms (touroperators, marketing campaigns...) foster, magnify and recreate new desirable leisure landscape imagery in the prospective tourist's mind, where the tourist's interpretation is explained according to his / her inner necessities and desires. As a result, that landscape is a resulting product clustered within another environment, which delivers quite different conceptions and understandings to the local communities in regard to the new-comers. All in all we assist to a disparity of social constructs fed and fuelled by tourists according to their respective backgrounds, length of stay, needs, expectations and intimate desires, and all of this it is fostered and till certain extent managed by domestic and foreign investors, international tour-operators and national institutions such as Secretaría de Estado de Turismo, INFRATUR (Department for the Development of the Tourism Infrastructure) called DEFINFRO from 1993 (www.asiex.org.do/instituciones.htm).

\section{CHANGING THE ENVIRONMENTAL PERCEPTION}

According to Ashworth and Dietvorst (1995), the increased environmental awareness of people from developed societies not only has become concerned for the negative impacts of tourism, but also has experienced the desire to enjoy nature around the world. Increasingly a part of domestic and international tourism is nature-based or is developed within an environmental or heritage landscape (Ashworth and Dietvorst, 1995). 
The way natural environmental landscapes are perceived and understood changes from one individual to another, from one time to another (epoch), from a nationality to another. According to Zube (1991, cited in Ashworth and Dietvorst, 1995) landscapes are environments that deliver meanings and values. Meaning is not an attribute of the observer or the observed, but an ability of the relation between own personal needs or preferences and the environment stimulus (Winker, 1991, cited in Ashworth and Dietvorst, 1995). According to Ashworth and Dietvorst (1995) changes in environmental preferences and understandings may be explained in several ways. Two major perspectives are distinguished: first, from an aesthetic perspective that unfolds, where environment and landscapes appreciations are seen like the outcome of the capacity to evaluate and see one landscape as a mystery, leading to its investigation and reading with the aim of visual information to be decoded (in this case, mythical landscapes and their imagined constructs to be deciphered and democratised); second, from a cultural perspective, where environment preferences are understood as the outcome of the relation between a culture and its geographical environment. A person's attitude on a determined landscape varies as a function, beliefs and values shaped through personal experience and social conditioning within the context of his/her culture. In this case, Western's aesthetical evolution is represented by myths born within South Seas geographies of the Garden of Eden replete with conceptual imagery that the Occident's Protestant and Judeo-Christian severe morality, geographic and socio-cultural economic environments have forced to idealise and magnify, becoming a deep embedded subconscious dream. Both perspectives help explain the Westerners' intimate desire to search for idyllic sceneries and myth (on marginal places) around the world where materialise those dreams.

Furthermore, from the perspective of whatever new transformed physical and social geography, it is necessary to recognise the role of space, the judiciary and institutional frameworks which construct it in order to understand any socioeconomic transformation within that destination. Moreover, the conceptual power of the destination is generated by theoretical constructs, which ties it neither to space nor to history within a given environment (Ringer, 1998). The development of tourism destinations is about an ongoing process constructed by a nation's government practices, cultural discourses and mediated social constructs' imagery delivered by destinations' producers such as governments, domestic and international tour-operators and hotel chains (Ringer, 1998).

\section{CONSTANT TRANSFORMATION OF SPACE: PLACE REPRESENTATION}

"Constant change and transformation are typical of tourism as a spatial phenomenon, which has much to do with meaning, image, stereotypes, brands and representation of tourist destinations, and with the identity and the 
cultural self-image of the people living in the region and consuming prospective visitors' expectations" (Ringer, 1998: 38).

What it is signified with regard to the ideas and concepts raised by Shield's quotation is the changing aspect of the socio-cultural construction and representation of same landscape, its invested meaning and values according to the residents and according to those of the visitors, as well as the role played by the mass media, literature, paintings, promotional campaigns, tour-operators' adverts, brochures, TV, movies and institutional media in the international promotion of a new idyllic landscape like Punta Cana and Bávaro Beach coconut plantations.

Poststructuralism interrelates structure and culture, the material and the symbolic, while postmodernism proclaims the end of certainty, opening a number of representation models, fostering the visual consumption. Both conceptual tools can help understand how the same landscape that has for centuries been forgotten and seen as hostile, unhealthy and useless has become extremely attractive for the international tourism being precisely its natural endowments the main source of attraction represented, produced and consumed as a leisure and aesthetic landscape concomitant with the rise of tourism. Not long ago these endowments were seen as the reason for its historical abandonment as marginal places of rejection, left behind due to their remoteness, unhealthy conditions and, first and foremost, due to its scarce economic profitability. However, the leisure and tourism industries have found a perfect pleasure periphery in those destinations, which have become a source of employment and economic profits acting as a strong multiplier, although social equity (the spread of tourism benefits throughout the host community) is not one of its main features, being the Other's marginality implicitly exogenous and explicitly endogenous.

\section{FURTHER SIGHTS / INSIGHTS: MYTH, PARADISE, NEOCOLONIALISM}

Using Punta Cana / Bávaro Beach endowments in the eastern side of the Dominican Republic, it is analysed the relatively recent transformation of those coastal plains (beach areas) from a historical and geographical space of wilderness (historic time) to a semi-exploited unpaved landscape (heritage time) and finally to a modern mass sustainable tourism landscape (visitor's time) formed by a new western concept of hospitality: all-inclusive resorts. They use space, scale, natural and man-made semi-wild landscapes within a western social construct of paradise, ready to fulfil somehow a wide range of domestic and international expectations that have and are constantly recreated, feeding the Western well-developed concept of paradise on Earth, fostered by the Romantic Movement and continuously maintained by the mass media imagery and related literature, spreading an iconography replete with myth and meaning. All of this exploits the subconscious Westerners' intimate desire to 
emulate that behaviour and privileges of a former higher social class that, thanks to the welfare state and the new technologies, modern middle class can afford. On the whole, it is a matter of matching Westerners' desires and needs to one materialised tourism product, which has modified and adapted literary idyllic paradise landscapes to meet Westerners' expectations. Materialising the imagined is the key concept in this case. This has been the main aim of Punta Cana and Bávaro Beach developers and accordingly, the Dominican Republic objective. This is another example of a marketable social construct. It fits and meets Western tourism's expectations. It reenacts its desires of idyllic environments, social status, and fulfilment.

\section{CHANGING SOCIAL SPATIALISATION: THE BEACH AS A ZONE OF EXCLUSION / INCLUSION}

There is not much doubt that for many tourists the beach remains a popular geography of pleasure. For centuries coastlines have fascinated humans-beings representing the fringe between what's known and that frightening unknown. For centuries beaches were places on the margin and zones of exclusion, often seen as dangerous and scary spaces as those immediate coastal plains, interpreted as unhealthy, hostile and useless. The Punta Cana and Bávaro Beach coastal plains were considered so due to the absence of fertile soil, fresh water and any economic utility, understood by colonial rulers as spaces of wilderness (historic time), while in the European context this former appreciation of the beach was changed becoming a place of medical recuperation during Victorian times. Once the beach became increasingly democratised, meanings of pleasure, leisure and social distinction raised as motives for its use (Ryan, 1977). Today, beaches enable different experiences by reason of different geographies. As such, they may be analysed in terms of expectations, desires, even zones of tolerance and like other tourist product, beaches are plural in their use and imagery (Ryan, 1977). Punta Cana and Bávaro Beach coastal plains were transformed from a historical and geographical space of wilderness (historic time) to a semi-exploited unpaved landscape (heritage time) by removing the primary rain forest to make room for the coconut plantations, acquiring a different status within the heritage domain that spread an iconography of poverty and isolation till so recently as the 1970s. In postmodern times, that iconography has turned out the main motto for the international tourism, which has finally transformed those semi-exploited unpaved landscapes into a perfect leisure landscape (visitor's time), recreated through the new hospitality concept called all-inclusive resorts within a framework of neo-colonialism much contested by post-colonialism.

\section{MYTH AND NEOCOLONIALISM}

Within the Punta Cana and Bávaro Beach self-contained resort areas, as in most of the Caribbean leisure landscapes, tourism has become the main monocrop of the new plantations called all-inclusive resorts, where 
former landlords' privileges have become democratised, allowing to a middle postmodern western social class to experience a distort and commoditised time within a neo-colonial conceptualised environment, looking for materialising Western's South Sea myths delivering promises of paradise for short and in short. In this way, reality is constituted by inauthenticity (Dann, 2002), which becomes another reality of social and cultural landscapes placed in and framed into a pastiche of Polynesian exoticism (Morgan and Pritchard) 1998), in opposition to the severe Protestant / Victorian morality and Judeo-Christian ways of seeing, understanding and tolerate the Other's realities, and all in all supported and existing within a man-made semi-exploited landscape (massive coconut plantations), which represents not their own space of realities but those of faraway eighteenth and nineteenth century conceptualised and idealised South Seas landscapes of redemption and escapism from a former industrialised and now postmodern centre toward pre-modern peripheries, which contributes to follow what colonizers started, who transformed those south-eastern Dominican coastal plains environments by means of massive clearances and substitutions of the primary rain forest and indigenous social constructs (Tainos / Caribs) into a semi-exploited wilderness (coconut plantations), which mass postmodern tourism has transformed further gazing upon them through Polynesian South Seas lenses, completing and fostering falsified social constructs, rewriting invested meanings coming from idyllic adapted literary imagery of inauthenticity, visual consumption and social inequity within a framework of neo-colonialism. By contrast, according to Memmi and Said (1967, 1978, cited in Actchison, Shaw and McLeod, 2002) "post-colonialism enables to reflect critically upon constructions of leisure and tourism destinations as foreign and exotic and the Other's space, rendering a critique on the legacy of colonialism that is manifest in many of the structures and practices of contemporary leisure and tourism" (Actchinson, 2002:17).

\section{CARIBBEAN LEISURE LANDSCAPES}

Caribbean leisure landscapes are being recreated in terms of South Pacific mythic imagery, where the question of why Polynesian aesthetics and not Caribbean realities arises. It is argued by Morgan and Pritchard (1998) that Polynesian stereotypes deliver serene, gracious and safe meaningful images in the prospective tourist's mind, while coloured Afro-Caribbean Western's stereotypes brings into scene memories of a much forgettable heritage built on Caucasian preponderance. A new perfect pleasure periphery has been recreated delivering a range of social constructs based on geographical and cultural closeness at half of the distance and price. In the case of Punta Cana and Bávaro Beach it was the reason for the 1970's tourism enclave model development free of former memories, hosts, and conditioning built heritage, where the particular quality of tourism to give space for 
the physical enactment of the imagined, by transferring reality to an otherwise intangible mythological universe, has been the main reason for its success.

The new residents of the all-inclusive enclaves are a minority of Caucasian managers and a majority of coloured Dominican workforce, for whom these coastal plains still deliver aesthetical and cultural memories of rejection and never a sense of home. They gaze upon idyllic economic icons spread and delivered by Westerners' wealthy landscapes, fostering concepts of escapism from these places on the margin. We assist to a variety of social constructs, which show quite opposed meanings and interpretations for the new residents (workforce) in regard Dominican elites and international tourism, who enjoy and consume place, space and scale within a neo-colonial environment, which somehow still deliver relations of white dominant social constructs of exclusion, becoming those temporary residents part and parcel of this new social construct aesthetically marketable based on a South Seas conceptualised environment within which the imagined is materialised by a combination of postmodernism discourses and, according to Baum (cited in Ryan, 1998) "by the no longer pertinent interpretation of servantmaster traditions in spite of their echoes down the corridors of history" (Ryan, 1998: 87). Next lines examine a case study as a kind of example.

CASE STUDY: The case of Punta Cana and Bávaro Beach. Dominican Republic.

Punta Cana and its neighbour Bávaro Beach are home of self-contained all-inclusive resorts. These areas are situated in the southeast of the Dominican Republic. It is a large isolated and sparsely populated region that has been traditionally forgotten formerly by the Spanish rulers and then by the Dominican authorities due to its hostile and unproductive surroundings. In the 1970's the Dominican government, jointly with national investors and some early international hotel chains, started promoting these two areas as an international tourism enclave. Only one little village called El Cortecito shows the local culture. The nearest town, called Higüey, capital of the province of La Altagracia, is situated 44 / $55 \mathrm{~km}$ inland from both resorts respectively. Punta Cana and Bávaro Beach enjoy $32 \mathrm{~km}$ of white sandy beaches enhanced by endless coconut plantations. At their back, a semiarid zone of pastures is open to the plain horizon. Both zones are man-made transformed landscapes. Formerly a dense rain forest covered the whole coastal plains as still it does in the Yucatan Peninsula, Mexico. Originally coconuts were absent from these areas (Ochse et al, 1961). Coconuts and cattle breeding were the unique economic exploitation. Nowadays, coconuts, white sandy beaches and isolation are the main icons, easily read and understood by the international tourists at the expense of all other facts and historical accuracy.

Punta Cana and Bávaro Beach promotional representation: A comparative analysis 
In tourism, images are used in a number of practical ways to convey ideas and messages. The tourism media uses images, especially throughout promotional campaigns and brochures, to counter negative while enhance positive perceptions of tourism products, destinations, and people. However, tourism identities are packaged according to particular dominant values systems and meanings (Morgan and Pritchard, 1998), which more often than not are those Westerners' ones. Image creators are themselves also products of particular societies or elites. The imagery and representations they recreate not only construct but also reinforce ideas, values and meanings at the expense of alternative ways of seeing and at the expense of the Others' realities (Morgan and Pritchard, 1998). When we look at tourism imagery (i.e. tour-operators' brochures) we can see places, spaces and identities manipulated by marketers, reflecting distort historical processes as well as colonial relations of Western power, dominance and subordination that in the Caribbean context serve "the impetus to represent and consume the world through the development of a landscape aesthetic concomitant with the rise of tourism" (Aitchison, Shaw and McLeod, 2002: 92) as it was and it is in the European context. Following paragraphs analyse how Punta Cana and Bávaro Beach are represented in tourism brochures and Internet regarding Varadero (Cuba), Cancun and La Riviera Maya (Yucatan Peninsula. Mexico).

Punta Cana resorts are quite separated and not many, while Bávaro Beach offers an opportunity of visiting other resorts since they are closer each other. Both areas, however, are thought for visitors who have no desire to walk outside the immediate area (www.debbiesdominicantravel.com) except to walk along the beach, a promenade to Plaza Bávaro (shopping centre) or making a tour. Great deal of care and attention is given to the surrounding tropical gardens and landscapes (Thomson brochure: Faraway Shores, 12-02/10-03). The airport looks like a native village thanks to the use of the native lodge called palapa (huts' roofs) integrated within the natural surroundings by using local materials. Both destinations do respect their environmental endowments as an iconography easily recognised and read by the prospective international tourism. With this philosophy in mind, 10 million square metres of land have been donated by the Punta Cana Ecological non-Profit Organisation as a reserve containing all the characteristic endowments of this part of the Dominican Republic. These endowments differ with regard to other Dominican enclaves and with regard to those of other Caribbean destinations such as Varadero (Cuba), whose natural and man-made enchantments present a social construct quite apart, dealing with opposed significance within a similar concept of tourism development. No endless coconut plantations fringed the Varadero Peninsula beaches (22 km long). North Americans planned Varadero, but nowadays the quality of landscape, both social and geographic, reflects the political Cuban regime, although advertised like a Caribbean 
resort, not much of the imagined western myths can be materialised within the area except sand, sun and sex (Thomson brochure: Faraway Shores.12-02/10-03).

Another enclave in the Caribbean Sea is Cancun. Cancun, situated in the northeast side of the Yucatan Peninsula, delivers a westernised city-tourist model of enclave, where high buildings, infrastructure and complementary supply are found everywhere. It is advertised and promoted as a resort full of activities to enjoy, exciting nightlife (Thomson brochure: Faraway Shores 12-02/10-03) and enchanted multi-coloured waters fringed by white beaches for all tastes. By contrast, La Riviera Maya is the main star within the promotional and advertising campaigns actually. La Riviera Maya is a new self-contained resort area recently developed that expands in meaning and extension. This enclave follows the Punta Cana and Bávaro Beach model, although the all-inclusive formula is not an imperative. Along this enclave from Cancun to Tulum one can observe the primary rain forest that covered the coastal plains of Punta Cana and Bávaro Beach before man's intervention, which removed the primary forest (like in Wales and Scotland) to make room for massive coconut plantation and, at their back, for cattle breeding. La Riviera Maya's landscape shows everywhere the primary natural endowments of Punta Cana and Bávaro Beach area. No endless coconut plantations enhanced the Yucatan Peninsula fine sandy and white beaches, but the rain forest still trying to colonise them.

The analysis of these destinations through tour-operators brochures and internet deliver a reality which emerges and spreads around the construction of images, which assign places, spaces and people roles in order to enhance the tourism product, looking for predetermined paradigms, myths and stereotypes (Morgan and Pritchard, 1998). In the case of Punta Cana and Bávaro Beach, coloured Dominicans hardly feature at all in this Garden of Eden of beaches, swimming pools and luxury, and when they do appear they do often as waiters, receptionists and beauty therapist or bar staff (Morgan and Pritchard, 1998). Caribbean-style resorts in places such as La Riviera Maya and Cancun heavily feature tourists, but once the tourist gaze moves beyond the beach and the hotel's fence, visitors are introduced into an older ethnic world, which delivers native representations in clear contrast with the Mayan cities grandeur (Morgan and Pritchard, 1998). One of the most interesting findings of this promotional representation content analysis is the use of local people as a part of the destination image or their systematic avoidance, relegating them to servant-master post-colonial social constructs. Indigenous Afro-Caribbean are somehow avoided due to the ever present images of slavery, while Latin continental America's ethnicities (i.e. Mayas in Yucatan Peninsula) are represented as an inherent part of the destination's scenery (Morgan and Pritchard, 1998) spreading concepts of pretended authenticity. Following images convey meaning and myth. 
In this aerial image it is clearly appreciated the man-made landscape for second time. The first time, the primary rain forest was cleared to make room to the formerly inexistent coconuts in the Dominican Republic. Hotels are built within the coconut plantations placed along the Bávaro beaches. These places on the margins have become a perfect pleasure periphery for the Western societies. They represent the cultural pole in relation to which these areas are physically, economically and culturally on the margin.

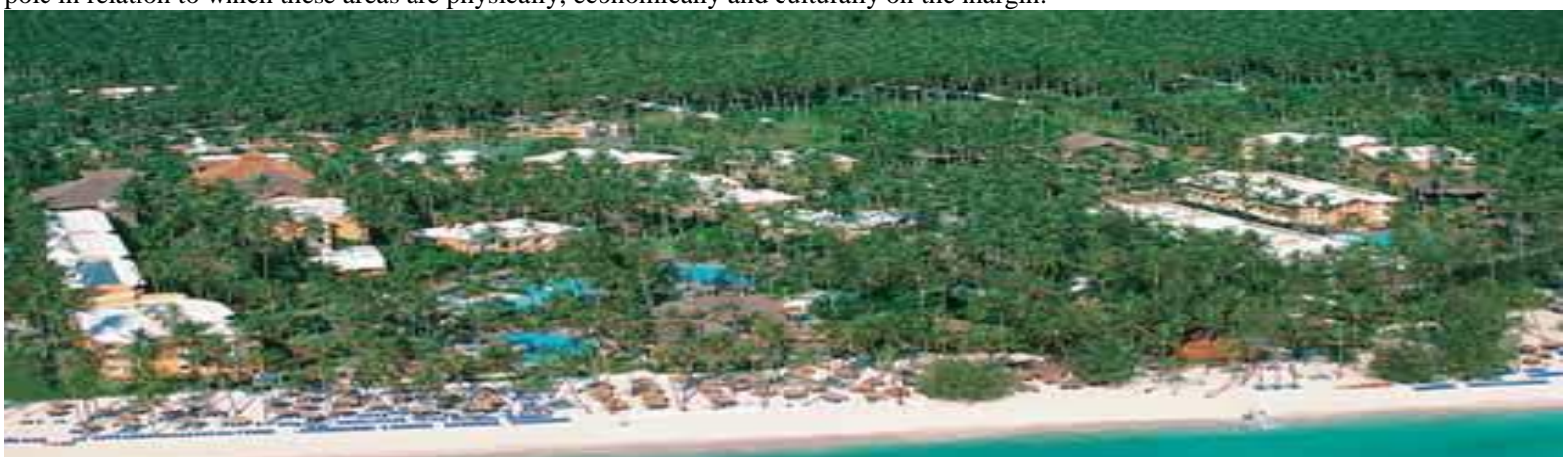

This image shows how same endowments on the margin have been further transformed to reenact the myth of paradise on earth.

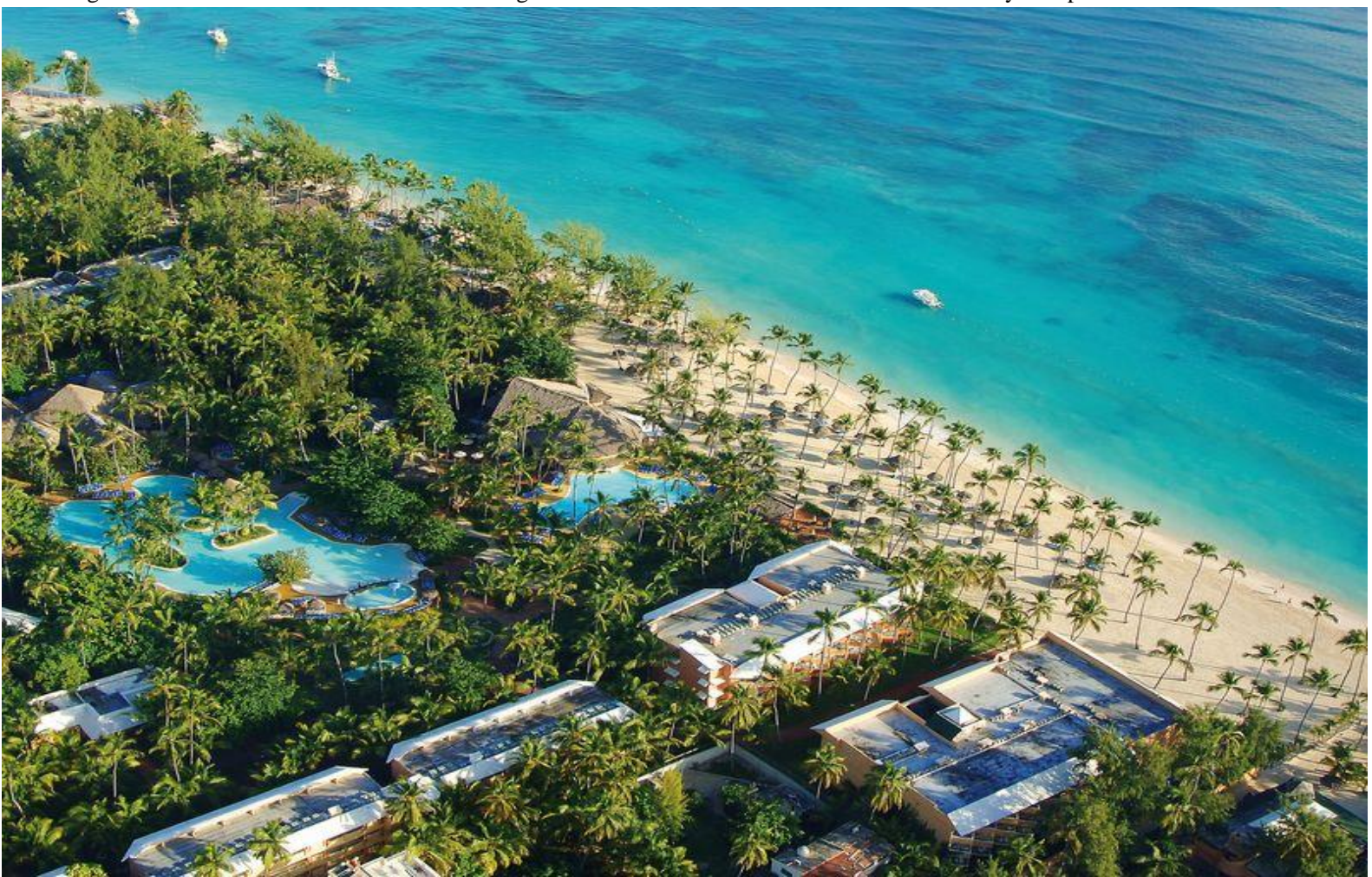

This picture shows how these places on the margin are seen, understood, and consumed by the post-modern golden hordes.

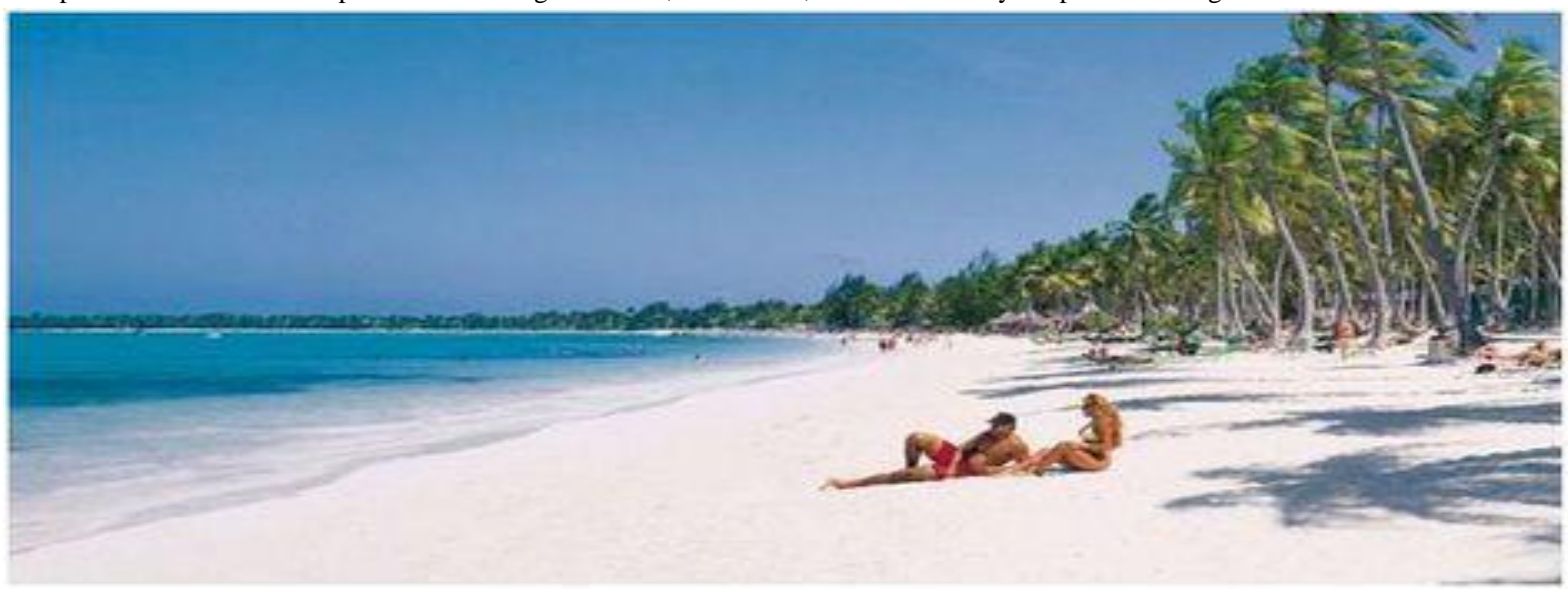




\title{
CHAPTER 3_ TOURISM, ECONOMIC PROGRESS, INEQUITY
}

\author{
POLITICAL ECONOMY, TOURISM PLANNING AND THE ROLE OF THE STATE TO OVERCOME \\ INEQUITY.
}

Many authors have argued that tourism development exacerbates or produces socio-economic inequalities in less developed countries (LDCs). The question is: To what extent states use tourism planning to overcome inequity.

\section{INTRODUCTION}

To great extent tourism literature deals with tourism development tendency to perpetuate or magnify traditional inequalities, or even generate new inequity in Third World destinations, although, also in the tourism literature, it is found that this should be overcome through tourism planning. According to Getz "planning is a process which seeks to optimise the potential contribution of tourism to human welfare and environmental quality" (1987:409, quoted by Timothy, 1999:371). In a similar but critical way Timothy points out that at rhetoric level "Places with carefully planned development are likely to experience the most success in terms of high tourist satisfaction level, positive economic benefits, and minimal negative impacts on local, social, economic and physical environments" (1999:371). On the other hand, however, Burns criticises Cater's views on tourism planning since it is too simplistic to assert that "with better informed tourism planning, there is no reason why the positive effects should not be maximised and the negative ones minimized" (Cater, 1987:223, quoted in Burns, 1999:329). However, any of the former quotes appear to specifically mention tourism planning as a tool to overcome socioeconomic inequalities.

Tourism planning has evolved from a narrow focus on economic expansion to contemplate a balance among economic, social and environmental factors (Timothy, 1999), following similar phases as development theory. In this vein Burns (1999) proposes a continuum where a number of tourism planning approaches in Third World countries may be classified, being one of its poles a 'Tourism First' approach focused on tourism development, addressed mainly to private sectors interests' achievement in tourism development that, more often than not, are found to be exogenous regarding the tourism destination and therefore, claimed to be behind this situation with the connivance of politicians and technocrats at national and local levels. The opposite pole of the proposed continuum is a 'Development First' approach, where planning is focused in integrating tourism within the overall development, where the latter should prevail, that is, the state should devise the appropriate institutional framework, where the national and local economic policies and planning emerge from stakeholders' consensus and, within which, private sectors and citizens have a say and a role to play. Unfortunately, this order of things 
appears to not guarantee an equitable wide spread of tourism benefits among the host population (direct, indirect or induced). Smith appears to sum up part of the underlying reasons: "In Third World societies the cleavages are great and the policies are devised by educated, upper class urbanites for application on rural, uneducated, lower income, poor people. As such, many development policies are not designed by the people they are supposedly to benefit, thus, policies and programs may be very inappropriate" (Smith, 1985:142, quoted by Timothy, 1999: 388). In this regard Timothy (1999) suggests that tourism planners should become learnt on local mores, socioeconomic realities and needs instead of transposing and imposing alien and incomprehensible (i.e. Western) concepts and ways of planning on the hosts to meet exclusively covered economic interests and the likes of prospective guests (visitors), leading to what Tuchman (1984, cited in Wilkinson, 1989:157) calls "a folly tourism development". Therefore, the question to pose would be to what extent can states use tourism planning to overcome such inequalities in Third World destinations. This question cannot be fully addressed without analysing till what extent a government's political economy is independent from other forces: endogenous and exogenous.

De Kadt (1979) claims that tourism development planning (being a western concept) may do little to equitably spread its benefits and therefore, reduce inequalities among those peoples living in the so called leisure periphery, more often than not situated in less developed countries (LDCs), if "those forces making for inequality are left a free rein" (1979:32). These forces are often seen to be exogenous regarding the tourism destination (i.e. politicians, technocrats, consultant planners, developers, tour operators, transnational corporations, the World Bank, the International Monetary Fund as well as the Structural Adjustment Lending Programs and Aid Agencies) leading to, as already mentioned, a folly tourism development characterised by "the pursuit by the governments or other decision-makers of policies contrary to their own interest, despite the availability of feasible alternatives" (Wilkinson, 1989:157, 161) in detriment of their country and its people's welfare but delivering large monetary benefits for local and national elites, among whose members politicians' and technocrats' relatives often are found (i.e. as in the case of Indonesia). De Katd (1979) points out that if local and national economic policies do not pursue a general socioeconomic development and therefore, poverty alleviation, and if they are not consistently implemented and audited, governments' political economy ability to determine the country's overall development will fail consistently to generate the public expected beneficial outcomes. According to De Kadt in the light of the former and bearing in mind real experiences coming from less developed countries "planning can do little to alter this fundamental fact" (1979:33). 
Britton (1982) further questions that if tourism has proven its ability to generate considerable benefits to many of those nations, supposedly in a perennial state of underdevelopment from the questionable western point of view, why tourism seems to maintain (even foster) prior national and local socio-economic inequities derived from elitism, generalised poverty, property rights' violation even displacement among many others. According to Britton (1982), in order to understand this all too common range of facts perpetuating underdevelopment features, a thorough investigation of the underlying mechanisms of international tourism as well as the analysis of "the economic and political structures within Third World countries" (Britton, 1982:333) and the historical forces responsible for the present range of common underdevelopment features in these peripheral economies is needed (Britton, 1982). These mechanisms and historical forces analysis may uncover that not always tourism per se (i.e. Burns' First Tourism planning approach) is the best strategy to achieve development as development is understood in the West. Britton (1982) adds that it is necessary to analyse how international tourism functions as well as to appreciate who benefits within these nations' political, socioeconomic and cultural frameworks. The analysis of those mechanisms and those forces may uncover the origin of the present situation in many of these countries / tourism destinations, allegedly less developed, underdeveloped or undeveloped.

Within the former background the next sections aim to analyse and evaluate to what extent states can use tourism planning to overcome inequalities in Third World destinations, bearing in mind that, more often than not, these states and their institutions are not totally independent from exogenous influences (and fierce endogenous interests) to devise adequate economic policies, disposing of "little room to manoeuvre" (Dahles and Bras, 1997: 68). A brief review of the main theories (or paradigms) of development will ease a conceptual framework within which to analyse such economic policies.

\section{CONCEPTUAL FRAMEWORK: THEORIES OF DEVELOPMENT}

According to Cowen and Shenton (1996) the embedded concept within the term development appears to resist a widely accepted definition due to its ambiguous nature. Authors such as Sharpley and Telfer (2002) agree in that the term development delivers a sense of a linear and constant change for the good as well as a plan leading to the achievement of development itself though, it is not so clear who benefits and what development is in other geographic and cultural contexts. The meaning of development is continuously changing. Its features have evolved from an exclusive economic sense to include a holistic view. Sharpley argues that the question to pose now is "how is development achieved in particular through tourism" (2002:4). Development and tourism have gone through similar stages although not much research has connected both areas of study (Telfer, 2002:76). 
From the 1950s onwards four development theories or paradigms have appeared: modernisation, dependency, economic neoliberalism and alternative development. Each one of them has evolved from the previous processes and experience, being the prior one left behind (Wall, 1997) although it might be argued that all of them may be found in a range of combinations, especially in the case of less developed countries. Getz (1987, cited in Hall, 2000:20) proposes four broad tourism planning traditions (approaches) that appears to closely parallel the four development theories evolution. They are: boosterism, industry-oriented, physical / spatial, and communityoriented. Later on, a sustainable model of tourism planning (Hall, 2000:21) emerged in tune with the spread of the sustainable development. Although already dealt with in the first part of this project, next lines briefly revisit and summarise each development theory as deemed convenient.

\section{MODERNISATION}

Modernisation development theory contains some former restructured economic models like a "laissez-faire utilitarianism" (Hall, 2000:21). It focuses on the achievement of constant economic betterment, leaving aside primary economics (agriculture), embracing vigorously industrial massive production of cheaper standardised goods, fostering the urbanite model of consumption affordable to most pockets. In this pursuit, economic mechanism were put in place to extend and accelerate the industrialisation model as a motor of material development (Telfer, 2002), following Taylor's observations (late 19th century) and Henry Ford entrepreneurial practices (early 20th century). Tourism is seen as a component of modernisation (boosterism approach) and as mechanism to multiply the former tangible benefits even more, expanding the expenditure's waves, producing steady foreign exchange flows to be invested in the country's modernisation and as a generator of plenty of employment for a majority of uneducated people (i.e. women employment). However, modernisation also leads to massive resource depletion, since it was implicit the idea that resources were at the service of development, free and endless. Regarding tourism planning, its main characteristic and critique was the absence of it (boosterism), in most cases leading to an unbridled tourism expansion.

\section{DEPENDENCY}

Dependency theory of development was already in vogue in the late 1960s and all 1970s, although it has never faded away. According to Lea (1988) it has informed much of international tourism research so far. This theory is based in forms of neo-colonialism and property regimes. Sharpley points out in this regard that "capitalism development in the metropolitan centres perpetuates underdevelopment in the periphery as a result of economic surpluses in the periphery being expropriated by foreign enterprises, misused by the state or appropriated by 
local elites" (2000:5). Sharpley (2000) further claims that there are clear links among dependency theory, the political economy and international tourism. However, some authors such as Oman and Wignaraja (1991, cited in Telfer, 2002:43) admit that there are peripheral economies where this model may lead to a previous inexistent economic development or take-off (i.e. Tunisia and Bermuda) by making wise use from foreign direct investment (FDI) and loans. Therefore, dependency theory is somehow criticised of being too pessimistic, dealing too much with alien agents and not so much with domestic factors that perpetuate underdevelopment characteristics and dependency.

\section{ECONOMIC NEOLIBERALISM}

The economic neoliberalism proclaims market liberalisation and borders clearance in favour of the free riding of know-how, money, manufactured goods and services. Economic neoliberalism advocates for the dismantlement of Western European state-led Keynesian model of economic development (intervened free market) in favour of market-led model of economic development. This model stands for the privatisation of public firms (as opposed to modernisation) and a global deregulation of the economy following Adams Smith's theory on the free market as the best resource distributor and Ricardo's competitive advantage of the countries. Within the economic neoliberalism model the maxim is to rise economic profits through a combination of technology and cheap labour where this combination might be, through the physical displacement of management from production and the use (and abuse) of outsourcing. Regarding tourism, Telfer points out that "economic neoliberalism appears to have received less attention" (2002:56). However, tourism has attracted considerable funds towards peripheral destinations to ease its development, where to generate capital accumulation (leakages) to be shifted back to metropolitan centres (Telfer, 2002). It might be thought that neoliberalism will lead to an increase in dependency levels, generating forms of neo-colonialism in Third World countries mostly, being tourism one of its facilitator but by no means the only one.

\section{ALTERNATIVE DEVELOPMENT}

According to Redclift (1987) this development paradigm proposes alternatives to and a change from the present western economic model of development, based on endless economic growth, allegedly unsustainable. In opposition to modernisation, dependency and economic neoliberalism this theory "proposes a bottom-up approach embracing sustainability, human and environmental concerns" (Sharpley, 2000:6). Other authors such as Butler (1998), Wall (1993) and Holden (2000) point out that tourism research has lately paid attention to sustainability within this alternative theory of development. Telfer refers to "indigenous tourism, local 
entrepreneurship, community participation in the making-process, the role of women in tourism and sustainable development" (2002:58) as some of the themes related to this development paradigm. Dernoi (1981) sees alternative tourism as a new approach to North-South and West-East relationship. Perhaps hosts' participation is the widest known mechanism inherent to this development theory.

Within the former conceptual framework the next lines present the case of Mexico and Lombok (Indonesia) to examine and evaluate in a contrastive manner to what extent can states use tourism planning to overcome inequity.

\section{DEVELOPMENT, INEQUALITIES, TOURISM PLANNING: THE CASE AND CONTEXT OF MEXICO} AND LOMBOK (INDONESIA)

The following case studies focus on the role of the state in tourism planning, whether states should intervene and how should they intervene to overcome inequalities using tourism planning. States dispose of a number of tourism planning and policy instruments to devise nations' welfare. According to Hall (2000:157-159) some of them are: regulatory (i.e. laws, permits, removal of rights ...), voluntary (i.e. education, assistance ...), expenditure (i.e. investments, public-private partnership, promotion ...), financial incentives (i.e. pricing, taxes, loans, subsides ...) and deliberate non-intervention (i.e. laissez fair). Tourism, due to its ability to generate steady and quick foreign exchange and massive low-skilled employment, is somehow targeted as a tool of development, although not always voluntarily as it was the case of Ghana (1983), among others, due to World Bank (WB) and the International Monetary Fund (IMF) restructuring programs enforcement (KonaduAgyemang, 2001). However, the international market (i.e. market imperfection and market failure) has an acute influence on states' political economy design and effectiveness to satisfy both social needs and the country's economic solvency (and exogenous and endogenous fierce demands). The evidence from Mexico (adapted from Clancy, 1999) and Lombok (adapted from Fallon, 2001) are examined in order to establish both states' ability (Mexican and Indonesian) to use tourism planning to overcome inequity and evaluate till what extent they are willing, allowed or learnt to fairly spread tourism benefits. Following Britton's observations (1982) both countries economic and political structures as well as those historical forces that have forged the current characteristics of tourism are contemplated, as well as the international tourism functioning characterised by "greater firm size, increasing horizontal and vertical integration (i.e. transport, wholesaling and accommodation) and the penetration of non-tourism capital" (Britton, 1982:336) plus the western superior expertise and financial capacity that allows tourists massive flows' diversion according to their own interests, exercising a considerable 
influence (and pressure) on states' autonomy (Britton: 1982), especially in the case of undifferentiated and longhaul tourism products such as, for instance, sun and sea package tours (Medik \& Middleton, 1973, cited in Britton, 1982).

THE CASE AND CONTEXT OF MEXICO: 25 YEARS OF TOURISM (Adapted from Clancy, 1999)

Mexico enjoys a diversified economy (i.e. oil export) and does not depend on tourism as opposite to most microstates or many neighbouring Caribbean Island-States (Wilkinson, 1989). Mexico shares of international tourists arrivals were 3.15\% in 1994, representing 3\% of the Gross Domestic Product (WTO, 1996, cited in Clancy, 1999). In order to investigate how tourism has become the second national generator of foreign exchange and employment, Clancy (1999) investigates the role of the state through questioning "What, if any, role did it play? Was it activist or did it allow the market operate freely? How, if at all, did it affect both growth and distribution of ownership?" (1999:9). Till 1960 tourism was market-driven limited to urban and border areas with the exception of Acapulco. There was no evidence of a social claim for tourism planning so far (Clancy, 1999). However, tourism was targeted by the state as a solution to the perennial deficits in the balance of payments and control of urban expansion through regional developments. Thus, the planning initiative came from the state with a multiyear master plan devised and implemented from the late 1960s by the ministry of tourism (SECTUR) and through a national tourism development trust fund (INFRATUR later called FONATUR), The state decided to enter into the international tourism industry through five new tourism large enclaves situated in the virginal but (unfortunately) inhabited coastal regions of Cancun, Ixtapa, Los Cabos, Loreto and Huatulco. Interesting enough is to point out that loans came from World Bank and Inter-American Development Banks to support these projects (Bosselman, 1978, cited in Clancy, 1999). The former governmental agencies planned, provided infrastructure, built hotels, created and owned tourism enterprises and provided financing for private sector investment in these new tourism resorts where nothing of that existed, following a pattern of polarising development (as in Indonesia). However, it was not without forced displacements, dubious massive property expropriation (no compensation), communal forests lodging and food production destruction, resistant's slaughter and communities impoverishment (Barking \& Pallés, 2002:248). On this basis, Clancy suggests that a statist approach and the international tourism structure explains better tourism rapid growth than a neoliberal or dependency or modernisation ones, though features of everyone may be traced all through the evolving phases.

Mexico acted as a development state (resembling those of East Asia), projected an autonomous master plan and implemented its first stages to make it worth for private investment via resource allocation, market prices 
alteration, franchises and management contracts initially, to end up selling public properties on passing all to the private sector. The second master plan phase was not feasible till the outburst of the debt crisis of 1982 (leading to structural adjustments). During the 1980s and 1990s there was a call for large tourism transnational and national firms to invest in and buy public tourism properties and enterprises. The state needed them to attract mass tourism flows to those resorts in order to pass from a former import-substitution (during the last 30 years) to an export-led growth economy in the hands of the private sector (Clancy, 1999). Clancy admits that at this point a statist explanation is not enough in that the international tourism industry "influenced ownership and control growth patterns" (1999:13), however, it might be argued that it was the Mexican state which planned in advance for that to occur. Between 1974 and 1992 around 100,000 new rooms were added to the 200,000 ones in existence, reaching tourism receipts from \$415 in 1970 to \$6.4 billion in 1994 (Clancy, 1999:9). To date, tourism development in Mexico "it is largely a product of state action" (Clancy, 1999:16). However, in the light of the former examination, the evaluation outcome on the state ability to overcome socioeconomic inequalities through tourism planning is quite negative. According to Clancy, public officials pursued in the name of the state: First, a systematic violation of local communities civil rights and properties (communal or individual). Second, fostered and protected "firms specific advantages, the ability to separate control from ownership and the nature of the hospitality product itself pointed to a narrow distribution of benefits. They all ensured that only MNCs and largescale Mexican capital would reap most of benefits associated with the industry" (Clancy, 1999:16). Third, the state eased measures and resources for large investors' benefit, at the same time that devised administrative barriers for the individual and family business to thrive within the tourism industry, since they were regarded as negative for the tourism development. What remains unclear is whether this master plan and the way it was implemented was an autonomous decision of Mexican state without any covered influence, pressure or imposition from exogenous interests and internal demands, given that it was heavily indebted.

THE CASE AND CONTEXT OF LOMBOK. INDONESIA. (Adapted from Fallon, 2001)

Tourism is still in a nascent stage in Lombok Island, what vividly contrast with more than 100 years of tourism development in Bali, 3.5 hours west by ferry. From 1974 onwards Indonesia opted for a polarising tourism development regulated by the second five-year national development plan designed by the Department of Tourism, Art and Culture (Fallon, 2001). Within this national plan, each province Department of Tourism adds regulations, programs and policies regarding tourism for that province (Timothy, 1999). However, the state plays an active authoritarian role contrary to a market-driven tourism development that affects both growth and ownership patterns. However, it is not free from exogenous interests and fierce endogenous demands, especially 
during Suharto era. Suharto's 30 years of government, characterised by corruption, collusion and nepotism, led to abuse and inequalities despite the "extensive land regulation enshrined in national legislation" (Fallon, 2001:487).

Local Sasak entrepreneurs and communities dealt with the first tourists in Lombok. Small guest houses and stalls, product of their own initiative and investment, were built (Cushnaham, 1999, cited in Fallon, 2001). However, soon a specific master plan for tourism development in Lombok Island targeted several areas to build new luxury tourism resorts. The Indonesian polarising model of tourism planning development selected Senggigi (where Mangsit village is situated) and Sire beaches, Gili Trawangan Islands, and Kute coast where Rowok village is situated among others. Government officials, police and army members intended to buy land under pressure and coercion, using privileged information and social status, imposing meagre compensations and unfair conditions. A complex network of agencies and organisms were created and managed by Suharto's sons, daughters, other relatives, politicians and technocrats in partnership with national and foreign private firms. Within this scenario two opposite examples of tourism development are found: Mangsit village in Senggigi Beach (North-West coast) and Rowok in Kute coast (Central South coast).

Mangsit villagers (Sasak people), the Holiday Inn Resort Lombok (opened in 1995) and the Sheraton Senggigi Resort mutually benefit from tourism development in the area of Senggigi Beach through cooperation and consultation. Sasak people in Mangsit village received food, clothes and medical attendance and respect for their properties (including land). In-house training was available to villagers and work positions offered accordingly. Villagers' living conditions consistently improved (Fallon, 2001). Villagers defended both hotels during the riots of January 2000 since both were viewed as a source of economic security. After those three days of destruction, these two hotels facilities remained as usual but without clients, though jobs were maintained waiting for tourists to return. The case of the village of Rowok is the opposite side of the tourism development planning coin. Rowok villagers (around 76 family groups) suffered continuously from the Indonesian state way of tourism planning and development. As opposed to Senggigi Beach, Rowok area was neither known nor developed. The aforementioned tourism developers tried to displace all villagers and free the entire area from people to build a luxury resort enclave as specified in the master tourism plan for Lombok Island. Villagers were offered "onetenth of the market value per hectare" (Fallon, 2001:489). Behind this pressure were a relative of Suharto (expelled in 1998) and a son of the region's Governor. Villagers rejected the offer and consequently their fields and houses were burnt, resulting some of them injured. In 1996 a court order proclaimed the eviction of people at 
Rowok (Fallon, 2001:490). They were moved $15 \mathrm{~km}$ away, however, they managed to return and rebuild their houses that were again knocked-down. Villagers' position met the legality but it did not worth much. At the end they managed to present the case in court and the foreseen tourism development was on hold at that moment (Fallon, 2001). As in the case of Mexico a statist development approach explains Indonesia tourism planning and development. The evaluation outcome on the Indonesian state ability to overcome socioeconomic inequalities through tourism planning is rather negative. The state has consistently planned and implemented a political economy to maintain inequalities and inequity so much in tourism planning as in any other sector.

\section{CONCLUDING REMARKS}

Having reached this point, Britton's (1982) observations regarding tourism development in Third World countries appears appropriate. Britton claims that it is necessary to analyse Third World countries' historical, cultural and socioeconomic factors that have been building the present domestic scenario, from which the international tourism structure and functioning appear to take fierce advantage (Britton, 1982). In the case that tourism were absent of these peripheral economies, socioeconomic inequalities and fierce inequity would be so acute as ever. Being so far Mexico from Indonesia (or Ghana), their respective states have used tourism planning to rise foreign exchange, alleviate the dangerous pressure from persistent unemployment and justify their legality. Both case studies appear to demonstrate that both statist political economies had no intention to use tourism planning as a strategy to overcome domestic socioeconomic inequalities. On the other hand there are voices in the tourism literature such as Wilkinson (1989) that propose a tourism development based on small and medium scale national and local entrepreneurship (as in Anguilla) as a strategy to overcome dependency from massive indebtedness, which leads to a loss of control over hosts' own interests. This strategy of tourism development would spread and make penetrate its economic benefits throughout the society avoiding massive leakages, whose pursuit usually leads to a folly tourism development (Tuchman, 1984, cited in Wilkinson, 1989).

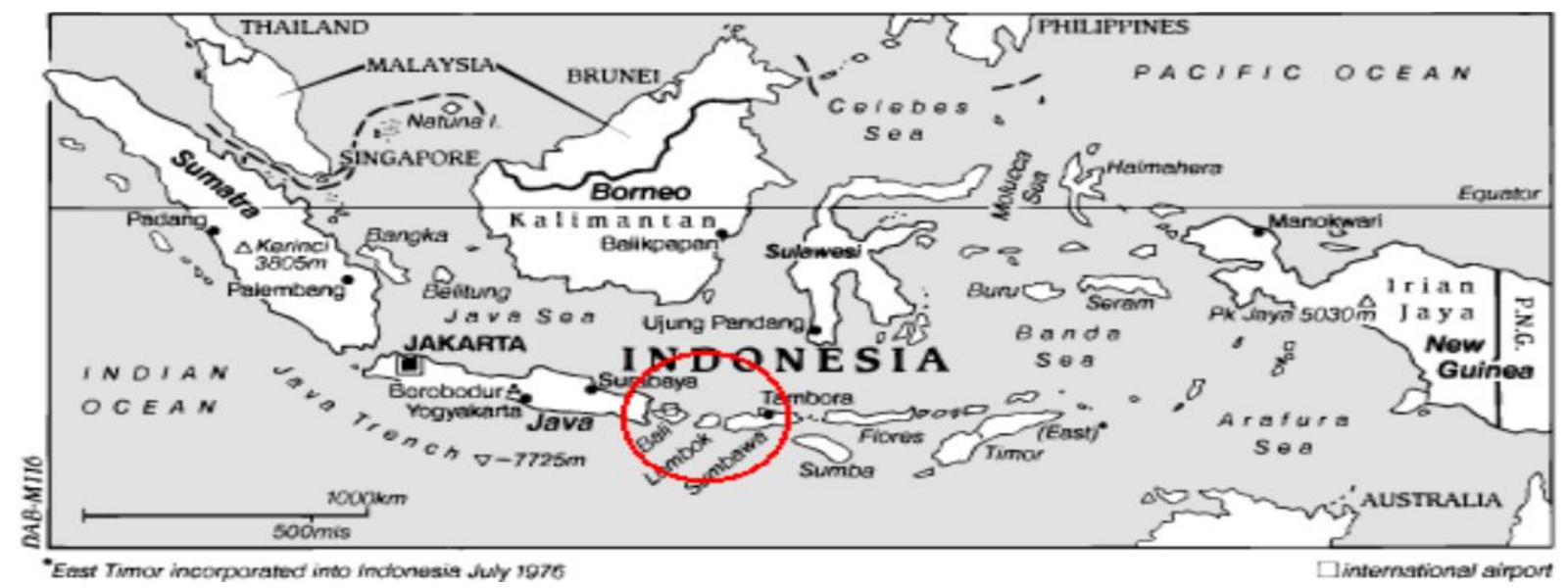




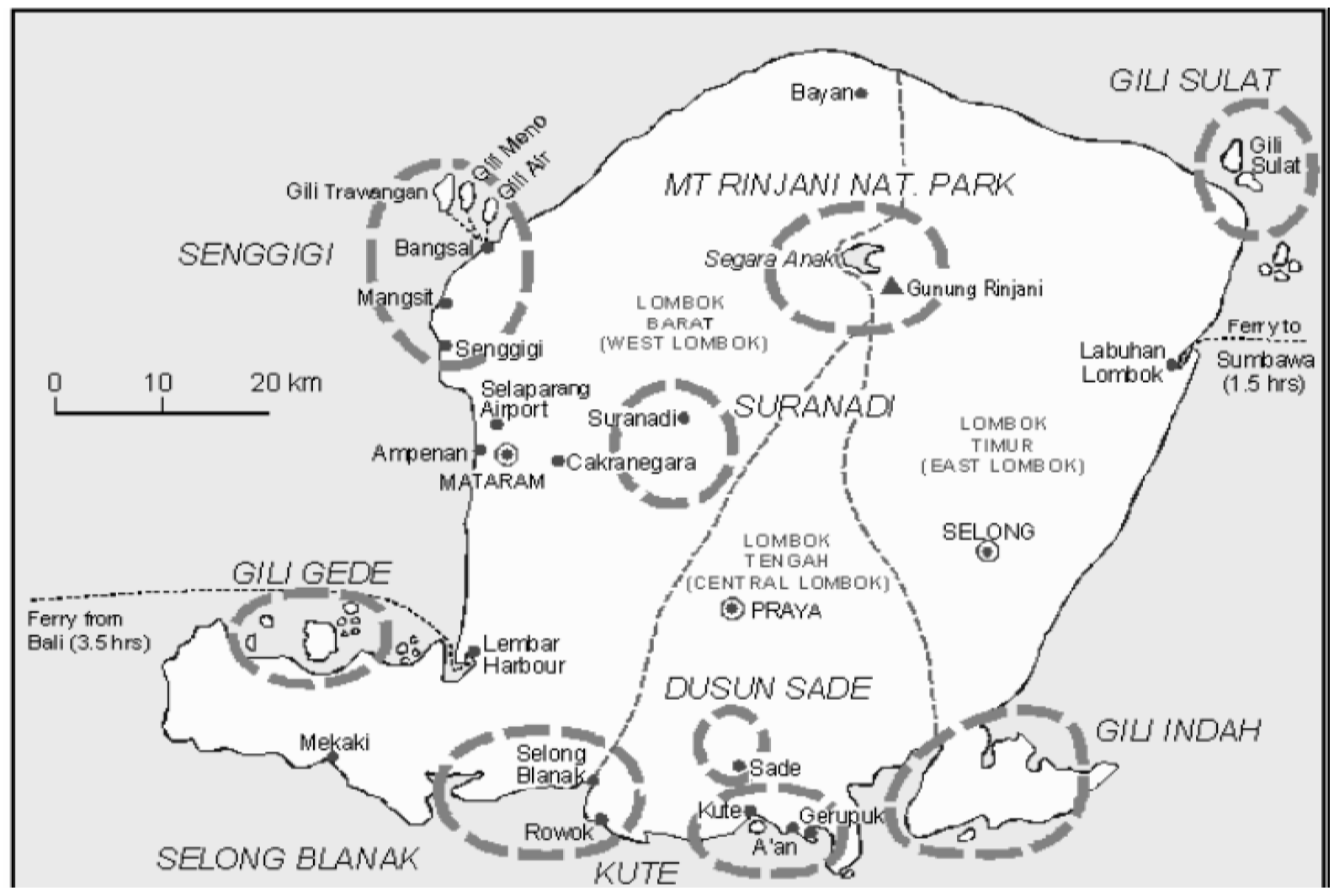

Holiday Inn Resort Lombok. Senggigi Beach. Lombok Island. Indonesia

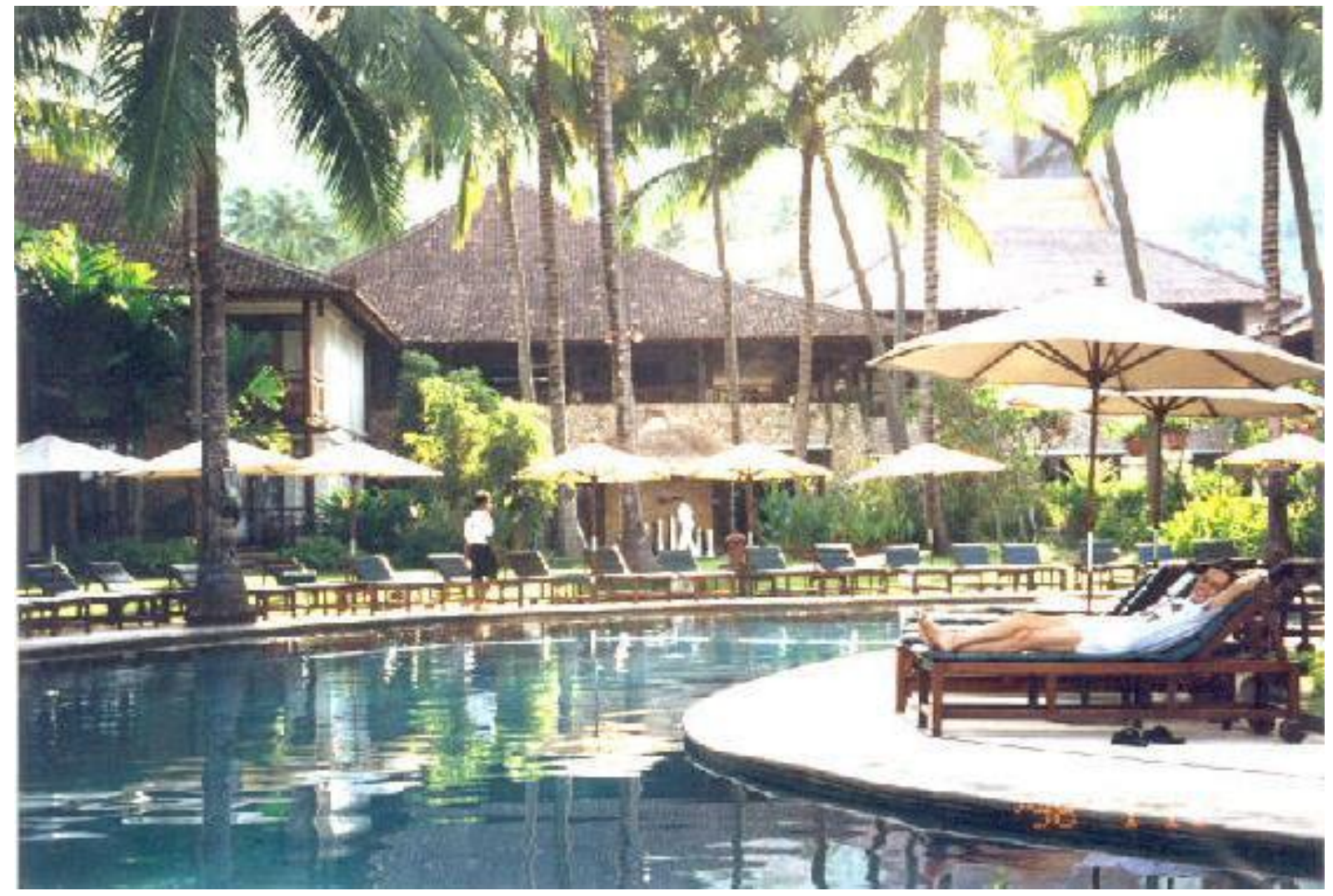




\section{CHAPTER 4_HOSTS, HOSPITALITY, ENTREPRENEURSHIP}

Within the private sector hosts' family owned businesses mostly constitute tourism entrepreneurship. They are who offer hospitality alike to prospective and repetitive tourists (guests) in destinations. However, as in the case of the term and concept of sustainability, entrepreneurship appears to suffer from a range of misunderstandings. Major tourism industries may or may be not entirely owned by entrepreneurs. Where shareholders are the owners, they run businesses through managerial staff, who are not entrepreneurs. However, there is an incomprehensible perennial understanding of managers as entrepreneurs, which it is not the case. They are just staff but not owners. Managers do not risk all. Entrepreneurs risk all. Next piece of research examines who is who, where, when.

\section{ON ENTREPRENEURSHIP: THE CASE AND CONTEXT OF SRI LANKA}

\section{Introduction: Overview}

Richard Cantillon (1680-1734), Robert Turgot (1721-1781), Jean Baptiste Say (1767-1832) and Joseph Schumpeter (1883-1950) laid the foundations of today's positions regarding entrepreneurship, though all of them from an economic perspective. According to Turgot's and Say's thinking an entrepreneur is somebody able to devise new businesses opportunities, while an entrepreneur as an exceptional innovator able to readdress the economy comes from Cantillon's and Schumpeter's thinking (Bruyat and Julien, 2000). However, research on entrepreneurship as an academic field of study started around Peterson and Berger seminal paper published in 1972, dealing with the analysis of those environmental and organisational factors influencing and therefore, affecting an organisation's activities (Zahara et al, 1999). Hereafter the term organisation in this context refers to small and medium enterprises (i.e. run by entrepreneurs) so as to multinational corporations (i.e. run by corporate management and lately corporate entrepreneurship). Since then, among others, Miller's theory has been used to examine possible linkages between strategic organisational variables and the environment, both in scope and in depth so as for shortcomings identification and entrepreneurship research contributions to the field. In this regard and according to Zahara, Jennings and Kuratko (1999), three empirical papers were published in the $1970 \mathrm{~s}$, ten in the $1980 \mathrm{~s}$ and thirty-two in the 1990s. These three decades of empirical research on entrepreneurship evolution have been disseminated mostly through journals such as Journal of Business Venturing (JBV) and Entrepreneurship Theory and Practice (ETP). These authors found out that around $85 \%$ of the former empirical research deals with secondary sectors (i.e. manufacturing), while tertiary sectors (i.e. services) have been barely studied in spite of being the fastest growing economic sectors. Zahara, Jennings and Kuratko argue that the cause of this lack of attention could be that "some researchers do not understand service companies' operations" (1999:2), which does not appear to explain the occurrence. Moreover, it was found that 
the "the lagged effect" prone to unfold among "sets of antecedents, entrepreneurship and performance variable" was not taken into consideration (Zahara et al, 1999:2).

Despite empirical research within this social science field, a clear agreement on the object of research seems to have not been reached yet, be due to its complexity or be due to a range of approaches leading to different standpoints. So far empirical studies have revealed the increasing heterogeneous nature of this phenomenon. Under a constructivist stance (understanding problems) Bruyat and Julien suggest that in order to understand entrepreneurship the individual, the environmental factors and the project unfolding relationships should be considered as enablers of success or failure and therefore, they ought to be clearly identified (2000:165). In this regard Busenitz et al examined 97 articles on entrepreneurship published between 1985 and 1999. They found out that although there was an upward tendency at that time span, subject's literature appears to remain in scarce supply. These authors point out entrepreneurship's permeable boundaries as a possible cause, which seems to hinder the evolution of entrepreneurship theory (Busenitz et al, 2003:165), however, the latter remains unclear.

Although authors such as Bruyat and Julien suggest that "Today, the field of entrepreneurship is to a large extent formed" (2000:166), others such as Aldrich and Baker argue that "entrepreneurship has made limited progress toward disciplinary status in a normal science framework" (1997, cited in Busenitz et al, 2003:286), to what Wiseman and Skilton adds that the subject remains at theory building level yet, though Benitz et al warn, as formerly seen, that its permeable boundaries seem to hinder its theoretical evolution, while Sexton wonders "Is the field of entrepreneurship growing or just getting bigger?” (1988:4, quoted in Busenitz et al, 2003), and Gartner further questions "Is entrepreneurship just a buzzword or does it have particular characteristics that can be identified and studied?" (1990:16, quoted in Bruyat and Julien, 2000:166). Sexton's and Gartner's inquisitive insights seem to remain unresolved. In addition, Bruyat and Julien point out that one proper definition of entrepreneur as a manageable concept and clear entrepreneurship boundaries also remained unresolved issues (2000:166). On the other hand, under a pure economic functionalist approach Schumpeter defines the entrepreneurs as "people who perform the function of reforming or revolutionising the productive system and they continue to be entrepreneurs only as long as they continue to perform that function" (Bruyat and Julien, 2000:167). However, the former definition seems somehow too limited within the theoretical purpose of this study, since Schumpeter's belief on capitalist and entrepreneur as being one entity contradicts Pelletier's (1990) review of Robert Turgot's Reflections on the Formation and Distribution of Wealth (1766) where, well before Jean Baptise Say (1767-1832), it is clearly distinguished the entrepreneur from the capitalist. The former 
"combines production factors in a new way" to create new wealth, the latter "provides the funds he needs" (cited in Bruyat and Julien 2000:167). Therefore, as Bygrave and Hofer suggest "Good science has to begin with good definitions" (1991:15, quoted in Bruyat and Julien, 2000:166) to what could be added that definitions should develop within a shared paradigm enriched by other disciplines' insights. In this vein, Buyart and Julien define the term entrepreneur as "the individual responsible of creating new value" that is "the individual without whom the new value would not be created" (2000:169). They further point out that "Defining the entrepreneur as an individual (or organisation) with certain specific features would appear to be possible only if all entrepreneurs in fact had those features, and if those features were exclusive to entrepreneurs" (2000:171), which it is not the case since the evidence so far indicates entrepreneurs are quite diverse in nature. It could be argued that it is because entrepreneurs and therefore, entrepreneurship do not exist in any vacuum. In whatever case, an entrepreneur is certainly "an individual, who owns, organises and manages a business and, in so doing, assumes the risk of either making profit or losing the investment.” (Encyclopedia of Business and Finance, 2001)

Within the former scenario the next lines aim to evaluate entrepreneurship in / and the global village through the analysis of what looks still missing in entrepreneurship research that quantitative method cannot address. This proposition acquires certain relevance since entrepreneurs are human beings, who generate wealth and provide jobs as by-products along the profit maximisation search process, though why some entrepreneurs and entrepreneurship surge and do well in some places at certain times while others do not is a central issue through this study. The next lines deem to evaluate entrepreneurship research from two different, although not mutually exclusive, theoretical and methodological standpoints: qualitative and quantitative.

\section{RESEARCH ON ENTREPRENEURSHIP}

The problem upon research on entrepreneurs and entrepreneurship resides and derives, not only from the issues overviewed in the former section, but in and from the inherent dichotomy between qualitative (in short supply) and quantitative (quite common) research methods and theoretical approach. It appears to be so regarding entrepreneurship's tangible achievements, which might be quantified and that of entrepreneurs' intangible common sense since they are, therefore, humans beings compiling at once a dual complexity, if not a paradoxical nature, since all appears to indicate the impossibility so far to produce exact replicas of their motivations, tacit and explicit knowledge, decisions, strategies, actions and achievements within an orthodox scientific framework (i.e. quantitative approach). This fact so far makes of the replicability issue a problem with respect to entrepreneurs' idiosyncratic nature, since under scientific principles any function, experiment or study must be 
able to be replicated delivering somehow equal explicable results time after time. If it is not the case results are discredited. In the light of the former, it could be questioned why a qualitative approach is in so scarce supply within the entrepreneur and entrepreneurship scenarios given their inherent duality: qualitative, quantitative.

Qualitative versus quantitative

Mike Scott firmly believed in the relevance of "qualitative methods and longitudinal studies" to break down the knowledge barrier frontier within the field of entrepreneurship (Gartner and Birley, 2002:387). Entrepreneurial processes feed from both the explicit (tangible and quantifiable) and from the idiosyncratic, tacit and implicit (intangible and qualitative) knowledge that the entrepreneur possess, devise, generates, absorb and finally further expands. All of which exceeds and certainly needs of something else than a traditional quantitative framework (i.e. objective), deemed insufficient to explain the phenomenon in its entirety and therefore, able to lead to misinterpretations (i.e. leading to a deadlock) at the same time that leaves behind substantive issues rarely addressed (Gartner and Birley, 2002) such as, for instance, the concept of creative destruction created by Schumpeter (Bruyat and Julien, 2000), example in itself of the former arguments since it cannot be fully explained exclusively through a blend of quantitative factors (i.e. deviations). In entrepreneurship, as in many other socioeconomic and business fields, facts and occurrences are not always fully objective but a mixture of known and explicable issues through, for instance, quantitative methods and unknown and inextricable range of dynamic subjectivities for which qualitative methods appear to be better equipped to decipher meanings, which may not always be explained through numbers, figures, deviations, chi-square tests or percentages to understand entrepreneurial success, success that managers may not be able to replicate applying same inputs, same processes. In a similar vein, capital accumulation might be not fully ascertained from a pure objective process, thus subject to replicability. That is, there is something missing, a subject/object dialogic, a conundrum that probably a qualitative stance is better suited for (Gartner and Birley, 2002).

\section{New perspectives}

According to Kodithuwakku and Rosa "both entrepreneurship and management are necessary for business success", further arguing that "they are interdependent and complementary" (2002:431), a dialogic relation. However, entrepreneurs or team of entrepreneurs tend to be seen as efficient managers while it is not so clear the opposite. Entrepreneurship pack resists disclosure into objectified processes and measurements ready to be learnt and applied alike by other entrepreneurs and managers. Even if it were the case, any similar achievement would be more in tune with a contextual chance than due to objective reasons. Therefore, Gartner and Birley views on 
quantitative proposition still apply: "There is something missing here" (2002:388). However, the concept of entrepreneurship appears to be enacted somehow differently in East Asian economies (i.e. Japan and Singapore) well intermingled with philosophic precepts operating on and under contemporary practices, precepts that seem to outweigh pure Western socioeconomic and managerial values based on individualistic protestant pragmatism. Japanese total quality teams, for instance, function within and under a Confucian and Shinto's disciplinary mode of understanding responsible work (rooted in Shushin moral education), acting and achieving entrepreneurs' like results in opposition to similar Western teams. Actually, Japan's government acts as an individual entrepreneur for the last six decades. It has fitted well with corporations, medium and small enterprises, which in turn have behaved as entrepreneurs' teams (family businesses like) doing entrepreneurial work rather than multinationals and enterprises doing managerial work. In fact, an apparent successful merge of both have generated since decades ago a new perspective on facing wealth creation quite differently from their Western counterparts. According to Morin (1989, cited in Bruyat and Juilen, 2000) this merge could be seen like a dialogic system where entrepreneurship and management combined form a new and complex unit "without their duality being lost in the combination" (Bruyat and Julien, 2000:169). This merge echoes Kodithuwakku and Rosa views on the interdependent and complementary aspects of both entrepreneurship and management (2002). This formula has been so successful for such a long time that it has attracted Western private sectors' and academia's attention. The former have pursuit to imitate bits of the whole according to each organisation's needs in time and context under a pragmatic vision, while the latter has tried to dissect the whole with the aim to explain the parts' inner functioning and, in so doing, make of it replicable. However, it remains to be seen if that merge succeeds within a Western socioeconomic and cultural scenario.

\section{ENTREPRENEURSHIP AND FIRM'S CREATION}

Entrepreneurship and entrepreneurs' firm creation form a unique blend of value generation at the back of the actual Western model of linear socioeconomic development and welfare state. The vast majority of stable jobs are generated by local and regional small and medium entrepreneurs. It seems to be an all too often overlooked fact. Multinational Corporations are in nature and functioning quite different from the aforementioned enterprise typology. In a global market scenario, Multinational Corporations look for rents' maximisation so much in tangible (i.e. monetary) as intangible terms (.i.e. market primacy) where and when these might be envisaged and risen, shifting benefits back to metropolitan centres. The former, on the other hand, create heterogeneous sources of wealth from and in their socioeconomic and geographic settings. In addition, small and medium enterprises are usually settled and run by local entrepreneurs (very often these are family businesses, new or inherited). By 
contrast, large corporations delocalise management from production, use unskilled cheap labour (not necessarily local), while expatriate Caucasians run production centres overseas (resembling colonial plantations). In this manner, the global experienced metropolitan centres extract rents from those inexperienced socioeconomic local settings, shifting back benefits or dismantling operations as soon as those a priori expected benefits do not materialise. In the light of the former, differences could be prone to be evaluated between entrepreneurial (individual entrepreneur) and managerial (i.e. corporate entrepreneurship) approaches regarding firm's creation, tangible and intangible profits generation and wealth distribution. In this regard, entrepreneurship as an academic subject is in a position to face busy times in the light of the former, where all appears remaining to be done, since what is available so far seems somehow partial (produced using only quantitative methods) and deemed inconclusive (since qualitative aspects are left aside). In views of Bruyat and Julien "A general discourse on the entrepreneur is bound to lead to a dead-end", to what they further add "typologies constructed empirically in absence of firm theories have now reached a deadlock" (2000:177).

The next section introduces a case study selected from five special articles using qualitative research methods, published by Garner, W and Birley, S (2002) in a special issue of Journal of Business Venturing, in order to empirically illustrate international debates on entrepreneurs and entrepreneurship. In a global market all appears too general and valid, however, it seems appropriate to investigate how rhetoric fits and weighs when applied locally (praxis), following the maxim of think globally and act locally. It remains to be seen how far propositions may be applied in local settings and how hosts can benefit or all the opposite from actual Western model of development through entrepreneurship.

\section{EXPERIENCES FROM THE GLOBAL IN A LOCAL SETTING}

With the aim to not only illustrate former debates but to substantiate this study propositions, the next lines present a qualitative and longitudinal study carried out in Sri Lanka on the entrepreneurship's subject alma matter, that is, why some entrepreneurs and entrepreneurship surge and do well in some places at certain times while others do not, a central issue in this study.

THE CASE AND CONTEXT OF SRI LANKA (Adapted from Kodithuwakku and Rosa, 2002)

The purpose of this study is to ascertain "why some rural entrepreneurs in Sri Lanka were much more successful than their fellow villagers" from a creative and opportunity-driven process perspective (Kodithuwakku and Rosa, 2002:432). Initially this study was conceived as a natural quasi-experiment carried on through both qualitative methods and a longitudinal study. Its purpose was to explore the entrepreneurial process in the context of a blend 
of controlled intervening variables within a constrained environment (Gartner and Birley, 2002) since, despite the so far available theoretical literature, there seemed to be some scarcity of studies dealing with "demonstrating the empirical dynamic operation of the entrepreneurial process" (Kodithuwakku and Rosa, 2002: 432), specially within a Sri Lankan varied and complex holistic socioeconomic context, where it is considerably difficult to disclosure the basics of the entrepreneurial process in order to measure them and at the same time to separate its socioeconomic outcomes from other possible causes. Kodithuwakku and Rosa (2002) focused on "how far entrepreneurial processes accounted for differential successes", that is, to uncover the success and failure dynamics, departing all participants from an equal semi-intervened blend of factors.

Ten years before the final eight months field work, in 1984, a portion the lower Mahaveli River's flood plain was artificially made ready for cultivation. Bushes were cleared; irrigation system and dams were built. Each family was allotted with 2.5 acres of land, food, equipment, on-purpose training and "some meagre government funds" (Kodithuwakku and Rosa, 2002:442). The rationale behind was based on the equal starting conditions for each participant family. Some participants did not know other families in advance but all of them were landless household villagers with meagre incomes, if any. From this stance, the research design eliminated possible future reasons for success or failure. In this vein, as entrepreneurs all families' members had same tangible limitations to extract value from "their perceptions, resources, motivations and skills" (2002:433). Thus, the ability to seek and take advantage from any opportunity became vital and therefore, a source of outcomes' differentiation with respect to each other participant family. However, possible external factors were taken into consideration.

According to Kodithuwakku and Rosa "Entrepreneurship is often envisaged as a process in which entrepreneurs spot opportunities others do not recognise" (2002:443). Presumably the former definition connotes novelty and innovation. However, according to Kodithuwakku and Rosa it was not the case at the starting point of their study. It was later that successful participants devised a myriad of combinations derived from knowledge and skills available to all participants (i.e. growing rice). Therefore, entrepreneurship strategies may well be used to escape from the perennial vicious circle self-fed by poverty and ill-borrowing that probably cannot be repaid in cash but losing property's rights due to punitive interest rates and middlemen intervention (resellers of participants' crops). The study's findings were quite diverse. From equal starting conditions, ten years later interviews made clear that those families dependent exclusively on crops and selling their labour "run into a vicious circle of impoverishment" (Kodithuwakku and Rosa 2002:442). Reasons behind this trend were meagre crops sold at unfavourable prices to middlemen, forcing the borrowing to plant next years' crops. Fortunately allotted land 
could not be sold but participants offered next crop and property rights as collateral. Those participants' families able to obtained larger crops at favourable self-negotiated prices wasted benefits "on nonsensical consumer spending" (Kodithuwakku and Rosa, 2002:442) running into debt. It seemed that those depending exclusively on farming and selling their labour run rapidly into debt. These authors point out that these participants cultivated an average of only 1 ha from the 2.5 acres they were allotted with. Although all participants started with same area of cultivable land, it was discovered that 42 families had lost control on the allotted land. By contrast, 37 families were patience and saved money during the first years in order to diversify income sources through investment in agricultural and commercial ventures, avoiding thus indebtedness. These authors described them as holding a "Weberian prudence and patience as well as capability in mastering skills" (Kodithuwakku and Rosa, 2002:443). They developed a learning capability to learn from mistakes. Ten years later the vast majority had failed to break down the poverty vicious circle in spite of the given opportunity, while only a few of participant families had succeed. Those devoted exclusively to agricultural tasks, with the exception of one family that managed to run 11 acres, run rapidly into perennial debt. Those that combined agricultural tasks and commercial activities had seen their income's sources diversified and increased. In both areas of work they did show an ability to learn quickly others' knowledge through social networking and from theirs and others' mistakes, applying the absorbed knowledge to their social and economic activities through investment. Curiously enough, this study revealed only few ways to fail and lots of ways to succeed, what is inversely proportional to participants' figures of failure and success. Thus, economic collapse (returning to a former state of perennial poverty) can be avoided through moderate consumerism, surpluses' investment and diversification of income sources through parallel networking and economic activities (i.e. acting as a land broker during spare time). Both authors are aware of the close interdependence of failure, success and vice versa, that is, local businesses cannot thrive easily when most villagers' household economies collapse. After ten years this new artificial human settlement has turned polarised into 40 successful families and 260 unsuccessful ones, starting all of them from equal material conditions. This research outcomes are explained through the use of qualitative methods, well equipped to investigate each family's former load of idiosyncratic, tacit and explicit knowledge. Knowledge is an input affecting results. Results require of further research into the intangible aspects of entrepreneurship.

\section{CONCLUDING REMARKS}

Settle a firm usually is an entrepreneur's or a team of entrepreneurs' risky decision. Basically the entrepreneur constitutes generally speaking the basic unit of Western economy, as the family is the basic unit of Western society. A family business can carry on extracting enough surpluses to maintain the business running and feed 
the family members, who are in fact owners, entrepreneurs, managers and employees all at once. Entrepreneurs at its most extreme (though quite frequent) run their small or medium enterprises without fixed work hours (i.e. more than 40 hours per week), without holidays and without free weekends. However, in contrast, employees need of an employer to hire them in exchange of a salary and social benefits. Therefore, an entrepreneur is defined in the first section as "an individual who owns, organises and manages a business and, in so doing, assumes the risk of either making profit or losing the investment" (Encyclopedia of Business and Finance, 2001). On the other hand a single employee may need or decide to work as a free-lance professional. In this case, this person becomes a type of single entrepreneur, subjected to success or failure. In the case of multinationals and corporations the entrepreneur is substituted by a hired chief executive or group of top managers, who work in the name and under the shareholders' brand, who in turn own the business. That means, the business is not run by entrepreneurs but by designated managers doing managerial tasks. These days, however, the term corporate entrepreneurship is in vogue. It may be defined as the sum of know-how, innovation, venturing and renewal of an organisation run like an entrepreneur would do it. It could be argued that corporate entrepreneurship is a formula to join managerial and entrepreneurial aspects combined to run a corporation with the purpose to attain both systems' benefits. However, so far it is not so clear what it is, what does it serve for and who are at the back of corporate entrepreneurship.

Throughout the former sections of this study, entrepreneurship's state-of-the-art regarding entrepreneurship qualitative research has been evaluated. Both, qualitative and quantitative methods are not mutually exclusive. Emphasis is made through the literature on many aspects of entrepreneurship that cannot be approached from a quantitative stance. As a consequence, research on this duality subject / object may turn out inconclusive or leading to a deadlock. Entrepreneurship, by its own nature presents a challenge for academia, but especially for those businesses that are in great need of entrepreneurs' intangible capabilities that resist replicability. In this vein, qualitative research is called to play a relevant role since "qualitative research goes beyond description to provide explanations", uncovering those aspects that quantitative research is not well equipped to clarify. "It goes into the why of the phenomenon studied" (Gartner and Birley, 2002:393). In sum, according to Singer "The way to become a connoisseur is to work on the entire spectrum of what's available," (2001:66, quoted in Gartner and Birley, 2002:394). Kodithuwakku and Rosa concluded regarding the presented empirical case study and the convenience of using a qualitative approach: "The qualitative approach was able to explore the complementarity and interdependence of the entrepreneurship and managerial functions, an aspect that has not been empirically well-explored" (2002:461), which means to replace "taken-for-granted beliefs" (Gartner and Birley, 2002:395). 
Due to former misconceptions I use: Lateral thinking; looking backwards in order to go forwards; the managing of selfishness from a win-win perspective; the needs of power vs the power of needs; the public choice theory; the paradox of voting; the paradox of plenty; and some other research methods, some other tools. At the end of the day, synergies, interrelation, dependence of: Tourism; the managing of sustainability; the tangible, intangible, and symbolic valuation of the common pool resources turn out paradoxical, where the latter two do not need the former, whereas the former needs the latter two. However, these days such paradoxical relation of dependency, or its absence, leads to a particular situation where in determined environments certain tourism segments could act like custodians giving them voice, be human and other than human. In other words, tourism might contribute to keeping them on hold by gaze-and-rent. As it is observed, the widespread peculiar synergies are everywhere.

From ancient times there is nothing so continuously practiced as the managing of sustainability so as the tangible, intangible, and symbolic valuation of the endogenous common pool resources. Therefore, why such a fuss on praxis? For instance, whatever traditional watering system implements for long the principles of sustainability as did it ancestors because what was, and still it is, at play is the unavoidable daily availability of food, fresh water, energy, dignity and self-esteem on the basis of running ownership and inheritance. Being autonomous by being autochthonous is far from dependency on what always appears out of reach, control, and understanding. This practice is at the far end of the dependency continuum. Some examples are: Traditional Subak watering systems in Bali ( $9^{\text {th }}$ century); traditional fishing reservoirs' management called Sasi in Raja Ampat, New Guinea; Nakaiy traditional calendar in Maldives Islands managing the sustainability of marine livelihoods; watered terraces ethnic system in Ifugao, Philippines, dating back 2000 years, and more peculiar ones. There are hundreds of traditional beautiful and bountiful systems still in use from where tourists (guests) have no idea. They are the outcome of the power of needs. It turns out somehow unexpected, and therefore amazing, that after such a long time devoted to the research project (long study with purpose), and other connected research, the investigation stubbornly leads by its own to the very beginning of all what's on with praxis. That's sustainability.

Following chapters are devoted to the examination of what's on with praxis. The power of needs naturally builds up praxis while the needs of power deal with other realms. However, both could go hand in hand for the benefit of all human and other than human environments. Gaia's laws engages all with all. These days' Western intractable problems surge when by passing such laws from which traditional systems have benefited for long side by side. Having a respectful look at would unfold that solutions somehow have always been over there/here. 


\section{CHAPTER 5_ OTHERNESS: RECOVERING LINKS}

Giftedness: "What if people are like ecosystems. Some are like meadows, some like deserts, and some like oceans. All are beautiful, valuable and necessary. Gifted folks are like the rainforest: extremely complex, highly sensitive, intense, colorful, and creative. And, like the rainforest, gifted individuals are capable of making important contributions to society and the planet. But to do that we need to allow them to be themselves. We need to put the chainsaws down and encourage their curiosity, idealism, sensitivity, and insight. Appreciate their lush and lively rainforest minds." 100 words of wisdom. Paula Prober. Feb 26, 2015 (SENG). It does fit in with Bhutan.

\section{BHUTAN KEEPS THE LINKS AMONG INHABITANTS, HABITS, HABITATS}

Ricardo Rozzi (2012) argues that rather than inventing what has already been practiced, we should pay attention to traditional pools of knowledge (i.e. Mapuches. Chile), where certain answers to these days Western intractable problems appear already somehow resolved. It looks like the case and context of Bhutan. Bhutan keeps the links among inhabitants, habits, habitats, being human and other than human beings. Bhutan spreads paradigmatic wise lessons worthwhile of careful attention. Bhutan was voluntarily closed to the rest of nations for long time. As a result of such situation its cultures and environments have reached these days well preserved, making of Bhutan attractive to outsiders. From 1961 these pristine bio-cultural landscapes call the attention of tourism as well from the World Bank (WB), the International Monetary Fund (IMF) and from an endless range of outsiders looking for what might be of any profit. Since the very beginning Bhutan has enforced an autochthonous policy in order to avoid ex ante an unbridled arrival of tourists: Low volume-high value. However, although it might already been previewed well in advance an all too exogenous folly Western-like right-now development, it is not equally so clear regarding outsiders other than some few tourists visiting this nation. Bhutan keeps alive same Buddhist culture as I saw around in Tibet, before. It does make of Bhutan an even more attractive destination. At the moment, this wise nation has shown some special kind of clairvoyance when dealing with seeds of identity and the always complex modern socioeconomic progress at its own pace. Let's see.

His Majesty often says: "Where we live must be clean, safe, organised, and beautiful, for national integrity, national pride, and for our bright future. This too is nation building”. So, there are other ways of understanding life issues: tangible, intangible and symbolic progress out from a prevalent quasi homogeneous Western model. What to choose: The power of needs or the needs of power. Both could go hand in hand as it looks like it is in Bhutan. One model should not exclude the other. Carry on being oneself does not forcibly restrain to catch up with those sources of equitable progress. Bhutan does it by keeping the links among inhabitants, habits, and 
habitats on the basis of a thoroughly embedded philosophic frame that runs all aspects of life. Out of place copies of any foreign socioeconomic model usually do not replicate their benefits within the OTHER's. They fail more often than not. Copies don't hold relation with own philosophy, what's far from other cultural geographies like authors such as Joseph Morgan Hodge (2007) and Oswaldo de Rivero (2001) have attentively countered.

Recognised as the father of modern Bhutan is the third king of Bhutan: Druck Gyalpo Jigme Dorji Wangchuck born the second day of May 1929. He is the Royal Grandfather of the present young King. Under his reign Bhutan was opened to development and modernisation. Modern education was stablished around; feudalism was abolished; modern technology and methods adapted progressively; in 1953 the judiciary system was reviewed; the first unicameral Parliament established. All within a farsighted catch up vision. His son, the fourth king, enforced constitutional democracy even though the majority of Bhutanese did not see any need. He renounced to hold power, which was passed onto the elected Parliament. However, as this second part of this project deals with, there is no maintainability, sustainability without a clearly balanced proper frame. According to the Prime Minister, Bhutan presents a $116 \%$ of indebtedness regarding nation's GDP. On the other hand, Bhutan it is the unique country that holds a clear primacy on Net Happiness Product / GNH (1979) over the Gross Domestic Product of $\$ 2$ billion (15-3-2017). It is something more than good poetic intentions since it is feasible from all standpoints. Oswaldo de Rivero (2001) argues on "Survival” (Rivero, 2001:157) rather than on an exogenous development's pursuit. He states: “Thus, increasing the supply of food, water, energy, reducing the rate of population growth and obtaining a strategic advantage become the decisive factors for national survival as the new millennium begins" (Rivero, 2001:163). He does refer to some other situations quite different from Bhutan's. However, it is not free from risk on opening its doors to foreign massive funds' arrival: The double edge sword. So far, electricity and tourism are the major exports providing proper owned foreign currencies.

The Darwinian effects of globalisation can easily prevent the rewards of development, according to Oswaldo de Rivero. "Their only option must be simultaneously to lower birth rate and modernise their production with more technological input" (Rivero, 2001:159. He does not clearly mention the wealth services are well equipped to generate although refers to Singapore as a paradigmatic case. Bhutan transients on another far shore, fortunately. It has a population of around 750.000 within wide mountainous geographies from tropics up to perennial snows. It is not lost. It has already arranged in advance its differentiated seeds of identity within which all is and will be, apparently, under Bhutanese people's will. That said, the $116 \%$ rate of debt might reverse good intentions, since the friendly donors and lenders of today ease massive loans to fiercely claim them tomorrow without compassion 
of any sort. It is: Dependency. One well-known strategy on behalf of a Western-like right-now development, which recreates copies of Third World where it did not exist starting a snowball of perennial poverty. In spite of these facts, actually, Bhutan appears to acknowledge who is who, where, when that's enough. However, certain tourism segments within some carefully designated regions' spots could ease the multiplier factor upon gazing Bhutan's unique biocultural landscapes, common pool resources human and other than human. So far, Bhutan has managed a kind of clairvoyance on aspects not seen in other larger or richer nations. Bhutan has not thrown away its healthy and wealthy pool of traditional wisdom: The golden eggs hen. That one tourism and tourists (guests) look for, precisely. Tourism provides a steady constant amount of domestic and foreign currencies with little investments, since all is about gazing and enjoyment. It meets and fits well with Bhutan's policies: Low volume-high value; Net Happiness Product (GNH). The question is how to design tourism like a bless making of guests custodians instead of one curse. In other words, Tourism: From evil to custodian.

Reflection: Bangladesh, the flat over populated versus the mountainous tiny and sparsely populated kingdom of Bhutan. Both say about respect and friendship. One, republic and Muslim. The other, constitutional kingdom and Buddhist. It is not taken into account the for-all portrait each philosophy delivers: Massive longstanding poverty versus its absence. Massive population growth inherently leads to an unsustainable scenario prone to inequity framed by perennial manmade acute scarcity. Bhutan is placed at the far end of this continuum. So close geographically, so far distant philosophically. Each philosophy generates quite distinctive ways of living and understandings on same issues within the private and the public spheres. Their respective outcomes are quite visible and even though in this case official friendship is possible. The first state to recognise Bangladesh as new nation on 6-12-1971, through the third king, was Bhutan. Friendship is possible in spite of differences.

All of this reminds me the wealth of opinions some key informants, I formally interviewed, told me. In London, one of them (private sector) told me that he did not expect governments learn from mistakes regarding tourism development. He argues that tourism is a far too large deliverer of cash. He insisted on that it will take 25 years to become aware of mistakes already well-known somewhere else. Another key interviewee in London (ABTA) stated that due to the noticeable absence of incentives from government, there was any motivation to behave differently regarding sustainability from the side of tourism and its consumers. Informal interviews in Spain and in London confirmed me that at the time of making purchasing decisions neither clients nor suppliers showed any interest regarding sustainability. Fortunately enough, Bhutan designs its tourism as not previewed by all key informants and all travel agencies' staff I did interview. Bhutan does spread key lessons worthwhile of attention. 
On 9 December 2016: His Majesty The King graced the closing ceremony of the 8th session of the Second Parliament. Ten years ago said: "I will protect you as a parent, care for you as a brother and serve you as a son."

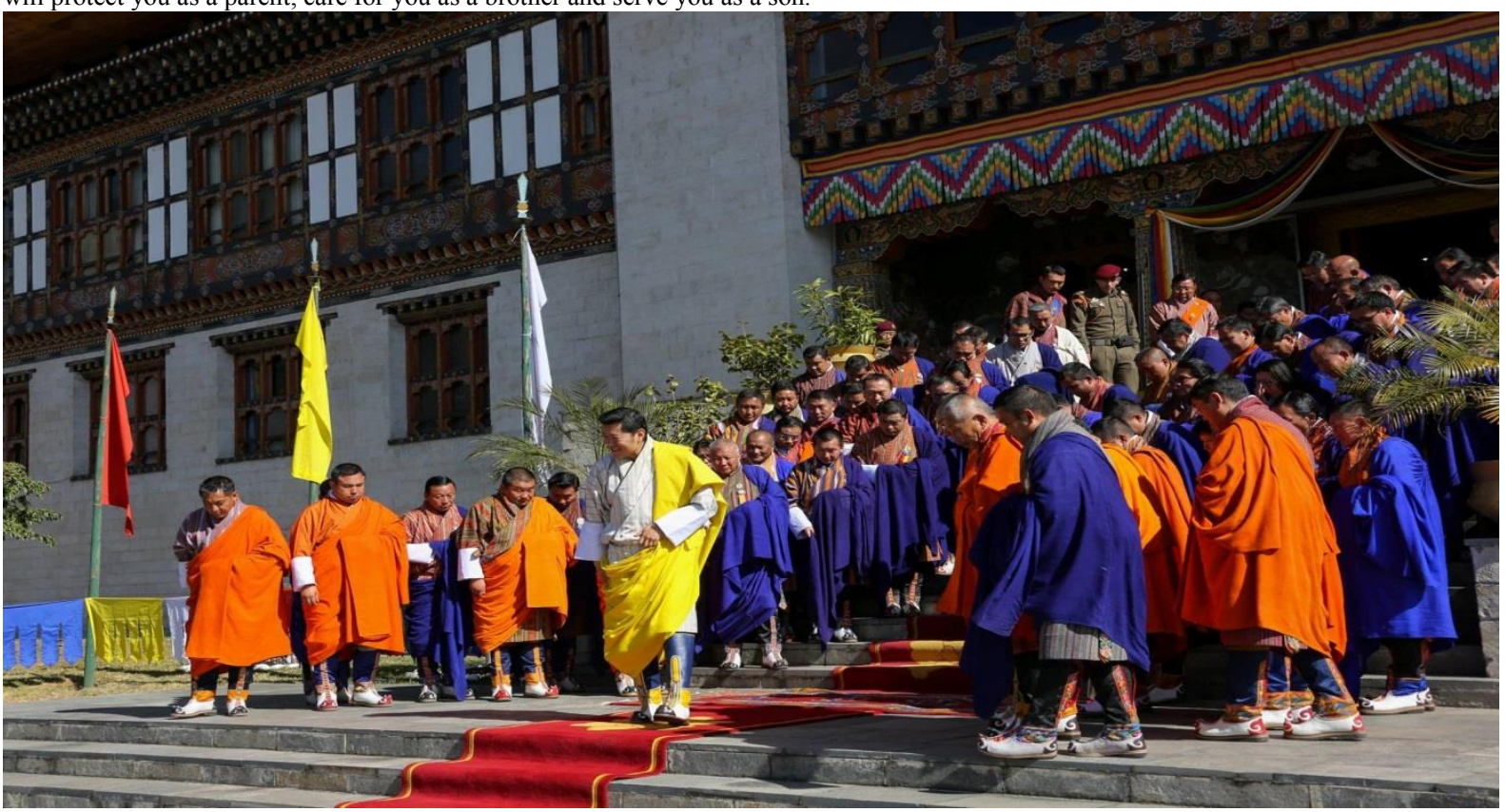

Beautiful and bountiful bio-cultural landscapes: The managing of sustainability valuing the common pool resources. Tourism, does it fit in?

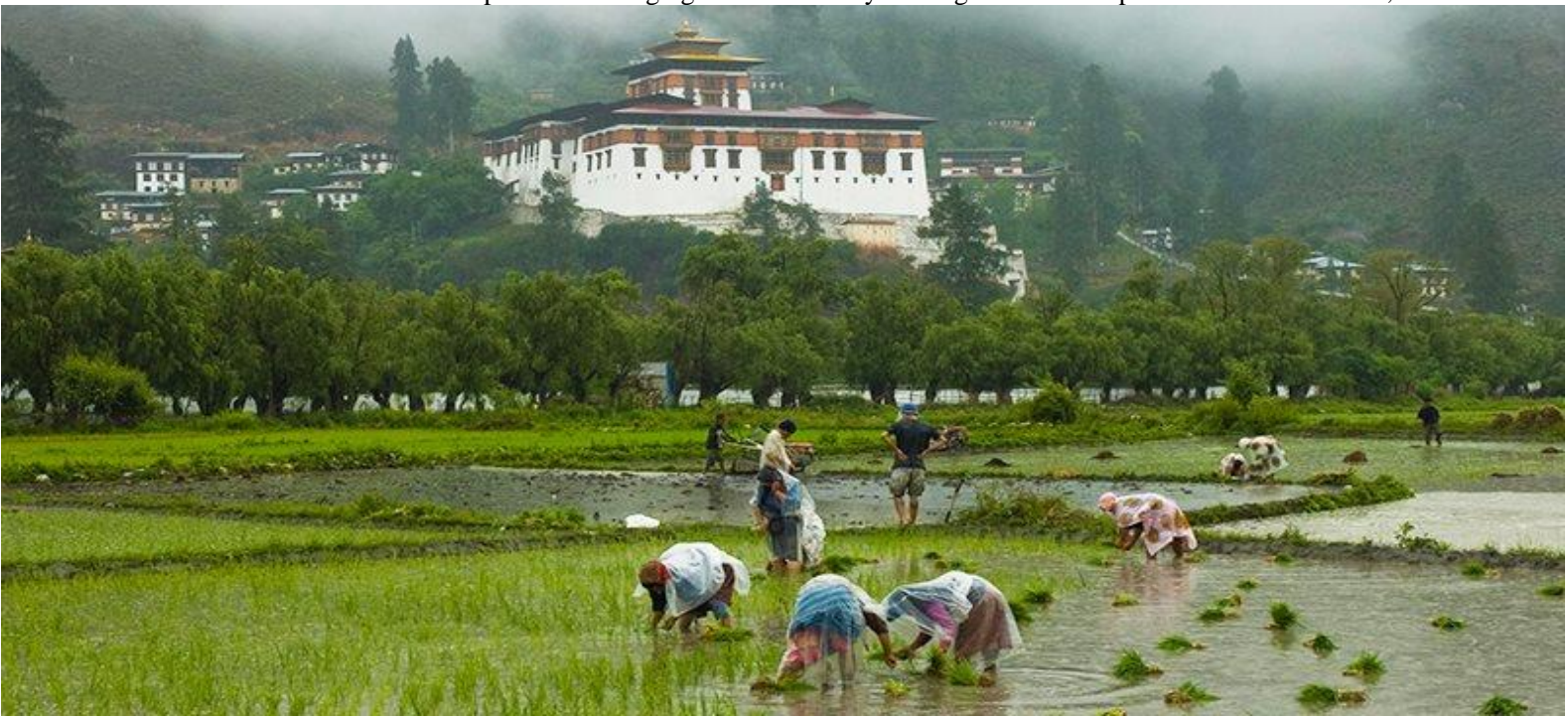

The Tiger Nest from a wide unusual perspective. The wise managing of the sustainability of common resources recreates unique landscapes

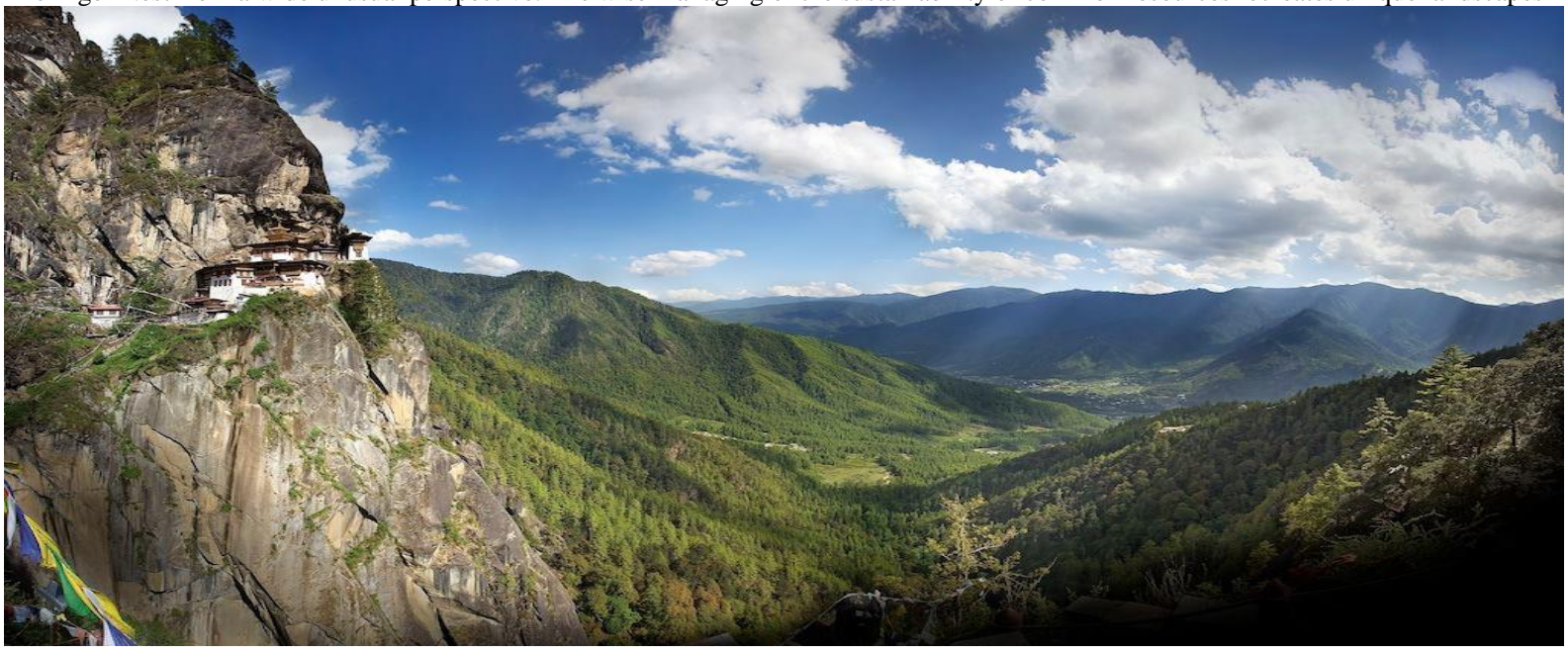




\section{CHAPTER 6_TRADITIONAL SYSTEMS: ANY LESSON?}

\section{ON THE LONG-STANDING SUSTAINABILITY OF ENDOGENOUS COMMON RESOURCES}

This Chapter examines evidences delivered by some selected traditional systems managing the sustainability of respective endogenous common pool resources. Subak, a watering system in Bali dating from the $9^{\text {th }}$ century. Nakaiy, a calendar developed in Maldives Islands managing sea livelihoods. Sasi system, traditional in some Indonesian archipelagos (i.e. New Guinea) managing social, terrestrial, and marine common pool resources. All are outcomes of the power of needs as a synergetic engine to develop sustainable ways of producing livelihoods without exhausting biotopes. All of them have created and sustained beautiful landscapes in tune with Gaia's laws. Mores, usages, taboos, consuetudinary laws, know-hows, property and inheritance regimes, have regulated the managing of sustainability and the tangible, intangible, and symbolic valuation of the endogenous common pool resources as time unfolds on the basis of reciprocity. It is what tourists love to gaze upon for enjoyment. The question is how for-so-long managed synergies have recreated such beautiful bio-cultural landscapes instead of spoiling them. However, in places where an all too often misunderstood alien development gets, hosts' pools of wisdom turn out shameful life's systems. It does happen with Sasi traditional system. Consequently, they are progressively or even abruptly left aside in search of El Dorado. This is the start point to recreate copies of Third World where did not exist, a product of the needs of power. Bali turns out an exception after more than one hundred years of caring foreign visitors. Those temporary guests were and are kin of enjoying on aesthetics, differentiated tangible, intangible, symbolic beauties. All is about gazing upon what is available on site, peculiar, unique, what visitors do not have at home. Perhaps, through these hundred years they have acted like custodians contributing somehow to the ongoing traditional managing of sustainability and the tangible, intangible, and symbolic valuation of human and other than human common pool resources. As I study theory, listen to rhetoric, and travel to experience what's on (praxis), I deem convenient sharing some few of my own field observations, some of them as a participant observer. I do it before examining afore mentioned systems.

Bali, Lombok, Gili Islands: I did enjoy of the exquisite refinement; also of the absence of conventional transport further on than a canoe full of women, fruits, vegetables, when going from Lombok to Gili Islands by my own; of a large house made of giant bamboo in Gili Air (a coral island); of the kindness of guest houses' owners; of a car and driver to go around by my own in Bali; of telling to a Balinese guide about an ethnicity he did not know much about living within the biggest volcano's caldera containing a lake; of going to visit it by means of a tiny canoe. We saw ancestors' bones and skulls carefully ordered. On the other lake's side, an eruption wiped out a village few years before, I was told. I walked on solid lava to know by myself what's on out of desk research. 
Kintamani Caldera. Bali. Field trip. Preventing possible bias I have used images other than mine.

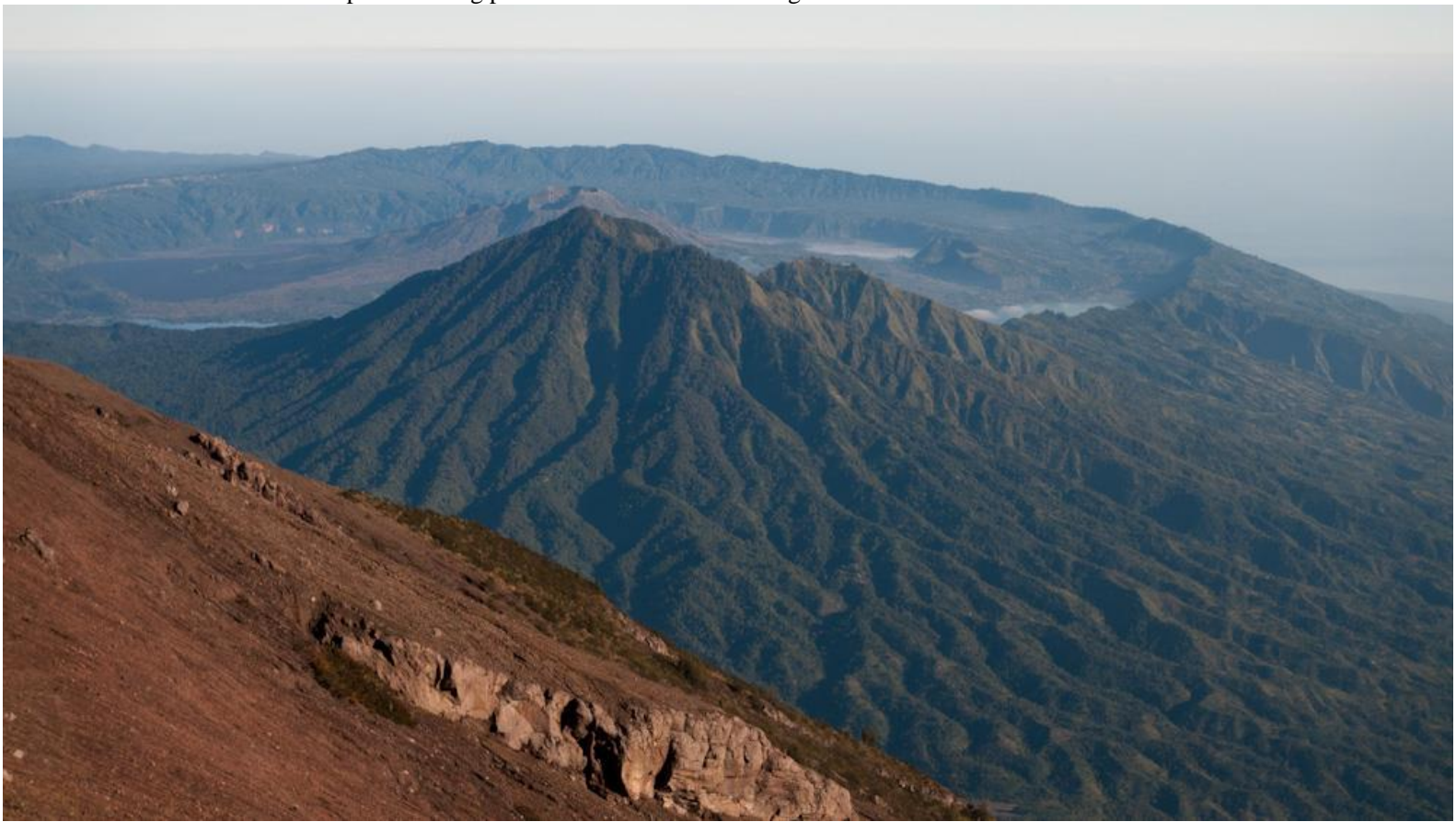

Lava wiped out a village few years before my visit. I walked on solid lava to experience by myself what's on out of desk research.

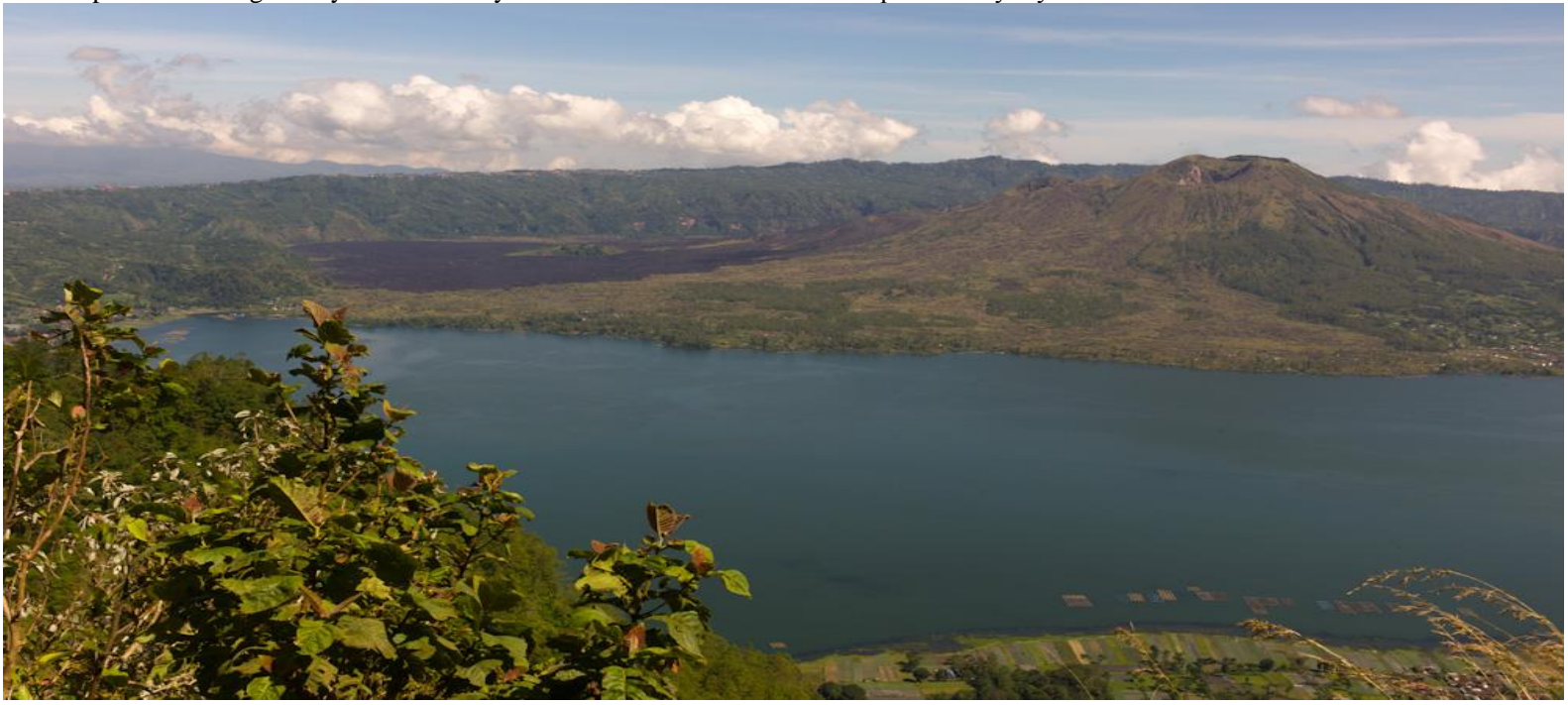

The ethnicity I wanted to visit lives in tiny plots between the lake and the average 500 metres high Kintamani caldera's cliffs.

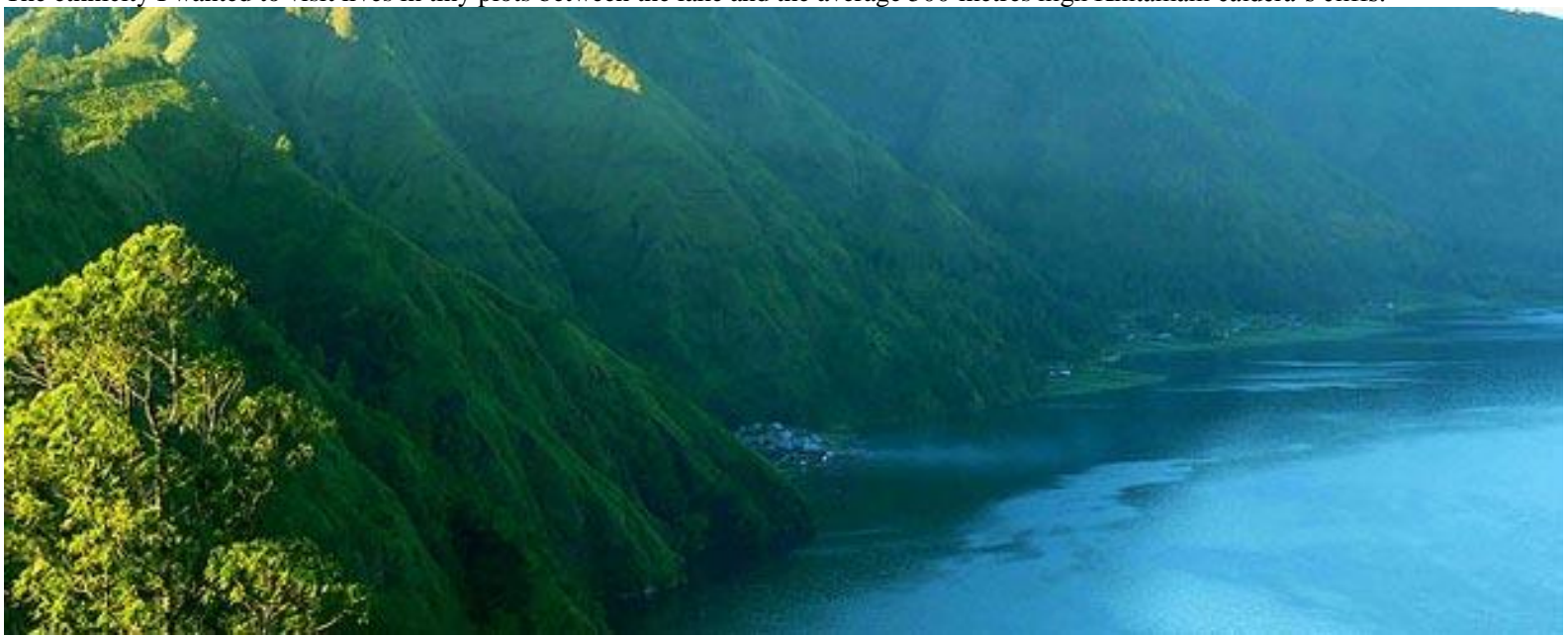


Within the Kintamani caldera another volcanic cone emerged. The lake still keeps water levels, a source feeding Subak system.

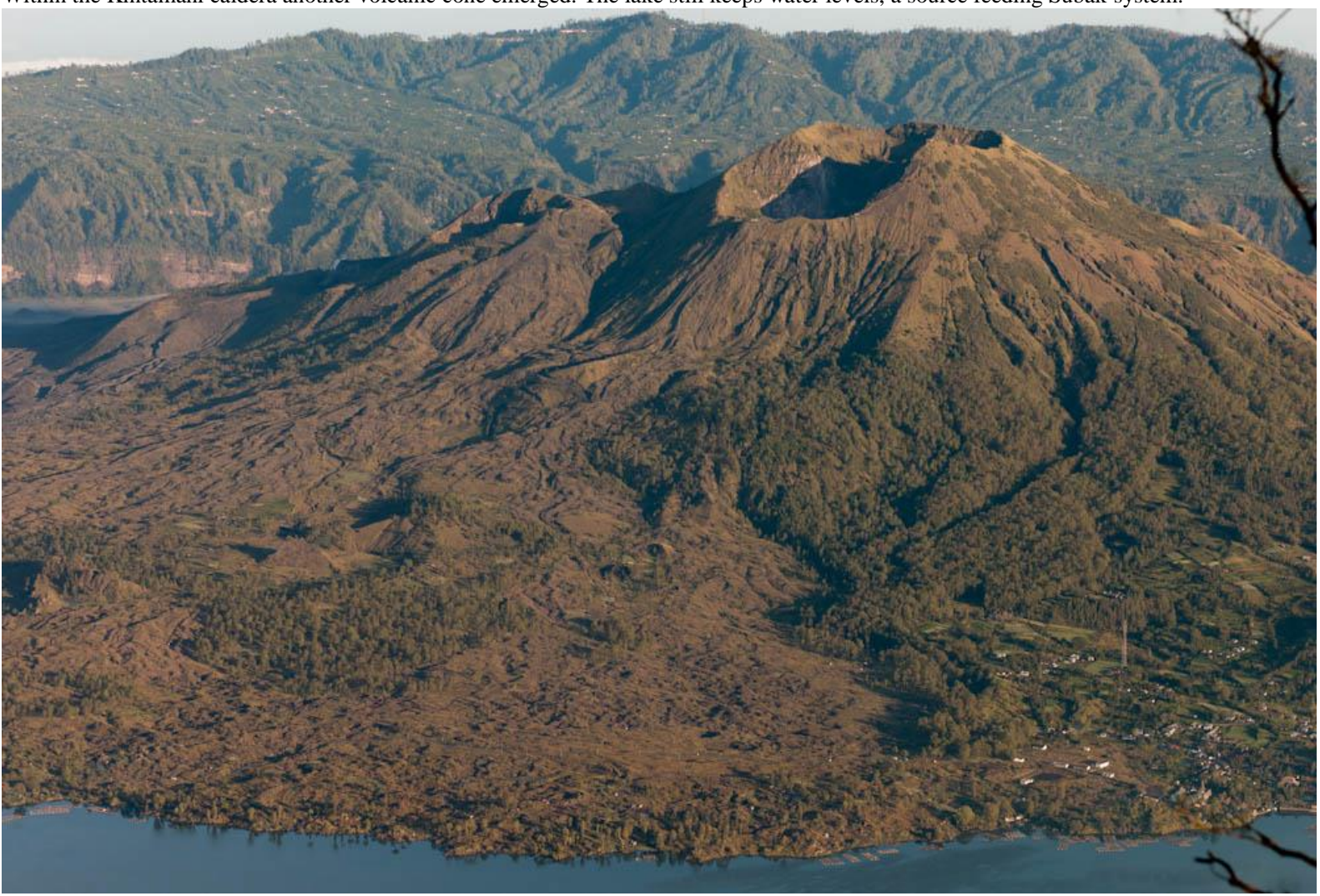

The oldest ethnicity of Bali. They place ancestors under scent trees. They have a quite differentiated culture.

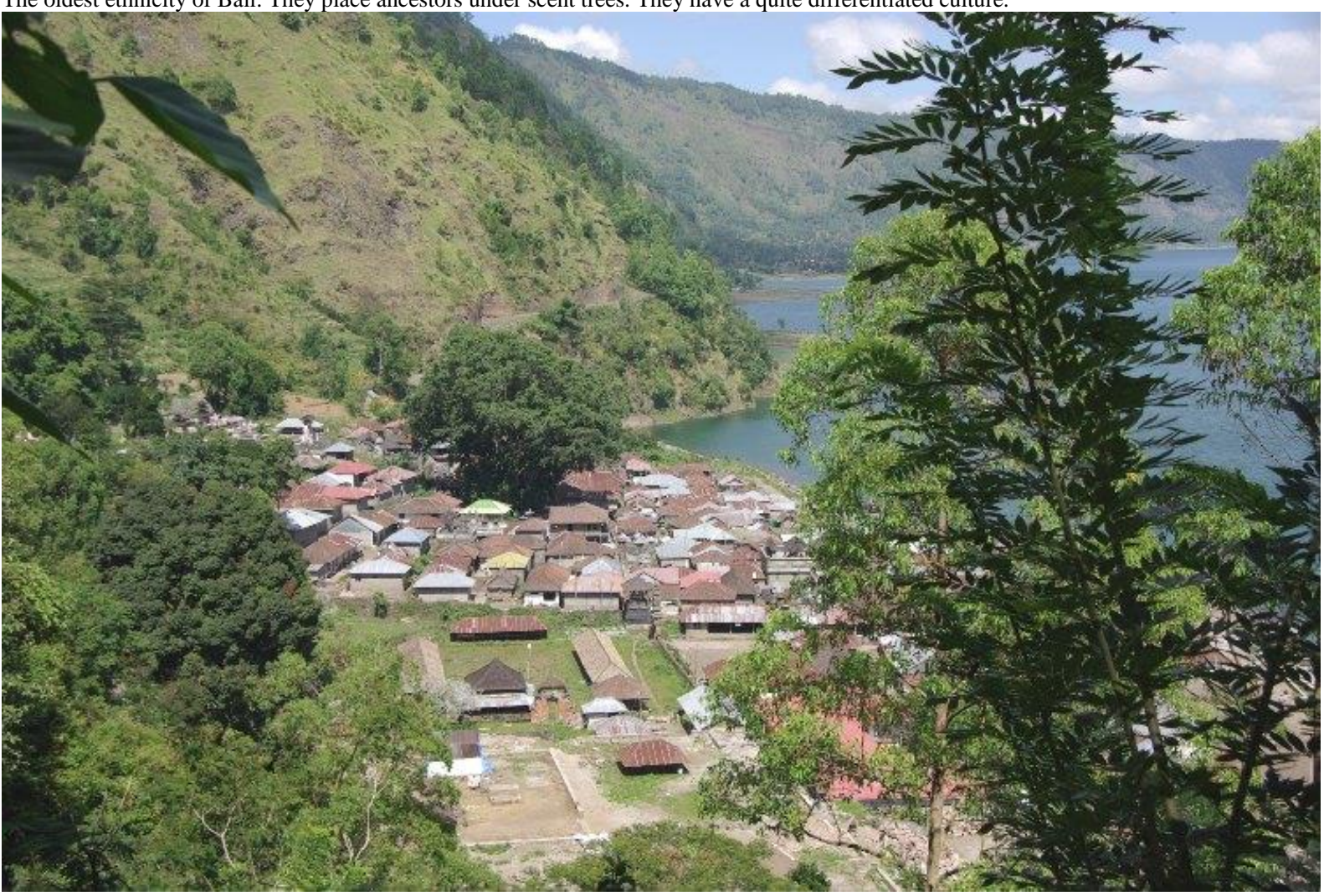


Bali. The Subak traditional watering system dates from the 9th century. It is a product of the power of needs. As time unfolds experience accumulates generating pragmatic know-how on the basis of tangible, intangible, and symbolic needs. It is so clever, complex and richly embedded into the Indo-Javanese culture that merits a thesis by its own. In this second part of the project, Subak traditional system turns out lively evidence on managing sustainability and valuing endogenous common resources. Therefore, traditional for-long praxis of sustainability is a fact, while seems to remain an unattainable political, institutional, academic rhetoric pursuit. These systems are free of public cost standing by their own. That makes of them also common resources. Hosts' autochthonous engineering, sustainable use, synergies, and maintenance on the basis of reciprocity counter The Tragedy of the Commons. Tragedy does not fit in with, which demystifies outsiders' conventional myths over there/here. Hosts' wisdom goes further on outsiders'. They show mastery and a healthy wealth of knowledge, that one they need. Praxis counters rhetoric.

Following synthesised details on Subak system are those published, among others like FAO, by LG. Suarja and Rik Thijssen. Subak system has demonstrated resilience over 1,000 years, adapting and solving issues by its own. Therefore, a sustainable productivity within limited environments as Bali is a volcanic mountainous island. The managing of sustainability resides in hosts' wisdom on valuing endogenous common resources. Sources of water are not many. Each Subak feeds from one. These mountainous geographies make of securing terraced watering complex. However, Balinese have engineered such astonishing durable, healthy and bountiful systems without spoiling biotopes. Furthermore, their remarkable beautifully integrated achievements have called the attention of visitors, who not only gaze upon but are willing to acquire unique master pieces produced by same hosts than in the morning work on their fields and by mid-afternoon produce such pieces of art. I have experienced myself these facts. Any modern engineering has surpassed these traditional systems designed by former illiterate hosts, who show mastery on what they depend. This is a key factor: The power of needs ensure equity by reciprocity on tasks of cooperation for the mutual benefit of nature, environment, and human and other than human sentient. In this way, I recognised the system in the region of Valencia (Spain) were I was born and brought up. I see many similitudes. In Bali, due a dry season from April to October, to carve tunnels and build channels is essential. The key issue resides in that all is performed by hosts themselves, which seems the secret of perdurable sustainability without the intervention of literate urbanites. Once again: Praxis counters rhetoric.

The managing of sustainability by valuing endogenous common resources comes from rights on reciprocity. It is in the major convenience of each Subak to fairly distribute the amount of water upstream alike downstream. It 
builds on social cohesion where all members collaborate and help (i.e. avoid pests). Once the system established it feeds itself within a circle constituted by cycles. It frees plenty of time to enjoy life, arts and crafts. Men and women are present at meetings where what's to do is reached by consensus. I have experienced myself all of this. According to these authors there were around 1,500 Subaks by 1999. Members choose their representatives. The activities are reciprocally distributed proportioned to the amount of water each one needs. Subak regulates needs through customary laws. The Subak traditional system was declared in 2012 UNESCO world heritage site. (I.G. Suarja and Rik Thijssen. Vredeseilanden Indonesia, Jalan Letda Kajeng 22,80234, Denpasar, Bali)

Sasi traditional system designates off limits certain areas in Mayalibit, Raja Ampat Islands (Indonesia). Hosts believe that entering those areas, called mon, can lead to illness or bad luck. Regarding traditional fisheries $29 \%$ of the bay including around $40 \%$ of its mangroves and reefs is no-take-zone, according to Brendan Borrell in Let the Fish Breath, Scientific American, April 2013: 56-61. The turning back to traditional Sasi system managing social, terrestrial and marine endogenous common resources comes from the lack of success imposing marine reserves from a Western stance. Hosts, as always, were refrained to manage their traditional livelihoods. Fishing was not any business, but a daily need to feed hosts; different view on fishing. Companies have taken fierce advantage of such folly understanding of what's all about sustainability by emptying traditional hosts' common resources. It is an all-around-similar behaviour of last-comers. It may be called development but not progress.

Nakaiy traditional calendar was developed in Maldives Islands. It is based on observations of expected changes: stars, sun, moon, their influence on tides, weather and on the endogenous common resources. Nakaiy are periods of time between thirteen and fourteen days. There are 27 periods. Nine belong to the dry season; eighteen to the rainy season, although Maldives enjoy two six-month monsoons. Each period is known by the name of one star, which brings certain kind of weather. Nakaiy allows to decide the appropriate moment to fish, where, when, how much, which species of marine livelihoods; agricultural and social activities are managed accordingly; even it does acknowledge ex ante modern tourism affairs. Nakaiy is in itself the managing of sustainability, the tangible, intangible, symbolic valuation of endogenous common resources. Maldivians depend on their traditional wisdom and know-how to survive within these isolated environments. Nakaiy calendar is the outcome of the power of needs. All in all, these astonishing traditional systems are worthwhile of attention by leaving aside the Western's lenses watching the needs of power to see what's on with the OTHER, being the other they and us. A return to fundamentals could unfold solutions to Western intractable problems. Pablo Bargueño wrote about Nakaiy on behalf Sociedad Geográfica de las Indias, who shared about Maldives Islands, where I was some days enjoying 
their endowments after a field trip to Sri Lanka. Next images are real. I saw first image. I enjoyed the second one. It turns out amazing to imagine how people have been able to live by themselves in such surroundings for so many centuries. These are lively evidences on managing sustainability using the power of needs. Once again: Praxis counters rhetoric.

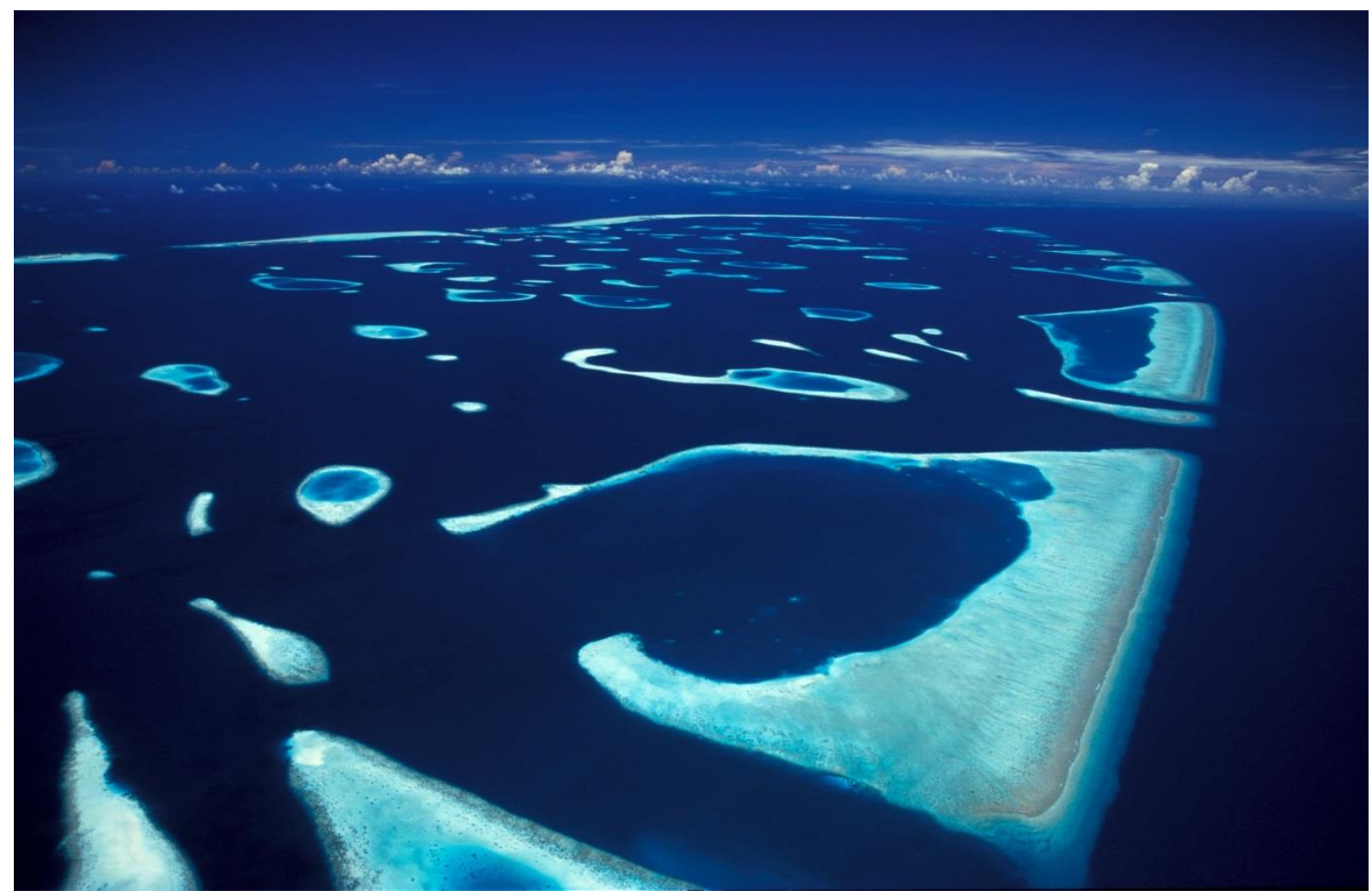

Tourism: From evil to custodian. Guests could act as custodians instead of like a curse. Tourism is allowed only in few separated islands.

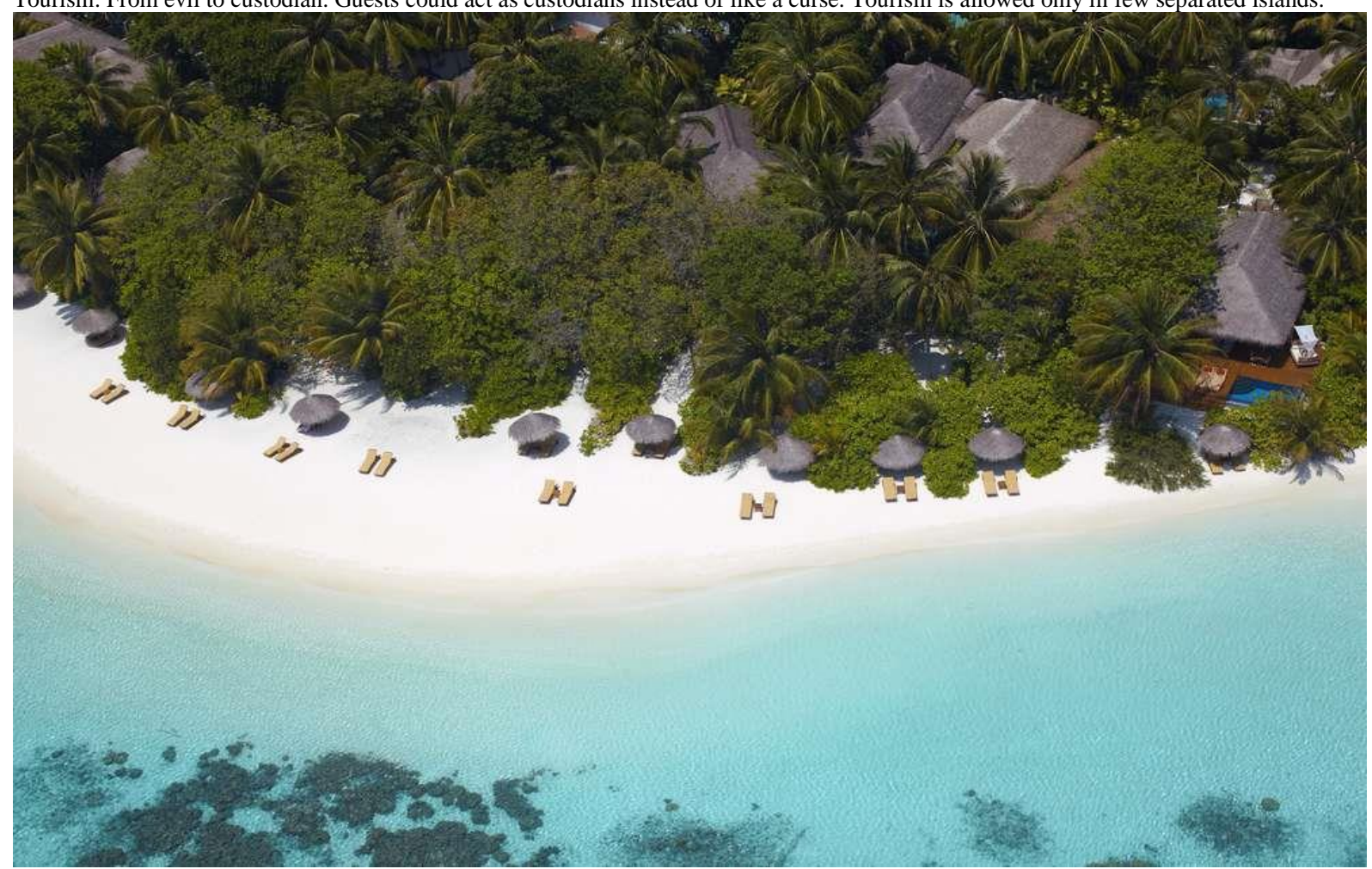




\section{CHAPTER 7_ OUTCOMES}

\section{ARMCHAIR THINKING, DESK RESEARCH, FIELD TRIPS}

I have come to realize how well fits the paradox of value, or the diamond-water paradox, with my own concept of a development following the needs of power (which could be the diamond) versus a development following the power of needs (which could be the water). The first one can be explained using the public choice theory, while the second can be explained applying my own concept of the managing of selfishness from a win-win perspective. However, I am aware that it could be asked, whose needs? I use lateral thinking as method to devise the answer. For instance: While water is so cheap as vital for living beings, diamonds are so expensive as unnecessary for staying alive, however, they do attach worth on what it is not locally available, while does not appreciate what is available locally for free. Public choice theory does explain "why politicians' decisions and bureaucrats' affairs generate personal and socioeconomic outcomes against citizens' private and public interests. Their behaviour's costs remain diffused while their benefits are concentrated. It does explain why minorities' voice so out loud, since they have much to gain, while general citizenship's voices remains unheard, with so much to lose" (www.answers.com). Hosts' principles of sustainability and how they value their common pool resources from a tangible, intangible and symbolic perspective have turned out tourists' main motto to travel so far away. Tourism segments could be used as a resource curse or like one bless. It is explained by the paradox of plenty; the public choice theory; the paradox of voting; the paradox of value or the water-diamond paradox.

Both, the water-diamond paradox and the paradox of plenty fit in also with cultural geographies well provided with nature's aesthetics, as it is the case of those aforementioned places and traditional systems. Therefore, such plenty is used and abused when appropriated by outsiders including major international tourism industry. Once again, the managing of sustainability and the tangible, intangible, and symbolic valuation of the endogenous common pool resources by hosts are clear evidences, fortunately ignored. Hosts' own progress has demonstrated resilience for long, while outsiders' development turns plenty into a curse. Something is wrong as quoted in page 254 by Joseph Morgan Hodge, pointing out how developers consistently fail in the life's betterment of those who ever have asked for such alien development. In contrast, from nomadic pastoralist to refined cultured hosts, it has not been experienced famine, perennial scarcity, moral misery, often delivered through outsiders' intervention. Demystifying myths around sustainability has been pursued through examining praxis and rhetoric using real life evidences challenging conventional wisdom, uncovering business opportunities, by examining the gap between rhetoric and praxis on sustainability, proposing tourism and guests as custodians of what they look for around. Next traditional system epitomised autonomous by autochthonous evidence on sustainability, valuation, praxis. 
Ifugao (Philippines) evidences the strong power of needs. It was declared UNESCO world heritage site in 1995,

but was included in the world heritage in danger list in 2001. Tourism as custodian could sustain it due its rents.

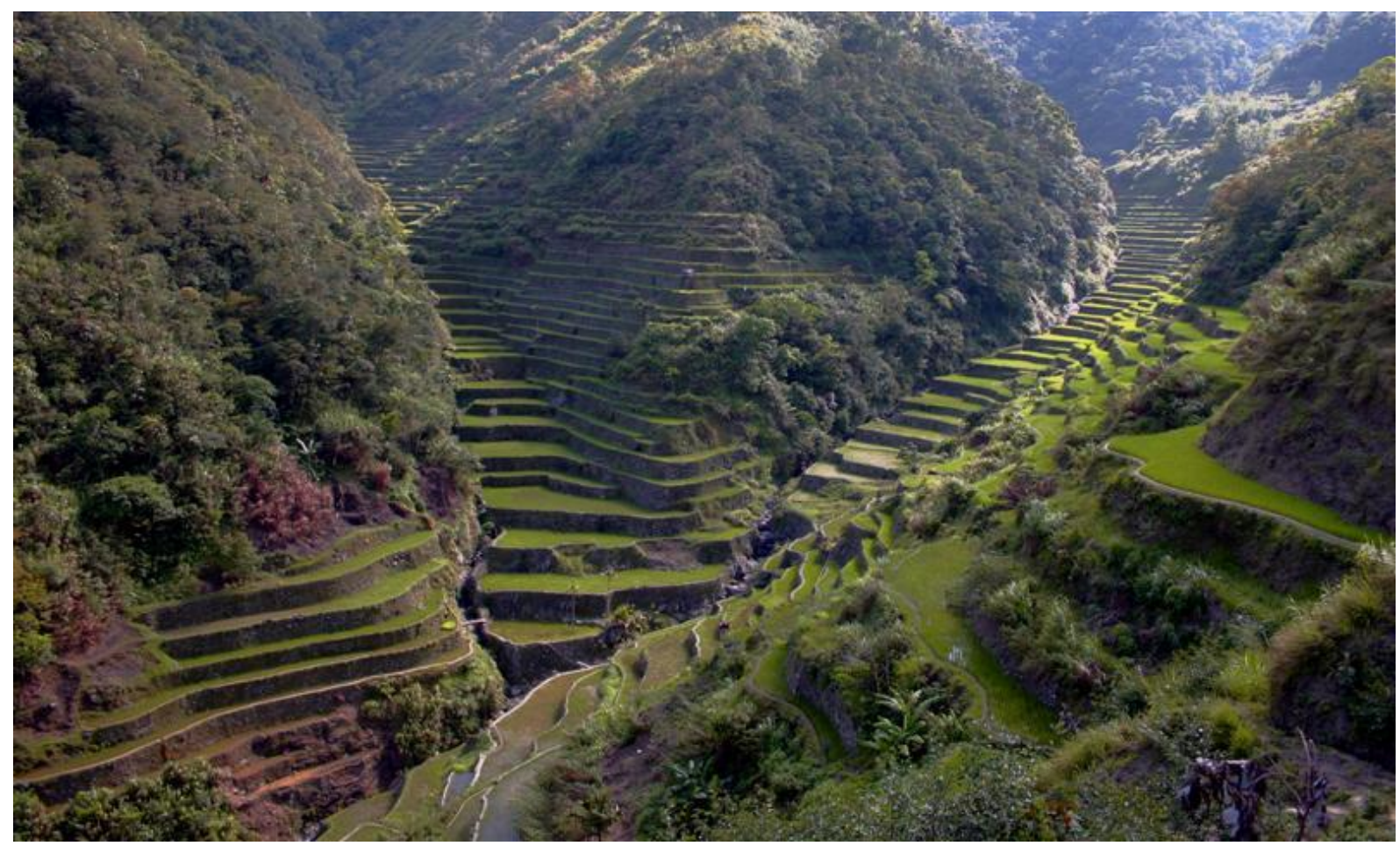

Next image shows details of the engineering work and know-how on the managing of sustainability and resources for 2000 years. The image of a human being gives a taste of size versus know-how. Earthquakes knock-down parts of the terraces, however, resilience carries on.

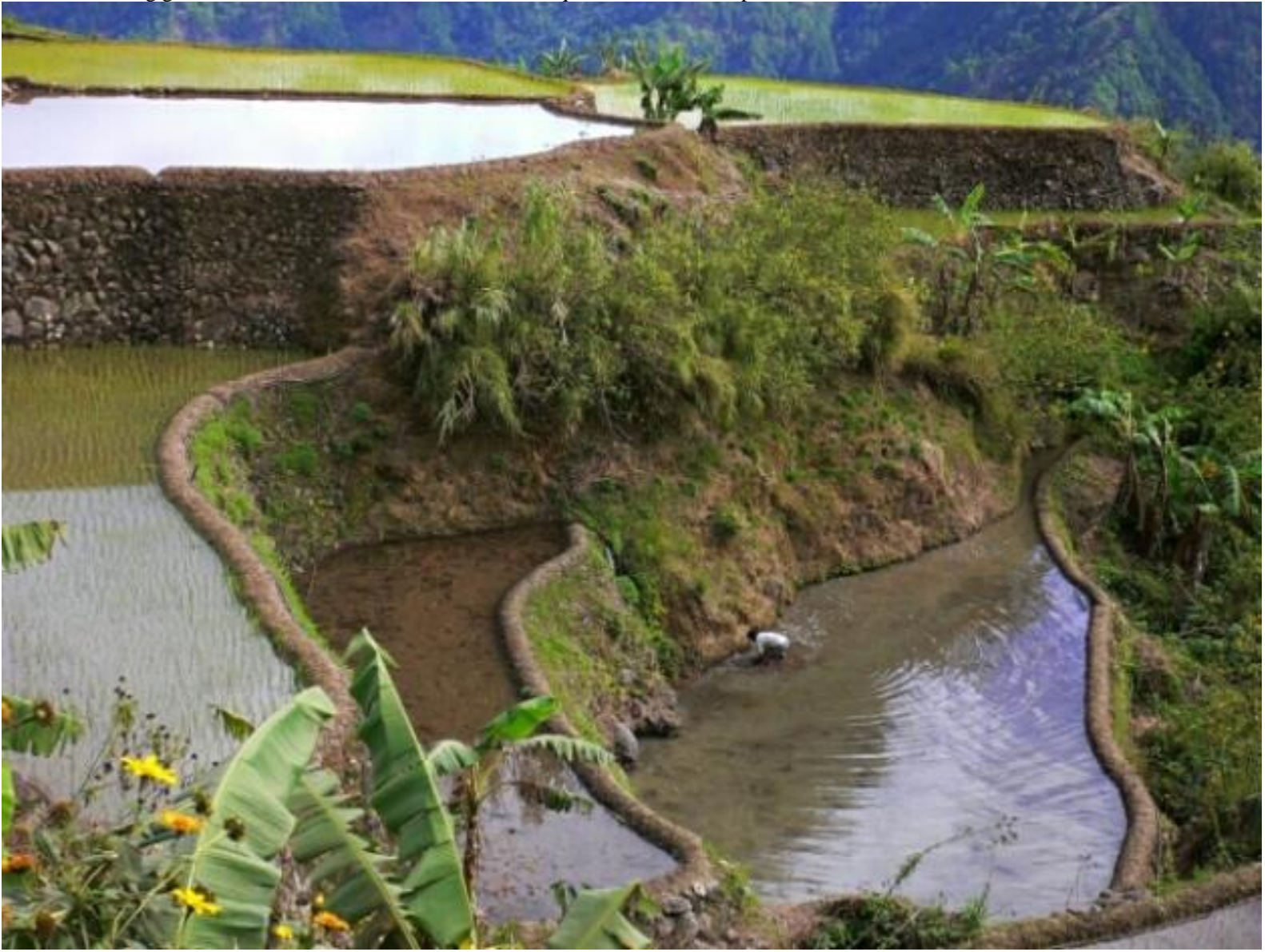


According to National Geographic: Sustainable tourism may offer hope for conservation. In fact, the region's value to the nation as a tourist destination likely exceeds that of its rice production.

Facts (from National Geographic, 15-11-2010):

For 2000 years the mountains of Ifugao province in the Philippines have been carefully cultivated with a seemingly endless series of terraced fields that climb thousands of feet.

The Ifugao Rice Terraces, which follow the natural contours of the mountains, only enhance the region's rugged natural beauty.

They also epitomize a harmonic, sustainable relationship between humans and their environment. These fields, and the knowledge to farm and sustain them, have been passed down from generation to generation for centuries. The structures' original builders used stone and mud walls to carefully carve and construct terraces that could hold flooded pond fields for the cultivation of rice. They also established a system to water these plots by harvesting water from mountaintop forests. These incredible engineering feats were done by hand as was (and is) the farming itself.

The rice terraces have long been central to the survival of the Ifugao peoples but they also occupy a central importance within their culture. Entire communities cooperate on cyclical, seasonal systems of planting, pest control, and harvest, which are tied to lunar cycles and sometimes accompanied with religious rituals.

But the world is changing and this region is not immune. Increasing numbers of young people are migrating toward urban areas in search of a far different future. With few left to work the fields according to the old ways their future is uncertain. Some 25 to 30 percent of the terraces are abandoned and beginning to deteriorate, along with irrigation systems.

Due to these threats the site was placed on the list of World Heritage in Danger in 2001 and it remains there today. Sustainable tourism may offer hope for conservation. In fact, the region's value to the nation as a tourist destination likely exceeds that of its rice production.

(Of my own) There is neither recorded hunger nor beggars within Ifugao's people (around 120,000 persons) for more than 2000 years. These two facts contrast with an impoverished Filipino's society. However, due to Western-like school influence, when teenagers they have already been shown and taught another range of needs that supposedly cannot be met taking care of their family fields and properties.

The former facts appear to confirm so much this project's outcomes as its three main research areas on tourism, the managing of sustainability and the common pool resources' tangible, intangible and symbolic valuation. Tourists as custodians added to tourism's multiplier effect could foster the revaluation of the young generations' seeds of identity providing use, rents, self-esteem anew. Visitors could transient from curse to bless; tourism from evil to custodian. That can contribute to Ifugao's bio-cultural landscapes on making attractive paradoxically to hosts' descendants keeping on hold their amazing wealth of wisdom, know-how, and achievements through customary laws during 2000 years. Evidence is that sustainability valuing endogenous common resources works out of outsiders' myth of development. However, traditional systems resent the search for El Dorado's dangers on be seen like shameful life`s ways. Another paradox: being them real; being El Dorado a myth. 


\section{REFERENCES. Second part}

Brendan Borrell (2013) Let the Fish Breath. Scientific American. April 2013: 56-61

Morgan, J (2007) Triumph of the experts: Agrarian doctrines of development and the legacies of British colonialism. Athens: Ohio University Press

Rivero, O (2001) The myth of development: the non-viable economies of the $21^{\text {st }}$ century. London: Zed Books ltd

Rozzi, R (2012) Biocultural Ethics: Recovering links between the inhabitants, habits, habitats. Environmental Ethics. Spring 2012, vol 34 (1) 2012: 27-50

References: First piece of research

Aitchison, C, Shaw, S and MacLeod, N. (2002) Leisure and Tourism Landscape: Social and Cultural Geographies. London: Routledge

Ashworth, G and Dietvorst, A (1995) Tourism and Spatial Transformations. Wallingford: CAB International Dann, G (2002) The Tourist as a Metaphor of the Social World. Wallingford: CAB International

Morgan, N and Pritchard, A (1999) Tourism Promotion and Power: Creating Images, Creating Identities. Chichester: John Wiley and Sons Ltd

Ringer, G (1998) Destinations: Cultural Landscapes of Tourism. London: Routledge

Ryan, C (1998) The tourist Experience: A new Introduction. London: Redbooks.

Selwyn, T (1996) The Tourism Image: Myths and Myth Making in Tourism. Chichester: John Wiley and Sons Ltd.

Thomson brochure's Faraway Shores 12-2002 / 10-2003

Shields, R (1991) Places on the Margin: Alternative Geographies of Modernity. London: Routledge

Urry, J (1995) Consuming places. London: Routledge.

www.asiex.org.do/instituciones.htm

www.debbiesdominicantravel.com 
References: Second piece of research

Barking, D and Pallés, C (2002) NGO-Community Collaboration for Ecotourism: A Strategy for sustainable Regional Development, Current Issues in Tourism, vol 5 (3-4) 2002: 245-253

Britton, S (1982) The Political Economy of Tourism in the Third World, Annals of Tourism Research, vol 9 ( ) 1982: 331-358

Burns, P (1999) Paradoxes in Planning: Tourism Elitist or Brutalism? Annals of Tourism Research, vol 26 (2) 1999: 329-348

Butler, R (1998) ‘Sustainable Tourism: Looking Backwards in Order to Progress?' In Hall, CM and Lew, A, Sustainable Tourism: A Geographical Perspective. Essex: Longman, p: 25-34.

Clancy, M (1999) Tourism and Development: Evidence from Mexico, Annals of Tourism Research, vol 26 (1) 1999: $1-20$

Cowen, M and Shenton, R (1996) Doctrines of Development. London: Routledge.

Dahles, H and Bras, K (1997) The State, the Market and the Role of NGOs in the Establishment of Sustainable Development: A Discussion. London: Atlas/Tilburg University

De Kadt (1979) Tourism: Passport to Development? London: Oxford University Press

Dernoi (1981) Alternative Tourism: Towards a New Style in North-South Relations, Journal of Travel Research, vol 22 (1) 1981: 46

Fallon, F (2001) Conflict, Power and Tourism on Lombok, Current Issues in Tourism, vol 4 (6) 2001: 481-497

Hall, CM (2000) Tourism Planning. Harrow: Prentice Hall

Holden, A (2000) Environment and Tourism. London: Routledge

Konado-Agyemang (2001) Structural Adjustment Programs and the International Tourism Trade in Ghana, 1983-1999: Some Socio-spatial Implications, Tourism Geographies, vol 3 (2) 2001: 187-206

Lea, J (1988) Tourism and Development in the Third World. London: Routledge.

Redclift, M (1987) Sustainable Development: Exploring the Contradictions. London: Routledge,

Sharpley, R (2000) Tourism and Sustainable Development: Exploring the Theoretical Debate, Journal of Sustainable Tourism, vol 8 (1) 2000: 1-15.

Sharpley, R and Telfer, D (2002) Tourism and Development. Concepts and Issues. Clevedon (UK): Cambrian Printers LTD.

Telfer, D (2002) 'The Evolution of Tourism and Development Theory', in Shapley, R. and Telfer, D (eds) Tourism and Development: Concepts and Issues. Clevedon (UK): Cambrian Printers LTD, 135-178.

Timothy, D (1999) Participatory Planning: A view of Tourism in Indonesia, Annals of Tourism Research, vol 26 (2) 1999: 371-391

Wall, G (1993) International Collaboration in the Search of Sustainable Tourism in Bali, Indonesia, Journal of Sustainable Tourism, vol 1 (3) 1993, 38-47

Wall, G (1997) 'Sustainable Tourism-Unsustainable Development', in Pigram, J and Wahab, S (eds) Tourism Development and Growth: The Challenge of Sustainability. London: Routledge, 33-49

Wilkinson, P (1989) Strategies for Tourism in Island Microstates, Annals of Tourism Research, vol 16 ( ) 1989 : 153-177 
References: Third piece of research

Bruyat, C and Julien, P A (2000) Defining the field of research in entrepreneurship. Journal of Business Venturing, vol 16, 2000: 165-180

Busenitz, L, West, G, Shepherd, D, Nelson, T, Chandler, G and Zacharakis, A (2003) Entrepreneurship Research in Emergence: Past Trends and Future Directions. Journal of Management, vol 29, 2003: 285-308

Encyclopedia of Business and Finance. The Gale Group, Inc, 2001. Answers.com 02 Oct. 2007. Retrieved from http://www.answers.com/topic/entrepreneurship-1

Gartner, W and Birley, S (2002) Introduction to the special issue on qualitative methods in entrepreneurship research. Journal of Business Venturing, vol 17, 2002: 387-395

Kodithuwakku, S and Rosa, P (2002) The entrepreneurial process and economic success in a constrained environment. Journal of Business Venturing, vol 17, 2002: 431-465

Zahara, A, Jennings, F and Kuratko, F (1999) The antecedents and consequences of Firm-level entrepreneurship: The state of the art. Entrepreneurship Theory and Practice, vol 24 (2) 1999: 45-65 


\section{APPENDICES}

First part

APPENDICES

1. SEMISTRUCTURED FORMAL INTERVIEWS. INTERVIEWEES' DETAIS …................127

2. INFORMAL INTERVIEWS IN VALENCIA (SPAIN). TRAVEL AGENTS' DETAILS .............128

3. INFORMAL INTERVIEWS IN CASTELLON (SPAIN). TRAVEL AGENTS' DETAILS ...........129

4. INFORMAL INTERVIEWS IN CENTRAL LONDON. TRAVEL AGENTS' DETAILS ............130

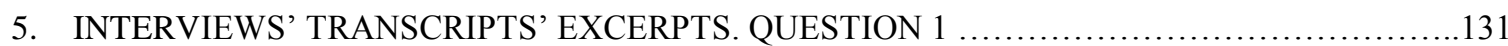

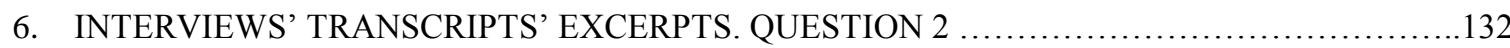

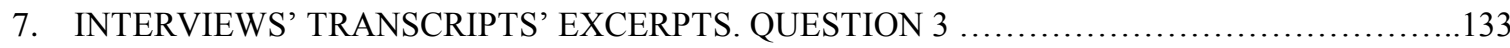

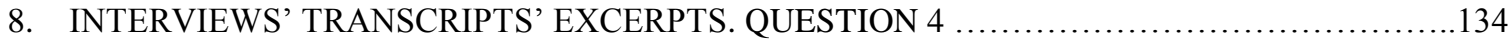

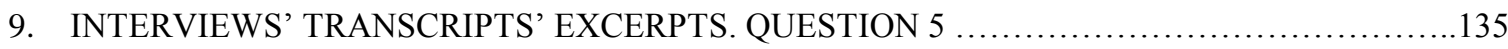

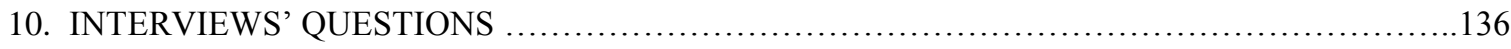

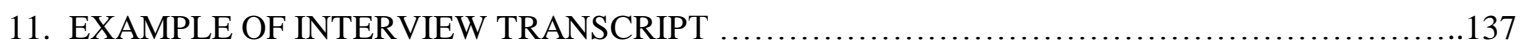




\section{APPENDIX 1_SEMIESTRUCTURED FORMAL INTERVIEW. INTERVIEWEES' DETAILS}

\begin{tabular}{|c|c|c|c|c|c|c|c|c|}
\hline $\mathbf{R} / \mathbf{N}$ & Place & Date & Code & Name & Position & Org & Time & Length \\
\hline $3 . \mathrm{N}$ & IB & T.14/8/03 & (PRASS) & $\begin{array}{l}\text { Manuel } \\
\text { Sendino }\end{array}$ & Manager & Ibiza FEH & $10.25 / 10.55$ & $0.30^{\prime}$ \\
\hline 5.R & VLC & M.3/11/03 & (PRTS) & $\begin{array}{l}\text { Carlos } \\
\text { Garcia }\end{array}$ & $\begin{array}{l}\text { Delegate in } \\
\text { Valencia }\end{array}$ & Politours & $18.05 / 18.20$ & 0.15 \\
\hline $6 . \mathrm{R}$ & VLC & T.6/11/03 & (PRTRS) & $\begin{array}{l}\text { Vicente } \\
\text { Blasco }\end{array}$ & $\begin{array}{l}\text { Executive } \\
\text { manager }\end{array}$ & Europa Travel & $9.30 / 9.50$ & $0.20^{\prime}$ \\
\hline 7.R & VLC & T.6/11/03 & (PRTS) & $\begin{array}{l}\text { Custodio } \\
\text { Garcia }\end{array}$ & Manager & Iberojet & $10.00 / 10.25$ & $0.25^{\prime}$ \\
\hline $8 . \mathrm{R}$ & VLC & T.6/11/03 & (PTS) & $\begin{array}{l}\text { Eduardo } \\
\text { Viana }\end{array}$ & $\begin{array}{l}\text { Institutional } \\
\text { relations }\end{array}$ & IMPIVA & $14.15 / 14.35$ & $0.20^{\prime}$ \\
\hline 9.R & VLC & T.6/11/03 & (PRASS) & $\begin{array}{l}\text { Monica } \\
\text { Morales }\end{array}$ & $\begin{array}{l}\text { Membership' } \\
\text { representative }\end{array}$ & FEHVP & $18.45 / 19.05$ & $0.20^{\prime}$ \\
\hline 12.R & $\mathrm{L}$ & F.28/11/03 & (PRTE) & $\begin{array}{l}\text { Alyn } \\
\text { Burgess }\end{array}$ & $\begin{array}{l}\text { Group } \\
\text { development } \\
\text { manager }\end{array}$ & $\begin{array}{l}\text { Emerald } \\
\text { Global } \\
\text { Limited }\end{array}$ & $11.10 / 11.30$ & $0.20^{\prime}$ \\
\hline 13.R & $\mathrm{L}$ & M.8/12/03 & (PRASE) & $\begin{array}{l}\text { Keith } \\
\text { Richards }\end{array}$ & $\begin{array}{l}\text { Head of } \\
\text { Consumer } \\
\text { Affairs }\end{array}$ & $\begin{array}{l}\text { Association } \\
\text { British Travel } \\
\text { Agents }\end{array}$ & $15.05 / 15.50$ & $0.20^{\prime}$ \\
\hline
\end{tabular}

Source: Martinez, 2004.

$\mathbf{N}$ : Not tape recorded, R: tape recorded.

Places in Spain: IB: Ibiza, VLC: Valencia, CS: Castellon. Places in UK: L: Central London

Interviewees' Codes:

S: Spanish,

E: English.

P: Public sector.

PTS: public sector and technician and Spanish.

PR: private sector.

PRTS: private sector and tour operator and Spanish.

PRT: private sector and tour operator and English.

PRTRS: private sector and travel agency / travel agent and Spanish.

PRTRE: private sector and travel agency / travel agent and English

PRASS: private sector and association and Spanish

PRASE: private sector and association and English.

These acronyms (interviewees' codes) are consistent throughout the constant comparative analysis (Guba and Lincoln, 1985)

of this study's qualitative data. 
APPENDIX 2_ INFORMAL INTERVIEWS IN VALENCIA (SPAIN). TRAVEL AGENTS' DETAILS

\begin{tabular}{|c|c|c|c|c|c|c|c|}
\hline $\mathbf{N}$ & D & Date & Name & Position & Org. & Time & NA/PA \\
\hline 1 & $\mathrm{M}$ & $10 / 11 / 03$ & $\begin{array}{l}\text { Francisco } \\
\text { Martinez }\end{array}$ & Director & Viajes Kontiki & $10.20 / 10.35$ & NA \\
\hline 2 & $\mathrm{M}$ & $10 / 11 / 03$ & $\begin{array}{l}\text { Yolanda } \\
\text { Dasilva }\end{array}$ & Travel agent & Viajes Marsans & $11.05 / 11.10$ & NA \\
\hline 3 & $\mathrm{M}$ & $10 / 11 / 03$ & $\begin{array}{l}\text { Alejandro } \\
\text { Miguel }\end{array}$ & Director & Viajes Gheisa & $11.20 / 11.25$ & NA \\
\hline 4 & $\mathrm{M}$ & $10 / 11 / 03$ & Margo Bosca & Travel agent & Viajes Barcelo & $10 / 11 / 03$ & NA \\
\hline 5 & $\mathrm{M}$ & $10 / 11 / 03$ & Vanesa Royo & Travel Agent & Halcon Viajes & $16.45 / 16.55$ & NA \\
\hline 6 & M & $10 / 11 / 03$ & $\begin{array}{l}\text { Jose } \\
\text { Dominguez }\end{array}$ & $\begin{array}{l}\text { Director and } \\
\text { owner }\end{array}$ & Ridocci & $17.15 / 17.30$ & NA \\
\hline 7 & $\mathrm{M}$ & $10 / 11 / 03$ & Alicia Roo & Travel Agent & Viajes Marsans & $17.50 / 18.00$ & NA \\
\hline 8 & $\mathrm{M}$ & $10 / 11 / 03$ & Isabel Vives & Head office & Viajes Iberia & $17.55 / 18.05$ & NA \\
\hline 9 & $\mathrm{M}$ & $10 / 11 / 03$ & Elvira Tormo & Travel agent & Viajes Ovni & $18.05 / 18.15$ & NA \\
\hline 10 & $\mathrm{M}$ & $10 / 11 / 03$ & $\begin{array}{ll}\text { Jose } & \text { Porta } \\
\text { Legua } & \end{array}$ & Travel Agent & Viajes orange & $18.45 / 18.55$ & NA \\
\hline 11 & M & $10 / 11 / 03$ & Mayte & Head Office & Viajes Crisol & $19.00 / 19.10$ & NA \\
\hline 12 & $\mathrm{M}$ & $10 / 11 / 03$ & $\begin{array}{l}\text { Salvador } \\
\text { Moreno }\end{array}$ & Head Office & Viajes Iberia & $19.15 / 19.25$ & NA \\
\hline 13 & $\mathrm{M}$ & $10 / 11 / 03$ & $\begin{array}{l}\text { Elvira } \\
\text { Ramirez }\end{array}$ & Travel Agent & Viajes Turia & $19.30 / 19.40$ & NA \\
\hline 14 & $\mathrm{~F}$ & $7 / 11 / 03$ & No name & Travel agent & $\begin{array}{l}\text { TUI Central de } \\
\text { Viajes }\end{array}$ & $18.00 / 18.10$ & NA \\
\hline 15 & $\mathrm{~F}$ & $7 / 11 / 03$ & No name & Travel agent & Hippo Viajes & $18.25 / 18.35$ & NA \\
\hline 16 & $\mathrm{~F}$ & $7 / 11 / 03$ & No name & Travel agent & Viajes Ecuador & $18.45 / 19.00$ & NA \\
\hline
\end{tabular}

$\mathbf{N}$ : Number of the Interview.

D: Weekday.

Or: Organisation.

NA: Negative response to the questions.

PA: Positive response to the questions. 
APPENDIX 3_ INFORMAL INTERVIEWS IN CASTELLON (SPAIN). TRAVEL AGENTS' DETAILS

\begin{tabular}{|c|c|c|c|c|c|c|c|}
\hline $\mathbf{N}$ & D & Date & Name & Position & Org. & Time & NA/PA \\
\hline 1 & $\mathrm{~S}$ & $8 / 11 / 03$ & $\begin{array}{l}\text { Imma } \\
\text { Gonzalez }\end{array}$ & Travel agent & Viajes Barcelo & $10.10 / 10.25$ & NA \\
\hline 2 & $\mathrm{~S}$ & $8 / 11 / 03$ & Elisa Tirado & Travel agent & Viajes Tirado & $10.30 / 10.40$ & NA \\
\hline 3 & $\mathrm{~S}$ & $8 / 11 / 03$ & $\begin{array}{l}\text { Anabel } \\
\text { Asensio }\end{array}$ & Travel agent & Viajes Equus & $10.55 / 11.15$ & NA \\
\hline 4 & $\mathrm{~T}$ & $11 / 11 / 03$ & Miguel Angel & Travel agent & Viajes Orange & $10.55 / 11.10$ & NA \\
\hline 5 & $\mathrm{~T}$ & $11 / 11 / 03$ & Elena Fonseca & Travel agent & Viajes Marsans & $11.20 / 11.30$ & NA \\
\hline 6 & $\mathrm{~T}$ & $11 / 11 / 03$ & $\begin{array}{l}\text { Carmen } \\
\text { Aranda }\end{array}$ & Travel agent & Viajes Equus & $11.35 / 11.45$ & NA \\
\hline 7 & $\mathrm{~T}$ & $11 / 11 / 03$ & Susana Perez & Travel agent & Viajes Iberia & $11.50 / 11.55$ & NA \\
\hline 8 & $\mathrm{~T}$ & $11 / 11 / 03$ & $\begin{array}{l}\text { Raquel } \\
\text { Beltran }\end{array}$ & Travel agent & Altretour & $12.10 / 12.20$ & NA \\
\hline 9 & $\mathrm{~T}$ & $11 / 11 / 03$ & $\begin{array}{l}\text { Montserrat } \\
\text { Conesa }\end{array}$ & Travel agent & Viajes Crisol & $12.30 / 12.35$ & NA \\
\hline 10 & $\mathrm{~T}$ & $11 / 11 / 03$ & $\begin{array}{l}\text { Maria Jose } \\
\text { Ceron }\end{array}$ & Head office & Viajes Halcon & $12.45 / 12.55$ & NA \\
\hline 11 & $\mathrm{~T}$ & $11 / 11 / 03$ & Alicia Fortea & Travel agent & Conicab Viatges SL & $13.15 / 13.20$ & NA \\
\hline 12 & Th & $13 / 11 / 03$ & Rocio Ruiz & Travel agent & Rural Viajes & $10.05 / 10.10$ & NA \\
\hline 13 & $\mathrm{Th}$ & $13 / 11 / 03$ & $\begin{array}{l}\text { Gemma } \\
\text { Querol }\end{array}$ & Manager & Viajes Castellon & $12.20 / 10.25$ & NA \\
\hline 14 & $\mathrm{Th}$ & $13 / 11 / 03$ & $\begin{array}{l}\text { Elena } \\
\text { Ferrando }\end{array}$ & Travel agent & Viajes Ecuador & $12.35 / 12.45$ & NA \\
\hline 15 & $\mathrm{~F}$ & $14 / 11 / 03$ & Crstian & Travel agent & Viajes Barcelo & $11.40 / 11.45$ & NA \\
\hline 16 & $\mathrm{~F}$ & $14 / 11 / 03$ & $\begin{array}{l}\text { Yael } \\
\text { Segurado }\end{array}$ & Travel agent & Viajes Azahar & $11.50 / 11.55$ & NA \\
\hline
\end{tabular}

$\mathbf{N}$ : Number of the Interview.

D: Weekday.

Org: Organisation.

NA: Negative response to the questions.

PA: Positive response to the questions. 
APPENDIX 4_INFORMAL INTERVIEWS IN CENTRAL LONDON. TRAVEL AGENTS' DETAILS

\begin{tabular}{|c|c|c|c|c|c|c|c|c|}
\hline $\mathbf{N}$ & D & Date & Name & Position & Org. & Time & NA/PA & IRJ \\
\hline 1 & $\mathrm{M}$ & $17 / 11 / 03$ & $\mathrm{x}$ & Travel agent & Going Places & $12.20 / 12.28$ & NA & \\
\hline 2 & $\mathrm{M}$ & $17 / 11 / 03$ & $\mathrm{x}$ & Travel agent & Thomas Cook & $12.45 / 12.50$ & & IRJ \\
\hline 3 & $\mathrm{M}$ & $17 / 11 / 03$ & $\mathrm{x}$ & Travel agent & First Choice & $12.40 / 12.44$ & NA & \\
\hline 4 & $\mathrm{~T}$ & $18 / 11 / 03$ & Olle & Travel agent & STA Travel & $10.15 / 10.20$ & NA & \\
\hline 5 & $\mathrm{~T}$ & $18 / 11 / 03$ & $\begin{array}{l}\text { Jordan } \\
\text { Williams }\end{array}$ & Travel agent & Thomas Cook & $11.10 / 11.57$ & NA & \\
\hline 6 & $\mathrm{~T}$ & $18 / 11 / 03$ & Daniels & Travel agent & $\begin{array}{l}\text { Virgin Travel } \\
\text { Store }\end{array}$ & $11.50 / 11.57$ & NA & \\
\hline 7 & $\mathrm{~T}$ & $18 / 11 / 03$ & $\begin{array}{l}\text { Fabrizio } \\
\text { Zibetti }\end{array}$ & Travel agent & $\begin{array}{l}\text { The Sicilian } \\
\text { Experience }\end{array}$ & $12.10 / 12.16$ & NA & \\
\hline 8 & $\mathrm{~T}$ & $18 / 11 / 03$ & $\mathrm{x}$ & Travel agent & Boscolo Tours & $12.25 / 12.30$ & & IRJ \\
\hline 9 & $\mathrm{~T}$ & $18 / 11 / 03$ & $\mathrm{x}$ & $\begin{array}{l}\text { Tourist } \\
\text { information } \\
\text { assistant }\end{array}$ & $\begin{array}{l}\text { The Big Bus } \\
\text { Company }\end{array}$ & $12.40 / 12.50$ & NA & \\
\hline 10 & $\mathrm{~W}$ & 19/11/03 & $\mathrm{x}$ & Travel agent & Going Places & $10.45 / 10.55$ & NA & \\
\hline 11 & $\mathrm{~W}$ & $19 / 11 / 03$ & $\mathrm{x}$ & Manager & $\begin{array}{l}\text { APA Travel } \\
\text { Service Ltd }\end{array}$ & $12.40 / 12.45$ & & AANS \\
\hline 12 & $\mathrm{~W}$ & $19 / 11 / 03$ & Debbie & Travel agent & $\begin{array}{l}\text { STA Travel UK } \\
\text { Division }\end{array}$ & $13.05 / 13.20$ & NA & \\
\hline 13 & $\mathrm{~W}$ & $19 / 11 / 03$ & $\mathrm{x}$ & Travel agent & Thomas Cook & $14.20 / 14.25$ & & IRJ \\
\hline 14 & $\mathrm{~W}$ & $19 / 11 / 03$ & $\begin{array}{l}\text { Tyron } \\
\text { Hamlin }\end{array}$ & Branch manager & Travel Care & $14.40 / 14.45$ & NA & \\
\hline 15 & $\mathrm{~W}$ & $19 / 11 / 03$ & $\mathrm{x}$ & Travel agent & Lunn Poly & $15.05 / 15.15$ & NA & \\
\hline 16 & $\mathrm{~W}$ & $19 / 11 / 03$ & $\mathrm{x}$ & Manager & First Choice & $15.35 / 15.40$ & NA & \\
\hline 17 & Th & $20 / 11 / 03$ & $\begin{array}{l}\text { Holly } \\
\text { Marella }\end{array}$ & Travel agent & Thomas Cook & $10.17 / 10.23$ & NA & \\
\hline 18 & $\mathrm{Th}$ & $20 / 11 / 03$ & $\mathrm{x}$ & Manager & First Choice & $10.25 / 10.32$ & NA & \\
\hline 19 & $\mathrm{Th}$ & $20 / 11 / 03$ & $\mathrm{x}$ & Travel agent & Lunn Poli & $10.45 / 10.52$ & & IRJ \\
\hline 20 & $\mathrm{Th}$ & $20 / 11 / 03$ & $\mathrm{x}$ & Travel agent & $\begin{array}{l}\text { L'Aventure } \\
\text { Travel }\end{array}$ & $11.03 / 11.06$ & NA & \\
\hline 21 & $\mathrm{~F}$ & $21 / 11 / 03$ & $\begin{array}{l}\text { Tim } \\
\text { Roncoroni }\end{array}$ & Travel agent & $\begin{array}{l}\text { Air New } \\
\text { Zealand }\end{array}$ & $10.40 / 10.50$ & NA & \\
\hline 22 & $\mathrm{~F}$ & $21 / 11 / 03$ & $\mathrm{x}$ & $\begin{array}{l}\text { Tourist } \\
\text { information } \\
\text { assistant }\end{array}$ & $\begin{array}{l}\text { Britain and } \\
\text { London Visitor } \\
\text { Center }\end{array}$ & $12.05 / 12.10$ & NA & \\
\hline 23 & $\mathrm{~F}$ & $21 / 11 / 03$ & $\mathrm{x}$ & $\begin{array}{l}\text { Tourist } \\
\text { information } \\
\text { assistant } \\
\end{array}$ & $\begin{array}{l}\text { Spanish Tourist } \\
\text { Office }\end{array}$ & $14.00 / 1410$ & NA & \\
\hline 24 & $\mathrm{M}$ & $24 / 11 / 03$ & $\begin{array}{l}\text { Cheryl } \\
\text { Simpson }\end{array}$ & Leisure manager & Baxter Hoare & $14.32 / 14.40$ & NA & \\
\hline 25 & $\mathrm{~T}$ & $25 / 11 / 03$ & Paige & $\begin{array}{l}\text { Specialist } \\
\text { consultant }\end{array}$ & $\begin{array}{l}\text { Bridge the } \\
\text { World }\end{array}$ & $12.38 / 12.42$ & NA & \\
\hline 26 & $\mathrm{Th}$ & $27 / 11 / 03$ & Sam Soh & Travel agent & $\begin{array}{l}\text { All Seasons } \\
\text { Tours }\end{array}$ & $14.02 / 14.05$ & NA & \\
\hline 27 & $\mathrm{~F}$ & $17 / 11 / 03$ & $\mathrm{x}$ & Office assistant & $\begin{array}{l}\text { Ana World } \\
\text { Tours }\end{array}$ & $13.27 / 13,30$ & & IRJ \\
\hline 28 & $\mathrm{~S}$ & $6 / / 12 / 03$ & $\mathrm{x}$ & Travel agent & $\begin{array}{l}\text { Stephen Neill } \\
\text { Travel }\end{array}$ & $10.30 / 10.37$ & NA & \\
\hline
\end{tabular}

$\mathbf{N}$ : Number of the interview.

D: Weekday.

X: Data not facilitated by the respondent.

Org: Organisation.

NA: Negative response.

PA: Positive response.

IRJ: Interview rejected.

AANS: Avoided answer. 


\section{APPENDIX 5_INTERVIEWS' TRANSCRIPTS' EXCERPTS. QUESTION 1}

PURPOSE: To examine what is meant by sustainable development in the literature and to assess practitioners' perceptions of this term and concept.

QUESTION 1: What is meant by sustainable development?

\begin{tabular}{|c|c|c|}
\hline Inter.R / N & Q 1 & Answer \\
\hline $\begin{array}{l}\text { Inter 3.N } \\
\text { (PRASS) }\end{array}$ & Sustainable development is that everybody is satisfied. & QNA \\
\hline $\begin{array}{l}\text { Inter 5.R } \\
\text { PRTS) }\end{array}$ & $\begin{array}{l}\text { Sustainable development is, as far as I can understand, in whatever market on which we are } \\
\text { talking, it is the economic increase of the sector each year in regard the former years. }\end{array}$ & QDA \\
\hline $\begin{array}{l}\text { Inter 6.R } \\
\text { (PRTRS) }\end{array}$ & $\begin{array}{l}\text { Sustainable development is very simple, it is a growth that keeps the balance between } \\
\text { supply and demand and that there is neither an excess of supply nor of demand. It is } \\
\text { important that there is no excess of supply otherwise what happens is a price war. }\end{array}$ & QDA \\
\hline $\begin{array}{l}\text { Inter 7.R } \\
\text { (PRTS) }\end{array}$ & $\begin{array}{l}\text { Common to see, sustainable development is the development wisely managed with respect } \\
\text { for the whole. }\end{array}$ & QDA \\
\hline $\begin{array}{l}\text { Inter 8.R } \\
\text { (PTS) }\end{array}$ & $\begin{array}{l}\text { We understand, although I have to answer in a personal way since it is me to whom this } \\
\text { question has been addressed, sustainable development is the capacity of working with the } \\
\text { minimum repercussion on the environment. }\end{array}$ & QDA \\
\hline $\begin{array}{l}\text { Inter 9.R } \\
\text { (PRASS) }\end{array}$ & $\begin{array}{l}\text { Sustainable development is what we are doing collectively. It is necessary to work hand in } \\
\text { hand with the Administrations, trying that the entrepreneurs do work in a professional way. }\end{array}$ & QSA \\
\hline $\begin{array}{l}\text { Inter 12.R } \\
\text { (PRTE) }\end{array}$ & $\begin{array}{l}\text { Sustainable tourism to me is tourism that grows with the wealth and with the populace. In } \\
\text { other words, tourism that is scanting too fast into a country that is not ready for it and can } \\
\text { cause a great deal of problems in so far too much money comes in too quickly, which } \\
\text { would lead to possible crime rates raising and lots of tourism negative factors come into } \\
\text { play. Sustainable tourism means to me that it should be growing slightly above what the } \\
\text { local cost of living is growing for that certain people can leave and grow and be employed } \\
\text { within tourism jobs, so, sustainable tourism means that it has to fit into the economy of that } \\
\text { country as well. }\end{array}$ & QNA \\
\hline $\begin{array}{l}\text { Inter 13.R } \\
\text { (PRASE) }\end{array}$ & $\begin{array}{l}\text { I think you're right. Everybody understands something different. There is no fix definition. } \\
\text { Nobody knows really what sustainability means. Nobody understands many of the other } \\
\text { labels in these areas. I mean people use labels like green and eco, responsible, you know, it } \\
\text { means different things to different people even the experts don't agree among themselves } \\
\text { but I mean from the point of view of business it means something you can set up and run as } \\
\text { a business and you can carry on doing well into the future. }\end{array}$ & QSA \\
\hline
\end{tabular}

Constant Comparative Model of Qualitative Data Analysis (Lincoln and Guba, 1985)

Inter: Interview,

R: Tape recorded,

N: Not tape recorded,

QDA: Question directly addressed,

QSA: Question semidirectly addressed,

QNA: Question not addressed regarding the Brundtland's definition (1987) of what is meant by sustainable development.

Interviewees' Codes:

S: Spanish,

E: English.

P: Public sector.

PTS: public sector and technician and Spanish.

PR: private sector.

PRTS: private sector and tour operator and Spanish.

PRTE: private sector and tour operator and English.

PRTRS: private sector and travel agency / travel agent and Spanish.

PRTRE: private sector and travel agency / travel agent and English

PRASS: private sector and association and Spanish

PRASE: private sector and association and English

These acronyms (interviewees' codes) are consistent throughout the constant comparative analysis of this study's qualitative data. 


\section{APPENDIX 6_INTERVIEWS' TRANSCRIPTS' EXCERPTS. QUESTION 2}

PURPOSE: To evaluate key practitioners' views on different types of tourism as strategic tools towards the objectives of sustainable development.

QUESTION 2: What types of tourism can become strategic tools towards the objectives of sustainable development?

\begin{tabular}{|c|c|c|}
\hline Inter & Q.2 & Answer \\
\hline $\begin{array}{l}\text { Inter 3.N } \\
\text { (PRASS) }\end{array}$ & $\begin{array}{l}\text { He said that mass tourism will carry on. However tourism has the capacity to adapt } \\
\text { itself to the demand. He did not believe in the Balearic sustainable speech. In the case } \\
\text { of Ibiza and Formentera seasonality is unavoidable }\end{array}$ & QNA \\
\hline $\begin{array}{l}\text { Inter 5.R } \\
\text { (PRTE }\end{array}$ & $\begin{array}{l}\text { Ok, but we are talking always about tourism. It is a complex subject. It is not the same } \\
\text { to talk about the Spanish tourists making tourism inside the country that those that go } \\
\text { abroad. It is quite rare that the Spanish tourist do ecotourism abroad, he / she does it } \\
\text { inside the country. Reasons are the language and the lack of knowledge about it. He } \\
\text { said that those customers are of lower average income. }\end{array}$ & QSA \\
\hline $\begin{array}{l}\text { Inter 6.R } \\
\text { (PRTRS) }\end{array}$ & $\begin{array}{l}\text { Tourism presents a broad variety. So, each place has to have its own market. For that } \\
\text { it has to have the resources in order to be able to be competitive. Each area must know } \\
\text { its resources to offer to the market. }\end{array}$ & QND \\
\hline $\begin{array}{l}\text { Inter 7.R } \\
\text { (PRTRS) }\end{array}$ & $\begin{array}{l}\text { Common to see, I would say that if we include also mass tourism we could say that } \\
\text { mass tourism can be combined with other types of tourism. In our case sun and sea } \\
\text { tourism combines with rural tourism and any other type of nature tourism. These } \\
\text { types of tourism should act as a complementary supply. }\end{array}$ & QSA \\
\hline $\begin{array}{l}\text { Inter 8.R } \\
\text { (PTS) }\end{array}$ & $\begin{array}{l}\text { It is obvious that we focus on the industry and not much on tourism. Well, here we are } \\
\text { supporting the industry of Valencia in order to foster it to work in a way that does not } \\
\text { damage the environment. In this sense we understand that the environment should be } \\
\text { in good conditions. In this sense we understand that if the environment is kept in good } \\
\text { conditions tourists we'll come and will enjoy themselves here. }\end{array}$ & QSA \\
\hline $\begin{array}{l}\text { Inter 9.R } \\
\text { (PRASS) }\end{array}$ & All of them. The wider the supply, the better. & QNA \\
\hline $\begin{array}{l}\text { Inter 12.R } \\
\text { (PRTE) }\end{array}$ & $\begin{array}{l}\text { I think I understand the question and I think it is very difficult to answer because } \\
\text { those things fit into a country's tourism development at different times. There are two } \\
\text { different positions. You have situations now where, I mean, we were talking about } \\
\text { ecotourism as being a marketing password. Tourism is far too big revenue driver for } \\
\text { governments and countries ... (?). I think one of the biggest things that is growing as } \\
\text { far sustainable tourism concerns is a new brand that in the old days were called } \\
\text { 'visiting friends and relatives' mainly between Americans and Europe and between } \\
\text { Europe and Australia but here there is a big market now that is growing now in Asia } \\
\text { and Europe. From the point of view of the number of people who study overseas now. } \\
\text { It is creating its own tourism bubble. We will be exposed to many more things coming } \\
\text { around in the next future and the ability to travel, to inform other continents means } \\
\text { that a whole new development is coming out }\end{array}$ & QDA \\
\hline $\begin{array}{l}\text { Inter 13.R } \\
\text { (PRASE) }\end{array}$ & $\begin{array}{l}\text { All of them can become strategic because if you really look at the impacts of } \\
\text { ecotourism and these small groups of people going to a destination and experience in } \\
\text { it for first time, let's say, the package holiday, the impacts are necessary any less let's } \\
\text { say than a large group coming with a package tour holiday because often what } \\
\text { happens with ecotourism is that people or more independent people are moving } \\
\text { around on their own but with packages you keep control of everybody. One could say } \\
\text { that the impacts are less than moving around. I actually think that mass market, that } \\
\text { sort of package tourism product, is a very good strategic tool. Ecotourism and niche } \\
\text { tourism have their place but it is very limited and I question whether it brings a kind } \\
\text { of benefits and have the lower adverse negative impacts on the destination where } \\
\text { mass market has a real potential to drive economic growth and, if you manage it } \\
\text { correctly, it can have even lesser impacts on the environment than the conventional } \\
\text { ecotourism. }\end{array}$ & QDA \\
\hline
\end{tabular}




\section{APPENDIX 7_INTERVIEWS' TRANSCRIPTS' EXCERPTS. QUESTION 3}

PURPOSE: To evaluate the links between tourism and the environment (as a whole), especially as perceived by key practitioners.

QUESTION 3: In real terms, bearing in mind the positive and the negative links between tourism and the environment, which could be the outcome?

\begin{tabular}{|c|c|c|}
\hline Inter $\mathbf{R} / \mathbf{N}$ & Q.3 & Answer \\
\hline $\begin{array}{l}\text { Inter 3.N } \\
\text { (PRASS) }\end{array}$ & $\begin{array}{l}\text { He said that it is positive in the case of Ibiza and Formentera. He said that in general } \\
\text { it is positive but from the point of view of the economic benefits. }\end{array}$ & QDA \\
\hline $\begin{array}{l}\text { Inter 5. R } \\
\text { (PRTS) }\end{array}$ & $\begin{array}{l}\text { Well, the outcome is positive because tourism produces economic benefits. Up to } \\
\text { now I think that the outcome is more negative. I think that we have not been able to } \\
\text { make the balance between tourism positive and negative effects in regard the } \\
\text { environment. }\end{array}$ & QDA \\
\hline $\begin{array}{l}\text { Inter 6.R } \\
\text { (PRTRS) }\end{array}$ & In general, nowadays tourism negative effects are larger than the positive ones. & QDA \\
\hline $\begin{array}{l}\text { Inter } 7 . \mathrm{R} \\
\text { (PRTS) }\end{array}$ & $\begin{array}{l}\text { Common to see. I am going to talk about the social, human and economic side. It } \\
\text { looks like tourism has prejudiced people due to the change in the people's habits. I } \\
\text { think that during the } 1970 \text { s and } 1980 \text { s we suffered too quickly changes for the } \\
\text { Spanish mentality. }\end{array}$ & QSA \\
\hline $\begin{array}{l}\text { Inter 8.R } \\
\text { (PTS) }\end{array}$ & $\begin{array}{l}\text { In my opinion the balance is positive. Human beings are also part of the environment } \\
\text { and affects and are affected. It is very difficult to evaluate it. The industrial activity } \\
\text { is not the mayor aggressive sector. }\end{array}$ & QDA \\
\hline $\begin{array}{l}\text { Inter 9. R } \\
\text { (PRASS) }\end{array}$ & $\begin{array}{l}\text { It depends on the type of tourism and it depends also on the place and the demand. } \\
\text { We, at entrepreneurial level, have a respect for the environment. It not only for good } \\
\text { feelings but also for the legislation put into force. }\end{array}$ & QSA \\
\hline $\begin{array}{l}\text { Inter 12. R } \\
\text { (PRTE) }\end{array}$ & $\begin{array}{l}\text { I think you cannot blame tourism, you cannot say that it is tourism that causes the } \\
\text { entire positive or the negative environmental impacts. It's again, it comes down the } \\
\text { government and it comes down the government affecting people the way they fear } \\
\text { about their environment. I mean, I observed that a lot of people litter when they are } \\
\text { on holiday but they would never do that when they at home. I do not know what it is, } \\
\text { whether they leave part of their person behind, same when you are away and you } \\
\text { change your towels every day and you don't think about the detergents. Things that } \\
\text { you would never do at home but until governments stand down on this and educate } \\
\text { people this problem will carry on. All is about education }\end{array}$ & QDA \\
\hline $\begin{array}{l}\text { Inter 13.R } \\
\text { (PRASE) }\end{array}$ & $\begin{array}{l}\text { It is a mix but the balance is probably more negative than positive. It depends on the } \\
\text { destination. }\end{array}$ & QDA \\
\hline
\end{tabular}




\section{APPENDIX 8 _INTERVIEWS' TRANSCRIPTS' EXCERPTS. QUESTION 4}

PURPOSE: To determine / examine to what extent practitioners perceive tourism as a feature of the sustainable development.

QUESTION 4: To what extent is or can be tourism a feature of the sustainable development?

\begin{tabular}{|l|l|l|}
\hline Inter R/N & Q.4 & Answers \\
\hline $\begin{array}{l}\text { Inter 3.N } \\
\text { (PRASS) }\end{array}$ & He said that 'yes' tourism is a feature of the sustainable development. & QDA \\
\hline $\begin{array}{l}\text { Inter 5.R } \\
\text { (PRTS) }\end{array}$ & I think 'yes'. I think so. & QDA \\
\hline $\begin{array}{l}\text { Inter 6.R } \\
\text { (PRTRS) }\end{array}$ & $\begin{array}{l}\text { The Valencian Community's GNP is around one point or two of the building sector. } \\
\text { I do not remember exactly but tourism is around 12\% and the building sector is } \\
\text { around 14\%. This clearly indicates the importance of tourism as an industry. }\end{array}$ & QDA \\
\hline $\begin{array}{l}\text { Inter 7.R } \\
\text { (PRTS) }\end{array}$ & $\begin{array}{l}\text { This is a difficult question to be answered. Common to see, the Administration can } \\
\text { make long run investments and it does not look for and immediate profitability. It } \\
\text { has to promote tourism so that the private sector be able to invest. }\end{array}$ & QNA \\
\hline $\begin{array}{l}\text { Inter 8.R } \\
\text { (PTS) }\end{array}$ & $\begin{array}{l}\text { I think tourism can be an activity that influences, of course, the environmental } \\
\text { behaviour. }\end{array}$ & QNA \\
\hline $\begin{array}{l}\text { Inter 9.R } \\
\text { (PRASS) }\end{array}$ & $\begin{array}{l}\text { For us tourism represents 12\% of the GNP. That is enough as an indicator of the } \\
\text { tourism importance for Valencia. }\end{array}$ & QDA \\
\hline $\begin{array}{l}\text { Inter 12.R } \\
\text { (PRTE) }\end{array}$ & $\begin{array}{l}\text { I mean, in the tourism industry there is massive opportunities for employment and it } \\
\text { is probably the only one of the sectors showing positive upturns in employment } \\
\text { opportunities for the number of arrivals, for the service sector that goes on this } \\
\text { country. I do not know any industry or any other sector that has that sort of one staff. }\end{array}$ & QNA \\
\hline $\begin{array}{l}\text { Inter 13.R } \\
\text { (PRASE) }\end{array}$ & $\begin{array}{l}\text { I think so. I mean tourism can be a feature of sustainable development. I think } \\
\text { nobody questions that. For various reasons you expect that. }\end{array}$ & QDA \\
\hline
\end{tabular}




\section{APPENDIX 9_INTERVIEWS' TRANSCRIPTS' EXCERPTS. QUESTION 5}

PURPOSE: To discuss practitioners' views on how far sustainable tourism can be encouraged while its ill effects controlled within a sustainable development.

QUESTION 5: How far sustainable tourism can be encouraged and its ill effects controlled?

\begin{tabular}{|l|l|l|}
\hline Inter.R/N & Q.5 & Answer \\
\hline $\begin{array}{l}\text { Inter 3.N } \\
\text { (PRASS) }\end{array}$ & $\begin{array}{l}\text { He said that everything could be done better in tourism. He claimed that hoteliers are } \\
\text { as ecological as anybody else. They are used to optimise their resources in order to } \\
\text { save money. He argued that the so called environmental awareness usually remains } \\
\text { good intentions since tourists are not so ready to pay for it implementation. }\end{array}$ & QSA \\
\hline $\begin{array}{l}\text { Inter 5.R } \\
\text { (PRTS) }\end{array}$ & $\begin{array}{l}\text { I think that this is for conferences. Sincerely, I had never thought what we could do } \\
\text { to not take people to destinations in order to not spoil them. I think it is only a dream. }\end{array}$ & QNA \\
\hline $\begin{array}{l}\text { Inter 6.R } \\
\text { (PRTS) }\end{array}$ & 'Yes'. I think that we have more or less already answered. Yes. It is possible. & QSA \\
\hline $\begin{array}{l}\text { Inter 7.R } \\
\text { (PRTS) }\end{array}$ & $\begin{array}{l}\text { Due to the legislation already in force and that one coming, they are avoiding wrong } \\
\text { practices and in so doing they are avoiding environmental disasters. I repeat, I think } \\
\text { that the Administration has realised of the need of legislating tourism's activities. }\end{array}$ & QSA \\
\hline $\begin{array}{l}\text { Inter 8.R } \\
\text { (PTS) }\end{array}$ & $\begin{array}{l}\text { I think that the future is based on this, which it is that the enterprises become aware } \\
\text { and adopt and implement the management of environmental systems. }\end{array}$ & QNA \\
\hline $\begin{array}{l}\text { Inter 9.R } \\
\text { (PRASS) }\end{array}$ & \begin{tabular}{l} 
Minimize 'yes', eradicate tourism negative effects, I do not think so. \\
\hline $\begin{array}{l}\text { Inter 12.R } \\
\text { (PRTS) }\end{array}$
\end{tabular} $\begin{array}{l}\text { I do not think it is unavoidable because I think you have a sort of world within } \\
\text { worlds when you come to tourism. }\end{array}$ & QNA \\
\hline $\begin{array}{l}\text { Inter 13.R } \\
\text { (PRASE) }\end{array}$ & $\begin{array}{l}\text { So, it is very difficult the balance between encouraging good practices and not } \\
\text { putting off the consumer by adding taxes or by saying you've got to consume this } \\
\text { kind of product and that kind of product. People do not like that. }\end{array}$ & QSA \\
\hline
\end{tabular}




\section{APPENDIX 10_INTERVIEWS QUESTIONS}

\section{FORMAL SEMISTRUCTURED INTERVIEWS: QUESTIONS}

Key informants' interviews.

1. What is meant by sustainable development?

2. In real terms, which types of tourism can become strategic tools towards the objectives of sustainable development?

3. Bearing in mind the positive versus the negative links between tourism and the environment (as a whole), which could be the outcome?

4. Actually, is or can be tourism a feature of the sustainable development?

5. How far sustainable tourism can be encouraged and its ill practices controlled within a sustainable development context?

\section{SHORT AND INFORMAL SEMISTRUCTURED INTERVIEWS: QUESTIONS}

Travel agents' interviews.

1. When customers ask for whatever kind of tourist product, do they show any kind of environmental awareness?

2. Suppliers, do they mention environmental issues to be sold? 


\title{
APPENDIX 11_EXAMPLE OF INTERVIEW TRANSCRIPT
}

\author{
INTERVIEW 12: Alyn Burgess. (Tape recorded) \\ PLACE: Emerald Global Limited. Tour Operator. (Central London. UK) \\ POSITION: Group Development Director. \\ TIME: $11.10 / 11.30$ \\ DATE: $18 / 11 / 03$
}

\section{QUESTION 1}

Researcher_ What is meant by sustainable development?

Interviewee_Are we talking on tourism generally?

Researcher_Yes.

Interviewee_Sustainable tourism to me is tourism that grows with the wealth and with the populace. In other words, tourism that comes in too fast into a country that is not ready for it and can cause a great deal of problems in so far too much money comes in too quickly, which would lead to possible crime rates raising and lots of tourism negative factors come into play. Sustainable means to me that it should be growing slightly above what the local cost of living is growing by certain people can leave and grow and be employed within tourism jobs, so, sustainable tourism means that it has to fit into the economy of that country as well.

\section{QUESTION 2}

Researcher_ In real terms, which types of tourism can become strategic tools towards the achievement of sustainable development?

Interviewee_ I think I understand the question and I think it is very difficult to answer because of those things fits into a country's tourism development at different times. If we were with a case study talking about a country just opening its doors to tourism, someone like China, this is somebody like Thailand which is very much dependent on its tourism and it is very professional in how it handles tourism in bound. They are two different positions. You have situations now where, I mean, we were talking about ecotourism as being a marketing password. Tourism is far too big revenue driver for governments and countries... (?). I think one of the biggest things is growing, as far sustainable tourism concerns, it is a new brand that of a far market, which in the old days were called 'visiting friends and relatives', mainly between Americans and Europe and between Europe and Australia but here there is a big market now that is growing now in Asia and Europe. From the point of view of the number of people who studies overseas now, it is creating its own tourism bubble if you like because twenty years ago there were few students travelling around the world to study, and twenty years ago you weren't be sitting in my office in the West End of London but maybe you wouldn't have the opportunity to travel and to study and you have a register of more than 20,000 more Chinese students coming to study in UK. That would bring the number of students studying in UK to one hundred thousand. That, in itself, does not do anything with tourism. They come to study and go home but while here their families come to see them and take a holiday in Europe while they're here so that's half million people with an average family size of five who are likely to travel through this country and in Europe in the next two or three years. So, that is proved to be a big area, a brand new area that tourism is generating, and the same goes for some of the ethnic groups that I should work with them, and take money for this tourism area, the Thai, nationals, the Philippines, the Filipino-nationals who live here the Singaporeans, the Malaysians. When you are with these ethnic groups that give you a market size of something near of one and a half million in this country about ethnic origins and, they all need to travel, and they have families and friends travelling back and forth wards that's one new massive market that's coming up and the other you said... what you've said... Ecotourism, which I think is already a marketing password (?), ah... sport tourism is growing very fast. Again it is the media, the world is getting smaller, the media that we watch now twenty four hours around the world. We will be exposed to many more things coming around and the ability to travel, to be informed from other continents means that a whole new development is coming out. Sports, for instance, with Olympics, with foot-ball, with the European championship etc, there is a whole tourism industry breaking out, the same you have grand prix in China and, in Bahrain, coming in Istanbul, in Tunis, so, again the world becomes smaller and there's a lot of sport tourism and I think the big thing for the future will be ... ah... regional tourism, something we done in Europe very, very well is taken English people to France, French people to Spain, Spanish people to France and UK and so on, that is interregional tourism. The same is happening massively in Asia whenever, you talk, where tourists come from. You have to put the Chinese factor into it. When the Chinese move, when they all start to move, it rattles in the other side of the world, because the massive quantity of people on the move. So, that are the areas I will consider. (End of the second question) 


\section{QUESTION 3}

Researcher_Bearing in mind the positive versus negative links between tourism and the environment (physical and socio-economic), which could be the outcome?

Interviewee_I think they are more negative.

Researcher_ At the moment?

Interviewee _ Correct.

Researcher__In the next future is it going to be the same or...?

Interviewee _ I think you cannot put all on tourism, you cannot say that is tourism the one industry that causes the positive or the negatives environmental impacts, and it's again... It comes down the government and it comes down from the government affecting people the way they fear about their environment ... I mean, the problem with tourism... we may live in an environment that we keep clean and tidy and we recycle and we save water and we think about the environment and we are using it. We think about food wastes and the chemicals in a swimming pool we are using, we can think of all of those things. When you are on holiday and you are a tourist you leave your conscious and most of the times your brain and everything at home and a lot of people, I mean, I observed that a lot of people litter when they are on holiday but they would never do when they at home. I do not know what it is, whether they leave part of their personality behind, same when you are away and you change your towels every day and you don't think about the detergents. Things that you would never do at home, but until governments stand down on this and educated. It is about education. Then, one can suppose than in a hundred years or so the world won't be the same place we all know now. You know. The oceans will be changed, the planet $(i$ ?) move will be changed, just by the way we treat our environment but I really do not think tourism is wholly to blame. The blame is greed, avarice, greed in money, greed in wanting to build something bigger. Our reclamation goes all around the world we are claiming lands now and you know it causes an impact in the oceans and it affects all of us. When we are talking on Dubai building the world largest underwater hotel, which is going to displace fishes species, but that's what we want allegedly. You know what it is all but... (End of the third question)

\section{QUESTION 4}

Researcher_ To what extent is or can be tourism a feature of the sustainable development?

Interviewee _ I am thinking on higher level of employment. The service levels....the..., I mean, in the tourism industry such as tourism there is massive opportunities for employment and it is probably..., it is the only one of the sectors showing positive upturns in employment opportunities for the number of arrivals, for the service sector that goes on this country. I do not know any industry or any other sector that has that sort of one staff. That's positive but there is a negative that comes with that as well as... Some parts of the world tourism are very seasonal, so it becomes seasonal employment, which put an extra stress on society during the season and nonseason. Ski is a classic example. You have to think about what happens to those places and these people when the resorts are closed. Employment massively... or... I think I cannot show anything else.

Researcher_ They say that tourism is the cleanest industry if you compare it with other sectors. I have not found up to now any research, any study at the moment where most of the negatives impacts are blamed on tourism ... really is it tourism? That is not clear most of the time.

Interviewee _ Sure.

\section{QUESTION 5}

Researcher _ How far sustainable tourism can be encouraged and its bad practices controlled within a sustainable development context?

Interviewee_I do not think it is unavoidable because I think you have a sort of world within worlds when you come to tourism. If you think about one of the earliest tourism, sustainable tourism development (?) that went on probably forty to fifty years ago in places ... I am thinking of the Spanish costas. If you think about how they grew up into concrete jungles rips (?) through skyline and totally used and abused the natural resources and took away the beauty of those places. That has become part of the Spanish history. Thirty or forty years down the line Spain has regret having put those there but it cannot do nothing, but they have learnt and then you have some beautiful resorts. If you come to some of the costas that were well developed, that are being developed for sustainable tourism, with low rise, with natural ... according to woods (?) and that sort of things (?), without putting anything on the beaches, then they learn from that. That's a country. Then you have a government and a country. After that, still now is emerging with tourism. You have now countries coming out with picturesque projects like Libya, which is now coming back into tourism. Oman is also pushing into tourism. You have very recently in the recent past South Africa opening up for massive tourism. They are all now looking at what has been done incorrectly in other countries. Are they learning from it? I think, they think they are learning from a grid point of view not necessarily for sustainable tourism development and natural resources of that country. I think it is a business model they know the way they build. They turned Cape Town into Costa Blanca. It would be a business model that would work fine twenty five years. There, in twenty five years that sort of model will 
almost die and so they are looking up for sustainable tourism that they believe right now that is ecotourism, which is building resorts back from the beach, keeping like sort natural... (?) is kept, the whale-watching and all sorts of things are going on. So, is it possible for them to learn and... Should they learn? Yes, I think they are for a number of good reasons. I still think they are so many now ecological groups and tourism groups that meet up every year as the Green Global World..., that sort of thing but I think that it is not enough done at government level and I saw something this year for the first time that I was quite pleased to see for the first time next year there would be a meeting of all of Ministers of Tourism from all the Common Wealth Countries will meet and have a conference about sustainable tourism within the Common Wealth. At the moment is for the British Common Wealth but I can imagine that it would grow into becoming a meeting where all the Ministers of Tourism of all over the world to come along and work together and say hey we got it wrong, we will do right, so don't do this but there is a danger in that. There is a danger in it for the countries ... I was very fortunate to work for Thai government around the tourist office five years ago so I know some of the steps governments go through... One of the main competitors at that time was Malaysia and we had a situation where Thailand built patia (?), we had the worst reputation for the sex tourism, for concrete jungle, for polluting the water, which would threat the worst plans (?). So we had these resorts built back the ARN LF ... (?) of American soldiers but they also had one of the most beautiful islands that were developed in the right way. So, we can meet a man from Libya in a conference may be, we can sit down and as Thailand, we can say hey don't do what we did, we got it wrong. If you learn from us do this and they would say that you should use your natural resources better, making tourism better and you get tourists to come, Then Thailand would say why all those tourists go to Libya and not coming to Thailand, so, keep everything secret for Thailand and don't tell anybody. Libya will find it up all for themselves, so it takes emerging countries twenty five years to make their mistakes while growing up. As much as a child very innocent, as a teenager, we were always troublesome and as adults we always go by one on the other, we never learn as teenagers, we think ... I can tell you now, don't do that, you shouldn't do that because it won't help you, but you still are going to do it. So, you cannot change the evolution. I don't think it won't ever happen for that reason. (End of the fifth question)

Researcher _ Ok, it is a very, very interesting point of view that of the secret of your own experience in order to avoid much competition for another...

Interviewee_ I mean it's still very open but there always that feeling that if you come up with something creative or do something that may cost money ... imagine putting a tax in. So, we are putting an ecology tax of five us dollars per person that comes into my country, I own the country and I want to get rid of, and I want to have one of the best sues try (?) and I want to have everything in a natural way ... natural woods, natural ceramics, nobody uses any industrial machines or when you build there is no pollution but I am going to charge every tourist with five us dollars to come. If another country would not charge that, so they would not go to my country, they will go to another country where they are not charged for that.

Researcher_You have a recent experience in Majorca in Balearic Islands, with the ecotax.

Interviewee _ Yes, which is she coming (?)

Researcher _ You have that $30 \%$ of Germans haven't come.

Interviewee _ Didn't come. Yes

Researcher_ Thank you very much.

Interviewee - You are welcome. (End of the interview with Alyn Burgess. Group Development Director. Emerald Global Limited. Tour Operator. London. UK). 


\section{OVERVIEW}

IN

SPANISH 


\section{IDENTIFICACIÓN DE LOS TEMAS DE ESTUDIO}

Una de las mayores restricciones para la implementación de los principios de la sostenibilidad en turismo reside en sus supuestos costes, por un lado, mientras que por otro, las percepciones de quienes tienen que gestionar e implementar tales principios de sostenibilidad aprecian que la inversión produce ratios inferiores en un análisis coste-beneficio (y por inercia cognoscitiva). Aunque haya analistas de negocios que parecen confirmar que pueden obtenerse beneficios tangibles generados por iniciativas medioambientales, los inversores y gestores perciben las características de la sostenibilidad y el medio ambiente como un coste y como un riesgo, pero no como potencial fuente valor añadido y de flujo positivo de ingresos (Greeno et al, 1998). En turismo, los turoperadores parecen reacios a reducir los impactos negativos por medio de inversiones monetarias a menos que sus beneficios puedan ser anticipados (Tepelus, 2005). De todas formas, en turismo es el sector privado quien tiene que financiar (de forma directa e indirecta) tal normalización como también los principios de la sostenibilidad, haciendo de ellos formas características integradas en la gestión. Sin embargo, el mundo de los negocios se gestiona e incentiva a través de realidades, fuerzas, reglas de mercado, como económicas (a menudo siguiendo intereses políticos más que principios economicistas), siendo retórica académica y discurso político fáciles (¿aburridos?) de escuchar superficialmente, pero difíciles de comprender a la hora de implementarlos por aquellas personas del sector privado, que son los profesionales que tienen que materializar todo ello en términos monetarios en su normal día-a-día (praxis) dentro de un contexto regido por el libre mercado globalizado.

\section{OBJETO Y PROPÓSITO}

Evaluar la viabilidad práctica del concepto de sostenibilidad aplicado en turismo dentro de la búsqueda general de cuál es el rol del turismo como estrategia de desarrollo sostenible. La investigación se sustancia a través de dos detallados análisis conceptuales (revisión literaria y exploración de la tesis), casos de estudio con autoridad representativa, y el análisis de las percepciones de informantes clave del sector privado en España y en el Reino Unido sobre la sustentabilidad económica del turismo sostenible al desmitificar mitos a través de la praxis real.

\section{CUESTIÓN A INVESTIGAR:}

¿Es el turismo sostenible económicamente sustentable?

\section{OBJETIVOS}

- Analizar la viabilidad estratégica del turismo sostenible en comparación con el presente modelo de desarrollo de un turismo de masas (sostenibilidad versus mantenibilidad) a través de la literatura y de las percepciones de informantes clave.

- Evaluar formas de probar que el turismo sostenible puede no solamente ser económicamente viable si no que también lo puede ser sustentable al examinar fuentes secundarias, analizar las percepciones de los profesionales informantes clave, y casos de estudio reales basados en la gestión de la sostenibilidad valorando los recursos comunes locales. 


\section{INTRODUCCIÓN_TESIS DEL PROYECTO \\ BASES DE LA INVESTIGACIÓN: TEÓRICA, CONCEPTUAL Y DE GESTIÓN}

Gestionar el capital natural (conjunto de recursos comunes) y el designar precio a los intangibles (ej, saber hacer en turismo) puede ser discutible aunque de alguna forma lo es inevitable. El turismo, por razones obvias, como industria debería ser llamado a devenir uno de los primeros sectores económicos en incorporar estos conceptos en su contabilidad (ej, las cuentas satélite) y no simplemente usarlos como estrategias de marketing conocidas como un lavado de imagen verde, a menudo disfrazado como sostenibilidad siendo de hecho una forma de mantener el modelo occidental convencional de desarrollo (capitalista, ahora neoliberal). Esta retórica reclama alguna consideración puesto que los factores de producción del turismo básicamente están constituidos por el capital natural (ej, playas, culturas), cuya degradación amenaza directamente la viabilidad del turismo a todos los niveles. Los intangibles (ej, servicios turísticos) complementan los componentes del capital natural siendo la forma obvia de hacerlos consumibles por los turistas / el público en general, quienes inconscientemente asumen como parte integrante de la oferta turística (Mihalic, 2002). Sin embargo, paradójicamente ambos han sido de alguna manera relegados a la última posición en las prioridades de la industria del turismo, hecho que puede conducir como también acelerar fases de estagnación en cualquier negocio turístico, en cualquier destino (ej, enclaves turísticos masificados en el Mediterráneo), puesto que si el atractivo del destino se desdibuja los turistas pueden desear encontrar tal atractivo original en otro lugar (ej, República Dominicana). El conjunto de los recursos comunes son aquellos recursos libres de coste, tales como son el sol, el clima, el paisaje, la cultura y así sucesivamente, recursos que de serles asignado precio constituirían un fundamental e integrado componente en los balances de pagos, haciendo de ellos algo más realista y a tener en cuenta, realidades que debieran situarse en el centro mismo de la viabilidad económica del desarrollo del turismo sostenible y de las preocupaciones de los negocios turísticos en los sectores privados, como en los debates en oposición a su mantenibilidad económica a través, por ejemplo, de una política estratégica de lavado de imagen verde.

\section{NATURALEZA Y RELEVANCIA DE LA TEMÁTICA}

¿Por qué esta temática a investigar? El sector privado (explícitamente) y los anfitriones (implícitamente) parecen clamar que retórica académica y legislación del sector público se arropan estando repletas de buenas intenciones con respecto a los principios y concepto de la sostenibilidad y, en este caso, con respecto al turismo sostenible. Los principales puntos a debate sobre sostenibilidad vienen constreñidos por realidades que impone la economía y por la inercia cognoscitiva. El trabajo de los académicos y la legislación de los gobiernos pueden llegar a ser inútiles si los sectores socioeconómicos no encuentran la sostenibilidad económicamente rentable como primera 
fase (Martinez, 2004). El marco retórico académico como legislativo podría ser interpretado y consecuentemente desviado para mantener las presentes dinámicas socioeconómicas disfrazadas de dicha sostenibilidad, henchidas de buenas intenciones que alimentan conferencias internacionales, discursos políticos, y todo este círculo vicioso cayendo aparentemente en el reino del lavado de imagen verde (ej, estrategias de marketing). Sin embargo, el sector privado parece reclamar que la sostenibilidad debería ser, en primer lugar, económicamente sustentable (Martinez, 2004). Con el objeto de alcanzar esta meta, la sostenibilidad aplicada debería probarse como rentable para los profesionales del sector privado en todos sus niveles, dadas las ganancias conseguidas en el eficiente y óptimo uso de los recursos (factores), consiguiendo importantes ahorros económicos al tiempo que consigue un producto / servicio de calidad que, consecuentemente, eleva la apreciación y valoración de la marca del destino y los negocios, que a su vez pueden permitir cargar precios extras al satisfacer, o incluso superar, las expectativas del presente como del probable cliente antes de perseguir un desarrollo del turismo social y medioambiental, que debería ser integrado dentro del resto de sectores que conforman, como un todo, el desarrollo sostenible. Con el objeto de examinar el estratégico potencial rol en el desarrollo del turismo sostenible Sharpley argumenta que "no debería ser visto aislado del amplio contexto del desarrollo del que el turismo sostenible es una parte" (Sharpley, 2000: 3). En resumen, si la sostenibilidad no es socioeconómicamente rentable y sus beneficios no solamente mantenidos sino sustentables, los sectores privados van a buscar producir beneficios donde y por los medios en que puedan ser generados e incrementados (ej, a través de la explotación masiva de los recursos). Los profesionales informantes clave de los sectores privados en España y en el Reino Unido, al ser entrevistados formalmente, han puesto de manifiesto estos debates y preocupaciones. A añadir a estas reclamaciones se constata, más a menudo que menos, que sostenibilidad y mantenibilidad son solapados tanto en significado como en la práctica. 


\section{EXTRACTO}

El presente estudio ha investigado diferencias entre retórica y praxis con respecto a los muy discutidos debates sobre la sustentabilidad económica del desarrollo sostenible y el turismo sostenible. Dentro de la búsqueda general de cuál es el rol del turismo como estrategia de desarrollo, este estudio pretende examinar hasta qué punto el turismo sostenible puede ser considerado económicamente sustentable y cómo algunos profesionales dentro de la industria turística en el Reino Unido y en España lo perciben. La cuestión a investigar ha tratado de evaluar la sustentabilidad económica del turismo sostenible. La aparente separación entre retórica y praxis ha sido examinada a través de cada uno de los objetivos de la investigación. La investigación de despacho se ha llevado a cabo desde marzo 2003 a mayo 2004 y desde marzo a mayo 2005 en el Reino Unido. La investigación de campo fue llevada a cabo en España y en el Reino Unido desde mayo a diciembre 2003. Ocho entrevistas formales semi estructuradas fueron realizadas cubriendo siete profesionales informantes clave en el sector privado y una en el sector público (industrias en general) con respecto al turismo y al desarrollo. Finalmente, sesenta agentes de viajes han sido visitados en España (32) y en el Reino Unido (28) al objeto de evaluar las percepciones de los agentes de viajes sobre el nivel de concienciación medioambiental y requerimientos de sus clientes a la hora de demandar servicios y productos turísticos. Este estudio ha encontrado un número de resultados presentados y analizados en el sexto capítulo. El objeto y propósito de la investigación son evaluados a través de la respuesta a la cuestión a investigar en el séptimo capítulo. La investigación ha averiguado que mientras los académicos han estado trabajando sobre la sostenibilidad y sus conexos términos, el desarrollo sostenible y el turismo sostenible hace tiempo, los profesionales en el sector público hace relativamente poco que están haciendo esfuerzos dirigidos a implementar conceptos y prácticas del desarrollo sostenible y el turismo sostenible, mientras que las iniciativas de los profesionales en el sector privado respecto a la sostenibilidad están enmarcadas, constreñidas y condicionadas por su viabilidad económica dentro de una restrictiva legislación y el marco de las directrices del mercado libre. Los profesionales informantes clave argumentan que la sostenibilidad necesita se haga económicamente provechosa si se pretende que el desarrollo sostenible y el turismo sostenible sean implementados. Finalmente, los agentes de viajes entrevistados en ambos países ponen de manifiesto que, hasta el momento, no se han enfrentado a requerimientos medioambientales de clase alguna por parte de sus clientes. La segunda parte de este estudio contrasta la praxis frente a la retórica produciendo vívidas evidencias y no tanto resultados convencionales al examinar el turismo, la gestión de la sostenibilidad, la valoración del conjunto de los recursos comunes desde la perspectiva del OTRO. Los sistemas tradicionales, autónomos por autóctonos, usan la gestión de la sostenibilidad de forma prolongada en el tiempo. Evidencia es de la viabilidad y sustentabilidad de su praxis frente a su retórica. 